\title{
Addressing gender-biased sex selection in Haryana, India: Promising approaches
}

Shireen J. Jejeebhoy

Population Council

Rajib Acharya

Population Council

Sharmistha Basu

Population Council

A.J. Francis Zavier

Population Council

Follow this and additional works at: https://knowledgecommons.popcouncil.org/departments_sbsr-pgy

Part of the Demography, Population, and Ecology Commons, Family, Life Course, and Society

Commons, Gender and Sexuality Commons, International Public Health Commons, Medicine and Health Commons, and the Women's Health Commons

How does access to this work benefit you? Let us know!

\section{Recommended Citation}

Jejeebhoy, Shireen J., Rajib Acharya, Sharmistha Basu, and A.J. Francis Zavier. 2015. "Addressing genderbiased sex selection in Haryana, India: Promising approaches." New Delhi: Population Council. 


\section{ADDRESSING GENDER-BIASED SEX SELECTION IN HARYANA, INDIA: PROMISING APPROACHES}

Shireen J Jejeebhoy

Rajtb Acharya Sharmistha Basu A J Francis Zavier

\section{POPULATION coUNCIL}

Ideas. Evidence. Impact.

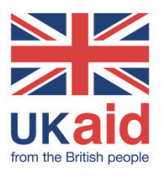




\section{- POPULATION COUNCIL \\ Ideas. Evidence. Impact.}

The Population Council confronts critical health and development issues-from stopping the spread of HIV to improving reproductive health and ensuring that young people lead full and productive lives. Through biomedical, social science, and public health research in 50 countries, we work with our partners to deliver solutions that lead to more effective policies, programs, and technologies that improve lives around the world. Established in 1952 and headquartered in New York, the Council is a nongovernmental, nonprofit organization governed by an international board of trustees.

\section{Population Council}

Zone 5A, Ground Floor India Habitat Centre, Lodi Road

New Delhi, India 110003

Phone: 91-11-24642901

Email: info.india@popcouncil.org

Website: www.popcouncil.org

\section{$\Delta \mathbb{2}$ \\ VAN \\ UKaid}

This project has been funded by UKaid from the UK Government; however the views expressed do not necessarily reflect the UK Government's official policies.

Suggested citation: Jejeebhoy, S. J., R. Acharya, S. Basu and A. J. F. Zavier. 2015. Addressing gender-biased sex selection in Haryana, India: Promising approaches. New Delhi: Population Council. 


\section{ADDRESSING GENDER-BIASED SEX SELECTION IN HARYANA, INDIA: PROMISING APPROACHES}

Shireen J Jejeebhoy

Rajib Acharya

Sharmistha Basu

A J Francis Zavier 


\section{Table of Contents}

List of Tables

List of Figures $\quad$ vii

Acknowledgements

Executive Summary

Chapter 1: Introduction 1

Chapter 2: Factors underlying unbalanced sex ratios 15

Chapter 3: What works to reduce gender-biased sex selection: Communication, advocacy and community mobilisation

Chapter 4: What works to reduce gender-biased sex selection: Perspectives of women and key informants on the enforcement of the PCPNDT Act

Chapter 5: What works to reduce gender-biased sex selection: Programmes to enhance the status of the girl child through educational entitlements and conditional cash transfers

Chapter 6: Key informant perspectives on changes in practices regarding the misuse of sex determination technology, factors underlying improvements in the situation in Kurukshetra, and the way forward

Chapter 7: Tying it all together: What worked and what next?

References

Authors 


\section{List of Tables}

Table 1.1: Sociodemographic profile of the study districts and Haryana State

Table 1.2: Coverage of the study: Survey participants, Kurukshetra and Sonipat

Table 1.3: Coverage of the study: Key informants according to occupation, Kurukshetra and Sonipat, Haryana State

Table 1.4: Selected sociodemographic characteristics of women who participated in the survey, according to residence, Kurukshetra and Sonipat

Table 2.1: Ideal and actual family size

Table 2.2: Attitudes about son preference

Table 2.3: Disclosure of the sex of the foetus by parity and sex of the previous child

Table 2.4: Experience of induced abortion and reasons for abortion

Table 2.5: Attitudes about gender-biased sex selection

Table 2.6: Son preference and experience of disclosure of the sex of the foetus: sociodemographic differentials

Table 3.1: Awareness of laws protecting women

Table 3.2: Sources of information about the PCPNDT Act and related behavior change communication messages

Table 3.3: Exposure to messages advocating equal treatment of boys and girls, and discouraging gender-biased sex selection

Table 3.4: Exposure to messages through the media

Table 3.5: Exposure to television programmes

Table 3.6: Messages received through television serials and films

Table 3.7: Exposure to signboards and notices in health care facilities

Table 3.8: Exposure to counselling by frontline health workers and nurses

Table 3.9: Exposure to educational activities conducted by NGOs

Table 3.10: Exposure to discourses by religious leaders 
Table 4.1: Perceptions about punishing violations or violators of the PCPNDT Act and effectiveness of the Act

Table 5.1: Awareness and use of educational entitlements for girls

Table 5.2: Awareness of conditional cash transfer schemes for girls

Table 5.3: Specific awareness of Ladli and Apni Beti Apna Dhan Schemes

Table 5.4: Perceived benefits of conditional cash transfer schemes

Table 5.5: Utilisation of the Ladli Scheme

Table 5.6: Intended use of the conditional cash transfer maturity amount

Table 7.1: Key factors underlying distorted sex ratios at birth, Kurukshetra and Sonipat

Table 7.2: Implementation of the PCPNDT Act: key findings from Kurukshetra and Sonipat

Table 7.3: Educational entitlements and conditional cash transfer (CCT) schemes for girls: summary of findings, Kurukshetra and Sonipat

Table 7.4: Communication, advocacy and community mobilisation: summary of findings, Kurukshetra and Sonipat

Table 7.5: Key informant perspectives on factors underlying the improvement in the sex ratio at birth in Kurukshetra: summary of findings, Kurukshetra and Sonipat

Appendix 1: India: Initiatives to ensure that the PCPNDT Act is implemented

Appendix 3: India: Selected central and state government schemes intended to increase the value of the girl child and counter disadvantages faced by girls 


\section{List of Figures}

Figure 2.1: Percentage of women with two children who expressed no preference for the sex of their children, according to residence, Kurukshetra and Sonipat

Figure 2.2: Indicators of son preference among women with two living children, according to residence, Kurukshetra and Sonipat

Figure 2.3: Percentage of women who had undergone an ultrasound test for foetal monitoring, according to residence, Kurukshetra and Sonipat

Figure 2.4a: Percentage of women who had obtained information about the sex of the foetus (any pregnancy, direct question), according to residence, Kurukshetra and Sonipat

Figure 2.4b: Percentage of women who had obtained information about the sex of the foetus (any pregnancy, anonymous (indirect) format), according to residence, Kurukshetra and Sonipat

Figure 2.4c: Percentage of women who obtained information about the sex of the foetus (any pregnancy, in response to direct and indirect questions), according to residence, Kurukshetra and Sonipat

Figure 2.5: Percentage of women who had undergone an ultrasound test for foetal monitoring, percentage of women who had ever experienced or were acquainted with someone who had obtained information about the sex of the foetus, and percentage of women who underwent a sex-selective abortion, Kurukshetra and Sonipat

Figure 3.1: Percentage of women reporting that a person seeking disclosure of the sex of the foetus can be jailed, according to residence, Kurukshetra and Sonipat

Figure 3.2: Percentage of women reporting that a service provider/doctor/person or any provider conducting the ultrasound examination can be jailed for disclosing the sex of the foetus, according to residence, Kurukshetra and Sonipat

Figure 3.3: Percentage of women who reported exposure to messages from frontline health workers, NGOs and religious leaders on equal treatment of boys and girls and discouraging gender-biased sex selection, Kurukshetra and Sonipat

Figure 4.1a: Percentage of women reporting that some health care providers do reveal the sex of the foetus

Figure 4.1b: Percentage of women who had heard about a doctor being prosecuted or a clinic being closed for providing sex determination services or revealing the sex of the foetus

Figure 4.1c: Percentage of women who had heard about raids conducted on some doctors in Kurukshetra and Sonipat because they were providing information about the sex of the foetus

Figure 4.1d: Percentage of women who had heard about a helpline for reporting cases of sex selection 


\section{Acknowledgements}

We are grateful to the UK Department for International Development (DFID) for supporting a regional initiative to shed light on the issue of gender-biased sex selection in Bangladesh, India, Nepal and Pakistan, and make evidence-based recommendations for actions that hold promise for responding to adverse sex ratios at birth in these settings.

This study, focused on primary research conducted in Haryana, India, has benefitted immeasurably from the inputs of many. In particular, we are grateful to Nupur Barua, South Asia Research Hub, DFID for her insights and comments on the study during critical phases. We would also like to express our thanks to our partners, Ubaidur Rob and Nooranabi Talukder, Population Council, Bangladesh; Zeba Sathar and Gul Rashida, Population Council, Pakistan; and Mahesh Puri and Anand Tamang, Centre for Research, Environment, Health and Population Activities (CREHPA), Nepal, for their inputs into this report.

We were privileged that T.V. Sekher and Vinoj Manning, both with wide experience and insights into the situation relating to gender-biased sex selection in India, agreed to review an earlier draft of this report. Their constructive criticism and suggestions are much appreciated, and have been incorporated into this final report. We would also like to acknowledge the role played by the members of the project's Technical Advisory Group in shaping the design of the project. We are particularly grateful to P.M. Kulkarni, Christophe Guilmoto and Ena Singh for their useful suggestions and guidance.

We benefitted hugely from the support provided by the Government of Haryana, as well as the district administrations of the two study districts, Kurukshetra and Sonipat. In particular, we would like to acknowledge our appreciation of the support and guidance provided to us by Smt. Navraj Sandhu, Additional Chief Secretary to the Government of Haryana, Development and Panchayats Department, and formerly Additional Chief Secretary to the Government of Haryana, Health Department, Panchkula, Haryana; Dr. N. K. Arora, former Director General (Health Services), Government of Haryana; Dr. Renu Pahal Mallik, Deputy Director (S.S.) PNDT (Health Services), Government of Haryana; Dr. J.S Punia, Civil Surgeon Sonipat, and Dr. K. K Sharma, Deputy Civil Surgeon, Kurukshetra.

In June 2015, we held a data interpretation workshop in Chandigarh at which we discussed our preliminary findings. Participants at the Chandigarh meeting provided very useful interpretations of some of our findings, and we are grateful to them for their comments and suggestions.

At the Population Council, several colleagues have supported us in both the technical and administrative aspects of this study. We are grateful to M.A. Jose for overseeing the administration of the project, Shilpi Rampal for her support in preparing tables and figures, and to Komal Saxena for reviewing the manuscript, correcting discrepancies, and for preparing it for publication. Their support is gratefully acknowledged. Jyoti Moodbidri was responsible for editing the manuscript; we are grateful to her for her contribution and careful attention to detail, which have made the report more readable and clear.

We would also like to acknowledge the dedication of our 20 investigators, who conducted interviews on a difficult topic with women, health care providers and programme implementers. Their efforts succeeded in obtaining for the project new evidence and deeper insights into gender-biased sex selection in Haryana.

Finally, we would like to record our deep appreciation of the women who participated in our survey, and the health care providers and programme implementers who provided their insights on gender-biased sex selection and related issues in the course of key informant interviews. We hope that our recommendations based on the insights and experiences that they shared with us will help shape programmes intended to restore balance in sex ratios at birth.

Shireen J Jejeebhoy

Rajib Acharya

Sharmistha Basu

AJ Francis Zavier 


\section{Executive Summary}

India has long been characterised by wide gender disparities and a strong preference for sons, historically manifested in postbirth disparities in feeding and health care patterns that have raised the mortality of daughters as compared to sons and resulted in unbalanced child sex ratios in favour of boys over girls. Since the 1980s, with the increasing availability of prenatal diagnostic technologies, postbirth discrimination has given way increasingly to prenatal gender-biased sex selection. As a result, sex ratios at birth have become skewed, far beyond the normal ratio of 105 male births per 100 female births or 952 female births per 1,000 male births. Indeed, in 2012, the sex ratio at birth stood at 908 female births per 1,000 male births. Further, the child sex ratio, as of 2011, had plummeted to 918 females aged 0-6 per 1,000 males from an already dismal 927 in 2001, and 945 in 1991. Persistently adverse sex ratios remain a challenge in India despite the enforcement of the PCPNDT (Pre-Conception and Pre-Natal Diagnostic Techniques) Act in 1994. Nevertheless, over the decade 2001-2011, positive shifts from very adverse to less adverse levels have occurred in a few states, particularly those in the north-western states of Haryana and Punjab, in which sex ratios have been particularly adverse.

Given the observed improvements in the sex ratios at birth and among children in some districts in the recent past, India is in a position to address the question: what works to reverse adverse sex ratios in some parts of the country. However, our knowledge about the reasons for these changes remains sparse. The objective of this report is to shed light on programmes and practices that may have resulted in recent improvements in the sex ratios at birth in a district recording very adverse sex ratios a decade ago. As such, we explore factors underlying improvements in the sex ratio at birth in some parts of India from very adverse to less adverse levels in the 2001-2011 period. With this goal, we compare the situation in two districts of Haryana, namely Kurukshetra and Sonipat, both of which reported extremely adverse sex ratios at birth and among children in 2001 but, among which, one district (Sonipat) showed no change in these sex ratios over the 2001-2011 period and the other (Kurukshetra) displayed some change.

Comparisons are drawn from three perspectives. First and foremost, we assess the experiences and attitudes of women who had given birth in the recent past; our analysis assesses the pregnancy histories of these women; their experiences of ultrasound use, disclosure of the sex of the foetus and gender-biased sex selection, as well as their knowledge about the PCPNDT Act, their exposure to communication, advocacy and community mobilisation activities for raising awareness of the Act and changing attitudes about the acceptability of gender-biased sex selection, and their access to conditional and unconditional cash transfer programmes intended to raise the status of the girl child. Second, we explore the experiences and practices of health care providers engaged in delivering ultrasound or reproductive health services as well as their perspectives on gender-biased sex selection in their areas and factors underlying changes, if any. Finally, we explore the perspectives and experiences of those implementing programmes intended to enhance the survival and value of the girl child; for example, those implementing the law or various conditional cash transfer programmes, and those implementing programmes intended to reverse son preference. The report, thus, explores the extent to which the selected districts differ in terms of implementation of initiatives intended to enforce the PCPNDT Act, build gender equality, and promote advocacy, communication and community mobilisation. Findings are expected to shed light on promising directions for programmes intended to counter gender-biased sex selection.

The research adopted a mixed method approach. It included a survey of 1,101 married women with at least two children, one of whom was aged 0-5 years. It also included key informant interviews with health care providers; public sector programme implementers, and NGO representatives. The survey explored, from the perspective of women, family size desires, the strength of son preference, and the extent of disclosure of the sex of the foetus and termination of pregnancies carrying a female foetus; it also explored women's knowledge of the PCPNDT Act, exposure to messages relating to raising the value of the girl child in general, and addressing gender-biased sex selection in particular. Primary research also explored the extent to which three types of programmatic interventions-law enforcement; communication, advocacy and community mobilisation efforts, and the provision of educational entitlements and conditional cash transfer programmes for girls have been implemented in each district, and the extent to which these interventions may have contributed to the sex ratio at birth in the contrasting districts under study. 
Findings highlight that the small family norm is widespread, as is son preference; disclosure of the sex of the foetus, possibly under-reported, was acknowledged by small proportions of women, with more women experiencing their third pregnancy from Sonipat so reporting than those from Kurukshetra (6\% versus $2 \%$ ), and more women from Sonipat than Kurukshetra reporting that they or someone they knew had been told the sex of their foetus (23\% versus $16 \%$ ). Sociodemographic differentials in both the extent of son preference and the experience of disclosure of the sex of the foetus were, by and large, insignificant; even so, in Kurukshetra, indifference about the sex of children increased notably with education and wealth status. Likewise, differences in experience of disclosure were narrow, but suggest that the practice was prevalent across all sociodemographic groups. While just 3-4 percent of women who had undergone an abortion reported they had done so for sex-selective reasons, key informants from both districts estimated that between one and fifty percent of pregnant women were likely to have done so.

In order to ascertain factors likely to have contributed to improvements in Kurukshetra, we explored the extent to which differences emerged in terms of the spread of educational entitlements and conditional cash transfers for girls, implementation and awareness of the PCPNDT Act on disclosure of the sex of the foetus, and implementation of and exposure to communication, advocacy and community mobilisation activities. As far as educational entitlements and conditional cash transfers are concerned, similar proportions of women reported accessing school-related entitlements and enrolling their daughters in the Ladli Scheme, a conditional cash transfer scheme for girls. However, key informants from both districts warned that while schemes and educational entitlements would contribute to increased educational attainment and delayed marriage among girls, it may not, at least in the near future, affect son preference or gender-biased sex selection.

With regard to the implementation of the PCPNDT Act, likewise, interdistrict differences were not observed: relatively few women had heard about doctors being prosecuted or clinics closed (41-42\%) or had heard about raids (21-26\%) taking place in their district. Key informants from both districts not only described such measures taken to implement the Act as inspections and raids, maintenance of detailed records of women and tracking of pregnant women, prosecution of violators, suspension of licences, sealing of equipment and facilities, and imposition of fines, but described such challenges as the absence of prosecution, in fact, of women and families seeking disclosure and/or sex-selective abortion, excessive paperwork and harassment of honest providers, poorly-trained law enforcement officials, interference by political leaders and other influential individuals to protect certain providers, and the undue burden placed on state and district health authorities to implement the Act.

In the case of communication, advocacy and community mobilisation initiatives, however, interdistrict differences were pronounced. More women from Kurukshetra than Sonipat were aware of the Act, and although similar and large proportions had been exposed to messages about the prohibition of disclosure of the sex of the foetus and about raising the status of girls, more women from Kurukshetra than from Sonipat, and more women in urban than in rural areas of the two districts had been so exposed. Notably, far more women from Kurukshetra than Sonipat had been exposed to interpersonal communication, for example, counselling by a frontline worker (31\% versus $23 \%$ ), and to discourses by religious leaders discouraging gender-biased sex selection (20\% versus $14 \%$ ), and while substantial proportions of rural women in Kurukshetra compared to those in Sonipat reported such exposure to a frontline health worker (38\% versus $29 \%$ ), conversely, the advocacy efforts of religious leaders were articulated by significantly more urban women in Kurukshetra (22\%) than rural women in both districts (13-19\%) and significantly more than their counterparts in Sonipat (15\%).

Moreover, key informant interviews revealed the far greater involvement of the public sector in communication, advocacy and community mobilisation activities in Kurukshetra than in Sonipat. Indeed, in Kurukshetra, weekly Night Halt and Open Durbar programmes were implemented by public sector officers at village level, monthly visits were made to schools and colleges during which oath-taking ceremonies were held to build commitment among students and teachers about gender equity and desisting from gender-biased sex selection. Overall, while frontline workers were a particularly important source of information and behavior change communication in rural areas, women in urban settings, notably those in Kurukshetra, benefitted from greater media exposure and talks by religious leaders. Kurukshetra, moreover, was marked by sustained interactive sensitisation and advocacy programmes by public sector programme implementers in schools, colleges and the community, practices less likely to have been described in Sonipat.

In addition, some key informants raised two additional factors they believed accounted for differences between the two districts: Sonipat's greater proximity to Delhi and Uttar Pradesh, where, they believed gender-biased sex 
selection was more freely available than in Haryana, and the dominant caste composition of the two districts, with a concentration of more gender inegalitarian castes in Sonipat than Kurukshetra. We emphasise that both of these factors reflect the perceptions of certain key informants, and others have dispelled these ideas, noting for example that mere geographic distance cannot inhibit a determined woman from accessing services, and that there is a danger in stereotyping castes as gender inegalitarian.

\section{The way forward}

Findings of our study are by no means conclusive, but provide a range of insights into both the potential for change in sex ratios at birth on the one hand and what works to improve these ratios on the other.

With regard to what works, findings have shown that the full array of interventions-implementation of the PCPNDT Act, provision of entitlements and conditional cash transfers for girls, and communication, advocacy and community mobilisation efforts to change gender inegalitarian norms and discourage gender-biased sex selection-are likely necessary to restore balance in sex ratios at birth. Even so, key informants (largely programme implementers) from both districts expressed a belief that while entitlements and conditional cash transfer programmes for girls were effective in enhancing girls' access to education and delaying their marriage, they were unlikely to influence parents' willingness to have a (higher order) daughter or only-daughter family in the short run, although their longer term impact should not be discounted. At the same time, findings from both districts have also suggested the huge challenges that prevail in implementing the law.

Perhaps the most promising programme-related finding, observed consistently, and distinguishing Kurukshetra from Sonipat, is the importance of communication, advocacy and community mobilisation efforts, which were more vigorously implemented and wide-ranging in Kurukshetra than in Sonipat. The evidence is strong: interpersonal communication by frontline workers, exposure to discourses by religious leaders, regular efforts made by public health officers to connect with communities at the village level, and in schools and colleges throughout the district on a regular basis, to change norms and attitudes and raise awareness about the law clearly distinguished the district in which improvement in the sex ratio at birth were observed from the one in which no such change was observed. Our findings, thus offer tentative support to the conclusion that while privileges for girls and implementation of the law are important, concerted efforts towards communication, advocacy and community mobilisation are essential to transform gender norms and discourage gender-biased sex selection. 


\section{Chapter 1 Introduction}

Persistently adverse sex ratios remain a challenge in India despite the enforcement of the PCPNDT (Pre-Conception and Pre-Natal Diagnostic Techniques) Act in 1994. Nevertheless, over the decade 2001-2011, positive shifts from very adverse to less adverse levels have occurred in a few states. Two districts in Haryana state-Kurukshetra and Sonipat-whose sex ratios displayed some and no improvement, respectively, are compared in an attempt to find promising programme directions to counter gender-biased sex selection. Comparisons are drawn from the attitudes and experiences of surveyed women and interviews with service providers and programme implementers, about sex-selection technology. Also addressed are differences in the implementation of three initiatives known to influence improvements in the sex ratio at birth, namely, those intended to enforce the PCPNDT Act, those intended to provide educational entitlements and conditional cash transfers for girls, and those that focus on communication, advocacy and community mobilisation to promote gender equality and discourage the practice of gender-biased sex-selection.

\section{Rationale}

India has long been characterised by wide gender disparities and a strong preference for sons, historically manifested in postbirth disparities in feeding and health care patterns that have raised the mortality of daughters as compared to sons and resulted in unbalanced child sex ratios in favour of boys over girls. Since the 1980s, with the increasing availability of prenatal diagnostic technologies, postbirth discrimination has given way increasingly to prenatal gender-biased sex selection. As a result, sex ratios at birth have become skewed, far beyond the normal ratio of 105 male births per 100 female births or 952 female births per 1,000 male births. Indeed, in 2012, the sex ratio at birth stood at 908 female births per 1,000 male births (110 male births per 100 female births) (Office of the Registrar General, India, 2013). Further, the child sex ratio, as of 2011, had plummeted to 918 females aged 0-6 per 1,000 males (109 males per 100 females) from an already dismal 927 in 2001, and 945 in 1991 (Office of the Registrar General and Census Commissioner, India, 2013). Estimates suggest that some ten million sex-selective abortions had taken place in India between 1981 and 2005, amounting to five percent of the female population aged below 15 (Kulkarni, 2007). As a result, about 0.5-0.6 million girls have been missing each year (Jha et al., 2006; United Nations Population Fund, 2010).

Adverse sex ratios persist, notwithstanding the PCPNDT (Pre-Conception and Pre-Natal Diagnostic Techniques) Act [and the Pre-Natal Diagnostic Techniques (Regulation and Prevention of Misuse) Act or PNDT Act that preceded it] that prohibits the disclosure of the sex of the foetus and indiscriminate use of technologies, and applies strict penalties for those found to have violated the Act (Ministry of Health and Family Welfare, 2003). Although the Act has been enforced since 1994, sex ratios have remained adverse and have even worsened in the twenty years following its enactment. The failure of the Act to curb adverse sex ratios has been attributed to the persistence of gender inequalities and norms favouring sons at any cost, unscrupulous clients and service providers willing to violate the Act, and difficulties in or indifference about enforcing the Act in many settings.

Even so, wide geographic and sociodemographic disparities have been observed in the sex ratios at birth and among children in the country. Adverse sex ratios are typically concentrated, for example, in a few states, among better off sub-populations and those in urban areas; there is a narrowing of these disparities and a suggestion that adverse sex ratios may encompass larger segments of the population as prenatal diagnostic technologies become more widely available (Jejeebhoy et al., 2015). At the same time, there are signs of a turnaround in a few states, such as, for example, Haryana and Punjab, that, while incipient, are signals of hope (Kumar and Sathyanarayana, 2012; Jejeebhoy et al., 2015; John, 2015). There is clearly an urgent need for evidence that highlights successful approaches to arresting and reversing adverse sex ratios at birth and among children; unfortunately, insufficient programme and research attention has been paid to identifying promising practices that may be effective in doing so or even those that may have contributed to the reversal in some parts of the country.

Recognising these gaps in understanding, and with support from UKAid, the Population Council's Bangladesh, India and Pakistan offices, and the Centre for Research, Environment, Health and Population Activities (CREHPA), Nepal, 
led by the Council's India office, undertook research to shed light on the issue of gender-biased sex selection in these countries and make evidence-based recommendations for actions that hold promise for responding to adverse sex ratios at birth in study settings. This report focuses on the research conducted in India; companion reports highlight key questions of relevance in Bangladesh, Nepal and Pakistan.

\section{Study objectives}

Given the observed improvements in the sex ratios at birth and among children in some districts in the recent past, India is in a position to address the question: what works to reverse adverse sex ratios in some parts of the country? There have been positive shifts in some states and districts, particularly those in the north-western states of Haryana and Punjab. However, our knowledge about the reasons for these changes remains sparse. The objective of this report is to shed light on programmes and practices that may have resulted in recent improvements in the sex ratios at birth in a district recording very adverse sex ratios a decade ago. As such, we explore factors underlying improvements in the sex ratio at birth in some parts of India from very adverse to less adverse levels in the 2001-2011 period. With this goal, we compare the situation in two districts of Haryana, namely, Kurukshetra and Sonipat, both of which reported extremely adverse sex ratios at birth and among children in 2001 but, among which, one district (Sonipat) showed no change in these sex ratios over the 2001-2011 period, and the other (Kurukshetra) displayed some change.

Comparisons are drawn from three perspectives. First and foremost, we assess the experiences and attitudes of women who had given birth in the recent past; our analysis assesses the pregnancy histories of these women; their experiences of ultrasound use, disclosure of the sex of the foetus and gender-biased sex selection, as well as their knowledge about the PCPNDT Act, their exposure to communication, advocacy and community mobilisation activities for raising awareness of the Act and changing attitudes about the acceptability of gender-biased sex selection, and their access to conditional and unconditional cash transfer programmes intended to raise the status of the girl child. Second, we explore the experiences and practices of health care providers engaged in delivering ultrasound or reproductive health services to assess their perspectives on gender-biased sex selection in their areas and factors underlying changes, if any. Finally, we explore the perspectives and experiences of those implementing programmes intended to enhance the survival and value of the girl child, for example, those implementing the law or various conditional cash transfer programmes, and those implementing programmes intended to reverse son preference. The report, thus, explores the extent to which the selected districts differ in terms of implementation of initiatives intended to enforce the PCPNDT Act, build gender equality, and promote advocacy, communication and community mobilisation. Findings are expected to shed light on promising directions for programmes intended to counter gender-biased sex selection.

\section{Background}

In India, juvenile or child sex ratios have been unbalanced, and far from those expected under natural circumstances, for many decades, but the leading factor accounting for this imbalance has not always been an unbalanced sex ratio at birth. Up to the 1980s, it was postnatal discrimination against girls through differential feeding and health care patterns on the one hand, and infanticide on the other that resulted in the excess mortality of girls compared to boys and, thereby, an unbalanced sex ratio. Thereafter, however, there has been a gradual shift and, today, the bulk of differences in the juvenile sex ratio results from the unbalanced sex ratio at birth, ${ }^{1}$ fuelled by gender-biased sex selection and termination of pregnancies carrying a female foetus. As a result, large parts of India may have an excess of young men by up to 20 percent by 2030 (Hesketh, Lu and Xing, 2011). Indeed, the proportion of India's population residing in states in which the child sex ratio is below 920 girls per 1,000 boys increased from 11 in 1991 to 43 in 2001 (Office of the Registrar General and Census Commissioner, India, 2004) to 51 in 2011 (Office of the Registrar General and Census Commissioner, India, 2013).

Since the 1980s, unbalanced postbirth sex ratios have been replaced by unbalanced sex ratios at birth. The wide availability of medical technologies such as ultrasound, and more recently even preconception techniques that detect the sex of the foetus, the desire for a small family and, at the same time, a desire to ensure one or two sons

\footnotetext{
1 The third possible factor influencing the juvenile sex ratio, namely, an undercount or age misreporting of girls, has no more than a nominal effect on the juvenile sex ratio and the trend in deliberately misrepresenting daughters has declined in recent years such that this component is irrelevant in accounting for observed sex ratios (Premi, 2002; Bhat, 2002; Kulkarni, 2007).
} 
has led many parents to undergo tests to detect the sex of their foetus and terminate pregnancies in which the foetus is found to be female (Bhat, 2002; Kulkarni, 2014). Indeed, it is estimated that the sex ratio at birth for the cohort born during the seven-year period prior to the 2011 Census was 923 female births per 1,000 male births at the national level, far below the 'normal' sex ratio at birth of 952 (Kulkarni, 2014). Other authors have noted an implied sex ratio at birth of 906 in 2009-2011, a steep decline from 935 in 1994-2000 and 923 in 2004-2010 (Kumar and Sathyanarayana, 2012).

State-level variation in the child sex ratio and the sex ratio at birth is wide. In general, the ratios are most adverse in the north-western states and most normal in the southern states (Bhat and Zavier, 2007; Jha et al., 2011; Kumar and Sathyanarayana, 2012; Bongaarts, 2013; United Nations Population Fund, 2010). The two states recording the lowest child sex ratios in 2011 (under 850 females per 1,000 males) are Haryana (834) and Punjab (846). A number of other major states have also recorded adverse child sex ratios: in 2011, there were six other states with child sex ratios below 900 females per 1,000 males and they include, apart from Punjab and Haryana, Jammu and Kashmir (862), Delhi (National Capital Territory or NCT) (871), Rajasthan (888), Gujarat (890), Uttarakhand (890) and Maharashtra (894). There are, in contrast, some states that show no signs of distortion in their child sex ratios. For example, the child sex ratio in 2011 was above 950 in four states, namely, West Bengal (956), Assam (962), Kerala (964) and Chhattisgarh (969), and between 940 and 950 in four states, namely, Jharkhand (948), Karnataka (948), Tamil Nadu (943) and Odisha (941).

The statewise picture with regard to the sex ratio at birth is similar (Bhat and Zavier, 2007; Jha et al., 2011; Kumar and Sathyanarayana, 2012; Bongaarts, 2013; United Nations Population Fund, 2010). Haryana and Punjab record extremely adverse sex ratios at birth, namely, 857 and 863 female births per 1,000 male births, respectively. Other states with substantially adverse sex ratios at birth (less than 900) include Delhi (NCT) (884), Maharashtra (896), Rajasthan (893), Uttar Pradesh (874) and Jammu and Kashmir (895). In eleven other states, sex ratios at birth range from 901 to 950: Andhra Pradesh, Assam, Bihar, Gujarat, Himachal Pradesh, Jharkhand, Madhya Pradesh, Odisha, Tamil Nadu, Karnataka, and West Bengal. In contrast, in such states as Kerala (966) and Chhattisgarh (979), sex ratios at birth have exceeded 952.

\section{Factors underlying the shifts in the sex ratio at birth}

Distortions in the sex ratio at birth are attributed to the convergence of three interlinked factors, namely, the persistence of patriarchal norms and inegalitarian gender roles and consequent son preference, fertility decline and declining family size preferences, and technological advances that permit the detection of the sex of the foetus (Guilmoto, 2011).

Prenatal diagnostic techniques are available today that are intended to detect genetic abnormalities in a foetus but are also able to detect the sex of the foetus. While prenatal diagnostic techniques have been available since the 1970s, they became commonly available in India only in the 1990s (Arnold, Kishor and Roy, 2002). Today, technological advances in the form of ultrasonography, amniocentesis, chorionic villus sampling and, more recently, simple blood tests and even preconception methods, have made it possible to detect the sex of the foetus and enable couples to achieve the desired sex composition of their children, in collusion with unscrupulous medical practitioners willing to circumvent laws forbidding the disclosure of the sex of the foetus (George, 2002). At present, ultrasonography is used most commonly in India as it is most widely available, inexpensive, non-invasive and easy to use; it is also a technology supported by medical practitioners to detect foetal defects and, thus, is a legitimate technology used by pregnant women (United Nations Population Fund, 2012).

Together with the advance of new technologies has been a sharp decline in fertility and family size preferences across the nation. For example, in India, the total fertility rate among women aged 15-44 fell from 3.36 in 1990-1992 to 2.84 in 1998-1999, and further to 2.66 in 2005-2006, and reached 2.4 in the period 2010-2012 (Office of the Registrar General, India, 2013). Over the period 1990-1992 to 2005-2006, moreover, the ideal number of children preferred by women fell from 2.9 to 2.4 and was even lower (2.0) among the youngest age group (ages 15-19) (International Institute for Population Sciences and Macro International, 2007).

While foetal sex-determination technology has become increasingly available and family size preferences have declined considerably, changes in patriarchal norms have not kept pace and strong son preference continues to prevail in India. Indeed, the availability of the technology has enabled couples to achieve a small family size while ensuring the birth of their desired number of sons. For example, an analysis of three rounds of the National Family 
Health Survey (NFHS) data highlights that where the first-born child is female, the sex ratio of the second child is highly skewed towards males; in contrast, where the first-born child is male, the sex ratio of the subsequent child is not affected. Sex ratios at birth were most distorted at parity two (as low as 762), clearly, the consequence of small family size preferences accompanied by persisting son preference and the need to ensure that at least one child is a boy (Kishor and Gupta, 2009). The link to sex selection is also evident from data suggesting that women who had undergone ultrasound examination during pregnancy reported a far lower sex ratio at birth than did those who had not done so (850 versus 943) (Arnold and Parasuraman, 2009).

\section{Legislation}

Concerns about the misuse of prenatal diagnostic techniques for the purpose of prenatal sex determination leading to the selective termination of pregnancies carrying a female foetus led to the passing of the Pre-Natal Diagnostic Techniques (Regulation and Prevention of Misuse) Act (the PNDT Act) in 1994 (Ministry of Health and Family Welfare, 2003). It was amended in 2003 to both emphasise the "prohibition" of sex selection and to widen its scope to include preconception techniques. It was renamed the Pre-Conception and Pre-natal Diagnostic Techniques (PCPNDT) (Prohibition of Sex Selection) Act (Ministry of Health and Family Welfare, 2003). The PCPNDT Act clearly differentiates between the legal use of diagnostic techniques to detect abnormalities in the foetus and the prohibition of its use for sex-selection purposes. The PCPNDT Act is intended "to provide for the prohibition of sex selection, before or after conception, and for regulation of pre-natal diagnostic techniques for the purposes of detecting abnormalities or metabolic disorders or chromosomal abnormalities or certain congenital malformations or sex-linked disorders and for the prevention of their misuse for sex determination leading to female foeticide and for matters connected therewith or incidental thereto."

Several restrictions are imposed through the PCPNDT Act: for example, all genetic counselling centres must be registered under the Act, the sale of ultrasound or imaging machines may only be made to facilities registered under the Act, all those conducting ultrasonography must declare that he or she has not disclosed the sex of the foetus to anyone, all those undergoing any such testing must declare that they do not wish to know the sex of the foetus, and all facilities are expected to prominently declare in writing that disclosure of the sex of the foetus is prohibited under the law. In addition, all facilities may be inspected for violations from time to time, and the authorised officer is empowered to seize equipment and seal facilities that violate the Act. Moreover, statutory bodies, by way of Appropriate Authorities, are empowered to suspend or cancel registrations of facilities without issuing a show cause notice if they perceive that it is necessary to do so in the public interest (Singh, 2013). A person or organisation that advertises facilities for prenatal sex determination faces three years imprisonment and a fine of Rs. 10,000. If a medical officer, owner or employee of any clinic contravenes any of the provisions of the Act, that person can be punished with imprisonment of up to three years and a fine of up to Rs. 10,000; the punishment for repeat offenders is five years and/or a fine of up to Rs. 50,000 (Ministry of Health and Family Welfare, 2006). Finally, any person who "seeks the aid" of a facility for sex determination is liable for the same punishment as is the provider; recognising that women are often coerced into obtaining sex-determination tests, the husband and/or his family are penalised in such cases (Singh, 2013; Ministry of Health and Family Welfare, 2006). While the PCPNDT Act is aimed at curbing sex selection through the misuse of technology, it must be emphasised that the Act in no way affects women's right to terminate a pregnancy in a host of conditions, as laid down in the Medical Termination of Pregnancy (MTP) Act of 1971 (Government of India, 1971; 2003).

The PCPNDT Act is implemented through state- and district-level Appropriate Authorities and Advisory Committees. At the state level, the Act lays down criteria for the appointment of multi-member state-level Appropriate Authorities. While the Supreme Court guidelines stipulate that Appropriate Authorities should be appointed at the district and sub-district levels with the responsibility of enforcing the Act, no criteria have been laid down with regard to who should be appointed to the position of Appropriate Authority at the sub-state level (Jaising, Sathyamala and Basu, 2007). Although under the provisions of the PCPNDT Act, there is no rule on the specific membership of the Appropriate Authority at the district level, in most states it is the Chief Medical Officer who serves as the District Appropriate Authority (DAA) (Jaising, Sathyamala and Basu, 2007). In Haryana, there is a multi-member District Appropriate Authority, whose members include a civil surgeon, a representative from the Women and Child Development Department, and a district attorney (Girls Count, 2014).

The PCPNDT Act empowers District Appropriate Authorities to monitor facilities and take legal action against health care providers found to have disclosed the sex of the foetus or conducted a sex-selective abortion. It also imposes 
strict punishment, by way of fines and imprisonment, on health care providers and families of pregnant women found to have violated the law. It is the prerogative of the Appropriate Authority to call upon the police in case of a law and order problem (Ministry of Health and Family Welfare, 2006; Public Health Foundation of India, 2010). The Act also provides for the constitution of an Advisory Committee to support the Appropriate Authority in performing its functions and recommend decisions on raids and inspections. These Advisory Committees are expected to include at least three medical experts from amongst gynaecologists, obstetricians, paediatricians and medical geneticists; one legal expert, one officer to represent the department dealing with information and publicity and three eminent social workers of whom at least one is a representative of a women's organisation. The Advisory Committee is expected to meet at least once in two months (Ministry of Health and Family Welfare, 2006; Public Health Foundation of India, 2010).

A recent state-level 'Report Card' on the implementation of the Act notes that unlike in several states, District Appropriate Authorities regularly conduct inspections, send the required reports to the state, audit documents submitted by service providers and facilities regarding pregnant women undergoing ultrasonography (Form F) and registration of the facility (Form $\mathrm{H}$ ), physically verify information pertaining to the registration of facilities, and draft court complaints where violations are observed (Girls Count, 2014).

\section{Initiatives intended to reverse the unbalanced sex ratio at birth}

The failure of the PCPNDT Act to curb adverse sex ratios has been attributed to the persistence of gender inequalities and norms favouring sons at any cost, unscrupulous clients and service providers prepared to violate the Act, and difficulties in and/or indifference about enforcing the Act. Three broad categories of initiatives have been undertaken to better translate policies and laws into action. These have included initiatives to ensure that the Act is implemented, to mobilise communities to better understand the Act and the implications of violating it, as well as to promote gender equality and raise the status of the girl child, and to provide special entitlements and conditional cash transfers for the survival and wellbeing of girls. Such initiatives have been undertaken both by the government as well as by civil society organisations. While these are promising, efforts to identify the challenges and successes they have experienced have been limited, and what is available suggests that gaps in understanding persist (see Appendices 1-3 for a summary of selected interventions).

One set of initiatives focuses on communication, advocacy and community mobilisation efforts that have multiple aims: to break down patriarchal norms, raise the status of the girl child and reduce son preference, as well as to raise community and provider awareness about the dangers of a gender-unbalanced society, and about the PCPNDT Act, more specifically. Activities range from public messaging and national campaigns to "save the girl" to more subtle and directed behaviour change communication programmes (see, for example, UNFPA and Breakthrough, 2015). Several programmes are tailored to specific sub-groups, such as students, and while many are delivered by nongovernmental organisations (NGOs), several advocacy and community mobilisation efforts have been led by government agencies, notably those implementing the PCPNDT Act, those in the Integrated Child Development Services (ICDS) Department and so on. Religious leaders and other prominent personalities have also played a role in informing communities about gender-biased sex selection and making efforts to modify patriarchal norms. Finally, the media has played a considerable role in addressing these issues through serials and public service advertisements. While these efforts have not been evaluated in their entirety, there is some indication that public messaging has not been particularly effective or may have served to confuse perceptions about the right to safe abortion and the illegality of sex-selective abortion (Bracken and Nidadovolu, 2005).

Second, a number of measures have been undertaken to strengthen enforcement of the PCPNDT Act. As described above, the Appropriate Authority is mandated with considerable power to inspect and raid facilities, seal premises, and identify and apprehend violators. Law enforcement has sometimes included efforts to identify those violating the law through sting or decoy operations conducted in facilities or among health care providers suspected to have violated the law; evidence so gathered is then used to prosecute and make an example of providers who violate the law. While some success has undoubtedly resulted, the process is laden with challenges. Efforts have been successful in that unscrupulous health care providers have been named and shamed and in some cases, practices affected, imprisonment and the prospect of lengthy court cases, perhaps acting as a deterrent for other providers. At the same time, sting and decoy operations have been hampered by the fact that detection is difficult, authorities are indifferent and many operations do not proceed to court for lack of appropriate evidence or pressure exerted by influential individuals (Jaising, Sathyamala and Basu, 2007). 
Finally, there has been a range of initiatives promoted by the government to raise the status of the girl child. These have included the provision of textbooks, school uniforms, bicycles and scholarships for girls, as well as conditional cash transfer schemes to girls and families of girls on the achievement of various milestones ranging from birth registration to immunisation, completion of a high school education and delayed marriage (see, for example, Sekher, 2015). Several programmes and schemes have been implemented. In Haryana; the two most prominent such schemes are the now discontinued Apni Beti Apna Dhan Scheme, and the Ladli Yojana. The Apni Beti Apna Dhan Scheme, launched in 1995 and discontinued for the cohort born in 1999, was restricted to poor families belonging to socially excluded castes and tribes (SC/ST/OBC) with two or more daughters. Under this Scheme, a bond was purchased in the name of the girl, which matured when the girl turned 18 and, on condition that she remained unmarried at maturity, the girl received Rs. 25,000 (Nanda, 2012). The Ladli Scheme was introduced in the state more recently (2005) and is ongoing; it is a national programme with considerable financial commitment, but has been modified at the state level. In Haryana, the Scheme is available to families with a second daughter; unlike the Apni Beti Apna Dhan Scheme, the Ladli Scheme is open to all, irrespective of caste and poverty status. Under this Scheme, a bond is purchased in the name of the second daughter (Kisan Vikas Patra) and cash transfers of Rs. 5,000 per year are made into this account at the time of registration (birth, for many) and for five years thereafter through the girl's mother/father/guardian. As in the case of the Apni Beti Apna Dhan Scheme, the bond matures when the girl reaches age 18 on condition that she remains unmarried till then. While the amount varies according to when the girl was registered, a girl who is registered at birth stands to receive an amount of close to Rs. 90,000 at age 18 (Department of Women and Child Development, Government of Haryana, n.d.). Other cash transfer schemes available in Haryana include the Indira Gandhi Priyadarshini Viwah Shagun Yojana (Department of Welfare of Scheduled Castes and Backward Castes, Government of Haryana, n.d), the Ladli Social Security Allowance Scheme (Directorate of Social Justice and Empowerment, Government of Haryana, n.d.), and the Devi Rupak Scheme (Department of Health and Family Welfare, Government of Haryana, n.d.). These schemes have different eligibility criteria, and different cash benefits, and are relatively less well known in the state. Although fraught with implementation challenges, evidence of their impact is sparse; while these initiatives may have had some success in increasing birth registration, immunisation of girls, school enrolment and continuation, their link to parents' demand for sons, in general, and gender-biased sex selection, in particular, remains unclear.

\section{Study setting}

The study was conducted in two districts of Haryana, one of which, Kurukshetra, had experienced some improvement in sex ratios at birth and among children by 2011 and a second, Sonipat, in which these ratios remained highly unbalanced. Both districts have largely similar sociocultural characteristics (percentage residing in urban areas, percentage of females who are literate, percentage of the population from socially excluded castes, percentage of the population that is Hindu, and the percentage of the working population engaged in cultivation); and both had similarly adverse sex ratios at birth and among children in 2001 (approximately 125 or worse). They differed, however, on the basis of these ratios in 2011, with Kurukshetra showing an improvement of at least 5-6 points and Sonipat showing hardly any change.

Table 1.1 presents the sociodemographic profile of the study districts and the state. The characteristics of the study sites highlight the sociodemographic similarities between the two districts, and differences in sex ratios in 2011. For example, sex ratios at birth and among children in Kurukshetra fell from 128.5 and 129.7 in 2001 to 122.3 and 122.2, respectively, by around 2011. In Sonipat, in contrast, sex ratios at birth and among children remained about the same at both times (124.2 and 126.9, respectively, in 2001, and 124.1 and 125.3, respectively, in 2011). In contrast, the two districts are roughly similar in terms of most available sociocultural characteristics and, by and large, resembled state averages on these indicators. For example, 29 percent and 31 percent of the populations of Kurukshetra and Sonipat, respectively, live in urban areas compared to 35 percent in Haryana as a whole (Office of the Registrar General, India, 2011), and they comprise, respectively, six percent and four percent of Haryana's population (total populations of nearly 1.5 and 1.0 million, respectively). The female literacy rate was 66 percent in Haryana as a whole, and 70 percent and 69 percent, respectively, in Sonipat and Kurukshetra. While religionwise distributions differ somewhat, with Hindus comprising a larger proportion of the population of Sonipat than that of Kurukshetra (94\% versus $80 \%$ ), proportions belonging to socially excluded castes were similar (19-22\%). Likewise, proportions of the working populations classified as cultivators were also similar (21-27\%). Finally, the total fertility rate of Sonipat (2.7), while similar to that of the state as a whole (2.7), was higher than that of Kurukshetra (2.3). 
Table 1.1: Sociodemographic profile of the study districts and Haryana State

\begin{tabular}{|c|c|c|c|}
\hline Indicators & Haryana & Kurukshetra & Sonipat \\
\hline Population (2011) ${ }^{a}$ & $25,351,462$ & 964,655 & $1,450,001$ \\
\hline Population in urban areas $^{a}(\%)$ & 34.8 & 29.0 & 31.2 \\
\hline \multicolumn{4}{|l|}{ Sex ratio at birth ${ }^{b}$} \\
\hline During 1994-2000 & 119.3 & 128.5 & 124.2 \\
\hline During 2004-2010 & 118.3 & 122.3 & 124.1 \\
\hline \multicolumn{4}{|l|}{ Child sex ratio } \\
\hline $2001^{c}$ & 122.1 & 129.7 & 126.9 \\
\hline $2011^{a}$ & 119.9 & 122.2 & 125.3 \\
\hline Female literacya & 65.9 & 68.8 & 69.8 \\
\hline Population belonging to scheduled castes ${ }^{a}(\%)$ & 20.2 & 22.3 & 18.6 \\
\hline Population belonging to the Hindu religion ${ }^{d}$ (\%) & 87.1 & 79.7 & 94.0 \\
\hline Working population engaged in cultivation ${ }^{c}(\%)$ & 27.8 & 20.5 & 27.2 \\
\hline Total fertility rate (2011) $^{\mathrm{e}}$ & 2.7 & 2.3 & 2.7 \\
\hline
\end{tabular}

Note: affice of the Registrar General and Census Commissioner, India, n.d; ${ }^{b}$ Kumar and Sathyanarayana, 2012; 'Office of the Registrar General and Census Commissioner, India, 2004; ${ }^{d}$ Calculated from district-level microdata of the District Level Household Survey (International Institute for Population Sciences, 2010); ${ }^{e}$ Guilmoto and Rajan, 2013.

\section{Study design}

The study was conducted in the rural and urban areas of the two selected districts of Kurukshetra and Sonipat in Haryana, and focused on a total of 10 primary sampling units (PSUs) (villages) in rural areas, and 10 PSUs (wards) in urban areas in each district. The study included three components, namely, a survey of married women with at least two children, the youngest of whom was born during the five years preceding the interview; and two qualitative components comprising key informant interviews-with health care providers (obstetricians and gynaecologists, radiologists, nurses and others engaged in conducting ultrasound and other prenatal diagnostic techniques) and with programme implementers/managers both in government positions and associated with NGOs.

Survey of women with children aged up to five years: A retrospective study design was employed in which married women with at least two children, the youngest of whom was born during the five years preceding the interview were questioned. Birth histories were ascertained, including the wantedness of each pregnancy, histories of terminations or pregnancy loss, contraception between two births, the use of ultrasound during pregnancy, and whether the sex of the foetus had been disclosed. Also probed were preferences about family size and composition, and attitudes relating to son preference or daughter aversion. Most important, the survey probed women's awareness of the PCPNDT Act and exposure to its implementation, their exposure to communication, advocacy and community mobilisation efforts intended to change attitudes about sons and daughters, in general, and about the acceptability of gender-biased sex selection, in particular.

Key informant interviews with health care providers: In each district, a range of health care providers from both public and private sectors-obstetricians and gynaecologists, radiologists, nurses and those engaged in conducting ultrasound and other prenatal diagnostic techniques-were interviewed in depth in order to obtain their perspectives on the prevalence of gender-biased sex selection in their district, the practices adopted by health care providers in disclosing the sex of the foetus; whether they were aware of inspections, raids and prosecutions of health care providers taking place in their district under the PCPNDT Act, and reasons underlying the improvement in the sex ratio at birth in Kurukshetra versus the persistent adverse sex ratio observed in Sonipat. Challenges faced and recommendations for community-level as well as programme-, system- or provider-level action were also probed.

Key informant interviews with programme implementers/managers in government positions: Key informant interviews were also held with public sector programme implementers and managers from the study districts and at the state level, more generally. Key informants included those district authorities responsible for implementing the law as also for raising awareness or administering various unconditional and conditional cash transfer 
programmes and schemes in each district. They included, for example, staff responsible for administering the PCPNDT Act, representatives of Appropriate Authorities, those supervising the ICDS programme, those responsible for implementing various conditional cash transfer programmes, and those conducting community mobilisation activities. Interviews with these key informants focused on their roles, their perspectives about the implementation of the PCPNDT Act and of various attitude and behaviour change related programmes and schemes, their views about the extent to which the practice of disclosing the sex of the foetus and terminating pregnancies carrying a female foetus persists in their district, and reasons for the differences in trends in the sex ratios at birth in the two districts. As in the case of health care providers, we also probed their perspectives about the challenges they faced and recommendations for community-level and programme- or system-level action.

Key informant interviews with programme implementers/managers of NGOs: The study also sought to interview NGO representatives engaged in implementing interventions relating to raising the status of women and girls, in general, and to stopping gender-biased sex selection, in particular, and those responsible for administering various conditional and unconditional cash transfer programmes for girls residing in the study districts. Unfortunately, there were no such NGOs in Kurukshetra, and hence, interviews with NGO representatives rely solely on those from Sonipat. Issues discussed with NGO representatives were similar to those discussed with programme implementers/ managers in government positions as described above, in that the interviews focused on their experiences, their perspectives about whether community attitudes and practices have changed, their views about the sex ratio situation in the two districts and reasons for the difference, the challenges faced in implementation, and recommendations for community-level and programme- or system-level action.

\section{Study samples and coverage}

Samples for all three components of the study were drawn from individuals residing in or responsible for delivering services in Kurukshetra and Sonipat. Details are provided in Tables 1.2 and 1.3.

Survey of women with at least two children, one of whom was aged 0-5 years: Our study design called for a sample of 1,000 (500 per district, 250 each from rural and urban areas) currently married women with two children, one of whom was aged 0-5 years. This number included inflation to take into account the refusal to participate in the study or the survey, which, together, we assumed to be 10 percent. We note that urban areas were over-sampled so as to enable sub-group analysis.

Ten villages and 10 urban wards were selected in each district based on probability proportional to size (PPS) to represent the district at large. In each selected PSU, a household listing exercise was conducted that listed, on average, 250 households in a village/urban ward; from this list, about 30 women were randomly selected for the interview. A total of 555 (of 603 identified) women in Kurukshetra and 546 (of 614 identified) women in Sonipat were successfully interviewed, suggesting response rates of 92 percent and 89 percent in Kurukshetra and Sonipat, respectively (Table 1.2). In all, 1,217 women were identified and 1,101 of these women were interviewed, yielding a response rate of 91 percent overall. All women were interviewed in their home.

Table 1.2: Coverage of the study: Survey participants, Kurukshetra and Sonipat

\begin{tabular}{lccc}
\hline District and site & $\begin{array}{c}\text { Number of married women with at least two children, } \\
\text { one of whom was aged } \mathbf{0 - 5}\end{array}$ & Response rate (\%) \\
\cline { 2 - 3 } & Identified & Interviewed & \\
\hline Kurukshetra Total & 603 & 555 & 92.0 \\
Kurukshetra Rural & 303 & 277 & 91.4 \\
Kurukshetra Urban & 300 & 278 & 92.7 \\
Sonipat Total & 614 & 546 & 88.9 \\
Sonipat Rural & 307 & 280 & 91.2 \\
Sonipat Urban & 307 & 266 & 86.6 \\
Total & $\mathbf{1 , 2 1 7}$ & $\mathbf{1 , 1 0 1}$ & $\mathbf{9 0 . 5}$ \\
\hline
\end{tabular}


For the qualitative component of the study, we interviewed a total of 50 key informants, as described below and detailed in Table 1.3.

Key informant interviews with health care providers: In each site, reproductive health service providers, including nurses, Auxiliary Nurse Midwives (ANMs), medical officers, obstetrician-gynaecologists, and those providing ultrasound and prenatal diagnostic services (technicians, radiologists) were identified. From amongst providers thus identified, respondents for key informant interviews were selected purposively, ensuring that the array of provider types was included, and that those serving the villages and wards in which our survey was conducted were adequately represented; efforts were made to focus on those serving the villages and wards covered by our survey. Key informant interviews were held with a total of 23 purposively selected health care providers-11 from Sonipat and 12 from Kurukshetra.

Key informant interviews with programme implementers/managers in government positions: In each site, in addition, we interviewed programme implementers/managers from various government sectors; district and state programme implementers included members of the Appropriate Authority responsible for implementing the PCPNDT Act, magistrates and law officers, and staff of the Women and Child Development Department, notably from the ICDS. As above, lists of public sector programme implementers were prepared, and from amongst the programme implementers identified, respondents for key informant interviews were selected purposively, ensuring that those serving the villages and wards in which our survey was conducted were adequately represented, and that those implementing different programmes were included, notably, for example, those responsible for implementing the PCPNDT Act, conducting raids or monitoring facilities, delivering various cash transfer programmes to raise the status of girls, or mobilising communities to raise the status of girls or reject gender-biased sex selection. In total, we conducted key informant interviews with a total of 15 such programme implementers/managers, six from Kurukshetra, six from Sonipat and three at the state level, from Panchkula.

Key informant interviews with programme implementers/managers of NGOs: We also interviewed programme implementers of NGOs working on raising the status of women and girls or on gender-biased sex selection issues, more specifically. As mentioned above, we found no NGOs working on these issues in Kurukshetra; but identified 12 NGOs involved in such work in Sonipat. Consequently, while interviews with NGO programme implementers were not conducted in Kurukshetra, we interviewed 12 such informants from Sonipat, all of whom worked on issues related to raising the status of women and girls, or, more directly, on preventing gender-biased sex selection and the termination of pregnancies carrying a female foetus.

Table 1.3: Coverage of the study: Key informants according to occupation, Kurukshetra and Sonipat, Haryana State

\begin{tabular}{|c|c|c|c|c|}
\hline Key informants & Kurukshetra & Sonipat & Haryana State & Tota \\
\hline A. Health care providers & 12 & 11 & - & 23 \\
\hline General physician/MBBS doctor & 2 & 4 & - & 6 \\
\hline Radiologist & 2 & - & - & 2 \\
\hline Obstetrician-Gynaecologist & 2 & 4 & - & 6 \\
\hline Nurse & 3 & - & - & 3 \\
\hline Auxiliary Nurse Midwife & 3 & 3 & - & 6 \\
\hline B. Programme implementers/managers & 6 & 18 & 3 & 27 \\
\hline In government positions & 6 & 6 & 3 & 15 \\
\hline Law enforcement officiala & 2 & 3 & 2 & 7 \\
\hline ICDS programme manager (PO/CDPO) ${ }^{\mathrm{b}}$ & 2 & 3 & 1 & 6 \\
\hline ICDS frontline worker (Anganwadi Worker or AWW) & 2 & - & - & 2 \\
\hline b. Working with NGOs & - & 12 & - & 12 \\
\hline C. Total & 18 & 27 & 3 & 50 \\
\hline
\end{tabular}

Note: ${ }^{a}$ Under law enforcement officials, we include all government functionaries who were interviewed from the Health Department, those serving in the judiciary and so on; we have clubbed these under law enforcement so as not to reveal identities; ${ }^{b} P O / C D P O$ (Programme Officer, Child Development Project Officer), ICDS, and functionaries of the Integrated Child Protection Scheme (ICPS) and Department of Women and Child Development. 
All three groups of key informants-health care providers and programme implementers/managers in government positions and those associated with NGOs-were drawn largely from urban areas; we note, however, that most of these key informants did indeed serve women from rural areas or were responsible for programmes carried out in rural areas.

\section{Data collection}

Data collection for all three components of the study was conducted simultaneously and took place from September to November 2014. A structured instrument was used to collect data from currently married women with two or more children, one of whom was aged 0-5 years. Key informant interview guidelines were used to interview health care providers and programme implementers/managers.

The survey questionnaire was designed to gather background information of the surveyed women as well as their birth and contraceptive histories, pregnancy loss and induced abortions in each birth interval, the wantedness of each birth and the use of ultrasound. Questions relating to whether the sex of the foetus was ever disclosed were asked for each pregnancy resulting in a live birth, as well as through a direct question about any experience of disclosure, and, at the end of the interview, an opportunity to respond anonymously, by ticking or crossing a card, placing the card in an envelope, sealing it and returning it to the interviewer. Direct questions about the experience of sex-selective abortions were also posed. Further, a range of questions sought to assess women's son preference and gender role attitudes. Aside from these, a series of questions probed women's awareness of the PCPNDT Act and attitudes about the effectiveness of the Act; exposure to messages and community mobilisation efforts relating to gender issues, in general, and gender-biased sex selection, in particular; and awareness about programmes intended to raise the status of girls, and the extent to which daughters were enrolled in any conditional cash transfer programme.

Guidelines for key informant interviews with health care providers comprised a few introductory questions that established the respondent's background and the broad thematic areas to be covered. The topics covered included perceptions about the demand and supply side factors underlying the practice of gender-biased sex selection. It explored provider perspectives on gender-biased sex selection; perceptions about the antenatal care of pregnant women and the routine use of prenatal tests; the extent of misuse of ultrasound technology; provider-client interaction, including counselling and client attitudes and demands for information about the sex of the foetus and subsequent termination of pregnancies carrying a female foetus; provider attitudes about disclosing the sex of the foetus and/or knowingly conducting a sex-selective abortion; provider interaction with authorities with regard to probes into violations of the PCPNDT Act and perceptions/experiences of monitoring of health care providers by the Appropriate Authorities, as well as provider perspectives about the factors underlying the improved sex ratio situation in Kurukshetra versus the persisting adverse situation in Sonipat. Key informants also offered their perceptions about the challenges inhibiting improvements in the sex ratio at birth, and their recommendations for strengthening action at community and provider or programme levels.

Guidelines for key informant interviews with programme implementers/managers covered many issues that were identical to those included in the key informant interview guide for health care providers. Other questions focused on their own areas of experience-conducting community mobilisation activities; raising awareness about the PCPNDT Act and related issues; implementing the Act, including conducting raids and dealing with law enforcement; implementing programmes to raise the status of girls, and finally managing conditional cash transfer programmes for girls. In particular, they were probed about the role of those in authority with regard to apprehending those found to violate the law, on the one hand, and on the other, their views about the extent to which conditional cash transfers and other programmes intended to empower girls, raise awareness and change behaviours had been successful in affecting parental preferences for sons and practices relating to gender-biased sex selection.

Study instruments were prepared in English, translated into Hindi, and pre-tested. Key informant interviews were taped, transcribed and translated into English.

A team of 12 interviewers, trained by Population Council staff, conducted the survey and key informant interviews. The interviewers underwent a four-day training that comprised a combination of classroom sessions, mock interviews and field practice in an urban slum area. Training focused on interviewing methods, the details of the questionnaire and research ethics including issues of confidentiality and privacy. The interviewers were divided into two teams; 
while female interviewers conducted interviews with women, male interviewers tracked respondents, facilitated contact between respondents and interviewers, and conducted the key informant interviews. Each team comprised one field editor who was responsible for field editing, back-checks and quality control of interviews; and one supervisor, responsible for the overall management of fieldwork and team-related logistics as well as assisting in field editing and back-checking.

The principal investigators made frequent visits to monitor and supervise data collection operations. Each team filled quality control sheets regularly, giving the team, the coordinator and principal investigators an opportunity to review the quality of ongoing fieldwork. These quality control sheets were designed to provide information on response rates in each PSU covered, and track reporting of sensitive issues and interviewer performance.

\section{Ethical considerations}

We recognised that serious ethical concerns could arise in both the survey and key informant investigations and adopted suitable precautionary measures. First and foremost, we recognised that women may fear adverse repercussions if they disclosed experiences of gender-biased sex selection. To allay these fears, we assured all respondents that all the data gathered were entirely anonymous; that the interviewers would not share their responses with anyone, including their family members, the authorities, or health care providers, and that names would never be recorded on the questionnaire. The following strategies were adopted, moreover, to maintain privacy and confidentiality.

The interviewers underwent extensive training in ethical issues. Emphasis was laid on explaining the content of the questionnaire, the respondent's right to refuse to participate or answer any question, and informed consent. At the same time, we trained interviewers on how to ask sensitive questions regarding disclosure of the sex of the foetus and the experience of sex-selective abortion in empathetic and non-judgemental ways, and emphasised the importance of offering to refer those in need to appropriate nearby organisations. Third, before entering a PSU, interviewer teams were instructed to apprise community leaders of the study and seek their support for its implementation in the community. This step ensured that community support was forthcoming and enabled team members to build rapport within the community easily. We note that despite the sensitive nature of the questions, not a single PSU refused permission to our teams on the grounds of study content.

Every effort was made to maintain privacy in the course of the interview. To ensure that the interviews were not overheard by family members or others, the interviewers conducted the interview in a separate room in the respondent's home, asked questions in whispers, called on a co-interviewer designated for this purpose to hold parallel discussions with adults or others interested in listening to the interview, or re-scheduled the interview so as to enable full confidentiality. Interviewers were permitted to skip to relatively non-sensitive sections in case the interview was observed by others. Each team was trained to assign one interviewer to conduct parallel discussion sessions with bystanders, thereby providing privacy to the interview. Finally, the interviewers were instructed that if privacy could not be ensured, the interview must be terminated without asking sensitive questions. Notwithstanding these efforts, we acknowledge that some women who had been informed about the sex of their foetus or had terminated a pregnancy carrying a female foetus may not have reported these events accurately during the interview.

All the questionnaires were anonymous and names were never recorded on them. In order to preserve the confidentiality of the respondent, signing the consent form was optional; however, the interviewer was required to sign that she or he had explained the content of the consent form to the respondent. Consent forms were detached and stored separately from the questionnaires.

Finally, we also recognised the need for responding appropriately to requests from respondents for help or information related to harassment because they do not have a son, or because they had refused to undergo gender-biased sex selection or an abortion, or, in contrast, information related to their eligibility for, access to or difficulties in accessing benefits from unconditional and conditional cash transfer (CCT) programmes. Our field staff members were trained and equipped to refer such requests to local NGOs or concerned government authorities in the selected districts as appropriate.

The protocol for this study was approved by the Population Council's Institutional Review Board. 


\section{Data processing}

All completed questionnaires were sent to the Council's office in New Delhi for editing and data processing. Completed questionnaires were rechecked and further edited in the office for omissions and consistency. Responses to open-ended questions were scrutinised and common responses were provided codes. For entering the edited data, a special software package was developed using CSPro 5.1. Data were entered twice by different entry operators to minimise entry problems. The raw data were validated and cleaned to remove possible inconsistencies. The analysis of data was carried out using SPSS 18.0 and STATA 13.0. In each district, the sample was weighted to adjust for oversampling in urban areas and non-response rates.

For textual data, a coding scheme was developed. Coded blocks of text relating to specific themes, for example, perceptions about the disclosure of the sex of the foetus in each district; about the extent to which the law was implemented and the kinds of typical practices employed; attitudes about whether laws and programmes would affect gender-biased sex selection; the array of reasons offered for the improvement of the sex ratio situation in Kurukshetra versus the persistently adverse situation in Sonipat, and recommendations for community-level and programme- or provider/system-level action.

\section{Sociodemographic characteristics of women}

Table 1.4 presents the sociodemographic characteristics of the women who participated in the survey. Findings show that the background characteristics of the women in the two districts were similar. Most were in their 20s, with a mean age of 28. The majority was Hindu in both districts (94-96\%); we note that in Kurukshetra, our sample contains a somewhat larger proportion of Hindus than in the district more generally (see Table 1.1). Most women in our sample came from households of similar socioeconomic status (standard of living index 32-34), and a similar proportion of women in both districts reported having worked for wages in the year preceding the interview (24\%).

Differences were also observed (Table 1.4). Castewise distributions suggest that somewhat more women in Sonipat than Kurukshetra belonged to general castes ( $47 \%$ versus $36 \%$ ), and correspondingly, fewer belonged to "other backward' castes (28\% versus $41 \%)$.

Table 1.4: Selected sociodemographic characteristics of women who participated in the survey, according to residence, Kurukshetra and Sonipat

\begin{tabular}{|c|c|c|c|c|c|c|}
\hline \multirow{2}{*}{$\begin{array}{l}\text { Sociodemographic } \\
\text { characteristics }\end{array}$} & \multicolumn{2}{|c|}{ Urban } & \multicolumn{2}{|c|}{ Rural } & \multicolumn{2}{|c|}{ Total } \\
\hline & Kurukshetra & Sonipat & Kurukshetra & Sonipat & $\begin{array}{l}\text { Kurukshetra } \\
(\mathrm{N}=555)\end{array}$ & $\begin{array}{l}\text { Sonipat } \\
(\mathrm{N}=546)\end{array}$ \\
\hline Age (years) & & & & * & & \\
\hline $18-19$ & 0.0 & 0.6 & 0.2 & 1.1 & 0.2 & 0.9 \\
\hline $20-24$ & 14.3 & 12.4 & 24.5 & 26.2 & 21.8 & 21.8 \\
\hline $25-29$ & 42.9 & 42.0 & 41.4 & 47.7 & 41.8 & 45.9 \\
\hline $30-34$ & 29.9 & 33.7 & 29.4 & 19.3 & 29.5 & 23.9 \\
\hline 35 and over & 12.9 & 11.2 & 4.4 & 6.1 & 6.7 & 7.5 \\
\hline Mean age in years & 29.2 & 29.3 & 27.7 & 27.3 & 28.1 & 27.9 \\
\hline Religion & & & & * & & $* * *$ \\
\hline Hindu & 90.5 & 88.7 & 94.6 & 99.7 & 93.7 & 96.1 \\
\hline Muslim & 2.7 & 8.9 & 0.7 & 0.3 & 1.3 & 3.1 \\
\hline $\begin{array}{l}\text { Other (Christian, Sikh, Buddhist } \\
\text { or Jain) }\end{array}$ & 6.8 & 2.4 & 4.6 & 0.0 & 5.0 & 0.7 \\
\hline Caste/ethnicity & & & & $* * *$ & & $* * *$ \\
\hline $\mathrm{SC} / \mathrm{ST}^{\mathrm{a}}$ & 16.3 & 10.1 & 24.7 & 31.5 & 22.5 & 24.8 \\
\hline OBC & 31.3 & 31.5 & 44.5 & 26.7 & 41.1 & 28.3 \\
\hline General & 52.4 & 58.3 & 30.8 & 41.8 & 36.4 & 47.0 \\
\hline
\end{tabular}


Table 1.4: (Cont'd)

\begin{tabular}{|c|c|c|c|c|c|c|}
\hline \multirow{2}{*}{$\begin{array}{l}\text { Sociodemographic } \\
\text { characteristics }\end{array}$} & \multicolumn{2}{|c|}{ Urban } & \multicolumn{2}{|c|}{ Rural } & \multicolumn{2}{|c|}{ Total } \\
\hline & Kurukshetra & Sonipat & Kurukshetra & Sonipat & $\begin{array}{l}\text { Kurukshetra } \\
(\mathrm{N}=555)\end{array}$ & $\begin{array}{l}\text { Sonipat } \\
(N=546)\end{array}$ \\
\hline Years of schooling & & $* *$ & & $* * *$ & & $* * *$ \\
\hline None & 19.2 & 7.8 & 17.4 & 10.3 & 17.8 & 9.7 \\
\hline $1-7$ & 17.1 & 15.0 & 42.8 & 31.7 & 36.0 & 26.6 \\
\hline $8-11$ & 23.3 & 20.4 & 22.0 & 35.2 & 22.3 & 30.6 \\
\hline 12 and above & 40.4 & 56.9 & 17.8 & 22.8 & 23.8 & 33.2 \\
\hline $\begin{array}{l}\text { Median years of schooling } \\
\text { completed }\end{array}$ & 10 & 12 & 7 & 8 & 7 & 9 \\
\hline $\begin{array}{l}\text { Standard of living index } \\
\text { [mean, range } 7 \text { to } 48 \text { ] }\end{array}$ & 32.3 & $33.8^{*}$ & 28.9 & $30.1^{* *}$ & 29.8 & 31.2 \\
\hline Wage work status & & & & & & \\
\hline $\begin{array}{l}\text { Engaged in any paid work during } \\
\text { the last } 12 \text { months }\end{array}$ & 23.7 & 25.1 & 24.2 & 23.0 & 24.1 & 23.6 \\
\hline Women's agency & & & & & & \\
\hline $\begin{array}{l}\text { Decision making: Makes } \\
\text { independent decisions on at } \\
\text { least one of the following: how } \\
\text { to spend money, to which school } \\
\text { to send children, and the facility } \\
\text { in which she delivered }\end{array}$ & 61.5 & 64.0 & 57.1 & 54.9 & 58.3 & 57.7 \\
\hline $\begin{array}{l}\text { Freedom of movement: is } \\
\text { allowed to go unescorted to } \\
\text { all three of the following: a } \\
\text { meeting/programme, to visit a } \\
\text { relative outside the tola/mohalla, } \\
\text { to a show or mela }\end{array}$ & 66.0 & 68.7 & 55.7 & $44.5^{* *}$ & 58.4 & $52.0^{*}$ \\
\hline $\begin{array}{l}\text { Self-efficacy: never finds it } \\
\text { difficult to express opinions to } \\
\text { her husband on working outside } \\
\text { the home, going out unescorted, } \\
\text { or the education and care of } \\
\text { children }\end{array}$ & 96.7 & 94.1 & 92.8 & $88.5^{*}$ & 93.8 & $90.2^{*}$ \\
\hline
\end{tabular}

Note: ${ }^{*},{ }^{* *}$ and ${ }^{* * *}$ indicate that differences between Kurukshetra and Sonipat, Kurukshetra urban and Sonipat urban, and Kurukshetra rural and Sonipat rural are significant at $p<0.05, p<0.01$ and $p<0.001$, respectively.

ancludes one woman in Kurukshetra and two women in Sonipat who belonged to Scheduled Tribes (ST); SC=Scheduled castes; $\mathrm{OBC}=$ Other Backward Castes.

${ }^{b}$ Household economic status was measured using a standard of living index composed of household asset data on ownership of selected durable goods, including means of transportation, as well as data on access to a number of amenities. The standard of living index was constructed by allocating the following scores to a household's reported assets or amenities: type of house: 2 for pucca; 1 for semi-pucca; 0 for kachcha; agricultural land owned: 4 for more than 10 acres; 3 for more than 5 to 10 acres; 2 for more than 2.5 to 5 acres; 1 for less than 2.5 acres or if respondent did not know how much land; 0 for no land; access to toilet facility: 4 for own toilet; 2 for shared or own pit toilet; 1 for a shared pit toilet; 0 for no facility; fuel for cooking: 2 for electricity, liquid petroleum gas, or biogas; 1 for coal/charcoal/kerosene/wood/crop residue/dung cakes; 0 for other fuels; source of drinking water: 4 for own piped water; 3 for own open well; 2 for public or shared piped water, hand pump or covered well; 1 for public/shared open well; 0 for other water sources; access to electricity: 3 for electricity; 0 for no electricity; ownership of different durable goods: 4 for car/truck, thresher or tractor; 3 each for motor cycle/scooter, refrigerator, computer/laptop, land line/mobile, colour television,; 2 each for bicycle, electric fan, sewing machine, water pump, animal drawn cart; 1 for a watch/clock The index score, so constructed, ranged from 0 to 49. 
Educational attainment levels and wage work status also differed somewhat. For example, women in Sonipat were better educated than their counterparts in Kurukshetra: more women in Sonipat than Kurukshetra had 12 or more years of education (33\% versus $24 \%$ ) and fewer were uneducated (10\% versus $18 \%$ ); median years of education completed, thus, ranged from seven in Kurukshetra to nine in Sonipat.

Differences were also evident in aspects of women's agency measured in terms of reported decision making authority, freedom of movement to visit various places unescorted, and self-efficacy or ability to express opinions to the husband. While decision-making authority was expressed by two-thirds of all women, irrespective of district and rural-urban residence, significantly more women from Kurukshetra than Sonipat reported freedom of movement to go unescorted to a meeting or programme, to visit friends or relatives outside the tola/mohalla (area of residence), and to attend a show or mela (a fair) (58\% versus $52 \%$ ); they were also significantly more likely to be able to express themselves freely to their husband on household matters (94\% versus $90 \%$ ). While interdistrict differences were narrow among urban women, they were marked among those from rural areas.

\section{Structure of this report}

This report has six main sections apart from this introductory chapter. Chapter 2 focuses on factors underlying unbalanced sex ratios in Kurukshetra and Sonipat, from survey and textual data drawn from women and key informants. Chapters 3, 4 and 5 discuss findings from both the survey and the key informant interviews with regard, respectively, to communication, advocacy and community mobilisation programmes; law enforcement experiences; and educational entitlements and conditional cash transfer programmes intended to enhance the status of the girl child. Chapter 6 presents the perspectives of key informants on four key issues: whether there has been a decline in their district in respect of the disclosure of the sex of the foetus and termination of pregnancies carrying a female foetus, and if so, the reasons for this decline; factors underlying the improvements in the sex ratio at birth in Kurukshetra compared with the stagnation in the sex ratio in Sonipat; and recommendations for future action to ensure balanced sex ratios. Chapter 7 integrates the findings of earlier chapters, to arrive at overall conclusions about what likely worked to improve the situation with regard to gender-biased sex selection and skewed sex ratios in Kurukshetra but not in Sonipat, and offers recommendations for future programmes and research. 


\section{Chapter 2 \\ Factors underlying unbalanced sex ratios}

In both districts, although women's attitudes to son preference were similar as were patterns of prenatal sex disclosure, compared to their counterparts in Kurukshetra, women in Sonipat were less likely to want no more children and to practise contraception if they had two sons as opposed to two daughters. However, they were more likely to seek disclosure at higher parities (three and above); and more likely to report that they or someone they knew had been told the sex of their foetus. Rural women were also significantly more likely than their urban counterparts to believe there is nothing wrong in seeking disclosure. Key informants-health care providers as well as programme implementers from both public and nongovernmental sectors-affirmed that son preference is declining among younger, better-educated couples, but acknowledged that change is gradual, and that many tend to succumb to pressure from elders. Overall, sex-selective abortion was reported by 3-4 percent of women who had undergone an abortion; key informant estimates were higher-ten to even fifty percent. Finally, the finding that sociodemographic differentials in both the extent of son preference and the experience of disclosure of the sex of the foetus were narrow, and particularly so in the case of disclosure, suggest the pervasiveness of the practice across all groups.

This chapter explores the factors underlying unbalanced sex ratios in Sonipat and Kurukshetra from survey and textual data drawn from women and key informants. Districtwise sex ratios of children ever born and surviving, as gleaned from our survey, are not provided in this report because the sample is too small to provide reliable estimates of sex ratios and because it was restricted to a subgroup of women who had two or more children, the youngest of whom was born in the five years preceding the interview.

From the survey of women with two or more children, one of whom was aged 0-5 years at the time of the interview, we focus on each of the three preconditions identified by Guilmoto (2011) as key in accounting for skewed sex ratios at birth, namely, preference for small families, persistent strong son preference, and access to prenatal diagnostic technology. We follow this discussion with the perspectives of key informants relating to two of these three preconditions, namely persistent strong son preference and access to prenatal diagnostic technology.

\section{A. Perspectives of women}

In this section, we explore the responses of the surveyed women on family size preferences, son preference, and access to prenatal diagnostic technology, and subsequent termination of pregnancies carrying a female foetus. We also explore women's attitudes about having a son on the one hand, and the acceptability of gender-biased sex selection, on the other.

\section{Small family size preferences}

Small family size norms are widely espoused by women in both districts. As seen in Table 2.1, more than four in five women reported a preference for two children, and some three to five percent for just one child. In contrast, just seven percent of women considered three or more children to be ideal. A small proportion of women (4-6\%), in addition, gave non-numerical responses.

As far as actual experiences were concerned too, small family sizes were reported (Table 2.1). On average, women reported 2.6 children ever born, with urban women reporting marginally smaller numbers of children $(2.4-2.5)$ than did rural women (2.7-2.8). As mentioned earlier, all women in the sample had at least two children and findings suggest that the majority did indeed have just two children (65-66\%). In addition, almost one-quarter (23-24\%) had three children, and about a tenth had four or more children (11\%). Irrespective of district and rural-urban residence, moreover, women reported an average of 1.2-1.3 sons. However, among women who had three children, those from Sonipat reported a slightly but significantly larger number of sons than did their counterparts from Kurukshetra (1.54 and 1.35, respectively). Moreover, the large majority (89\% in each district) wanted no more children, reiterating the strength with which the two-child norm was held by women in both districts. 
Table 2.1: Ideal and actual family size

Percent distribution of women by their ideal family size preference and actual family size, according to residence, Kurukshetra and Sonipat

\begin{tabular}{|c|c|c|c|c|c|c|}
\hline \multirow[t]{2}{*}{ Family size and preferences } & \multicolumn{2}{|c|}{ Urban } & \multicolumn{2}{|c|}{ Rural } & \multicolumn{2}{|c|}{ Total } \\
\hline & Kurukshetra & Sonipat & Kurukshetra & Sonipat & Kurukshetra & Sonipat \\
\hline \multicolumn{7}{|l|}{ Ideal number of children } \\
\hline 1 & 4.1 & 5.9 & 2.9 & 4.2 & 3.2 & 4.8 \\
\hline 2 & 85.6 & 81.1 & 85.8 & 82.0 & 85.8 & 81.7 \\
\hline 3 & 4.8 & 6.5 & 6.8 & 5.3 & 6.3 & 5.7 \\
\hline $4+$ & 0.7 & 1.2 & 0.7 & 1.9 & 0.7 & 1.6 \\
\hline $\begin{array}{l}\text { Up to God/Non-numerical } \\
\text { response }\end{array}$ & 4.8 & 5.3 & 3.7 & 6.6 & 4.0 & 6.2 \\
\hline $\begin{array}{l}\text { Mean (among those providing } \\
\text { a numerical response) }\end{array}$ & 2.0 & 2.0 & 2.1 & 2.1 & 2.1 & 2.1 \\
\hline Children ever born (mean) & 2.5 & 2.4 & 2.7 & 2.8 & 2.6 & 2.6 \\
\hline \multicolumn{7}{|l|}{ Surviving children } \\
\hline 2 & 69.2 & 76.2 & 65.4 & 59.8 & 66.4 & 64.8 \\
\hline 3 & 23.3 & 17.9 & 22.5 & 26.7 & 22.7 & 24 \\
\hline $4+$ & 7.5 & 6.0 & 12.0 & 13.5 & 10.8 & 11.2 \\
\hline Mean & 2.4 & 2.3 & 2.5 & 2.6 & 2.5 & 2.5 \\
\hline \multicolumn{7}{|l|}{$\begin{array}{l}\text { Mean number of sons at } \\
\text { different parities }\end{array}$} \\
\hline Parity 2 & 1.05 & 1.13 & 1.16 & 1.18 & 1.13 & 1.16 \\
\hline Parity 3 & 1.39 & $1.63^{+}$ & 1.33 & 1.51 & 1.35 & $1.54^{*}$ \\
\hline Parity 4+ & 1.90 & 1.63 & 1.65 & 1.55 & 1.69 & 1.56 \\
\hline All & 1.23 & 1.26 & 1.28 & 1.34 & 1.27 & 1.31 \\
\hline \multicolumn{7}{|l|}{ Desire for additional childrena } \\
\hline Don't want more children & 88.3 & 89.9 & 89.2 & 88.7 & 89 & 89.1 \\
\hline Want additional children & 10.6 & 7.8 & 9.7 & 10.2 & 9.9 & 9.5 \\
\hline It depends & 1.1 & 2.3 & 1.1 & 1.1 & 1.1 & 1.5 \\
\hline Number of women & 278 & 266 & 277 & 280 & 555 & 546 \\
\hline
\end{tabular}

Note: + and ${ }^{*}$ indicate that differences between Kurukshetra and Sonipat, Kurukshetra urban and Sonipat urban, and Kurukshetra rural and Sonipat rural are significant at $p<.10$ and $p<.05$, respectively. ${ }^{a}$ Sterilised women are assumed to want no more children.

In short, the small family size norm was well entrenched among women from both districts and from both rural and urban areas.

\section{Son preference}

A second precondition for skewed sex ratios at birth is the extent of son preference expressed by women and their families. We measured the extent of son preference in several ways. First, using a direct question posed to assess the number of sons and daughters a woman considered ideal, we calculated the proportion of women who had two living children and did not express a preference for sons over daughters when asked about their ideal number of sons and daughters. A second indicator of son preference was the extent to which a woman's desire to continue childbearing depended on the sex composition of her living children. In order to measure this, we compared, among those who had two living children, the proportion of women with two sons wanting no more children with the proportion of women with two daughters wanting no more children. Clearly, if there were no preference for sons versus daughters, the ratio of these two proportions would be 1.0, and the higher the value of the ratio, the stronger 
is the son preference. Finally, since we know son preference affects the family planning behaviour of couples, we examined the extent to which a woman's use of contraception was associated with the sex composition of her living children. A simple indicator was constructed to measure this-we compared, among those who had two living children, the proportion of women with two sons currently using contraception with the proportion of women with two daughters using contraception. As above, if there were no preference for sons over daughters, the ratio of these two quantities would be 1.0, and the higher the value of the ratio, the stronger is the son preference.

Findings suggest that son preference was strong in both districts. On the first of the three indicators, ideal family size, differences were muted. For example, only one in five women with two living children did not express a preference for a particular sex, and percentages were similar in both districts (20\%). Some difference was observed among women in rural versus urban areas, however. Overall, more urban than rural women reported that the sex of children did not matter to them; districtwise differences suggest, however, that more urban women from Sonipat than Kurukshetra (30\% versus 23\%), and more rural women from Kurkukshetra than Sonipat (19\% versus $15 \%$ ) so reported (Figure 2.1).

Figure 2.1: Percentage of women with two children who expressed no preference for the sex of their children, according to residence, Kurukshetra and Sonipat

Indifference about the sex of children, women with two children

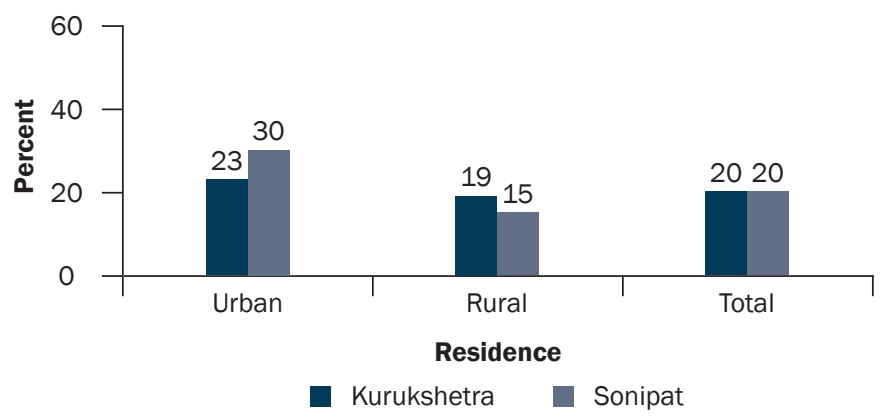

Our second and third indicators affirm a strong preference for sons in both districts. Now, interdistrict differences are apparent, and, as seen in Figures $2.2 \mathrm{a}$ and $2.2 \mathrm{~b}$, son preference as assessed by these two measures, appears to be far stronger in Kurukshetra than in Sonipat. For example, the ratio of women with two sons versus two daughters expressing a desire for no more children was significantly greater in Kurukshetra (3.0) than in Sonipat (1.8) (Figure 2.2a). This picture was similar in both urban and rural areas of the two districts as well. So too, the ratio of women with two sons versus those with two daughters who were practising contraception at the time of the survey was significantly higher in Kurukshetra (1.58) than in Sonipat (1.36); differences were particularly pronounced in rural areas (2.31 versus 1.53) (Figure 2.2b).

Figure 2.2: Indicators of son preference among women with two living children, according to residence, Kurukshetra and Sonipat

2.2a. Women who wanted no more children among those with two sons versus two daughters (ratio)

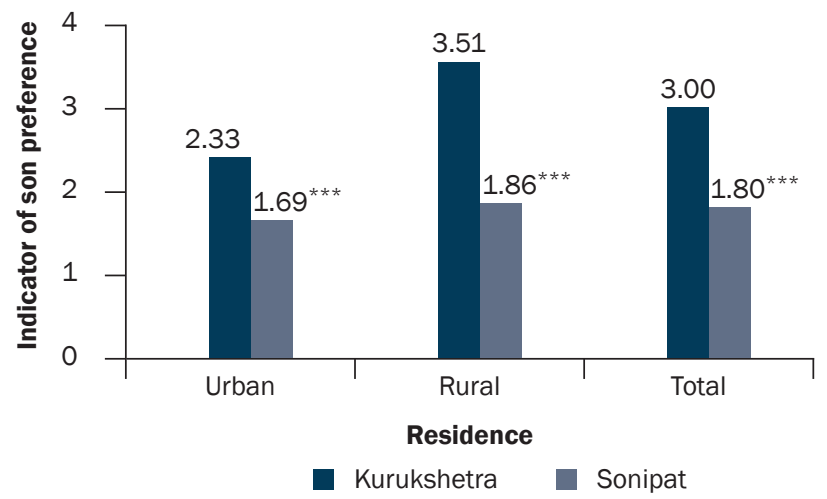

2.2b. Women currently using contraception among those with two sons versus two daughters (ratio)

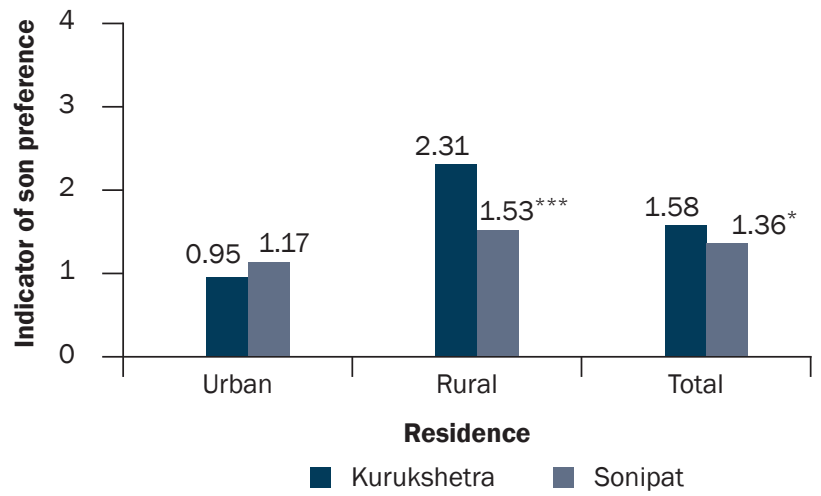

Note: * and *** indicate that differences between Kurukshetra and Sonipat, Kurukshetra urban and Sonipat urban, and Kurukshetra rural and Sonipat rural are significant at $p<.05$ and $p<0.001$, respectively. 
Finally, we assessed women's attitudes about having sons and daughters, and again, as depicted in Table 2.2, it is clear that son preference was prevalent in both districts. Indeed, considerable proportions believed that a son is essential to continue the family line (66-69\% overall), that having a son determines a woman's status in her family (42-49\%), and that a family without a son gets less respect in society than one with sons (32-38\%). Although fewer, considerable percentages of women also agreed that a woman with just daughters is unfortunate (16-17\%). While women in rural areas of each district were more likely than their urban counterparts to display attitudes suggesting strong son preference, interdistrict differences were somewhat narrow in most cases except in two instances. In urban areas, for example, women from Kurukshetra were significantly more likely than their counterparts from Sonipat to believe that a son is essential to continue the family line, and that a son determines the status of the woman (mother). In contrast, in rural areas, significantly fewer women from Kurukshetra than Sonipat believed that the presence of a son affected the status of women in their family.

In order to summarise the extent of son preference, an index was created that summed women's responses on these four indicators of son preference. The index ranged from 0 , if respondents did not report attitudes favouring boys over girls in all four statements, to 4 if responses reflected son preference on all four statements. Findings suggest that women reported attitudes reflecting son preference on an average of 1.6-1.7 of the four statements, overall; attitudes were more likely to reflect stronger son preference among urban women from Kurukshetra than their counterparts from Sonipat; in contrast, interdistrict differences among women in rural areas were negligible.

Table 2.2: Attitudes about son preference

\section{Percentage of women reporting various attitudes relating to son preference, according to residence,} Kurukshetra and Sonipat

\begin{tabular}{|c|c|c|c|c|c|c|}
\hline \multirow{2}{*}{$\begin{array}{l}\text { Attitude about son } \\
\text { preference }\end{array}$} & \multicolumn{2}{|c|}{ Urban } & \multicolumn{2}{|c|}{ Rural } & \multicolumn{2}{|c|}{ Total } \\
\hline & Kurukshetra & Sonipat & Kurukshetra & Sonipat & Kurukshetra & Sonipat \\
\hline \multicolumn{7}{|l|}{ Women who agreed that: ${ }^{1}$} \\
\hline $\begin{array}{l}\text { It is important to have sons } \\
\text { because only they can } \\
\text { continue the family line }\end{array}$ & 59.8 & $43.8^{* *}$ & 72.2 & 75.6 & 68.9 & 65.8 \\
\hline $\begin{array}{l}\text { It is important to have } \\
\text { sons because having a son } \\
\text { determines a woman's status }\end{array}$ & 32.5 & $19.4^{*}$ & 45.3 & $62.1^{* *}$ & 41.9 & 48.9 \\
\hline $\begin{array}{l}\text { If a family does not have a } \\
\text { son, it gets less respect in } \\
\text { society }\end{array}$ & 31.9 & 19.1 & 40.8 & 37.3 & 38.4 & 31.7 \\
\hline $\begin{array}{l}\text { A woman with only daughters } \\
\text { is unfortunate }\end{array}$ & 9.7 & 6.3 & 18.9 & 20.7 & 16.5 & 16.3 \\
\hline Index of son preference $(0-4)$ & 1.34 & $0.89^{*}$ & 1.77 & 1.96 & 1.66 & 1.63 \\
\hline Cronbach's alpha & 0.64 & 0.66 & 0.68 & 0.62 & 0.67 & 0.69 \\
\hline Number of women & 278 & 266 & 277 & 280 & 555 & 546 \\
\hline
\end{tabular}

Note: ${ }^{*}$ and ${ }^{* *}$ indicate that differences between Kurukshetra and Sonipat, Kurukshetra urban and Sonipat urban, and Kurukshetra rural and Sonipat rural are significant at $p<.05$ and $p<0.01$, respectively. ${ }^{1}$ Remaining percentages of women either disagreed or were uncertain;

\section{Access to technology enabling disclosure of the sex of the foetus}

The third precondition for distorted sex ratios at birth is the use of technologies to detect the sex of the foetus and selectively terminate pregnancies carrying a female foetus. In India, the most commonly used method of detecting the sex of the foetus is ultrasonography. While ultrasonography is used by large proportions of women for monitoring the growth and development of the foetus, disclosure of the sex of the foetus is not permitted under the PCPNDT Act. Yet, many health care providers do disclose such information to women and/or their families, resulting in the subsequent abortion of female foetuses. 
In this section, we explore women's access to technologies enabling disclosure of the sex of the foetus, the extent of termination of pregnancies carrying a female foetus and attitudes about the acceptability of gender-biased sex selection.

Experience of seeking disclosure of the sex of the foetus: Several questions were posed to assess the extent to which women reported disclosure of the sex of the foetus during any of their pregnancies. For one, for each pregnancy, our survey asked whether ultrasound testing had been undertaken, and specifically, whether the doctor had disclosed to them the sex of the foetus. Second, a direct and general question was posed, that asked whether the woman had ever received information about the sex of the foetus she was carrying. And finally, recognising that women may be unwilling or uncomfortable about revealing, in a direct face-to-face situation, that they had violated the law, we also inquired about disclosure of the sex of the foetus indirectly, in an anonymous (but linked) format. For this, at the end of the interview, women were handed a card and were asked to mark a tick if the sex of the foetus had been disclosed to them after an ultrasound or any other prenatal diagnostic test during any of their pregnancies, and a cross if not. They were also told to place the card in an envelope provided by the interviewer, seal it, and return it to the interviewer. The interviewer did not observe this part of the interview but informed the respondent that Council staff in Delhi would be able to link the response on the card with other responses made in the main body of the interview. In addition, we also inquired about the respondent's acquaintance with a friend, relative and/or someone in the community who had received information about the sex of their foetus.

Figure 2.3 and Figures 2.4a to 2.4c illustrate the prevalence of ultrasonography use and disclosure of the sex of the foetus in the study districts, respectively. Findings presented in Figure 2.3 suggest that ultrasonography was widely used to monitor the growth and development of the foetus in both districts. Overall, more women from Kurukshetra than Sonipat reported the experience of ultrasonography (93\% versus $88 \%$ ). While interdistrict differences were not found in urban areas (90-92\% of women reported undergoing ultrasonography), they were significant in rural areas, with 94 percent of the women from Kurukshetra and 87 percent of those from Sonipat reporting the experience of ultrasonography.

Figures $2.4 \mathrm{a}$ to $2.4 \mathrm{c}$ present the prevalence of the disclosure of the sex of the foetus among women as reported by direct questioning (Figure 2.4a) as well as through the indirect, anonymous format (Figure 2.4b), and the combined direct and indirect approaches (Figure 2.4c). Overall, only few women reported that they had sought or had been informed about the sex of their foetus after an ultrasound. In face-to-face reporting, about six percent (5.7-6.3\%) of women from Kurukshetra and Sonipat admitted that they had obtained information about the sex of the foetus during one or more of their pregnancies (Figure 2.4a).

Figure 2.3: Percentage of women who had undergone an ultrasound test for foetal monitoring, according to residence, Kurukshetra and Sonipat

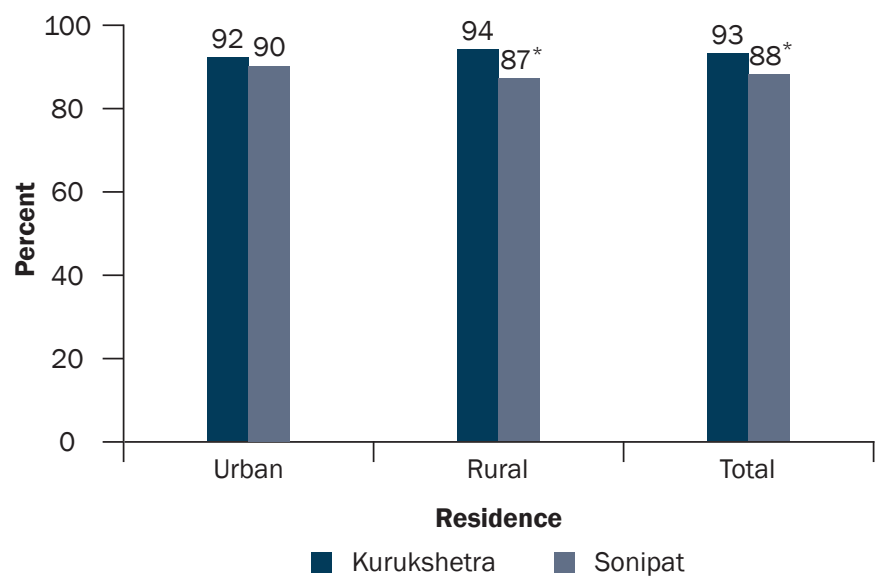

Note: Experience of ultrasonography was not asked in the case of pregnancies ending in a stillbirth or miscarriage. *Indicates that differences between Kurukshetra and Sonipat, Kurukshetra urban and Sonipat urban, and Kurukshetra rural and Sonipat rural are significant at $p<.05$.
When responses made in the face-to-face format were supplemented by those made in the anonymous format $(6-7 \%$ as shown in Figure $2.4 \mathrm{~b})$, percentages increased: about eight percent (7.7-8.4\%) of women from Kurukshetra and Sonipat indicated that they had been told the sex of their foetus (Figure 2.4c). Districtwise differences in combined responses to direct and indirect questions were not evident either in urban areas (5.4-5.5\%) or in rural areas (8.5-9.6\%), however, rural-urban differences were clearly evident with more women from rural than urban areas reporting disclosure of the sex of the foetus after an ultrasound (Kurukshetra: $8.5 \%$ versus $5.4 \%$; Sonipat: $9.6 \%$ versus $5.5 \%$ ).

Findings also suggested that women were clearly more willing to admit that they knew someone (a relative, friend and/or acquaintance in their community) who had undergone gender-biased sex selection than they were to admit their own experience (not shown in the figure). Indeed, familiarity with gender-biased sex selection-either through personal experience or acquaintance with 
Figure 2.4a: Percentage of women who had obtained information about the sex of the foetus (any pregnancy, direct question), according to residence, Kurukshetra and Sonipat

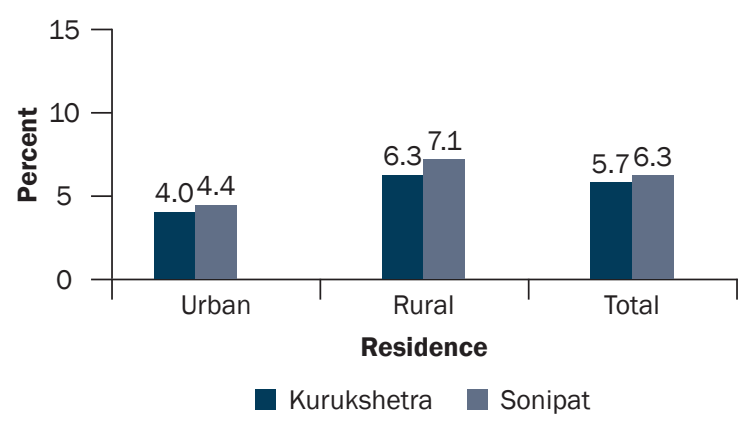

Note: Experience of ultrasonography was not asked in the case of pregnancies ending in a stillbirth or miscarriage.

Figure 2.4b: Percentage of women who had obtained information about the sex of the foetus (any pregnancy, anonymous (indirect) format), according to residence, Kurukshetra and Sonipat

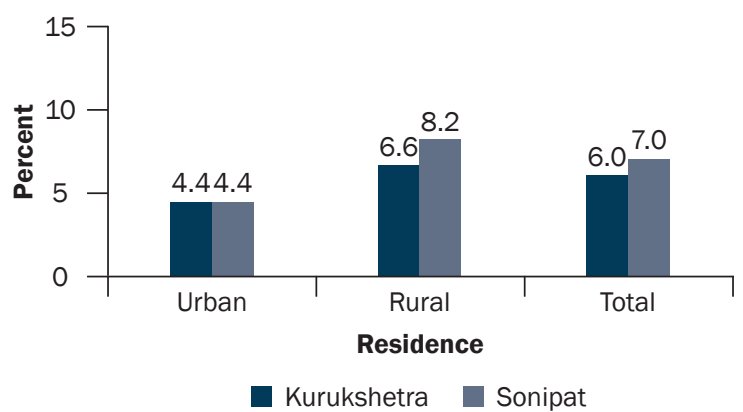

Note: Experience of ultrasonography was not asked in the case of pregnancies ending in a stillbirth or miscarriage.

Figure 2.4c: Percentage of women who obtained information about the sex of the foetus (any pregnancy, in response to direct and indirect questions), according to residence, Kurukshetra and Sonipat

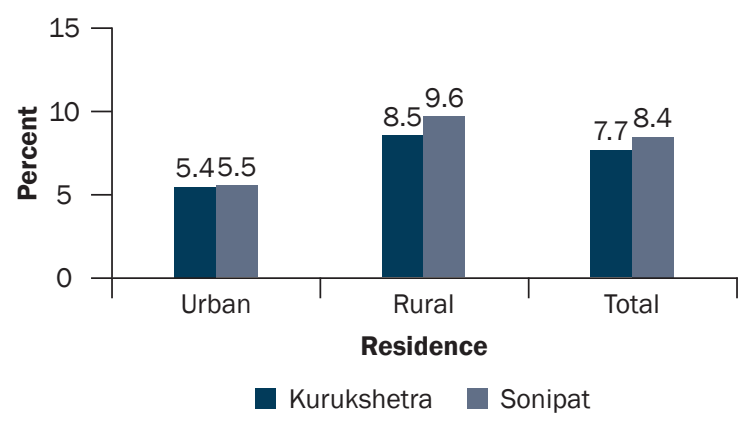

Note: Experience of ultrasonography was not asked in the case of pregnancies ending in a stillbirth or miscarriage. someone with personal experience-shows that gender-biased sex selection was widespread in both districts but indeed more common in Sonipat than Kurukshetra (23\% versus $16 \%$ ). Again, the practice was most frequently reported in rural Sonipat, in which 26 percent of women reported a personal experience or the experience of someone they knew, compared to 17 percent in rural Kurukshetra; among urban women, similar proportions reported such experiences ( $16 \%$ and $14 \%$, respectively).

A paritywise assessment, presented in Table 2.3, suggests that, as others have shown, there is a fairly systematic increase by parity in percentages of women reporting disclosure of the sex of the foetus. This was particularly so in Sonipat, where percentages of women so reporting increased from 1.6 and 2.6 at parities 1 and 2, respectively, to 5.7 and 8.4 at parities 3 and 4, respectively; a similar pattern was observed in rural and urban areas of the district. In contrast, in Kurukshetra, increases were not as pronounced, increasing from 1.6 percent and 2.9 percent at parities 1 and 2 to 4.1 percent at parity 4 and above, with a small decline among women at parity 3 .

Districtwise differences in the extent of disclosure of the sex of the foetus widened at increasing parities. For example, at parities 1 and 2, similar percentages of women from each district reported disclosure (1.6 at parity 1 and 2.6-2.9 at parity 2 ). By parity 3 , significantly more women in Sonipat than in Kurukshetra-six percent versus two percent-reported such disclosure, and at parities 4 and above, eight percent versus four percent so reported.

Table 2.3 also presents the percentage of women at each parity who had been informed about the sex of their foetus, according to the sex of the previous child. Findings are mixed and difficult to interpret; indeed, there is no clear picture of greater disclosure if the previous child was a daughter than a son. The only exception was among women at parity 3 from Sonipat, among whom, the proportion who reported the experience of disclosure (6.7\%) was greater if the previous child was a daughter than a son (4.1\%). Overall, at parity 3, while 6.7 percent of women from Sonipat whose second child was a daughter reported that they had been told the sex of the foetus, just 1.7 percent of those from Kurukshetra so reported.

In short, we acknowledge that reports of disclosure of the sex of the foetus were likely to be under-reported, given the widespread publicity across both districts about the PCPNDT Act. Even so, findings suggest that the practice was prevalent in both districts. What is notable is the paritywise distinction between the two districts. Clearly, while disclosure patterns at lower parities are similar across both districts, divergence becomes significant at higher parities, with women in Sonipat significantly more likely than those in Kurukshetra to report disclosure of the sex of the foetus. 
Resort to abortion following disclosure of a female foetus: In a separate section from the one on pregnancy histories and disclosure of the sex of the foetus, our survey explored women's abortion-related experiences. Findings presented in Table 2.4, indicate that about one in ten women (9\% in Kurukshetra, 10\% in Sonipat) reported the experience of an induced abortion over the course of their married life, and in urban Sonipat, some 14 percent so reported (compared to $8 \%$ in rural Sonipat, and $9 \%$ in both rural and urban Kurukshetra). The numbers are small and findings are thus presented at district level only, and even so, must be interpreted cautiously.

Reported reasons for abortion raise further questions about the likely under-reporting of abortion for sex-selection reasons. Indeed, the reasons suggested in our study are somewhat different from those suggested in the literature. While most studies conducted in India suggest that the key reasons relate to mistimed or unwanted pregnancy and, to a lesser extent, concerns about the health of the mother (see, for example, Santhya and Verma, 2004), our findings suggest that the overwhelming majority have cited medical reasons including doctor's recommendation, mother's health concerns and foetal complications (54-59\%). In addition, 13-17 percent reported a mistimed pregnancy, and 23-28 percent an unwanted pregnancy. Very few women who had undergone an induced abortion $(2-4 \%)$ reported that they had done so for sex-selection reasons. It is possible that some of those reporting medical reasons may, in fact, have been masking sex-selective motives for their abortion.

Table 2.3: Disclosure of the sex of the foetus by parity and sex of the previous child

Percentage of women by personal experience of disclosure of the sex of the foetus by parity and sex of the previous child, according to residence, Kurukshetra and Sonipat

\begin{tabular}{|c|c|c|c|c|c|c|}
\hline \multirow[t]{2}{*}{ Sex-selection practices } & \multicolumn{2}{|c|}{ Urban } & \multicolumn{2}{|c|}{ Rural } & \multicolumn{2}{|c|}{ Total } \\
\hline & Kurukshetra & Sonipat & Kurukshetra & Sonipat & Kurukshetra & Sonipat \\
\hline \multicolumn{7}{|c|}{$\begin{array}{l}\text { Disclosure of the sex of the } \\
\text { foetus by children ever born } \\
\text { and sex of the previous child } \\
\text { (Number of women) }\end{array}$} \\
\hline Parity 1 & $\begin{array}{r}0.8 \\
(278)\end{array}$ & $\begin{array}{r}1.9 \\
(266)\end{array}$ & $\begin{array}{r}1.9 \\
(277)\end{array}$ & $\begin{array}{r}1.4 \\
(280)\end{array}$ & $\begin{array}{r}1.6 \\
(555)\end{array}$ & $\begin{array}{r}1.6 \\
(546)\end{array}$ \\
\hline Parity 2 & $\begin{array}{r}1.8 \\
(278)\end{array}$ & $\begin{array}{r}2.6 \\
(266)\end{array}$ & $\begin{array}{r}3.3 \\
(277)\end{array}$ & $\begin{array}{r}2.5 \\
(280)\end{array}$ & $\begin{array}{r}2.9 \\
(555)\end{array}$ & $\begin{array}{r}2.6 \\
(546)\end{array}$ \\
\hline $1^{\text {st }}$ child-son & $\begin{array}{r}1.9 \\
(111)\end{array}$ & $\begin{array}{r}4.7 \\
(129)\end{array}$ & $\begin{array}{r}3.7 \\
(110)\end{array}$ & $\begin{array}{r}3.2 \\
(128)\end{array}$ & $\begin{array}{r}3.2 \\
(221)\end{array}$ & $\begin{array}{r}3.7 \\
(257)\end{array}$ \\
\hline $1^{\text {st }}$ child-daughter & $\begin{array}{r}1.8 \\
(167)\end{array}$ & $\begin{array}{r}0.7 \\
(137)\end{array}$ & $\begin{array}{r}3.1 \\
(167)\end{array}$ & $\begin{array}{r}2 \\
(152)\end{array}$ & $\begin{array}{r}2.7 \\
(334)\end{array}$ & $\begin{array}{r}1.6 \\
(289)\end{array}$ \\
\hline Parity 3 & $\begin{array}{r}2 \\
(100)\end{array}$ & $\begin{array}{r}4.1 \\
(71)\end{array}$ & $\begin{array}{r}1.8 \\
(107)\end{array}$ & $\begin{array}{c}6.1+ \\
(128)\end{array}$ & $\begin{array}{r}1.9 \\
(207)\end{array}$ & $\begin{array}{c}5.7^{*} \\
(199)\end{array}$ \\
\hline $2^{\text {nd }}$ child-son & $\begin{array}{r}0 \\
(37)\end{array}$ & $\begin{array}{r}3.4 \\
(29)\end{array}$ & $\begin{array}{r}3.3 \\
(30)\end{array}$ & $\begin{array}{r}4.2 \\
(46)\end{array}$ & $\begin{array}{r}2.3 \\
(67)\end{array}$ & $\begin{array}{r}4.1 \\
(75)\end{array}$ \\
\hline $2^{\text {nd }}$ child-daughter & $\begin{array}{r}3.2 \\
(63)\end{array}$ & $\begin{array}{r}4.5 \\
(42)\end{array}$ & $\begin{array}{r}1.2 \\
(77)\end{array}$ & $\begin{array}{l}7.1+ \\
(82)\end{array}$ & $\begin{array}{r}1.7 \\
(140)\end{array}$ & $\begin{array}{c}6.7^{*} \\
(124)\end{array}$ \\
\hline Parity 4 & $\begin{array}{r}3.4 \\
(29)\end{array}$ & $\begin{array}{r}0 \\
(24)\end{array}$ & $\begin{array}{r}4.3 \\
(47)\end{array}$ & $\begin{array}{r}10.4 \\
(48)\end{array}$ & $\begin{array}{r}4.1 \\
(76)\end{array}$ & $\begin{array}{r}8.4 \\
(72)\end{array}$ \\
\hline $3^{\text {rd }}$ child-son & NC & NC & NC & NC & $\begin{array}{r}0.0 \\
(21)\end{array}$ & $\begin{array}{c}9.8+ \\
(13)\end{array}$ \\
\hline $3^{\text {rd }}$ child-daughter & NC & $\mathrm{NC}$ & NC & NC & $\begin{array}{r}0.0 \\
(55)\end{array}$ & $\begin{array}{l}6.7+ \\
(59)\end{array}$ \\
\hline
\end{tabular}

Note: ${ }^{+}$and ${ }^{*}$ indicate that differences between Kurukshetra and Sonipat, Kurukshetra urban and Sonipat urban, and Kurukshetra rural and Sonipat rural are significant at $p<.10$ and $p<.05$, respectively; $N C=$ not calculated. 
Table 2.4: Experience of induced abortion and reasons for abortion

Percentage of women who underwent an induced abortion by reasons for abortion, Kurukshetra and Sonipat

\begin{tabular}{lrr}
\hline Experience of abortion & Kurukshetra & Sonipat \\
\hline Experience of an induced abortion & 9.1 & 10.1 \\
Urban & 8.7 & 13.8 \\
Rural & $\mathbf{5 5 5}$ & 8.4 \\
Number of women & $\mathbf{5 4 6}$ \\
Reasons for abortion & 16.5 \\
Did not want another child at that time/last child was too young & 23.2 \\
Did not want another child at all & 4.2 \\
Husband did not want another child & 3.1 \\
Was too young/old & 53.5 \\
Medical reasons (doctor advised, concerns about mother's health, foetal complications) & 3.9 \\
Foetus was female & 3.9 \\
Number of women who had ever undergone an induced abortion & $\mathbf{4 9}$ \\
\hline
\end{tabular}

Attitudes toward disclosure of the sex of the foetus: In order to understand women's attitudes about gender-biased sex selection, we asked women whether they agreed with three statements related to the acceptability of disclosure of the sex of the foetus and termination of pregnancies carrying a female foetus. Findings are presented in Table 2.5. Notwithstanding the likelihood that many women provided socially desirable responses, findings highlight that substantial minorities of women favoured the disclosure of the sex of the foetus (17-20\%) and as many as 13-14 percent reported the view that women with two or more daughters were better off terminating a pregnancy carrying a female foetus than bringing up many daughters. Overall, interdistrict variation was mild. However, differences were evident among women in rural and urban areas. In urban areas, interdistrict variation was negligible; in rural areas, women from Sonipat were significantly more likely to believe there is nothing wrong with disclosure of the sex of the foetus (23 versus 17\%). Of the entire sample, moreover, just three to four percent of women from the two districts reported that they or someone they knew had undergone a sex-selective abortion (not shown in the table).

Table 2.5: Attitudes about gender-biased sex selection

Percentage of women reporting various attitudes toward gender-biased sex selection, according to residence, Kurukshetra and Sonipat

\begin{tabular}{|c|c|c|c|c|c|c|}
\hline \multirow[t]{2}{*}{ Attitude towards sex selection } & \multicolumn{2}{|c|}{ Urban } & \multicolumn{2}{|c|}{ Rural } & \multicolumn{2}{|c|}{ Total } \\
\hline & Kurukshetra & Sonipat & Kurukshetra & Sonipat & Kurukshetra & Sonipat \\
\hline \multicolumn{7}{|l|}{ Women who agreed that: ${ }^{1}$} \\
\hline $\begin{array}{l}\text { There is nothing wrong about } \\
\text { seeking services to know the sex } \\
\text { of the foetus }\end{array}$ & 15.1 & 12.7 & 17.0 & $23.3^{*}$ & 16.5 & 20.0 \\
\hline $\begin{array}{l}\text { Abortion of a female foetus is } \\
\text { o kay if the family already has } \\
\text { daughters }\end{array}$ & 2.9 & 5.2 & 3.5 & 4.5 & 3.4 & 4.7 \\
\hline $\begin{array}{l}\text { It is better for a woman with two } \\
\text { or more daughters to have a test } \\
\text { and abort a female foetus than } \\
\text { bring up many daughters }\end{array}$ & 14.5 & 10.1 & 12.2 & 15.3 & 12.8 & 13.7 \\
\hline Number of women & 278 & 266 & 277 & 280 & 555 & 546 \\
\hline
\end{tabular}

Note: ${ }^{*}$ indicates that differences between Kurukshetra and Sonipat, Kurukshetra urban and Sonipat urban, and Kurukshetra rural and Sonipat rural are significant at $p<.05 .{ }^{1}$ Remaining percentages of women either disagreed or were uncertain. 
Figure 2.5 which puts together the findings on prenatal sex selection and sex-selective abortion in both districts, suggests the widespread use of ultrasonography for monitoring foetal growth and development (used by 88-93\% of women) and highlights that significant proportions of women acknowledged that they had obtained information about the sex of their foetus or that someone they knew had done so (16-23\%). Figure 2.3 also shows that despite these findings and those that support the persisting preference for male children in the two districts (see Table 2.5), just three to four percent of women from the entire sample acknowledged that they or someone they knew had undergone a sex-selective abortion.

In order to assess, in a more indirect way, the practice of sex-selective abortion, we explored the extent to which women who reported that they had been informed about the sex of the foetus in any pregnancy also reported at least one abortion. Findings (not presented in the table) show that of the 38 and 42 women from Kurukshetra and Sonipat, respectively, who reported disclosure of the sex of the foetus either in the face-to-face or anonymous format, 25 percent of those from Kurukshetra (nine women) and 28 percent of those from Sonipat (12 women) had ever had an induced abortion. Given the likelihood of the termination of pregnancies following the disclosure of a female foetus, we argue that a large proportion, if not all, of these terminations were indeed sex-selective, and suggest that experience of sex-selective abortion was likely under-reported in Figure 2.5. Indeed, the percentages estimated by key informants were higher-ten to even fifty percent (health care providers), one to fifteen percent (public sector programme implementers), or more-15-50 percent (NGO programme implementers).

Figure 2.5: Percentage of women who had undergone an ultrasound test for foetal monitoring, percentage of women who had ever experienced or were acquainted with someone who had obtained information about the sex of the foetus, and percentage of women who underwent a sex-selective abortion, Kurukshetra and Sonipat

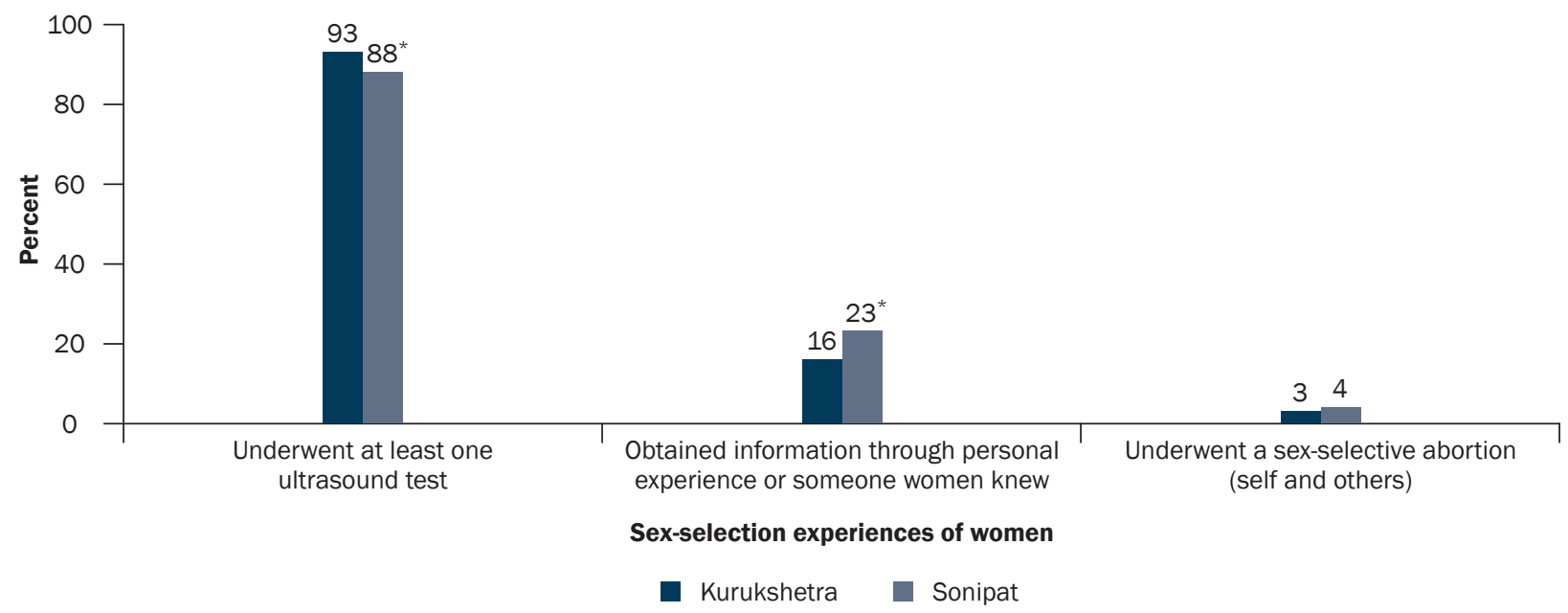

Note: Experience of ultrasonography was not asked in the case of pregnancies ending in a stillbirth or miscarriage. *Indicates that differences between Kurukshetra and Sonipat, Kurukshetra urban and Sonipat urban, and Kurukshetra rural and Sonipat rural are significant at p<.05.

\section{Son preference and experience of disclosure of the sex of the foetus: sociodemographic differentials}

Table 2.6 explores the extent of variation, by selected sociodemographic indicators in son preference and experience of disclosure of the sex of the foetus. Findings, by and large, suggest that among women with two children, differentials are narrow and rarely significant. Even so, some patterns are notable. Indifference about the sex of children increased notably with education and wealth status, significantly in Kurukshetra. Likewise, more of those from general castes as compared with others, were more likely to report indifference about the sex of their children. Sociodemographic differences in the experience of disclosure of the sex of the foetus were, likewise, muted, for the most part, but findings do suggest that such experiences are reported by both poorly and well-educated women, by those from economically disadvantaged and well-off women, and those from different caste groups. In Sonipat, significantly more non-working than working women so reported (10\% versus $4 \%$ ); in all other cases, differences were not significant. 
Table 2.6: Son preference and experience of disclosure of the sex of the foetus: sociodemographic differentials

Percentage of women with two living children reporting no preference for the sex of their children, and the percentage of all women reporting the experience of disclosure of the sex of the foetus by selected sociodemographic characteristics, Kurukshetra and Sonipat

\begin{tabular}{|c|c|c|c|c|}
\hline \multirow[t]{2}{*}{$\begin{array}{l}\text { Sociodemographic } \\
\text { characteristics }\end{array}$} & \multicolumn{2}{|c|}{$\begin{array}{l}\text { Among those with two living children, } \\
\% \text { who expressed no preference for } \\
\text { their children }\end{array}$} & \multicolumn{2}{|c|}{$\begin{array}{l}\% \text { of all women reporting the experience } \\
\text { of disclosure of the sex of the foetus }\end{array}$} \\
\hline & Kurukshetra & Sonipat & Kurukshetra & Sonipat \\
\hline \multicolumn{5}{|c|}{ Number of years of schooling } \\
\hline None & 13.5 & - & 12.8 & 12 \\
\hline $1-7$ & 17.6 & 14.5 & 6.2 & 10.7 \\
\hline $8-10$ & 17.0 & 16.2 & 4.3 & 10.4 \\
\hline $11-12$ & 16.8 & 26.7 & 11.8 & 4.5 \\
\hline \multirow[t]{2}{*}{$13+$} & 33.9 & 26.8 & 7.3 & 3.6 \\
\hline & * & NS & NS & NS \\
\hline \multicolumn{5}{|l|}{ Caste } \\
\hline SC/ST & 8.7 & 16.2 & 7.1 & 9.1 \\
\hline OBC & 20.6 & 17.9 & 6.7 & 6.2 \\
\hline \multirow[t]{2}{*}{ General } & 24.9 & 23.0 & 9.1 & 9.3 \\
\hline & NS & NS & NS & NS \\
\hline \multicolumn{5}{|c|}{ Paid work in the last 12 months } \\
\hline No & 19.9 & 21.5 & 7.2 & 9.8 \\
\hline \multirow[t]{2}{*}{ Yes } & 20.6 & 15.2 & 9.2 & 3.6 \\
\hline & NS & NS & NS & * \\
\hline \multicolumn{5}{|l|}{ Religion } \\
\hline Hindu & 19.7 & 19.5 & 7.3 & 8.4 \\
\hline \multirow[t]{2}{*}{ Non-Hindu } & $(25.4)$ & - & $(12.6)$ & 9.0 \\
\hline & NS & NS & NS & NS \\
\hline \multicolumn{5}{|l|}{ Wealth status } \\
\hline Lowest quintile & 16.3 & $(17.4)$ & 9.5 & 11.2 \\
\hline $2^{\text {nd }}$ qunitile & 5.7 & 19.1 & 4.2 & 4.0 \\
\hline $3^{\text {rd }}$ qunitile & 24.5 & 14 & 6.5 & 10.3 \\
\hline $4^{\text {th }}$ qunitile & 26.4 & 17.2 & 5.8 & 7.8 \\
\hline \multirow[t]{6}{*}{ Highest quintile } & 23.6 & 29.8 & 12.8 & 9.1 \\
\hline & 13.5 & -- & 12.8 & 12.0 \\
\hline & 17.6 & 14.5 & 6.2 & 10.7 \\
\hline & 17.0 & 16.2 & 4.3 & 10.4 \\
\hline & 16.8 & 26.7 & 11.8 & 4.5 \\
\hline & 33.9 & 26.8 & 7.3 & 3.6 \\
\hline
\end{tabular}

Note: NS: No significant difference between categories; " : Differences between categories significant at $p<=0.05 ;--:$ Not calculated as the denominator is less than 25 unweighted cases; ( ): Based on 25-49 unweighted cases. 


\section{B. Perspectives of key informants on factors underlying unbalanced sex ratios at birth}

Key informant interviews with health care providers, public sector programme implementers, and NGO programme implementers covered many of the issues that were addressed in the course of the survey with married women. The topics encompassed their perspectives on two of the three broad factors identified as key determinants of unbalanced sex ratios, namely, persistent son preference and access to sex-selection technology. It also addressed their perspectives about the implementation of the PCPNDT Act at the district level and its effectiveness in controlling violations of both the PCPNDT and MTP Acts; about communication, advocacy and community mobilisation efforts in their districts; and finally, about special programmes of cash and non-cash transfers for girls, and the effectiveness of these schemes in deterring families from seeking disclosure of the sex of the foetus and terminating pregnancies carrying a female foetus.

In this section, we explore the perspectives of key informants on the persistence of son preference on the one hand, and misuse of technology to disclose the sex of the foetus and terminate pregnancies carrying a female foetus, on the other. Given the three groups of key informants, namely, health care providers, district and state public sector programme implementers engaged in implementing the PCPNDT Act or supervising ICDS action at the community level from both study districts, and NGO programme implementers from Sonipat, we describe the perspectives of each of these groups separately; however, perceptions about the persistence of son preference being similar across all three groups, we have combined the discussion below. For illustrative purposes, we provide the numbers of key informants from each category who responded in a particular way.

\section{Persistence of son preference}

Almost all key informants ( 21 of 23 health care providers, 14 of 15 public sector programme implementers, and 11 of 12 NGO programme implementers from Sonipat, who discussed son preference) acknowledged the persistence of son preference, reiterating the experiences and attitudes of women. They reiterated the well-known motivations expressed in previous studies for preferring sons: their support in old age, their performance of last rites for their parents, their ability to tend to the family property, and their role in carrying forward the family name. On the other hand, daughters were perceived to require large dowries, leave the home once married and provide little support for their parents; some also mentioned that fears about violence against girls deters couples from wanting daughters as also fears that married daughters would claim property rights and thereby divide family property. Many key informants (20 of 23 health care providers, 13 of 15 public sector programme implementers, and all 12 NGO programme implementers from Sonipat, who discussed son preference) described the jubilation that surrounds the birth of a son versus the grief that surrounds the birth of a daughter, as represented below:

Yes, people do behave differently. After the birth of a son everybody becomes happy; they distribute sweets and congratulate one another, whereas after the birth of a daughter, they get depressed-although they accept their daughter, still somewhere in their mind they stay depressed!..... After the birth of a son, sweets are distributed among the hospital staff and they are given gifts along with some money; but after the birth of a daughter, no such activities are carried out. [Female, obstetrician-gynaecologist, aged 60, Sonipat]

Sometimes, when people don't want a daughter, it is visible; the sadness shows on their faces, they look disappointed. If a woman has a son, her mother-in-law treats her very well, but if a daughter is born, they (female family members) start crying and make her cry as well. (One) does not know what happens after they get back home, but they differentiate so even in front of us..... [Female, obstetrician-gynaecologist, aged 50, Kurukshetra]

There is great celebration when a boy is born, but they become sad in the case of a girl. They think that their expenditure will go up with the birth of a daughter (marriage, dowry), and so they distribute sweets (only) at the birth of a son. [Male, NGO programme implementer, aged 67, Sonipat]

In most cases, people react differently; they distribute sweets with joy when a son is born, and become upset when it's a girl. [Female, AWW, aged 52, Kurukshetra]

Key informants also suggested that women who gave birth to daughters were treated with less respect than were those who gave birth to sons, for example: 
In the same family, the mother of a son is treated with more respect than the mother of a daughter. [Male, law enforcement officer, aged 56, Kurukshetra]

More attention is given to a son's mother; she has more value and more respect is given to her, whereas a daughter's mother faces such harsh behaviour as if she has committed a serious crime by giving birth to a daughter; she is cursed every time. [Male, NGO programme implementer, aged 52, Sonipat]

Even so, key informants-health care providers, public sector programme implementers, and NGO programme implementers alike-believed that the situation was changing, with young, urban and better-educated couples displaying no son preference, and increasing numbers stopping childbearing after one or two daughters. Many cautioned, however, that change is slow, with the older generation still pressurising the young to have a son, and even young couples displaying a desire for a son. Indeed, narratives of many key informants, from both districts suggest a recognition that while son preference was declining, decline was slow and even the young, urban and educated succumbed to pressure to ensure the birth of a son (reported by six of 12 health care providers and three of six district programme implementers from Kurukshetra, who discussed the issue; eight of 11 health care providers, four of six district officials, and seven of 11 NGO programme implementers from Sonipat, who discussed the issue). For example:

Yes; with education, and in urban areas, it (son preference) is less, but it is still there in rural areas. Earlier, 100 percent wanted boys, now it may be down to 70-80 percent. The young are less concerned about having sons but have to obey the older generation. [Female, general physician/MBBS doctor, aged 40, Sonipat]

If you notice, parents nowadays do not discriminate between sons and daughters in respect of education and nutrition but they do get depressed on the birth of daughters, although later, they do not discriminate between them in any way..... (In fact, if you observe, you will also see couples who do not opt for a third child even after the birth of two daughters; but, their number is small. About five percent are like this, the other 95 percent retain a desire for sons. A few days back, I calculated the percentage of parents having one and two daughters and the number was shockingly low; therefore, it validates the fact that even today parents prefer sons over daughters. [Female, law enforcement officer, aged 66, Sonipat]

The situation is changing now. Like here (in this facility), a daughter was born, and the family was very happy. Even two days ago, another baby girl was born, who has just got discharged from hospital, and the family was very happy too. At the same time, there was a Sikh family who had a boy the day before; they already had a daughter and if they had not got a son this time, I feel they might not have been happy. This happens because of lack of education and the mindset of the people. Educated people don't think like that; the young don't either, unless pressurised by the mother-in-law or older women in the family. [Female, obstetrician-gynaecologist, aged 50, Kurukshetra]

I see a change. I know some who are happy with one daughter and are not planning a second child. Nowadays, educated people don't discriminate, young couples don't either; but the elders of the family try to influence their thinking. [Female, ANM, aged 42, Kurukshetra]

But now people are more aware and there is a change in the traditional mindset of people..... son preference has been weakening; young couples are more compassionate and don't differentiate between a son and a daughter. [Female, PO/CDPO, ICDS, aged 52, Kurukshetra]

\section{Misuse of technology}

Most key informants from both districts were familiar, either through their own interactions or those of their colleagues and/or the communities they served, with violations of the law in respect of both disclosure of the sex of the foetus and aborting female foetuses. Some suggested that these practices no longer existed but were taking place till a few years ago. Given their likely different experiences, we discuss separately, the perspectives of health care providers, district and state officials and NGO representatives on each of these issues. 


\title{
Disclosure of the sex of the foetus
}

\author{
Perspectives of health care providers
}

Most health care providers agreed that women continued to seek information about the sex of the foetus during routine ultrasound examinations. Overall, nine of 11 health care providers from Sonipat and 10 of 12 from Kurukshetra acknowledged that requests for disclosure of the sex of the foetus did take place in their district, and most of them suggested that irrespective of the counselling they provided, many women did go on to access services, either from unscrupulous service providers in their own district, or from a neighbouring district or state. For example:

Yes people ask, but we explain that disclosure (of the sex of the foetus) is not allowed. In order to get an ultrasound examination, they (women) have to complete a lot of paperwork and sign a statement saying that they are not getting an ultrasound done to know the sex of the foetus..... In a day, if I see 50 patients, then one or two patients ask this (sex of the foetus). [Male, general physician/MBBS doctor, aged 38, Sonipat]

I have never been asked. But other ANMs may have been asked. I think there would be at least one or two who do such work (of disclosing the sex of the foetus) because this work is still going on in some places. No woman would know where to go, (so) they would have to be told by someone and taken there by someone. ANMs who are doing these things must be working secretly. There may be one or two out of every ten pregnant women who take these services. Sometimes, a woman may want to know (the sex of her foetus) of her own will, but in most cases she is pressurised by her family, including her mother-in-law, husband and, sometimes, her own mother. They (those seeking information about the sex of the foetus) are of every type-educated and uneducated, rich and poor.... I have heard of one or two women who already had one or two daughters, so they took these services in Karnal district; first they got tested using ultrasound and when they found it was a girl, they aborted it right there...... maybe, one or two out of a hundred women (do this). [Female, ANM, aged 48, Sonipat]

When it is established that certain doctors do it (disclose the sex of the foetus) and others don't, then women who want to know, just go to such doctors. They do not come to (doctors like) us. It doesn't happen here. And if they do come here, they would return knowing our answer and would not visit again. The number of providers doing that (disclosing the sex of the foetus) here is very small; perhaps, someone may come and ask, otherwise they don't come. I think 20-40 percent of people might be doing it; those who are with their first child would usually not want to know. If they have daughters already, then they may want to find out. Such women are fewer in villages; it is mostly educated women, like those from Sikh families or the Jat community.... (Nevertheless), people who want to do it (sex-selection test) can still do it by going somewhere else. Those who are poor cannot afford all these services; only those who are connected are able to do so. I have a couple of patients who had got it (sex-selection test) done outside, from Uttar Pradesh-there was one who did not get an abortion done; she told me she has a daughter but she did not undergo an abortion and her pregnancy is continuing. There are many who visit my clinic upto 3 or 31/2 months of pregnancy and then they disappear; they stop coming. I don't know where they go but the assumption is that they have got the baby aborted.... Patients hide things from us; in recent years, I have seen very few such instances, but it's not improbable-they can go outside (the state) and get it done in UP or Bihar. Of all the patients I have had, two told me: one did the test but did not have an abortion; the other got the pregnancy aborted, and even she got it done outside-she did not tell me where; she had come to me because she was bleeding after the abortion-this happened two or three months ago. [Female, obstetrician-gynaecologist, aged 50, Kurukshetra]

If the in-laws pressurise a woman to have a son instead of a daughter, she requests the provider to reveal the sex of the foetus. In my opinion, one or two of every ten women would demand such information while visiting a health care provider. These women can be from any group, they can be educated or uneducated. It has become very difficult for a pregnant woman to find out the sex of the foetus, she has to travel far and invest a lot of money to obtain such services. It is difficult for a pregnant woman to do so in Kurukshetra, but people may be put in contact privately with those who conduct sex selection clandestinely. I have received a few requests (from women) to disclose the sex of the foetus but I have counselled them and finally, they 
did not go for it.... in Kurukshetra, out of ten providers, one or two would reveal the sex of the foetus. I once accompanied a pregnant woman who had gone for an ultrasound to Ambala and the doctor openly informed her that the foetus is female. [Female, Staff Nurse, aged 27, Kurukshetra]

People do ask (for the sex of the foetus). Not everyone, but some do. Some out of curiosity; they say it is their first child so it (the baby's sex) doesn't matter, that they are just curious. We tell them that we are not allowed to tell them and they would find out for themselves once the baby is born. There are others who say, 'We have daughters already, so see if there is any way in which you could help us'. They ask like this (tactfully) because they know that no one is going to tell them (if they ask directly). Maybe seven to eight percent of pregnant women seek such information; (they are) mostly from villages but some from cities too, and more from business families, not so much from professional families; but, it could be anyone. There was a lady from the village who came to me, maybe seven or eight years ago. She had one or two daughters, and was not pregnant but trying to conceive. She said, 'On the one hand, the government says you should have only two children, and on the other, it says that you should not do these things (sex determination test/sex-selective abortion). What does the government think? Everyone wants to have a son.' This is the mentality here... If there are a hundred doctors, one or two are doing wrong (illegal) things, and they are definitely not those who have MD degrees. These illegal activities are done by those who are not properly qualified. I have a MD in Radiology but everyone has been granted permission by the government to own an ultrasound machine. Even those with six months training are allowed to fix up an ultrasound machine, (even though) they don't have the qualifications and are not radiologists. [Female, radiologist, aged 40 , Kurukshetra]

Most health care providers revealed the clandestine ways in which the sex of the foetus is disclosed to women and their family: by invoking gods versus goddesses (Jai Sri Krishna for a boy and Jai Ma Durga for a girl, by gifting the couple a calendar with a photo of Lord Ganesh for a boy and a female goddess for a girl), by conveying emotions of happiness and grief ('happiness is coming, get sweets' or 'the family will become burdensome'), or through colours (pointing to something blue for a boy and pink for a girl). Indeed, just two health care providers from Sonipat and four from Kurukshetra suggested that they were unaware about how information about the sex of the foetus is disclosed. An ANM from Sonipat and a Staff Nurse from Kurukshetra described incidents, respectively, where after being informed about the sex of the foetus, the woman was asked to exit the facility from a back door, and agents were used to inform the family about the sex of the foetus (and collect the fee) after the woman had left the facility. The following excerpts corroborate this:

They (health care providers) reveal it openly because often, people are uneducated and may not understand a secret code. I once accompanied a pregnant woman who had gone for an ultrasound test to Ambala and the doctor openly informed her that the foetus is female, but the test took place clandestinely and they asked her to take a different route to leave the nursing home. [Female, Staff Nurse, aged 27, Kurukshetra]

Providers who practice illegal activities often work through an agent. I think providers give this information to the family indirectly through this agent. Radiologists never inform the family of the result within the clinic but call them up a while later. Payment is done separately via the agent. [Female, Staff Nurse, aged 40, Kurukshetra]

\section{Perspectives of public sector programme implementers}

Public sector programme implementers were unanimous that the practice of disclosing the sex of the foetus is continuing in their district. Many described their own experiences, and confirmed that not only unqualified health care providers, but far more frequently, unscrupulous doctors, including those in the public sector, continued the practice. For example:

I have dealt with two such cases so far. One of them was about portable ultrasound machines and another concerned the abortion of a female foetus. [Female, law enforcement officer, aged 35, Sonipat]

Whatever the reason behind it; for example, poverty, dowry, low status of girls, poor education etc, it is well evident that there is rampant sex-selective abortion going on. [Male, law enforcement officer, aged 57, Sonipat] 
Once, five to six months ago, I heard that one ANM was caught with an unregistered ultrasound machine; her license was cancelled. Nowadays, it is a rare event here. [Female, PO/CDPO, ICDS, aged 36, Sonipat]

Sex-selection practices do take place in society and often, it is doctors from various medical institutes who influence parents to do this so that they (doctors) can earn some money. Today, more hospitals are coming up and more such things are happening. [Male, law enforcement officer, aged 56, Kurukshetra]

Often people from the Health Department are involved in sex selection (tests). They easily manage to carry out multiple ultrasound examinations for which they are paid a small commission. It is a big nexus; health workers themselves inform the local people where to go and how to get the procedure; identifying these people (workers) is another challenge. Recently, we had a case of a dai (traditional birth attendant) who was caught in Jajjhar with a diary containing a record of 500 sex-selective abortions; there were five court cases based on that. These things (sex-selective abortions) do not happen only in rural areas, educated people also do this and so do the rich. But facilities are more easily available in urban than in rural areas, and people there are richer too. [Female, law enforcement officer, aged 52, Panchkula]

Frontline ICDS workers are also responsible for raising awareness and deterring women from seeking sex-selection services. Narratives suggest that they are responsible for registering pregnant women, but they too recognise that women who wish to know the sex of their foetus conceal their pregnancy from ICDS staff; at the same time, AWWs report some success in counselling women and deterring them from undergoing gender-biased sex selection as the following excerpts show:

I remember one case when a woman's in-laws wanted her to have a son after she had given birth to two daughters. So, the woman tried a number of times to get the foetus aborted but we convinced her to carry the child to term, and she had another daughter. I am happy that my efforts to save the baby girl were successful. [Female, AWW, aged 38, Kurukshetra]

I cannot deny that people opt for sex determination to make sure of the birth of a boy..... The Anganwadi Worker only registers the pregnancy when it is physically visible, that is, approximately after five months. Women who opt for sex selection hide their pregnancy and abort it within the first few months of pregnancy, so it is impossible for workers to be aware of the pregnancy. These women do not take benefits like nutritional supplements or immunisation before they go for a sex detection test so that they can perform the test and abortion (if the foetus if female) in secret. I have no idea where they go. We are not informed about the clinic or nursing home where people go, and women keep their pregnancy hidden from us. [Female, PO/CDPO, ICDS, aged 50, Kurukshetra]

As in the case of health care providers, public sector programme implementers were aware that disclosure is conducted clandestinely, but also suggested a referral link that extends from frontline workers to diagnostic facilities; for example:

Maybe, nobody gives such information now and, even if one or two doctors do so, they do it secretly because everybody is afraid of the consequences. I think the doctors give such information very astutely; what I mean is that while conversing with the client, they ensure that there is no evidence (that such information has been given). I mean to say that no written prescription or no document is given to the woman or her family. [Female, law enforcement officer, aged 66, Sonipat]

Generally, these activities (disclosure of the sex of the foetus) are performed during off (non working) hours, and there are some intermediaries and ANMs through whom people avail of such practices..... ultrasound tests (and disclosure) do happen in this area, despite the law. [Female, PO/CDPO, ICDS, aged 57, Sonipat]

I hear that they (doctors) use codes to convey the message; for example, 'lakshmi' (a goddess) for a girl, and 'laddu lao' (bring sweets), if a boy. [Female, law enforcement officer, aged 52; Kurukshetra]

There are 21 cases wherein we have convicted persons other than doctors. We have a list, which includes pandits (priests), hakims, managers and even directors of companies who have been accused of illegal involvement. [Female, law enforcement officer, aged 27, Panchkula] 


\section{Perspectives of NGO programme implementers}

NGO programme implementers came only from Sonipat, as mentioned earlier, and all 12 suggested that gender-biased sex selection did indeed take place in the district, although some suggested it was very rare, and others that women seek services from neighbouring states because services have become difficult to obtain in Sonipat. They reported that they made efforts to counsel those who sought their advice with regard to undergoing ultrasonography to detect the sex of the foetus, and several reported success in convincing parents not to undergo such practices, as described in the following excerpts:

As far as I know, ultrasonography services for sex selection are not provided in Sonipat. But I also think that people from here may travel to some place outside to get the banned services. Earlier, ultrasound services cost Rs. 2,000; now, one has to pay Rs. 5,000 and some even charge Rs. 10,000 or more... this is also happening in hospitals..... A couple of times, parents have asked me whether I know doctors who provide these services as they wanted to know the sex of the foetus. I told them that I did not know any such doctor and advised them not to do such things..... [Male, NGO programme implementer, aged 46, Sonipat]

Literate and rich people are the ones who demand these (illegal) services because in villages many are not even aware that there is a machine through which they can detect the sex of the foetus; moreover, it is not possible for the poor to invest so much and obtain these services. Therefore, sex diagnosis and abortion are carried out by those people who are literate and rich! ......According to my knowledge, in Sonipat there are about 100-125 doctors who have ultrasound machines but only some of them are involved in providing these services, and the government is very well acquainted with those who are and those who are not involved in this work. Apart from this, because Sonipat shares its border with Delhi and UP, people easily avail of these services from these places. I would definitely say that the people of Sonipat travel to the neighbouring states and obtain these services! I would like to state an example from my family itself. One of my uncles has three daughters and wanted at least one son. So, the next time his wife got pregnant, he got her ultrasonography done and came to know that she is again pregnant with a girl. Subsequently, after we persuaded him, he did not get the child aborted and his wife gave birth to her daughter. [Male, NGO programme implementer, aged 46, Sonipat]

A few NGO programme implementers offered their views about the number of pregnant women who sought services for the disclosure of the sex of the foetus; most estimated that about 20 percent of women who want a son do so. Most also acknowledged the clandestine nature of the transaction, and several recognised the nexus between various informants and the provider who conducts the illegal procedure. For example:

Nothing takes place in the open because the doctors are also scared of the consequences and by this way (being secretive), everybody saves themselves. Either the compounder or the other staff members of such doctors remain involved in this work so that nobody doubts the doctor and he/she is protected from any problem. Lady doctors have Sisters (nurses) and male doctors have compounders, and it is these workers only who give all the information to the woman's family. ...... Once, I went to a health centre with someone, where somebody said, 'Bhaiya check karwaliya, khushi anewali hai.' ('We have checked, there is good news'). Therefore, it was apparent that it's a boy. At times, mothers request the doctor to tell them whether it is a boy or a girl and the doctor tells them to be happy and not to worry because it's good news; then the woman knows that she is going to give birth to a boy. [Male, NGO programme implementer, aged 31, Sonipat]

\section{Persistence of sex-selective abortion}

\section{Perspectives of health care providers}

Health care providers were forthcoming about the prevalence of selective abortion of female foetuses. Indeed, six of the 11 health care providers from Sonipat, and 10 of 12 from Kurukshetra believed that sex-selective abortions continued to take place, and many, especially medical officers, suggested that it was largely 'unqualified' persons, Accredited Social Health Activists (ASHAs), dais, ANMs, Ayurveds (BAMS) and nurses-who were the key violators. Health care providers estimated that anywhere between one in 10 and five in 10 abortions taking place among women in their districts were sex-selective. For example: 
Five of ten abortions are illegal and all these are for sex selection. [Female, obstetrician-gynaecologist, aged 40 , Sonipat]

Maybe one or two of ten abortions are sex-selective. [Female, obstetrician-gynaecologist, aged 60, Sonipat]

About three months ago, a raid was conducted on a housing society and an unqualified lady was caught carrying out abortions. She was arrested and a case was filed against her; but after that, I don't know what happened to her. Can't say (for sure), but (I think) all illegal abortions are sex-selective. [Female, obstetrician-gynaecologist, aged 47, Sonipat]

One or two of ten abortions must be illegal and all following sex selection. I admit there are still one or two centres which provide these services. Maybe they have a fixed time for conducting abortions so that the raiding team cannot catch them or they get information about raids in advance. [Female, ANM, aged 42, Sonipat]

One or two of ten abortions may be sex-selective..... In villages there are dais or even ANMs who have retired and know the job, more or less; even they do it (sex-selective abortions). [Female, obstetriciangynaecologist, aged 50, Kurukshetra]

One out of ten (abortions are sex-selective). Two years ago, I heard about one such case where unregistered machines were found in a nursing home and were sealed; the doctors were prosecuted. [Female, ANM, aged 31, Kurukshetra]

Only one out of ten abortions take place against the law in this district. [Female, Staff Nurse, aged 27, Kurukshetra]

All the health care providers agreed that once informed that the foetus is female, most women-either of their own will, or, more likely, under family pressure-find a way of terminating their pregnancy, and that neither counselling nor fear of apprehension can deter these women as these excerpts affirm:

Some understand (when counselled); I had three or four such cases. But, there are some who, however much you persuade them, stay determined that they do not want a girl and go for an abortion to any place. I think (abortion) services are provided in UP and people can obtain services there easily. [Female, obstetrician-gynaecologist, aged 60, Sonipat]

The woman who has already decided that she does not want a girl would do anything to get an abortion, whatever the expense or distance (to the facility). Sometimes, we can convince women to change their mind, but just one or two percent may be so convinced. Women who already have two or three daughters and want a son will go for these services (sex-selective abortion). [Female, ANM, aged 50, Sonipat]

See, this is the mentality of the people. Those who already have a daughter do not want to go ahead with the pregnancy, and try and get it aborted. We refuse outright; but there are service providers who conduct abortions, and those who want an abortion, can get it done anywhere. If it is not possible in their own state, they get it done somewhere else. [Female, general physician/MBBS doctor, aged 57, Kurukshetra]

In almost all cases, a woman would terminate the pregnancy if told she is carrying a girl. There are very few instances, say one in a hundred, where a woman has not opted for an abortion out of fear or after receiving counselling. [Female, Staff Nurse, aged 27, Kurukshetra]

Health care providers also unanimously agreed that abortion providers who conducted sex-selective abortions were aware of the reason for the abortion. When asked whether medical officers and others who were approached to terminate a pregnancy would know the reason, 10 of 11 health care providers from Sonipat and 11 of 12 of those from Kurukshetra reported that any provider would know; for example:

They know everything and only after getting this information (the reason for the abortion), they provide such services and the reason (for conducting the abortion) is money. Sex-selective abortion is carried out in the second trimester and no doctor would provide such a service without knowing the reason. [Female, obstetrician-gynaecologist, aged 34, Sonipat]

There are a lot of times when patients try to hoodwink me. They tell me that they have two children, a son and a daughter, or they tell me that they do not want a third child-but they are lying because this 
(abortion) usually happens after three months (of pregnancy). I know that they have been told the sex of the foetus and I send them back.... Doctors who do it (abortion) in the second trimester would know. [Female, obstetrician-gynaecologist, aged 50, Kurukshetra]

\section{Perspectives of public sector programme implementers}

Public sector programme implementers were less likely than health care providers to acknowledge that sex-selective abortion took place in their districts. Yet, in both districts, their own recent personal experiences suggested that they were all (15 in all) familiar with the practice in their district as the following excerpts suggest:

I have dealt with two such cases so far. One of them was about portable ultrasound machines and the other concerned the abortion of a female foetus. [Female, law enforcement officer, aged 35, Sonipat]

Once we had information of such an activity (sex-selective abortion) and conducted a raid. We found a woman with money who was getting ready for an operation. People generally perform such procedures at night or on holidays. [Male, law enforcement officer, aged 57, Sonipat]

I think one or two out of 100 women may terminate her pregnancy if told that the foetus is a girl. [Female, AWW, aged 52, Kurukshetra]

They often opt for sex-selective abortion to ensure a son. But this is more prevalent in the cross-border areas than in the district itself. We have cases where local people have travelled to UP and Punjab to have a sex-selective abortion and spent Rs. 30,000 for such procedures..... I have not experienced any such kind of activity. [Female, law enforcement officer, aged 52, Kurukshetra]

\section{Perspectives of NGO programme implementers}

NGO programme implementers suggested, on the basis of their community-level linkages, that sex-selective abortion continued to be widely prevalent in Sonipat district. Most NGO programme implementers perceived that women who underwent sex-selective abortion were pressurised to undergo the procedure by their husband and family members, and reiterated that a large proportion of women who know they are carrying a female foetus do indeed terminate their pregnancy. For example:

I think five percent of doctors provide such banned activities due to which the remaining 95 percent get a bad name. [Male, NGO programme implementer, aged 67, Sonipat]

I think it is a 50-50 situation. Out of 100 pregnant women, 50 women terminate their pregnancy because of some pressure whereas the remaining 50 continue their pregnancy. [Male, NGO programme implementer, aged 46 , Sonipat]

I think out of 100 pregnant women who get to know that they are pregnant with a girl child, 15 to 20 terminate their pregnancy. [Female, NGO programme implementer, aged 73, Sonipat]

I think no mother would like to have an abortion, but does so under severe family pressure. She becomes helpless under this massive pressure. [Male, NGO programme implementer, aged 49, Sonipat]

A woman will never take such a decision and would never want to abort her daughter. Under pressure from her family or her husband, she takes such a decision.... I think if a woman and her family have already decided that they don't want a girl child, then they will go anywhere to obtain such services. However, there are also some who understand (that sex-selective abortion is wrong) and decide to continue with their pregnancy, thus giving birth to a daughter. [Male, NGO programme implementer, aged 52, Sonipat]

\section{Summary of the perspectives of women and key informants about son preference, disclosure of the sex of the foetus, and termination of pregnancies carrying a female foetus}

This chapter has highlighted that all three preconditions identified by Guilmoto (Guilmoto, 2007) remain widespread in the study districts. Women had, on average, 2.5 surviving children in each district. Most women wanted just two children (82-86\%) and most wanted no more children (89\% in both districts). 
While son preference was prominent in both districts, findings were mixed. For one, while the number of sons was identical at parity 2 (1.1-1.2), among those at parity 3, women from Sonipat had significantly more sons than did their counterparts from Kurukshetra (1.54 versus 1.35). At the same time, attitudes towards son preference were identical among women in the two districts. However, more in-depth measures of son preference (the ratio of the percentage of women with two sons versus those with two daughters who reported wanting no more children, and were practising contraception) suggests that women in Kurukshetra had a markedly stronger son preference than did those from Sonipat: indeed, they were three times more likely to want no more children if they had two sons than if they had two daughters; those from Sonipat were, in contrast, twice as likely to so report. Women from Kurukshetra were 1.6 times more likely to practise contraception if they had two sons than if they had two daughters; those from Sonipat were 1.4 times more likely to do so. All key informants-health care providers, as well as public sector and NGO programme implementers-reiterated that son preference remains strong; several suggested that younger and better-educated couples held more egalitarian preferences with regard to the sex composition of their children, but that pressure from the older generation made many succumb.

Misuse of technology was reported by similar proportions of women in the two districts. Eight percent of women who had undergone ultrasonography reported that they had been told the sex of their foetus in at least one pregnancy, and about one-quarter of women to whom the sex of the foetus in at least one pregnancy had been disclosed, also reported at least one abortion. At the same time, among those who had three children, six percent of those from Sonipat as compared to two percent of those from Kurukshetra reported that they had been told the sex of the foetus in the course of their last pregnancy, and significantly more women from Sonipat than Kurukshetra reported that they and/or someone they knew had been told the sex of their foetus (23\% versus $16 \%$ ). All three groups of key informants also strongly agreed that the misuse of technologies-both disclosure of the sex of the foetus and termination of pregnancies carrying a female foetus-persisted in both districts, although they agreed that these practices had become less openly available than before and were, in fact, carried out covertly. They highlighted that services were provided not only by unqualified health care providers, but also qualified but unscrupulous providers in their own districts, or from neighbouring districts and states. Health care providers and NGO programme implementers, in particular, perceived that women who underwent sex-selective abortion were pressurised to undergo the procedure by their husband and family members, and reiterated that a large proportion of women who know they are carrying a female foetus do indeed terminate their pregnancy. Public sector programme implementers were less likely than health care providers to acknowledge that sex-selective abortion took place in their districts; yet, in both districts, their own recent personal experiences suggested that they were all familiar with the practice in their own district.

Finally, sociodemographic differences in both the extent of son preference and the experience of disclosure of the sex of the foetus were narrow and for the most part, not significant. Even so, we note that in each district, better educated and economically better off women were more likely than others to report no preference for the sex of their children; the absence of differences in the case of the experience of disclosure of the sex of the foetus highlight that disclosure is prevalent among all women, irrespective of religion, caste, educational attainment levels or household economic status.

In short, findings are mixed. Two measures of son preference suggest that women from Kurukshetra were more likely than their counterparts from Sonipat to want no more children and to practise contraception if they had two sons as opposed to two daughters, but attitudes toward son preference were similar across women in both districts. With regard to misuse of technology, in contrast, there was no evidence to suggest that the practice had reduced, although at higher parities it appeared that women from Sonipat were indeed more likely than those from Kurukshetra to have sought disclosure of the sex of the foetus. Finally, sociodemographic differentials in both the extent of son preference and the experience of disclosure of the sex of the foetus were narrow, and, particularly in the case of disclosure, suggest that the practice was prevalent across all sociodemographic groups. 


\section{Chapter 3}

\section{What works to reduce gender-biased sex selection: Communication, advocacy and community mobilisation}

Women in both districts displayed high awareness of and exposure to messages about the law from various sources, and low to moderately high exposure to messages on gender-biased sex selection/abortion. Exposure levels were greater in Kurukshetra than Sonipat and are attributed to stronger and more wide-ranging information-giving activities, the strong role played by frontline health workers, religious leaders and district programme implementers. While frontline workers were a particularly important source of information and behavior change communication in rural areas, women in urban settings, notably those in Kurukshetra, benefitted from greater media exposure and talks by religious leaders. Kurukshetra, moreover, was marked by sustained interactive sensitisation and advocacy programmes by public sector programme implementers in schools, colleges and the community, practices less likely to have been described in Sonipat.

Communication, advocacy and community mobilisation programmes hold promise for changing patriarchal norms and son preference in general, and reducing the practice of gender-biased sex selection, more specifically. The programmes aim to reduce discrimination against girls and foster a more equal environment for sons and daughters as also to directly focus on discouraging gender-biased sex selection and the termination of pregnancies carrying a female foetus. They include public sector programmes, programmes conducted by NGOs, media messages as well as the efforts of religious leaders. In this chapter, we explore women's exposure to the variety of activities conducted to change norms relating to son preference and such practices as sex determination tests and sex-selective abortions.

We also provide insights from key informants about the key players-from both the public sector and NGOs-working on raising community awareness, changing patriarchal norms and building equitable gender relations, and addressing gender-biased sex selection in their district. Key informants described the kinds of communication, advocacy and community mobilisation activities they had encountered or implemented, or that had been implemented in their district more generally, and their perceptions about the effectiveness of these programmes.

\section{A. Perspectives of women}

In this section, we explore women's awareness about various laws for women, including the PCPNDT Act, the extent of their exposure to behaviour change communication messages delivered through the media, and by doctors, nurses and frontline health workers, as well as religious leaders and NGO programme implementers.

\section{Women's awareness of the PCPNDT Act and other laws protecting women}

The survey probed women's awareness of key laws affecting women, including those relating to child marriage, inheritance, dowry violence against women, disclosure of the sex of the foetus, and abortion. The findings suggest that the majority of surveyed women were aware of these laws (Table 3.1). Almost all women (97-99\%) in both districts were aware of laws on child marriage; in contrast, just 70-72 percent of women in the two districts were aware of the MTP Act. Moreover, among women who were aware of the MTP Act, no more than two-thirds (64-67\%) knew that according to the Act, it is a woman's right to seek abortion under certain conditions, and just 20-25 percent were aware that abortion is legally permitted only up to 20 weeks of gestation (not shown in the table).

Overall, interdistrict disparities in awareness of laws were stark. Women in Kurukshetra were significantly more likely than those in Sonipat to be aware of five of the six laws about which we probed. While awareness levels were similar among women residing in the urban areas of the two districts, differences in awareness were particularly wide in rural areas. For example, while 83 percent of women in rural Kurukshetra were aware of laws relating to equal inheritance rights for girls, just 72 percent were similarly aware in rural Sonipat (Table 3.1). 
Table 3.1: Awareness of laws protecting women

Percentage of women reporting awareness of the different laws protecting women, according to residence, Kurukshetra and Sonipat

\begin{tabular}{|c|c|c|c|c|c|c|}
\hline \multirow[t]{2}{*}{ Laws protecting women } & \multicolumn{2}{|c|}{ Urban } & \multicolumn{2}{|c|}{ Rural } & \multicolumn{2}{|c|}{ Total } \\
\hline & Kurukshetra & Sonipat & Kurukshetra & Sonipat & Kurukshetra & Sonipat \\
\hline Prohibition of Child Marriage Act & 99.6 & 98.9 & 98.9 & $96.5^{*}$ & 99.1 & $97.2^{*}$ \\
\hline $\begin{array}{l}\text { Hindu Succession (Amendment) } \\
\text { Act, 2005, (Women's right to } \\
\text { inherit property) }\end{array}$ & 83.7 & 85.6 & 82.5 & $71.9^{* * *}$ & 82.8 & $76.2^{* *}$ \\
\hline $\begin{array}{l}\text { Dowry Prohibition Act (Prohibition } \\
\text { of payment of dowry) }\end{array}$ & 97.4 & 93.6 & 94.6 & $84.7^{* * *}$ & 95.4 & $87.4^{* * *}$ \\
\hline $\begin{array}{l}\text { Protection of Women from } \\
\text { Domestic Violence Act (Prohibition } \\
\text { of domestic violence against } \\
\text { women) }\end{array}$ & 97.8 & 97.1 & 96.8 & $86.6^{* \star *}$ & 97.1 & $89.8^{* * *}$ \\
\hline $\begin{array}{l}\text { MTP Act (that women have the } \\
\text { right to seek abortion) }\end{array}$ & 74.4 & 76.4 & 68.1 & 69.9 & 69.8 & 71.9 \\
\hline $\begin{array}{l}\text { PCPNDT Act (that disclosure of the } \\
\text { sex of the foetus is illegal) }\end{array}$ & 96.8 & 92.5 & 95.3 & $83.7^{* * *}$ & 95.7 & $86.4^{* * *}$ \\
\hline Number of women & 278 & 266 & 277 & 280 & 555 & 546 \\
\hline
\end{tabular}

Note: ${ }^{*}{ }^{* *}$ and ${ }^{* * *}$ indicate that differences between Kurukshetra and Sonipat, Kurukshetra urban and Sonipat urban, and Kurukshetra rural and Sonipat rural are significant at $p<0.05, p<0.01$ and $p<0.001$, respectively.

Findings further suggest that awareness of the PCPNDT Act (that is, that there is a law that prohibits disclosure of the sex of the foetus) was widespread, with some interdistrict variation. Overall, while almost all (96\%) of women from Kurukshetra were aware of such a law, 86 percent of their counterparts from Sonipat were so aware. Differences were mild in urban areas (97\% versus 93\%) but wide in rural areas, with 95 percent of women from Kurukshetra compared to 84 percent of those from Sonipat.

Figure 3.1: Percentage of women reporting that a person seeking disclosure of the sex of the foetus can be jailed, according to residence, Kurukshetra and Sonipat

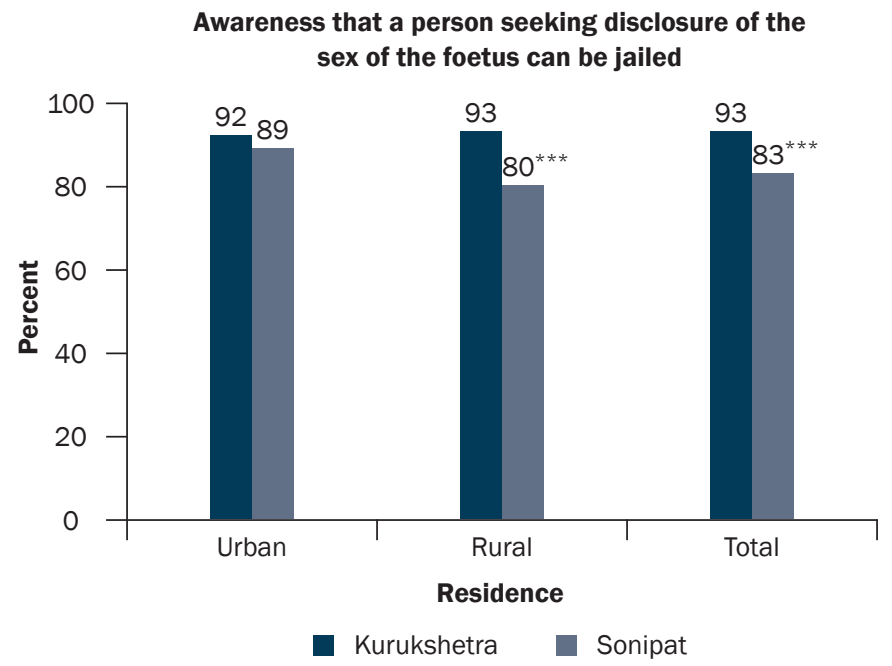

Note: ${ }^{* * *}$ indicate that differences between Kurukshetra and Sonipat, Kurukshetra urban and Sonipat urban, and Kurukshetra rural and Sonipat rural are significant at $p<0.001$. reporting awareness of such a law (Table 3.1).

Women who were aware of the existence of the PCPNDT Act were also probed about their knowledge about specific aspects of the law; for example, that a person seeking disclosure of the sex of the foetus as well as a person conducting such tests may be jailed, and that there is a complaints mechanism for reporting cases of disclosure of the sex of the foetus or abortion of a female foetus. In Figures 3.1 and 3.2, we present the percentage of all women in our sample who reported such specific awareness of the PCPNDT Act. Findings suggest that large proportions of women in both districts and in both rural and urban areas were aware that a person seeking disclosure of the sex of the foetus can be jailed (Figure 3.1) and that a health care provider conducting sex-selective ultrasonography can also be sent to jail (Figure 3.2). However, once again, awareness levels differed significantly by district, with significantly more women from Kurukshetra than Sonipat reporting awareness that a person seeking disclosure (93\% versus $83 \%$ ) and a service provider 
Figure 3.2: Percentage of women reporting that a service provider/doctor/person or any provider conducting the ultrasound examination can be jailed for disclosing the sex of the foetus, according to residence, Kurukshetra and Sonipat

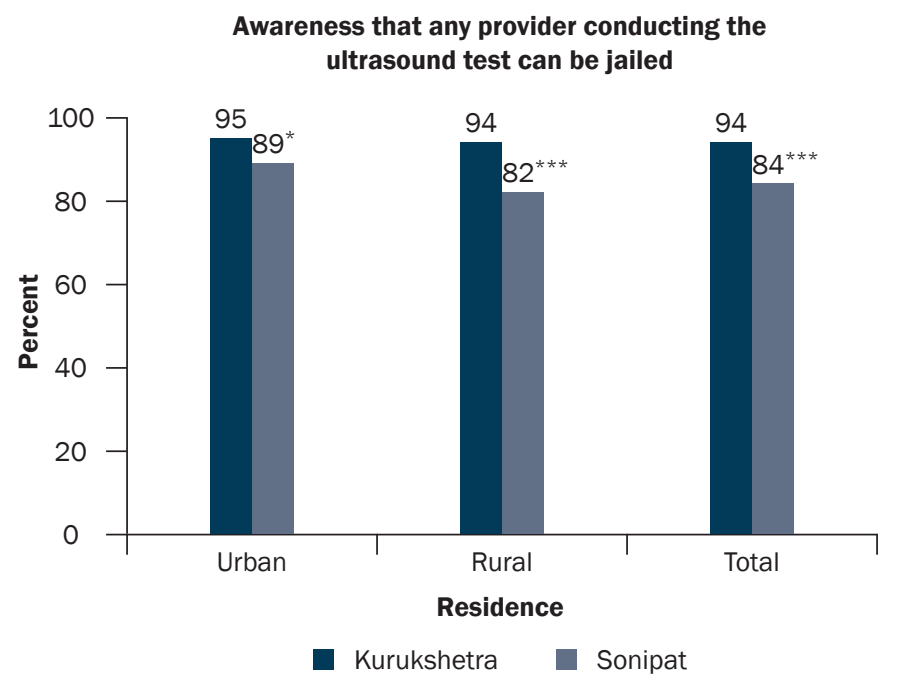

Note: * and ${ }^{* * *}$ indicate that differences between Kurukshetra and Sonipat, Kurukshetra urban and Sonipat urban, and Kurukshetra rural and Sonipat rural are significant at $p<0.05$ and $p<0.001$, respectively. revealing the sex of the foetus (94\% versus $84 \%$ ) can be jailed Figures 3.1 and 3.2, respectively). Differences were wider among rural than urban women.

\section{Women's exposure to communication, advocacy and community mobilisation initiatives}

The survey explored women's exposure to information about the PCPNDT Act, as well as, more generally, related behaviour change communication messages, namely, those challenging patriarchal norms and advocating equal treatment of girls and boys, from various sources, including messages through the media, interpersonal communication with health care providers, advertisements in health facilities, contacts with NGOs, messages acquired through group meetings, interpersonal counselling, and contacts with other forums and informal networks.

Sources of information about the PCPNDT Act and related behaviour change communication messages challenging patriarchal norms and

advocating equal treatment of girls and boys are presented in Table 3.2. Findings suggest that such information and messages came largely from the media (television or TV/newspaper/radio) with 76-87 percent of women from the two districts citing the media as a key source of information. Considerably fewer women reported that they had received information through posters and signboards placed in health facilities (29-38\%) or through public hoardings (20-21\%). Just 22-23 percent of women from the two districts named schools and colleges or health care providers as sources providing information about the Act and related behaviour change communication messages. Finally, several women-more from Kurukshetra (34\%) than Sonipat (27\%)-said that they had obtained their information from informal sources, by and large, neighbours, family and friends (26-34\%). Interdistrict differences were significant in respect of the media as an information source: significantly more women in Kurukshetra (87\%) than Sonipat (76\%) had been exposed to media messages; likewise, differences were significant in urban areas $(93 \%$ versus $84 \%$ ) as well as in rural areas (85\% versus $72 \%$ ), and more urban than rural women from the two districts had been so exposed (85-93\% versus $72-84 \%)$.

We also explored women's exposure to messages, programmes and campaigns advocating equal treatment of boys and girls, and discouraging gender-biased sex selection. Our survey probed whether women had been exposed to any advocacy activity or message delivered through a variety of sources, ranging from the media to informal networks. We note that although we tried to elicit information on women's awareness of and exposure to campaigns-notably the Beti Bachaon Andolan (Save the Girl Child Campaign)-intended to raise the value of the girl child and prevent gender-biased sex selection, many women were unable to distinguish between the specific programme entitled Beti Bachao Andolan, and other programmes and interactions that focused on saving the girl child. As seen in Table 3.3, almost all the women had heard general messages on raising the status of the girl child or promoting equal treatment of sons and daughters (90-93\%), with negligible differences between women in the two districts and in rural versus urban areas. Somewhat fewer reported exposure to specific messages discouraging genderbiased sex selection or sex-selective abortion, and now interdistrict differences were significant. For example, more women in Kurukshetra (84\%) than in Sonipat (77\%) had been exposed to such messages, and differences were mild in urban areas (86\% versus $80 \%$ ), but significant in rural areas (83\% versus $75 \%$ ).

The media were widely cited as a source of information about both raising the status of the girl child in general, and discouraging gender-biased sex selection in particular. As evident from Table 3.4, women from Kurukshetra were more likely than those from Sonipat to have been exposed to media messages, both those relating to equal 
Table 3.2: Sources of information about the PCPNDT Act and related behavior change communication messages Percentage of women reporting various sources of information about the PCPNDT Act, and behaviour change communication messages challenging patriarchal norms and advocating equal treatment of girls and boys, according to residence, Kurukshetra and Sonipat

\begin{tabular}{|c|c|c|c|c|c|c|}
\hline \multirow[t]{2}{*}{ Sources of information } & \multicolumn{2}{|c|}{ Urban } & \multicolumn{2}{|c|}{ Rural } & \multicolumn{2}{|c|}{ Total } \\
\hline & Kurukshetra & Sonipat & Kurukshetra & Sonipat & Kurukshetra & Sonipat \\
\hline \multicolumn{7}{|l|}{ A. Media } \\
\hline Television/Radio/Newspapers & 92.6 & $84.3^{*}$ & 84.9 & $71.7^{* * *}$ & 86.9 & $75.6^{* * *}$ \\
\hline B. Hoardings and advertisements & 57.4 & 52.4 & 40.6 & 33.2 & 45.0 & 39.2 \\
\hline Hoardings & 29.0 & 27.5 & 17.0 & 18.6 & 20.2 & 21.3 \\
\hline $\begin{array}{l}\text { Advertisements and signboards in } \\
\text { health facilities }\end{array}$ & 47.6 & 43.7 & 34.5 & $22.9^{* *}$ & 37.9 & $29.3^{*}$ \\
\hline $\begin{array}{l}\text { c. Health care providers and } \\
\text { educational institutions }\end{array}$ & 19.6 & 18.8 & 24.6 & 23.1 & 23.2 & 21.8 \\
\hline ASHA/AWW/ANM & 1.8 & 1.5 & 8.1 & 7.0 & 6.4 & 5.3 \\
\hline Other health care provider & 10.4 & 13.2 & 12.5 & 12.2 & 11.9 & 12.5 \\
\hline School/College & 8.1 & 5.7 & 5.8 & 5.9 & 6.4 & 5.8 \\
\hline D. Community members/meetings & 34.3 & 29.3 & 34.4 & 26.0 & 34.4 & 27.1 \\
\hline Self-Help Group meeting & 1.9 & 0.4 & 0.0 & 0.7 & 0.5 & 0.6 \\
\hline Religious leader & 1.1 & 0.7 & 0.3 & 0.4 & 0.5 & 0.5 \\
\hline $\begin{array}{l}\text { Other (mostly friend, neighbour } \\
\text { and/or family member) }\end{array}$ & 31.4 & 28.2 & 34.4 & 25.0 & 33.6 & 26.0 \\
\hline Number of women & 278 & 266 & 277 & 280 & 555 & 546 \\
\hline
\end{tabular}

Note: ${ }^{*},{ }^{* *}$ and ${ }^{* * *}$ indicate that differences between Kurukshetra and Sonipat, Kurukshetra urban and Sonipat urban, and Kurukshetra rural and Sonipat rural are significant at $p<0.05, p<0.01$ and $p<0.001$, respectively.

Table 3.3: Exposure to messages advocating equal treatment of boys and girls, and discouraging gender-biased sex selection

Percentage of women reporting exposure to messages advocating equal treatment of boys and girls, and discouraging gender-biased sex selection, according to residence, Kurukshetra and Sonipat

\begin{tabular}{|c|c|c|c|c|c|c|}
\hline \multirow[t]{2}{*}{ Exposure to messages on: } & \multicolumn{2}{|c|}{ Urban } & \multicolumn{2}{|c|}{ Rural } & \multicolumn{2}{|c|}{ Total } \\
\hline & Kurukshetra & Sonipat & Kurukshetra & Sonipat & Kurukshetra & Sonipat \\
\hline $\begin{array}{l}\text { Raising the status of the } \\
\text { girl child; encouraging equal } \\
\text { treatment of sons and daughters }\end{array}$ & 96.0 & 94.3 & 91.8 & 88.5 & 92.9 & 90.3 \\
\hline $\begin{array}{l}\text { Discouraging gender-biased sex } \\
\text { selection and/or abortion of a } \\
\text { female foetus }\end{array}$ & 86.3 & 80.4 & 83.4 & $74.9^{* *}$ & 84.2 & $76.6^{* *}$ \\
\hline Number of women & 278 & 266 & 277 & 280 & 555 & 546 \\
\hline
\end{tabular}

Note: ${ }^{* \star}$ indicates that differences between Kurukshetra and Sonipat, and Kurukshetra rural and Sonipat rural are significant at $p<.01$. 
Table 3.4: Exposure to messages through the media

Percentage of women reporting exposure to media messages advocating equal treatment of boys and girls, and discouraging gender-biased sex selection, according to residence, Kurukshetra and Sonipat

\begin{tabular}{|c|c|c|c|c|c|c|}
\hline \multirow[t]{2}{*}{ Exposure to media messages } & \multicolumn{2}{|c|}{ Urban } & \multicolumn{2}{|c|}{ Rural } & \multicolumn{2}{|c|}{ Total } \\
\hline & Kurukshetra & Sonipat & Kurukshetra & Sonipat & Kurukshetra & Sonipat \\
\hline \multicolumn{7}{|c|}{$\begin{array}{l}\text { A. Received messages about } \\
\text { raising the status of the girl child; } \\
\text { encouraging equal treatment of } \\
\text { sons and daughters }\end{array}$} \\
\hline $\begin{array}{l}\text { Through Television/Radio/ } \\
\text { Newspapers/Films }\end{array}$ & 93.9 & 92.4 & 89.6 & 83.9 & 90.7 & 86.5 \\
\hline Through hoardings & 10.0 & $19.6^{*}$ & 9.5 & 10.1 & 9.6 & 13.0 \\
\hline \multicolumn{7}{|l|}{$\begin{array}{l}\text { B. Received messages } \\
\text { discouraging gender-biased sex } \\
\text { selection and/or abortion of a } \\
\text { female foetus }\end{array}$} \\
\hline $\begin{array}{l}\text { Through Television/Radio/ } \\
\text { Newspapers/Films }\end{array}$ & 81.6 & 75.9 & 73.0 & $65.9^{*}$ & 75.3 & $69.0^{*}$ \\
\hline Through hoardings & 16.1 & 18.9 & 13.7 & 10.1 & 14.3 & 12.8 \\
\hline Number of women & 278 & 266 & 277 & 280 & 555 & 546 \\
\hline
\end{tabular}

Note: ${ }^{*}$ indicates that differences between Kurukshetra and Sonipat, Kurukshetra urban and Sonipat urban, and Kurukshetra rural and Sonipat rural are significant at $p<.05$.

treatment of boys and girls (91\% versus $87 \%$ ) and those discouraging sex-selective abortion (75\% versus $69 \%)$. and women in urban areas of the two districts were more likely than those in rural areas to report exposure to messages on both these issues (92-94\% versus $84-90 \%$ ), and $76-82 \%$ versus $66-73 \%$, respectively). Relatively few women in Kurukshetra, in contrast, could recall hoardings displaying messages about treating girls and boys alike and about gender-biased sex selection (10-14\%), though, as in the case of the media, women in urban areas were more likely than those in rural areas of the two districts to have seen these messages on hoardings (10-20\% versus $10 \%$ and $16-19 \%$ versus $10-14 \%$, respectively).

Women were also asked if they had been exposed to specific television serials, exhibited nationally and in Haryana, that deliver messages relating to gender-biased sex selection. Findings, presented in Table 3.5, show that among the four television serials or soap operas about which we had inquired, $\mathrm{Na}$ aana is des laado, a serial based on a Haryanvi family that depicts stark differences in how boys and girls are treated in the area had been most widely viewed, by 51 percent and 57 percent of women from Kurukshetra and Sonipat, respectively. Also viewed by relatively large proportions of women were Ghar ki Lakshmi betiyaan (38\% and 36\%, respectively) and Betiyaan apni ya paraya dhan (16\% and 15\%, respectively). While in most cases, differences between the two districts were narrow, more women from urban Sonipat than urban Kurukshetra reported that they had watched the serial, Na aana is des laado (75\% and 58\%, respectively). Finally, about five percent of women from both districts had been exposed to the more recently aired television serial, Mein kuch bhi kar sakti hoon. In addition, respondents were also asked whether they had seen Beti ki bidaai, a short film broadcasted by the Government of Haryana on the equality of boys and girls, and child marriage. Only about five percent of women from Kurukshetra and eight percent of those from Sonipat reported watching this film.

Women reporting exposure to various television serials/film listed in Table 3.5, were probed about the key messages they had received from these programmes. As evident from Table 3.6 the most common responses included 'treating boys and girls equally' (46-48\%), 'letting a girl be born' (34\% in Sonipat and $46 \%$ in Kurukshetra), 'treating daughters well' (31-38\%) and 'stopping violence against women and girls' (31-37\%). Somewhat fewer reported that the key messages that they had gathered were that girls are capable of looking after their parents (17-19\%), about women's rights (13-16\%) and that disclosure of the sex of the foetus is wrong (11-13\%). Differences between the districts were generally narrow, both in urban and rural areas. 
Table 3.5: Exposure to television programmes

Percentage of women reporting exposure to television serials and films carrying messages related to gender equality, women's rights and child marriage, according to residence, Kurukshetra and Sonipat

\begin{tabular}{lcccccc}
\hline \multirow{2}{*}{$\begin{array}{l}\text { Exposure to television } \\
\text { programmes }\end{array}$} & \multicolumn{2}{c}{ Urban } & \multicolumn{2}{c}{ Rural } & \multicolumn{2}{c}{ Total } \\
\cline { 2 - 6 } & Kurukshetra & Sonipat & Kurukshetra & Sonipat & Kurukshetra & Sonipat \\
\hline $\begin{array}{l}\text { Ever watched the following } \\
\text { serials/short film: }\end{array}$ & & & & & & \\
Serial: & 3.2 & 1.9 & 4.3 & 6.1 & 4.0 & 4.8 \\
$\quad$ Mein kuch bhi kar sakti hoon & 57.9 & $75.2^{*}$ & 48.3 & 48.9 & 50.8 & 57.0 \\
$\quad$ Na aana is des laado & 47.5 & 43.6 & 34.3 & 32.7 & 37.8 & 36.0 \\
$\quad$ Ghar ki Lakshmi betiyaan & 14.2 & 14.1 & 16.6 & 14.7 & 16.0 & 14.5 \\
$\quad$ Betiyaan apni ya paraya dhan & & & & & & \\
Film: & 4.0 & 4.1 & 5.9 & 9.2 & 5.4 & 7.6 \\
$\quad$ Beti ki bidaai & $\mathbf{2 7 8}$ & $\mathbf{2 6 6}$ & $\mathbf{2 7 7}$ & $\mathbf{2 8 0}$ & $\mathbf{5 5 5}$ & $\mathbf{5 4 6}$ \\
Number of women &
\end{tabular}

Note: ${ }^{*}$ indicates that differences between Kurukshetra and Sonipat, Kurukshetra urban and Sonipat urban, and Kurukshetra rural and Sonipat rural are significant at $p<.05$.

Table 3.6: Messages received through television serials and films

Among those who watched specific television serials/films, percentage of women reporting the messages received through these programmes, according to residence, Kurukshetra and Sonipat

\begin{tabular}{|c|c|c|c|c|c|c|}
\hline \multirow[t]{2}{*}{ Messages received } & \multicolumn{2}{|c|}{ Urban } & \multicolumn{2}{|c|}{ Rural } & \multicolumn{2}{|c|}{ Total } \\
\hline & Kurukshetra & Sonipat & Kurukshetra & Sonipat & Kurukshetra & Sonipat \\
\hline Women can be empowered & 2.0 & 6.2 & 2.4 & 7.6 & 2.3 & $7.1^{*}$ \\
\hline $\begin{array}{l}\text { Women can die if they have an } \\
\text { unsafe abortion }\end{array}$ & 4.0 & 1.4 & 0.6 & $4.7^{*}$ & 1.6 & 3.5 \\
\hline Traditional life is best for a woman & 1.6 & 3.9 & 1.8 & 2.9 & 1.7 & 3.2 \\
\hline $\begin{array}{l}\text { Checking the sex of the foetus is } \\
\text { wrong }\end{array}$ & 15.1 & 14.0 & 9.3 & 11.9 & 11.0 & 12.7 \\
\hline Daughters take care of parents & 18.9 & 20.1 & 19.4 & 15.6 & 19.3 & 17.3 \\
\hline Treat daughters well & 30.4 & 40.5 & 31.1 & 36.8 & 30.8 & 38.2 \\
\hline Let the girl child be born & 45.2 & 41.8 & 46.5 & $29.1^{* *}$ & 46.1 & $33.8^{* *}$ \\
\hline Other social issues & 11.1 & 10.6 & 5.5 & 4.6 & 7.2 & 6.9 \\
\hline Treat boys and girls equally & 45.7 & 57.2 & 45.6 & 42.7 & 45.6 & 48.1 \\
\hline Women's rights & 20.4 & 17.2 & 14.5 & 10.0 & 16.3 & 12.7 \\
\hline $\begin{array}{l}\text { To stop violence against girls and } \\
\text { women }\end{array}$ & 36.2 & 39.2 & 37.8 & $26.1^{*}$ & 37.3 & 31.0 \\
\hline Educate girls & 2.1 & 2.9 & 2.6 & 5.3 & 2.4 & 4.4 \\
\hline Can't remember & 14.7 & 9.6 & 13.1 & 15.1 & 13.6 & 13.1 \\
\hline $\begin{array}{l}\text { Number of women who had } \\
\text { watched any of the television } \\
\text { serials/films mentioned in } \\
\text { Table } 3.5\end{array}$ & 198 & 209 & 164 & 168 & 362 & 377 \\
\hline
\end{tabular}

Note: * and ${ }^{* *}$ indicate that differences between Kurukshetra and Sonipat, and Kurukshetra rural and Sonipat rural are significant at $p<0.05$ and $p<0.01$, respectively. 
We also probed about whether women had been exposed to health sector messages, and more specifically, signboards and posters in health care facilities and interpersonal communication from frontline health care providers and nurses. Table 3.7 suggests that exposure to signboards and notices in health care facilities indicating that the facility did not provide sex determination tests was reported by large proportions of women (60-65\%); women from Kurukshetra were slightly more likely than their counterparts in Sonipat to have been exposed to such messages at facility level (74\% versus $70 \%$ in urban areas; $61 \%$ versus $55 \%$ in rural areas).

Table 3.7 further indicates that fewer women reported reading/seeing a message about what information doctors are permitted to provide when a woman undergoes ultrasonography; now, significantly more women from Sonipat (50\%) than Kurukshetra (38\%) reported reading/seeing such a message. Differences were mild in urban areas (49\% in Kurukshetra versus $42 \%$ in Sonipat) and wide in rural areas, with far more women from Sonipat than Kurukshetra reporting exposure to this information (54\% and 33\%, respectively). Most women had been exposed to these messages in their physician's office (4-6\%), the facility in which they had undergone ultrasonography (31-36\%), or in the hospital in which they had sought pregnancy-related services (24\% each) (not shown in the table).

Table 3.7: Exposure to signboards and notices in health care facilities

Percentage of women reporting exposure to signboards and notices displaying information about the provision of various details of ultrasonography, according to residence, Kurukshetra and Sonipat

\begin{tabular}{|c|c|c|c|c|c|c|}
\hline \multirow{2}{*}{$\begin{array}{l}\text { Exposure to messages in } \\
\text { health care facilities }\end{array}$} & \multicolumn{2}{|c|}{ Urban } & \multicolumn{2}{|c|}{ Rural } & \multicolumn{2}{|c|}{ Total } \\
\hline & Kurukshetra & Sonipat & Kurukshetra & Sonipat & Kurukshetra & Sonipat \\
\hline $\begin{array}{l}\text { Ever seen a signboard saying } \\
\text { that a particular facility } \\
\text { does not provide the sex } \\
\text { determination test }\end{array}$ & 74.3 & 69.7 & 61.3 & 55.0 & 64.7 & 59.5 \\
\hline $\begin{array}{l}\text { Ever read/seen a message } \\
\text { about what information doctors } \\
\text { can give if a woman undergoes } \\
\text { an ultrasound examination }{ }^{1}\end{array}$ & 49.0 & 41.8 & 33.4 & $53.9^{* *}$ & 37.5 & $50.2^{*}$ \\
\hline Number of women & 278 & 266 & 277 & 280 & 555 & 546 \\
\hline
\end{tabular}

Note: ${ }^{*}$ and ${ }^{* *}$ indicate that differences between Kurukshetra and Sonipat, Kurukshetra urban and Sonipat urban, and Kurukshetra rural and Sonipat rural are significant at $p<0.05$ and $p<0.01$, respectively. ${ }^{1}$ Multiple responses possible.

Frontline health workers, namely, ASHAs, ANMs and AWWs as well as nurses also convey information about genderbiased sex selection in the course of their interactions with women at community and/or facility levels. As Table 3.8 shows, relatively few women had been exposed to interpersonal communication delivered by frontline health workers or nurses. Even so, interdistrict disparities were evident: while 23 percent of women from Sonipat reported interpersonal contact with a frontline health worker or nurse about equitable treatment of sons and daughters or saving the girl child, almost one-third of those from Kurukshetra (31\%) so reported. We note that while interdistrict differences were negligible in urban areas (8-10\%), they were substantial in rural areas, with almost two in five (38\%) of the women from Kurukshetra, compared to 29 percent from Sonipat reporting exposure to such interpersonal communication delivered by a frontline health worker.

Table 3.8 further shows that with regard to exposure to specific messages delivered by the frontline health worker, among women who had a contact with any health worker regarding these issues, most (55\%-64\%) reported being counselled on discouraging gender-biased sex selection or sex-selective abortion, followed by the importance of educating girls (44-46\%), and treating boys and girls equally (25-38\%). Slightly lower proportions of women from both districts reported having discussed the fact that sex selection is against the law-18 percent from Kurukshetra and 28 percent from Sonipat.

Table 3.9 presents women's exposure to various educational activities conducted by NGOs. Findings indicate that few women reported exposure to activities conducted by NGOs. Just 6-9 percent had attended group sessions, meetings or camps, or dramas and nukkad nataks (street dramas) discouraging gender-biased sex selection, with little 
Table 3.8: Exposure to counselling by frontline health workers and nurses

Percentage of women who reported being counselled by frontline health workers and nurses about treating daughters and sons alike and/or about saving the girl child, and the specific messages they received, according to residence, Kurukshetra and Sonipat

\begin{tabular}{|c|c|c|c|c|c|c|}
\hline \multirow{2}{*}{$\begin{array}{l}\text { Exposure to counselling by } \\
\text { health workers }\end{array}$} & \multicolumn{2}{|c|}{ Urban } & \multicolumn{2}{|c|}{ Rural } & \multicolumn{2}{|c|}{ Total } \\
\hline & Kurukshetra & Sonipat & Kurukshetra & Sonipat & Kurukshetra & Sonipat \\
\hline \multicolumn{7}{|l|}{$\begin{array}{l}\text { Frontline health workers who ever } \\
\text { talked about treating daughters } \\
\text { and sons alike and/or about } \\
\text { saving the girl child }\end{array}$} \\
\hline ANM & 0.4 & 2.2 & 4.7 & $11.0^{* *}$ & 3.6 & $8.3^{*}$ \\
\hline Nurse & 2.2 & 1.1 & 6.0 & $1.4^{* *}$ & 5.0 & $1.3^{* *}$ \\
\hline ASHA & 1.1 & 0.7 & 19.7 & $9.0^{*}$ & 14.8 & $6.5^{\star}$ \\
\hline AWW & 7.7 & 4.8 & 25.4 & 19.2 & 20.7 & 14.8 \\
\hline Any of above & 9.8 & 7.7 & 38.4 & 29.3 & 30.8 & 22.7 \\
\hline Number of women & 278 & 266 & 277 & 280 & 555 & 546 \\
\hline \multicolumn{7}{|l|}{$\begin{array}{l}\text { Messages conveyed by frontline } \\
\text { health workers or nurses }\end{array}$} \\
\hline $\begin{array}{l}\text { It is against God's will to abort a } \\
\text { female foetus }\end{array}$ & 7.1 & 4.9 & 5.0 & 5.9 & 5.2 & 5.8 \\
\hline We must let the girl child live & 52.0 & 52.7 & 64.8 & 55.0 & 63.7 & 54.8 \\
\hline Families with girls are blessed & 22.8 & 19.4 & 15.7 & 8.5 & 16.3 & 9.6 \\
\hline We must educate girls & 49.1 & 33.5 & 43.2 & 47.9 & 43.7 & 46.4 \\
\hline $\begin{array}{l}\text { We must not keep girls locked } \\
\text { up }\end{array}$ & 11.0 & 9.6 & 4.6 & 4.7 & 5.1 & 5.2 \\
\hline Sex selection is against the law & 25.6 & 9.6 & 17.4 & 30.1 & 18.1 & 27.9 \\
\hline $\begin{array}{l}\text { We must treat boys and girls } \\
\text { equally }\end{array}$ & 33.0 & 28.3 & 38.1 & 24.4 & 37.7 & 24.8 \\
\hline $\begin{array}{l}\text { Number of women exposed to } \\
\text { interpersonal counselling from } \\
\text { frontline health workers or nurses }\end{array}$ & 27 & 21 & 107 & 82 & 134 & 103 \\
\hline
\end{tabular}

Note: ${ }^{*}$ and ${ }^{\star *}$ indicate that differences between Kurukshetra and Sonipat, Kurukshetra urban and Sonipat urban, and Kurukshetra rural and Sonipat rural are significant at $p<0.05$ and $p<0.01$, respectively.

variation between districts or rural-urban residence. Even fewer women had received interpersonal communication or counselling from an NGO (2-4\%), and again, interdistrict and rural-urban differences were negligible. In summary, just 8-10 percent of the women had been exposed to one or both of these activities conducted by NGOs.

We also inquired about whether women had been exposed to discourses conducted by religious leaders that discouraged gender-biased sex selection and the specific messages that they had received through such talks. As evident from Table 3.10, significantly more women from Kurukshetra than Sonipat (20\% versus 14\%) reported so; likewise, interdistrict differences were significant in urban areas (22\% versus $15 \%)$, but not so in rural areas. The main messages conveyed by religious leaders, as reported by women, were: to let girl children live (7-13\%), to educate girls $(5-6 \%)$, to recognise that families that have girls are blessed (3-7\%) and that it is against the will of God to abort a female foetus (3-9\%). Overall, more women from Kurukshetra than Sonipat, and more women in urban areas than rural areas of the two districts, reported exposure to most key messages delivered by religious leaders. 
Table 3.9: Exposure to educational activities conducted by NGOs

Percentage of women who reported attending group sessions or street dramas and receiving counselling from NGO staff on equal treatment of boys and girls and/or saving a girl child, according to residence, Kurukshetra and Sonipat

\begin{tabular}{|c|c|c|c|c|c|c|}
\hline \multirow[t]{2}{*}{ Exposure to NGO activities } & \multicolumn{2}{|c|}{ Urban } & \multicolumn{2}{|c|}{ Rural } & \multicolumn{2}{|c|}{ Total } \\
\hline & Kurukshetra & Sonipat & Kurukshetra & Sonipat & Kurukshetra & Sonipat \\
\hline $\begin{array}{l}\text { Attended a group session or } \\
\text { drama in the village/ward } \\
\text { about discouraging seeking } \\
\text { disclosure of sex of the foetus }\end{array}$ & 5.8 & 4.1 & 10.4 & 6.9 & 9.2 & 6.1 \\
\hline $\begin{array}{l}\text { Received counselling from } \\
\text { a NGO worker on equal } \\
\text { treatment of boys and girls } \\
\text { and/or about saving the girl } \\
\text { child }\end{array}$ & 0.7 & 0.8 & 1.8 & 4.7 & 1.5 & 3.5 \\
\hline $\begin{array}{l}\text { Exposure to either of the above } \\
\text { activities conducted by NGOs }\end{array}$ & 6.1 & 4.5 & 11.5 & 9.4 & 10.1 & 7.9 \\
\hline Number of women & 278 & 266 & 277 & 280 & 555 & 546 \\
\hline
\end{tabular}

Table 3.10: Exposure to discourses by religious leaders

Percentage of women reporting exposure to discourses by religious leaders, discouraging gender-biased sex selection, according to residence, Kurukshetra and Sonipat

\begin{tabular}{lcccccc}
\hline \multirow{2}{*}{$\begin{array}{l}\text { Exposure to discourses by } \\
\text { religious leaders }\end{array}$} & \multicolumn{2}{c}{ Urban } & \multicolumn{2}{c}{ Rural } & \multicolumn{2}{c}{ Total } \\
\cline { 2 - 6 } & Kurukshetra & Sonipat & Kurukshetra & Sonipat & Kurukshetra & Sonipat \\
\hline $\begin{array}{l}\text { Heard discourses where } \\
\text { religious leaders discouraged } \\
\text { gender-biased sex selection, } \\
\text { saying: }\end{array}$ & & & & & & \\
It is against the will of God to & 21.6 & $14.9^{*}$ & 18.9 & 13.1 & 19.6 & $13.6^{*}$ \\
abort a female foetus & 10.3 & $4.8^{*}$ & 7.8 & $2.5^{*}$ & 8.5 & $3.2^{* *}$ \\
Let the girl child live & 13.9 & $8.2^{*}$ & 12.2 & $6.0^{* *}$ & 12.6 & $6.7^{* *}$ \\
Families with girls are blessed & 7.1 & 3.7 & 6.4 & 2.8 & 6.6 & $3.1^{*}$ \\
We must educate girls & 5.4 & 6.3 & 6.3 & 3.8 & 6.0 & 4.6 \\
We must not keep girls locked & & & & & & \\
up & 2.1 & 3.0 & 1.8 & 1.5 & 1.8 & 1.9 \\
Sex selection is against the law & 2.5 & 0.8 & 0.4 & 1.4 & 0.9 & 1.2 \\
Treat boys and girls equally & 1.1 & 0.8 & 2.9 & 3.8 & 2.4 & 2.9 \\
Number of women & $\mathbf{2 7 8}$ & $\mathbf{2 6 6}$ & $\mathbf{2 7 7}$ & $\mathbf{2 8 0}$ & $\mathbf{5 5 5}$ & $\mathbf{5 4 6}$ \\
\hline
\end{tabular}

Note: ${ }^{*}$ and ${ }^{* *}$ indicate that differences between Kurukshetra and Sonipat, Kurukshetra urban and Sonipat urban, and Kurukshetra rural and Sonipat rural are significant at $p<.05$ and $p<.01$, respectively.

Other important sources of both types of messages were informal networks, notably community members, relatives, neighbours and friends ( $27-28 \%$ and $26-31 \%$, respectively) (not shown in the table).

Rural-urban differences were marked. Frontline health workers were a key source of behavior change communication reported by more rural than urban women in each district (38\% versus 10\% in Kurukshetra, and 29\% versus $8 \%$ in Sonipat, were counseled by a frontline health worker). The advocacy efforts of religious leaders, conversely, were 
articulated by significantly more urban women in Kurukshetra (22\%) than rural women in both districts (13-19\%) and significantly more than their counterparts in Sonipat (15\%). In contrast, while few women in both districts reported exposure to such efforts delivered by NGOs, more rural than urban women in both settings so reported (12\% versus $6 \%$ in Kurukshetra; $9 \%$ versus $5 \%$ in Sonipat).

Interdistrict differences in exposure to messages from frontline workers, NGOs, religious leaders discouraging disclosure of the sex of the foetus and/or advocating equal treatment of boys and girls and saving the girl-child are summarised graphically in Figure 3.3. Findings reiterate that one-on-one counselling by frontline health workers and efforts by religious leaders discouraging gender discrimination as also gender-biased sex-selective practices were significantly more likely to be reported by women in Kurukshetra than in Sonipat. It also shows that few women reported attending an educational activity and/or counselling conducted by NGOs on these issues.

Figure 3.3: Percentage of women who reported exposure to messages from frontline health workers, NGOs and religious leaders on equal treatment of boys and girls and discouraging gender-biased sex selection, Kurukshetra and Sonipat

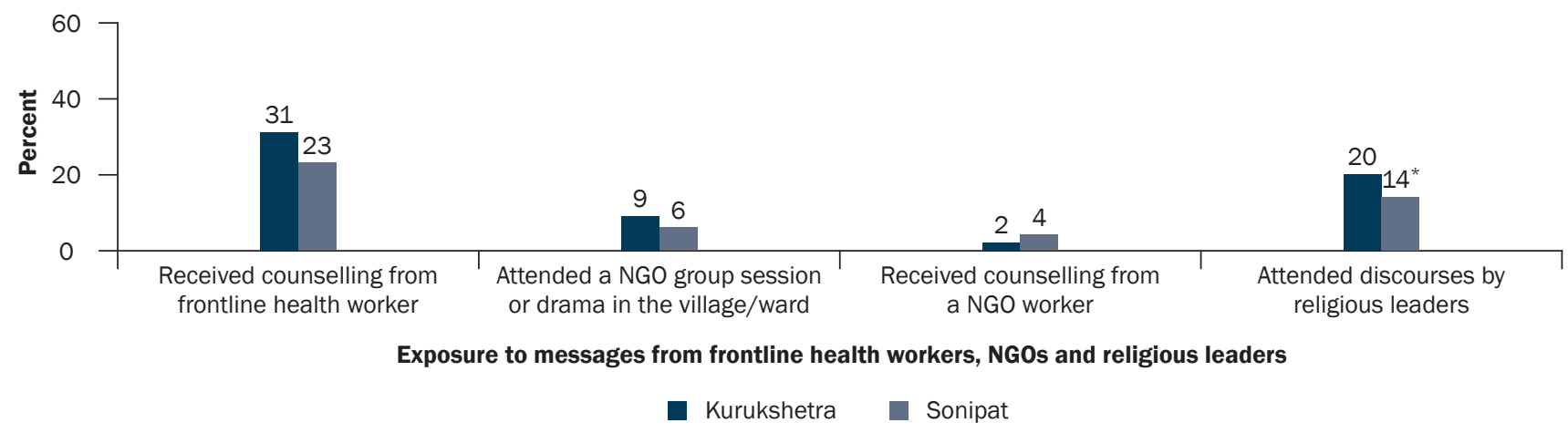

Note: ${ }^{*}$ indicates that differences between Kurukshetra and Sonipat, Kurukshetra urban and Sonipat urban, and Kurukshetra rural and Sonipat rural are significant at $p<.05$.

\section{B. Perspectives of key informants}

All key informants-health care providers, public sector programme implementers and NGO programme implementers-were probed about communication, advocacy and community mobilisation activities conducted in their district, by a range of players from the public sector and NGOs, lawyers and others, that focused on the issue of gender-biased sex selection as also the kinds of communication, advocacy and community mobilisation activities they had encountered or implemented. While all three groups had some familiarity with efforts made through the media, it was largely public sector programme implementers and NGO programme implementers who shed light on communication, advocacy and community mobilisation efforts.

\section{Perspectives of health care providers}

Health care providers tended to be unfamiliar about the presence of NGOs in general, and NGO-executed communication, advocacy and community mobilisation activities in particular, in their respective districts. Indeed, of the 23 health care providers we interviewed, just seven reported any awareness of NGOs working in the area, and even these seven were unable to name the NGO or describe its work. Health care providers from Kurukshetra, where there are only a few NGOs, were rarely able to articulate the communication, advocacy and community mobilisation activities in their district, although reference was made to meetings held with the Deputy Commissioner (DC) to raise awareness and change provider attitudes, and at least one provider described advocacy efforts made by politicians and religious leaders as the following excerpt suggests:

We hear politicians speaking; they pick up this issue (gender-biased sex selection) and call it a social evil. Even when people go to the gurdwara (place of worship of Sikhs), they (politicians) tell them (people) these things. [Female, radiologist, aged 40 , Kurukshetra] 
Health care providers in Sonipat, in contrast, were more familiar with advocacy efforts. Some eight health care providers lauded the media for focusing on gender-biased sex selection and the value of the girl child; even so, they could not be specific on the kinds of programmes implemented. For example:

There are some NGOs in Sonipat who are working on these issues. I don't know their names. Through their activities and publicity, they are trying to spread awareness about these issues and also trying to change the mindset of the people. Sometimes, they organise rallies of schoolgoing children to reduce people's attitude of discriminating between sons and daughters. [Female, general physician/MBBS doctor, aged 63 , Sonipat]

The media are also working better these days to raise people's awareness. Through advertisements and news items, the media are telling people that parents should not differentiate between a son and a daughter, that both should be treated equally.... I will say that as compared to earlier times, the authorities as well as the media and NGOs are working really well to properly implement the law. Religious leaders are also trying to raise people's awareness; they tell people about the value of daughters through their songs and speeches. People have started to understand. [Female, ANM, aged 48, Sonipat]

\section{Perspectives of public sector programme implementers}

Narratives of public sector programme implementers from the districts and state under study highlight that these officials were themselves involved in communication, advocacy and community mobilisation activities. For example, those engaged in the delivery of the ICDS programme discussed their role in both holding meetings for women to change attitudes about sons and daughters, and tracking and counselling pregnant women who already have one or two daughters. Those associated with the implementation of the PCPNDT Act organised meetings and events that stressed the value of girls as well as highlighted the longer-term consequences of terminating pregnancies carrying a female foetus. Lawyers and magistrates discussed their role in providing legal services and spreading awareness at the community level about various laws. Most public sector informants described media measures to change attitudes towards daughters and raise the status of women, and many described the communication, advocacy and community-level activities of the public sector, notably the ICDS and Health Department. Advocacy efforts clearly did not just focus on PCPNDT issues; rather, they focused on raising the value of girls, advocating equal treatment of and aspirations for daughters and sons, and so on, as well as efforts to build life skills among girls and provide livelihood opportunities for women.

District programme implementers from Sonipat focused on awareness-raising campaigns, changing community attitudes, and building life and livelihood skills. Several referred to the engagement of NGOs or suggested that NGOs collaborated with them in these activities. A few criticised the media for portraying women in a negative light, and criticised NGOs for interference in their activities. The following excerpts represent these views:

We arrange meetings for mothers to make them aware that there is no difference between a son and a daughter..... dowry is another subject, which we discuss. We mobilise people and make them understand that an independent woman does not need to pay a dowry and tell them not to marry their children into families that make such illegal dowry demands.... We also arrange awareness camps in villages, programmes in life skills for girls for improving livelihood prospects and so on. Mostly older women come to these programmes; they attend meetings but no positive change happens to their attitudes..... [Female, PO/CDPO, ICDS, aged 57, Sonipat]

For example, an NGO named Breakthrough has been working on the sensitisation of ASHA workers, AWWs and the locals. We also organise workshops and seminars in collaboration with NGOs to increase awareness. And, we have a Sakhshar Mahila Samiti (Literate Women's Group) where we mobilise educated women of the area who have ten or more years of schooling and train them to impart education to illiterate women. We also organise rallies, wall painting sessions and poster competitions to change the mindset of people..... Awareness campaigns etc are very useful in bringing change in the attitudes of people. People participate in these activities and attend meetings.... There is a campaign called Beti Bachao Beti Padhao Abhiyan (Save the Daughter, Educate the Daughter Campaign), which operates at the district and block levels. They have fixed an annual target of a 10-point increase in the sex ratio..... It is most important to sensitise the local people and change their mindset..... [Female, PO/CDPO, ICDS, aged 52, Sonipat] 
At the community level, we display posters and banners to showcase our core messages, and we also discuss these issues with the local people and Panchayats to increase awareness. We arrange awareness programmes in schools, and ask people to conduct 'kuan pujan' ('a ceremony to welcome the birth of male child by worshipping a well (kua) or a drinking water source) on the tenth day of the birth of a girl just as they do for boys. We also encourage women to perform the last rites of their father to break the age-old social custom..... Of course, TV programmes are making some difference in society; awareness at any level will help bring about change. [Male, law enforcement officer, aged 57, Sonipat]

In our district (Sonipat), some NGOs are also working towards spreading awareness among people. From time to time, they arrange programmes that give messages about the value of daughters, treating both sons and daughters equally, and to stop carrying out female foeticide. Their work helps to a certain extent; for example, they arrange mass marriages that release people from the burden of getting their daughters married, but they do not provide information about the rights of girls or about existing laws in favour of girls. Yes, TV serials and movies also do influence people but up to a point; for example, the TV serial 'Na aana is des laado'-also shows negativity. It shows that the villain is also a woman; this creates a wrong impression among people because women are not as negative as shown in these serials. [Female, law enforcement officer, aged 66, Sonipat]

There are two NGOs working on sex selection. They do not conduct any constructive activities, but rather they interfere in our activities. They don't have sufficient funds to do large-scale activities. [Male, law enforcement officer, aged 57 , Sonipat]

In Kurukshetra, where NGOs play an insignificant role in discouraging gender-biased sex selection or raising the status of the girl child, communication, advocacy and community mobilisation activities were conducted, to a considerable extent, by the public sector. Several key informants described programmes in which the administration interacted with various constituencies, including students, teachers and village communities at large. For example:

I think IEC (information, education, communication) programmes have some influence at the community level and result in change. Here, schools and colleges are the main target groups..... There are also different awareness-raising programmes which even involve school teachers and students. Every first Tuesday of the month, we have oath ceremonies in schools and colleges..... [Male, law enforcement officer, aged 52, Kurukshetra]

Also described was the "Night Halt" or "Open Durbar" programme. The programme was titled "Night Halt" because visits were conducted at evening time; more recently (with the new political party in power), the programme has been re-titled "Open Durbar". In this programme, government officials (the Chief Medical Officer, Medical Officers, and/ or the District Magistrate and the District Attorney) and other staff members from the Health and ICDS Departments pay weekly visits to villages in their jurisdiction. The programme allows the administration to interact with community members at the village level; address issues relating to son preference and the value of the girl child; raise awareness about various programmes and laws, including the PCPNDT Act and the consequences of violating it, and provide village communities an opportunity to register their grievances with the authorities, as evident from these excerpts:

The former DC conducted village-to-village awareness campaigns for people and for health providers. He organised meetings and training programmes, and has sensitised people to a great extent. The current $D C$ is also working hard in this regard and organising Night Halts/Open Durbars to make people aware of various schemes for reducing gender-biased sex selection. Night Halts take place twice a month after $5 \mathrm{pm}$ when all government health officers are present, and take an oath to offer dedicated services and discuss issues relating to sex selection in their divisions. In addition, the DC and Civil Surgeon also visit schools and colleges to inform students about such matters on the second Tuesday of each month. We also make efforts to sensitise people with the help of AWWs. [Female, PO/CDPO, ICDS, aged 50, Kurukshetra]

There is also a programme called 'Night Halt' where officials spend a night in a particular village and try to increase awareness among the locals through discussions and documentaries. [Male, law enforcement officer, aged 52, Kurukshetra]

Recently, our DC organised a special Night Halt programme where a lecture was delivered by a swami (religious leader) to ensure that more people understand the evils of sex selection and that it is against 
the law. Beti Bachao Beti Padhao is another campaign, which aims to increase people's awareness of the issue. Meetings are held to raise awareness... [Female, PO/CDPO, ICDS, aged 52, Kurukshetra]

A few public sector programme implementers highlighted the role of the media, but were mixed about its effect, some arguing that exposure to the media had contributed to changing attitudes about girls, and others suggesting that programmes were not aired regularly enough to change attitudes. For example:

Also, TV programmes have made some difference in what people think about girls. [Female, PO/CDPO, ICDS, aged 52, Kurukshetra]

At least one district official, an AWW, focused on economic empowerment activities for women conducted by the government as well as an NGO, stating:

Many government and non-governmental activities have focused on changing community attitudes in our district. Government self-help groups are doing remarkable work in this regard and provide loans to women. Women collect money and sew, cook, and make pickles and soap to earn a living. Our former legislator Naveen Jindal has started an NGO to teach women skills that will make them economically independent. [Female, AWW, aged 52, Kurukshetra]

\section{Perspectives of NGO programme implementers}

NGO programme implementers from Sonipat were not only familiar with communication, advocacy and community mobilisation activities, but were instrumental in conducting these activities. All 12 NGO programme implementers reported that their NGOs conducted programmes intended to raise awareness about gender-biased sex selection, or promoting the health and education of the girl child; activities were conducted at community and/or school/college levels. Several described their work to empower adult women and suggested that by empowering women, attitudes about having a daughter would change. Their responses are quoted below:

We work to spread awareness about having a girl child. We provide vocational training to girls so that they become independent through their own earnings. We also teach them sewing. Other than this, we organise programmes to send a message to people that they should not differentiate between a son and daughter, that both are the same, that they should not kill a female foetus after sex determination; we impress upon them that all these activities are wrong. We teach these things to community members.... On the issue of sex determination, we work on spreading awareness among people. [Male, NGO programme implementer, aged 49 , Sonipat]

We mainly work on education and related issues, raise awareness. We invite doctors to our programmes and try to raise awareness through them; we also hold camps where we convey ideas like 'no foeticide'. This year, we are focusing on education and have adopted 14 children and pay all their education expenses.... there is a lot of work going on through NGOs, like sewing, making candles and papad (thin Indian wafer) etc. There are many organisations that teach women and help them to get loans from banks to start their own enterprises. When a wife helps in running the household or gives her husband part of her earnings then, definitely, the husband's thinking changes. These schemes operate in both rural and urban areas. Although there are TV programmes, they are less effective than the awareness-raising activities carried out by NGOs. [Male, NGO programme implementer, aged 41, Sonipat]

We celebrate Balika Diwas; on that day, we go to schools, colleges, villages, cities and other places and organise ceremonies/seminars to make people more aware and understand the value of girls. The main theme of our organisation is: 'Shikshit Balika, Sashakt Mahila' (Educated Girl, Empowered Woman). We also organise 'kanya pujan'(a ceremony during the Navratri festival when nine young girls (kanya), each representing a form of Mahamaya, the supreme cosmic force, are worshipped) in which we make people understand the harsh reality that if we continue to conduct sex-selective abortion, for how many more years would we be able to do this pujan? Aside from these activities, we also conduct activities to spread awareness among girls in colleges because, after all, they are the future of our society. The district court sometimes organises seminars to provide legal information about dowry, inheritance etc. but these are just formalities; most of the time they are conducted casually. It is only social organisations, NGOs and educational institutions that are doing a much better job of making people aware of their rights and creating awareness on a larger scale. These organisations arrange seminars where they invite doctors, 
lawyers, judges, teachers etc. and with their help, spread awareness. All these experts give information about their own fields-the laws, different rights and the schemes that are provided in their field. Some NGOs organise programmes to train women in stitching, weaving etc, to give them a chance to become independent; but, in villages, NGOs work with limited resources and do not have the required funds to carry out skill-building programmes everywhere. [Male, NGO programme implementer, aged 46, Sonipat]

Our organisation implements several programmes to raise awareness about sex selection and also arranges mass marriages so that people don't consider a daughter as a liability. In mass marriage ceremonies, there are 5,000-7,000 people who take a pledge never to seek sex selection. [Male, NGO programme implementer, aged 62, Sonipat]

Finally, NGO programme implementers were somewhat disparaging about media efforts to change norms, arguing that television serials depicted women as weak and even as perpetuating gender-biased sex selection and were, as a result, ineffective in changing norms; for example:

The media also play an important role-they convey messages to the people and raise their awareness... But TV is also called sweet poison because people adopt bad things from it more quickly than they do right things. So, I don't think it has much of an effect..... [Male, NGO programme implementer, aged 39, Sonipat]

\section{Summary of the perspectives of women and key informants about communication, advocacy and community mobilisation efforts in their districts}

This chapter has highlighted, from women's perspectives, their awareness about the PCPNDT Act and their exposure to various communication, advocacy and community mobilisation activities that have focused on changing attitudes about son preference and discouraging practices to disclose the sex of the foetus and terminate pregnancies carrying a female foetus. In particular, we explore their exposure to the media, informal networks, health care providers and frontline health workers, NGO programme implementers and religious leaders. The chapter has also explored the perspectives and experiences of key informants with regard to communication, advocacy and community mobilisation activities in their district. We note that few health care providers were familiar with such activities and hence, our insights come largely from the two other groups, namely, programme implementers from the public sector and from NGOs.

Although most women had heard of the PCPNDT Act and were aware that those seeking disclosure of the sex of the foetus and those who disclose such information can be prosecuted, significantly more women from Kurukshetra than Sonipat reported such awareness (93-94\% versus 83-84\%).

The key source of information about the Act, and messages challenging patriarchal norms and advocating gender equality cited by women was the visual and print media. Significantly more women in Kurukshetra (87\%) than Sonipat (76\%) reported exposure to messages from the media, and differences were significant in urban areas $(93 \%$ versus $84 \%$ ) as well as in rural areas (85\% versus $72 \%$ ); more urban women than their rural counterparts in the two districts (85-93\% versus $72-84 \%$ ) mentioned the media as their prime source of information.

Almost all women had been exposed to television serials that depicted issues related to son preference and termination of pregnancies carrying a female foetus; the one depicting a Haryanvi family was most widely watched. The messages transmitted by these serials included girls' right to be born, reported by significantly more women from Kurukshetra than Sonipat (46\% versus $34 \%$ ); the evils of violence against women and girls, also more likely to be reported by women in Kurukshetra than Sonipat (37\% versus 31\%); and equal treatment of boys and girls, reported by 46-48 percent of women from the two districts. Many women had been exposed to signboards in health facilities-60-65 percent had seen a signboard, and 38 percent of women from Kurukshetra and 50 percent of those from Sonipat had been exposed to messages explaining the kind of information health care providers can and cannot provide to women seeking a prenatal diagnostic test.

One-on-one interactions were also reported and again, more women from Kurukshetra than Sonipat reported exposure to such interactions. Frontline health workers were a key source of behavior change communication reported by more women from Kurukshetra (31\%) than Sonipat (23\%), and by more rural than urban women in each district (38\% versus 10\% in Kurukshetra, and 29\% versus 8\% in Sonipat, were counseled by a frontline health worker). Likewise, the advocacy efforts of religious leaders were also articulated, again by significantly more women in Kurukshetra (20\%) than Sonipat (14\%); again, urban women in Kurukshetra (22\%) were more likely than rural 
women in both districts (13-19\%) and significantly more likely than their counterparts in Sonipat (15\%) to report so. In contrast, few women in both districts reported exposure to such efforts delivered by NGOs (8-10\%).

Key informants described a range of measures through which awareness was raised and efforts made to change patriarchal norms and preference for sons, and discourage gender-biased sex selection. Programmes were implemented by an array of players, including the public sector and NGOs; they targeted a range of audiences from students and teachers to communities, more generally. The contribution of the media was also described.

Communication, advocacy and community mobilisation activities conducted by the public sector included, in both districts, community meetings held by frontline health workers under ICDS and those directly responsible for enforcing the PCPNDT Act to sensitise communities, as well as one-on-one interactions between frontline health workers and women, for example. In contrast, it was in Kurukshetra that the narratives of public sector programme implementers suggested that programme officials of the district played a key role in communication, advocacy and community mobilisation activities. In particular, the Night Halt or Open Durbar programme enabled these district officials, including senior officials, to interact with village communities and make efforts to change patriarchal mindsets and raise awareness about various laws and programmes including the PCPNDT Act; it also offered an opportunity to community members to present their concerns to district officials. Also described by these key informants in Kurukshetra were programmes conducted by the Deputy Commissioner and Civil Surgeon in schools and colleges; these programmes offered the senior officials an opportunity to interact with students and teachers, and more specifically, to sensitise students and obtain pledges from teachers to desist from gender-biased sex selection.

NGO programmes largely focused on raising the status of the girl child, including activities intended to empower women. More specifically, all NGOs worked to raise awareness among students in schools and colleges, holding community-level meetings and so on.

All the key informants concurred that television was a powerful medium through which to change behaviours, but described other community-level activities undertaken to raise awareness and change attitudes as more effective.

In short, while communication, advocacy and community mobilisation activities took place in both districts, these activities appeared to be stronger and more wide-ranging in Kuruksehtra than in Sonipat. For example, more women from Kurukshetra than Sonipat were aware of the PCPNDT Act; so too, one-on-one counselling by frontline health workers and efforts by religious leaders appeared to be significantly more likely to be reported by women in Kurukshetra than in Sonipat. Findings also suggest that while initiatives of frontline health workers were more concentrated in rural than in urban areas, and exposure to advocacy efforts by public sector officials were similar in both districts, attendance at discourses by religious leaders and mass media exposure was greater in urban than in rural areas, and most notably in urban Kurukshetra. Likewise, although more NGO activities were conducted in Sonipat than in Kurukshetra, Kurukshetra reported a strong commitment to community mobilisation on the part of the district administration, including regular interaction with village communities on the one hand, and with students and teachers on the other. 


\section{Chapter 4}

\section{What works to reduce gender-biased sex selection: Perspectives of women and key informants on the enforcement of the PCPNDT Act}

As many as one-third of women in each district, believed that, or were undecided whether women with two or more daughters should be permitted to know the sex of the foetus and terminate a pregnancy carrying a female foetus, although almost all agreed that both those seeking and providing disclosure should be punished. Notwithstanding their greater awareness of the law and greater familiarity with law enforcement efforts, women in Kurukshetra were more sceptical than those in Sonipat about whether law enforcement efforts would reduce sex-selection practices; several challenges were articulated:

- Deliberate disregard of violations: advance warning about impending raids

- Corruption: interference by politicians/powerful individuals; paying off raiding teams or avoiding prosecution

- Action concentrated on service providers, those seeking disclosure rarely punished: impedes compliance with and community support for the law

- Excessive paperwork for sex-determination test: undue harassment of law-abiding health care providers

- Poorly-trained law enforcement officials: inadequate collection and compilation of evidence deters pursuance of court cases

- State and district authorities overburdened with work

- Exclusion of NGOs from law enforcement teams (suggested by NGO programme implementers): adversely affects the ability of the Appropriate Authority to implement the law

At the district level, the PCPNDT Act empowers the District Appropriate Authority to monitor ultrasonography facilities and take action against health care providers found to have disclosed the sex of the foetus. It also imposes strict punishment, by way of fines and imprisonment, on health care providers and families of pregnant women found to have violated the law. Notwithstanding these punitive measures, violations continue. In this chapter, we present the perspectives and experiences of women, health care providers, and programme implementers from the public and NGO sectors with regard to the enforcement and effectiveness of the PCPNDT Act. Specifically, among women, we explore perceptions about the effectiveness of the law and its ability to act as a deterrent to disclosure of the sex of the foetus, awareness of the helpline mechanism through which complaints may be registered, and attitudes about whether the law should be relaxed in certain circumstances.

Stronger evidence on law enforcement comes from the perspectives of key informants. Key informants have provided insights from their own varied perspectives as health care providers, and programmes implementers from the public sector and NGOs. Specifically, we describe below their perspectives about whether the law is effective, how it is enforced, how it is subverted, and what action may be taken to ensure a more balanced sex ratio at birth in the state and in study districts.

\section{A. Perspectives of women}

In order to understand women's perspectives about the PCPNDT Act, we explored their perceptions about whether the law is appropriately enforced in their district, and their attitudes about whether gender-biased sex selection should be permitted in certain conditions. 


\section{Perceptions about the extent of adherence to and enforcement of the PCPNDT Act}

In order to explore women's perceptions about adherence to the PCPNDT Act, we asked them whether they believed that some health care providers do reveal the sex of the foetus. The findings are illustrated in Figures 4.1a to 4.1d.

As Figure 4.1a indicates, the majority of women in both districts acknowledged that doctors did indeed continue to reveal the sex of the foetus (70-72\%). Correspondingly, relatively few women were aware of incidents in which the PCPNDT Act had been enforced in their areas (Figures 4.1b and 4.1c). For example, 41-42 percent of women from the two districts had heard about a doctor being prosecuted or a clinic being closed for disclosing the sex of the foetus to women or their family (Figure 4.1b). Even fewer, just 21 percent of those in Sonipat and 26 percent of those in Kurukshetra, had heard about raids on doctors (Figure 4.1c). While interdistrict differences were mild in urban areas (31-33\%), in rural areas, significantly more women from Kurukshetra than Sonipat were aware of raids on doctors (24\% versus 16\%). A small proportion (12-15\%) were aware, moreover, of the availability of an anonymous complaint mechanism, namely the helpline, through which citizens are encouraged to report violations of the Act (Figure 4.1d).

Figure 4.1a: Percentage of women reporting that some health care providers do reveal the sex of the foetus

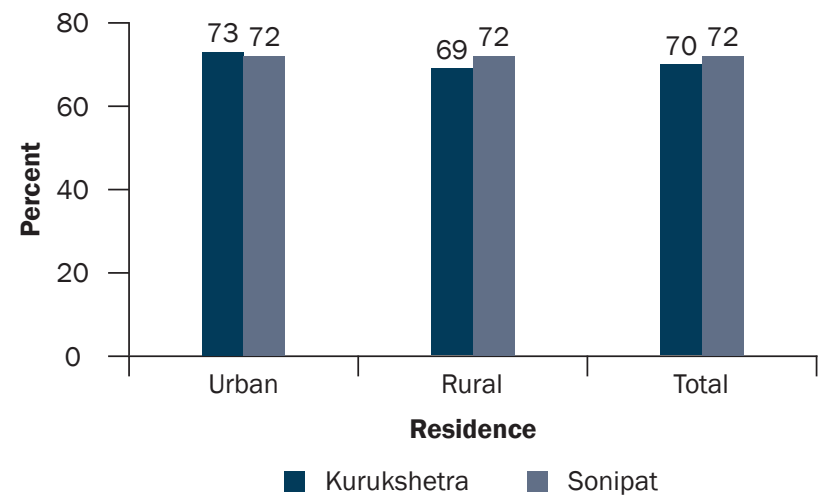

Figure 4.1c: Percentage of women who had heard about raids conducted on some doctors in Kurukshetra and Sonipat because they were providing information about the sex of the foetus

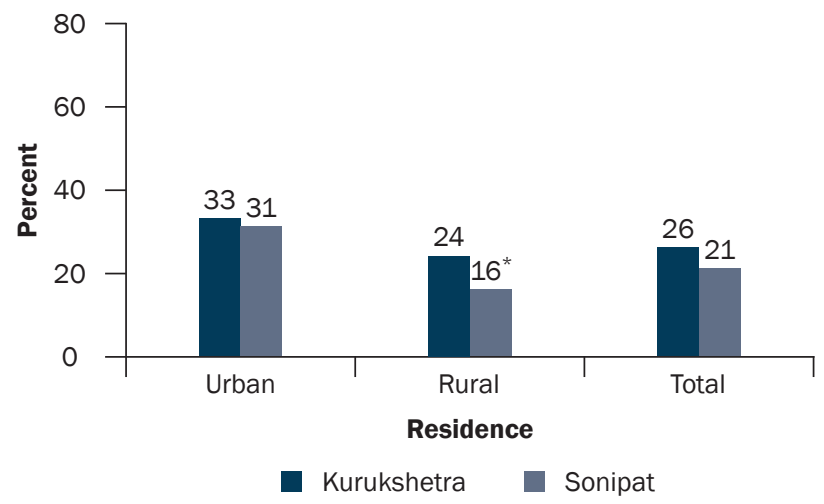

Figure 4.1b: Percentage of women who had heard about a doctor being prosecuted or a clinic being closed for providing sex determination services or revealing the sex of the foetus

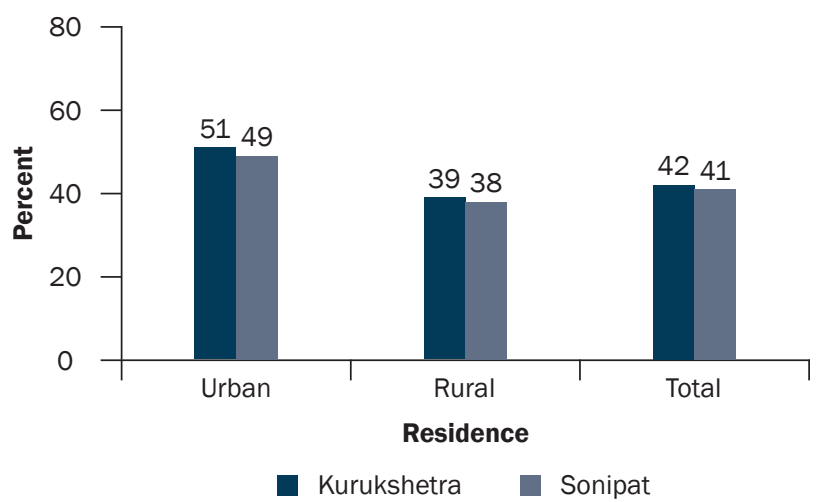

Figure 4.1d: Percentage of women who had heard about a helpline for reporting cases of sex selection

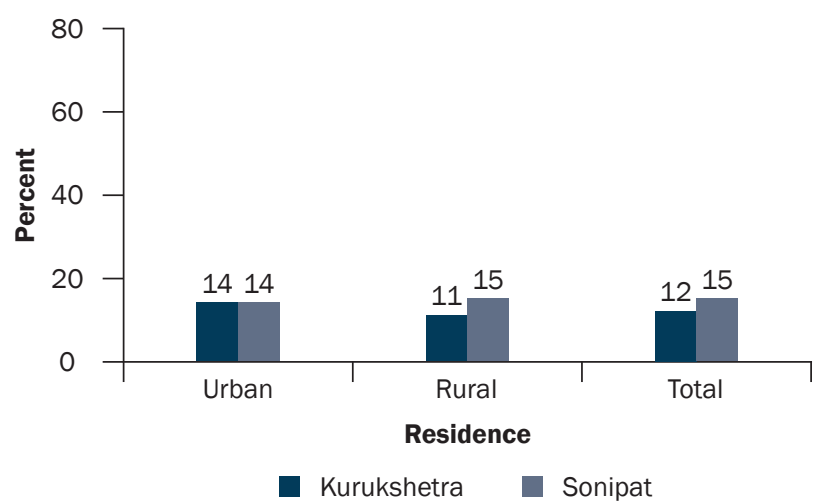

Note: ${ }^{*}$ indicates that differences between Kurukshetra and Sonipat, Kurukshetra urban and Sonipat urban, and Kurukshetra rural and Sonipat rural are significant at $p<.05$. 


\section{Attitudes about strict enforcement of the PCPNDT Act}

The survey presented a range of statements to women and inquired whether they agreed with each statement, seeking their views regarding the need to enforce the PCPNDT Act. Findings, presented in Table 4.1, are mixed. Almost all women (93-94\%) agreed that both those who seek disclosure of and those who disclose the sex of the foetus should be punished. At the same time, just two-thirds (64-65\%) maintained that the law should not be relaxed for couples with two or more daughters but no sons. Even fewer women-significantly more from Sonipat (30-31\%) than Kurukshetra (23-25\%)-believed that fear of the law would discourage doctors and women/families from engaging in these practices.

Table 4.1: Perceptions about punishing violations or violators of the PCPNDT Act and effectiveness of the Act

Percentage of women reporting opinions on strict enforcement of the PCPNDT Act, and whether this would reduce gender-biased sex selection and disclosure of the sex of the foetus, according to residence, Kurukshetra and Sonipat

\begin{tabular}{|c|c|c|c|c|c|c|}
\hline \multirow{2}{*}{$\begin{array}{l}\text { Perceptions about enforcement of } \\
\text { the PCPNDT Act and its impact }\end{array}$} & \multicolumn{2}{|c|}{ Urban } & \multicolumn{2}{|c|}{ Rural } & \multicolumn{2}{|c|}{ Total } \\
\hline & Kurukshetra & Sonipat & Kurukshetra & Sonipat & Kurukshetra & Sonipat \\
\hline $\begin{array}{l}\text { Agree that people who ask for } \\
\text { the sex of the foetus should be } \\
\text { punished }\end{array}$ & 92.8 & 95.8 & 93.5 & 91.1 & 93.3 & 92.5 \\
\hline $\begin{array}{l}\text { Agree that health care providers } \\
\text { who disclose the sex of the foetus } \\
\text { should be punished }\end{array}$ & 93.8 & 96.2 & 93.5 & 91.4 & 93.6 & 92.9 \\
\hline $\begin{array}{l}\text { Disagree with the statement that } \\
\text { the law should allow sex selection } \\
\text { if a couple has two or more } \\
\text { daughters and no son }\end{array}$ & 63.6 & 71.0 & 65.5 & 61.5 & 65.0 & 64.4 \\
\hline $\begin{array}{l}\text { Agree that doctors will stop the } \\
\text { practice of revealing the sex of the } \\
\text { foetus because they fear raids }\end{array}$ & 20.6 & 29.1 & 24.4 & $31.0^{*}$ & 23.4 & $30.4^{* *}$ \\
\hline $\begin{array}{l}\text { Agree that people will stop asking } \\
\text { doctors to reveal the sex of the } \\
\text { foetus because of raids }\end{array}$ & 19.8 & 26.8 & 26.6 & 32.1 & 24.8 & $30.5^{*}$ \\
\hline Number of women & 278 & 266 & 277 & 280 & 555 & 546 \\
\hline
\end{tabular}

Note: ${ }^{*}$ and ${ }^{* *}$ indicate that differences between Kurukshetra and Sonipat, Kurukshetra urban and Sonipat urban, and Kurukshetra rural and Sonipat rural are significant at $p<.05$ and $p<.01$, respectively.

\section{B. Perspectives of key informants}

All three groups of key informants were probed about their experiences with regard to the implementation of the PCPNDT Act, and their perceptions about the effectiveness of law enforcement. Many reported their own interactions with law enforcement, or information gleaned from colleagues and in the course of discharging their responsibilities. Many expressed a sense of frustration that just service providers and not clients were penalised, as also scepticism about the effectiveness of the implementation of the Act. Again, because the experiences of the three groups of key informants differ, we describe them individually.

\section{Implementation of the PCPNDT Act}

\section{Perspectives of health care providers}

Every single provider among the doctors, nurses and ANMs in our sample, across both districts, described their perspective on how the PCPNDT Act is implemented in similar ways-display of information in all prenatal diagnostic 
facilities that services for disclosure of the sex of the foetus are not provided, regular inspections, occasional raids, periodic meetings for health care providers, and extensive documentation of all women seeking ultrasound services, including, for example, maintaining records of Form " $\mathrm{F}$ " containing extensive personal details of all women undergoing an ultrasound examination for tracking purposes. Most described the Appropriate Authority as a committee headed by the Chief Medical Officer (CMO) that conducted inspections and raids, but rarely sting operations, on diagnostic clinics and facilities providing pregnancy- and abortion-related services. For example, in response to the question-How is this law enforced in this district?-health care providers responded as follows:

Here, inspection and raids are conducted intermittently. There is a team under the CMO, which conducts this task. Without prior information, the team visits any centre and checks all its records to find out whether everything is functioning properly or not, or whether there has been any foul play or not. They also interact with the patients present at that time in the clinic or nursing home and try to gather information from them. We are also ordered to keep the records of the patients, their identity proof, photograph, mobile number, and Form $F$ which all those who come for an ultrasound must fill. We follow this rule. [Female, obstetrician-gynaecologist, aged 60 , Sonipat]

There are raids from time to time. A committee has been established under the Chief Medical Officer which comprises seven to eight members, and at regular intervals, they make inspections. They inspect every radiology centre and nursing home to ensure that nothing illegal is happening anywhere. These inspections occur suddenly, without saying anything to anyone. If they inform the facility in advance, what is the use of the inspection? [Female, general physician/MBBS doctor, aged 62, Sonipat]

There are raids and inspections under this law here, in this district. I do not know the exact time interval (regularity), but sometimes we read about them in the newspaper. Sometimes, machines are sealed and sometimes action is taken against the doctor. These raids and inspections are done by the CMO's office and there is a team of seven to eight officers. They inspect the nursing home and check the records. I have never heard of any license cancellation or case filed against a doctor or anyone else. I think inspections take place suddenly, because they will not get anything if the doctors are told in advance. [Female, ANM, aged 50 , Sonipat]

First of all, there is a form filled under the patient's name... a record is prepared regarding this (ultrasound test) along with photo ID proof, and only after this form is filled is the ultrasound done. (Not even) the patient's escort/attendants etc.-no one is allowed in the room where this is done. In addition to this, the CMO conducts inspections, they (CMO's team) come every two months or so. And prosecution does happen, mostly in case of radiologists, from what I've seen. [Female, radiologist, aged 35, Kurukshetra]

We keep having meetings on and off in the CMO's office. So many times there are meetings, and data (on the prevalence of sex selection) are discussed as well as ways through which it can be reduced; ways through which we can improve the sex ratio. Also, the CMOs from the civil hospital..... come every two or three months, and that visit happens all of a sudden, unannounced. So, they can definitely find out at that time if the person (service provider) is doing something wrong (illegal). [Female, obstetrician-gynaecologist, aged 44 , Kurukshetra]

The law is well enforced in Kurukshetra. There is a team, which conducts inspections and raids on a regular basis. The health workers are also watchful about pregnant women and take care of their (pregnancy-related) details through a tracking system in both rural and urban areas. Suspension of the (doctor's) license, seizing of machines, and sealing of the nursing home are some steps taken if caught during the inspection or raids..... Raids take place every four to six months. In the past five years, there were two cases of doctors who were caught during such sex-selective operations..... The doctor is prosecuted and fined if found guilty. [Female, ANM, aged 42, Kurukshetra]

Regular inspections and raids are conducted to enforce the law in this district. Machines are seized, hospitals are sealed, and doctors are given punishment if caught practising any illegal operations..... Raids are conducted by government agencies, with the help of the police, if they get any information on sex-selective operations. [Female, Staff Nurse, aged 27, Kurukshetra]

Only two health care providers-one Medical Officer and one ANM, both from Sonipat-suggested other methods used to enforce the law, in addition to those reported above. Clearly, at the district level, various strategies have been 
applied to discourage violations, ranging from provider-level pledges to monetary rewards for reporting violations as described below:

By the way I would like to share something with you: in Sonipat, all authorised doctors and radiologists are made to swear by placing their hand on the Bhagavad Gita (ancient Hindu scripture), in front of the District Collector, that they would never perform sex determination tests and sex-selective abortions! [Female, obstetrician-gynaecologist, aged 60, Sonipat]

One new thing that has been recently introduced is that if somebody provides information about any incident of sex selection and sex-selective abortion in the district, then he/she will be rewarded Rs. 51,000, with a promise that their identity would not be revealed in public. [Female, ANM, aged 48, Sonipat]

\section{Perspectives of public sector programme implementers}

All public sector programme implementers were engaged in some way in activities intended to enforce the PCPNDT Act. They described the Appropriate Authority as a three-member committee headed by the Civil Surgeon and comprising membership from amongst lawyers as well as senior district-level officials from the ICDS Department. The Appropriate Authority in both districts was described as conducting regular inspections and raids, seizing equipment and sealing prenatal diagnostic facilities, suspending doctors' licences, and preparing cases for court. Several public sector programme implementers, from both states, described their reliance on ASHAs, ANMs and AWWs to track pregnant women, especially those with one or two daughters and no sons, and report any cases that appeared suspicious to them. Also discussed were meetings of the District Advisory Committee (DAC) intended to guide the Appropriate Authority about implementation issues; and of the District Task Force (DTF), headed by the District Magistrate and including representatives from the Appropriate Authority and NGOs, and intended to make decisions about raids and prosecutions. They also discussed the regular meetings called by the Civil Surgeon for various categories of health care providers to review findings from inspections and raids, and monitor the progress made by the Appropriate Authority; at these meetings, health care providers are informed about their role in implementing the PCPNDT Act, the kinds of infringements that are considered violations, and the progress made in terms of raids and convictions. A few public sector programme implementers also described efforts to encourage people to report violations, including an anonymous helpline facility and incentives for those who report violations to the authorities. For example:

The CMO's team is mainly responsible for enforcing this law. The team keeps continuous vigilance and watches which hospitals and doctors are carrying out such services (sex determination tests and sexselective abortions). For this, the team goes for regular inspections; help from the police is also taken so that action can be taken against violators and a legal case can be slammed against them. [Female, law enforcement officer, aged 66, Sonipat]

I think the law is well implemented in this area. Government hospitals are most strict in this regard. There are more frequent checks now than ever before. At the state level, the inspection team comes twice in a month while at the district level, it happens every month. In the past one year, the state-level team has become more stringent..... If we come across any news about female foeticide in our catchment area, we ask our Anganwadi Workers to pay special attention to pregnant women. We keep an eye on them to track whether they have had an ultrasound examination and if the baby was born. We also ask our workers to pay special attention to those women who already have one or two daughters, as once a girl is born, the tendency is not to encourage the birth of another girl child. [Female, PO/CDPO, ICDS, aged 36, Sonipat]

Officers appointed as Appropriate Authorities have to keep a close watch on the registration of ultrasound machines, their usage and cases of abortion. We conduct surveys and prepare reports to understand the situation in different localities. The ASHA, AWW and ANM are part of the vigilance team which acts as an observer and informs us whenever there is any such sex-selection incident. We then make a team and conduct raids, check the forms and reports and file cases if anything illegal is found......Punishments include suspension, cancellation of licences, seizure of machines or three years' imprisonment and fines as well. Cases can also go to court if there is a major violation of the law. If guilty, the accused can be punished with..... The law is well enforced in our area. The nodal officer is responsible for implementation (of the Act) and conducts raids if we get information about illegal activities. There are regular action-oriented inspections by trained teams, a regular medical audit of forms, monthly DTF meetings and Advisory Committee meetings every two months. Workshops are held for doctors and stakeholders to 
go over various provisions of the Act, and awareness campaigns are conducted in low sex ratio pockets. [Male, law enforcement officer, aged 57, Sonipat]

Raids and inspections take place on a regular basis. The Civil Surgeon is the head of the inspection team. Doctors are never informed in advance. Doctors and families (seeking disclosure and/or sex-selective abortion) are prosecuted if caught red-handed. Cancellation of licences, sealing of machines and nursing homes, and filing cases in the court do happen. Last year, there was such a case of sealing. [Male, law enforcement officer, aged 56, Kurukshetra]

We go for regular inspections of ultrasound centres and conduct raids if there has been a complaint. We seal centres if they violate the (PCPNDT) Act and suspend the accused immediately. There are three members in the DAA: the District Attorney, Project Officer (ICDS,), and the Civil Surgeon as chairman. The District Task Force, the DAA and the DAC are the three different entities that work on the (implementation of the) Act. The DAA passes orders to us for sealing, raids or suspension. In general, there are problems regarding filling of forms, and often it is found that someone who is not an authorised operator has taken charge of the ultrasound machine..... Sometimes, people inform us. Once or twice, we have tried to perform a sting operation. Once, we sent one of our employees as a pregnant woman to a clinic to pursue a sex-selection test. She had her phone on (for recording) and also a camera. We went inside as soon as the radiologist started the operation and caught him red-handed. He was punished with three months' suspension..... We also arrange audits to keep a constant watch on pregnant women of the area. If we have any information about a woman undergoing an ultrasound test, we call and inquire about the child. We then go for inspection if anything appears wrong. But we don't get any reports about sex selection from ASHAs and AWWs..... Meetings of the District Task Force are held regularly to maintain coordination between the different departments and discuss the status of the sex ratio, implementation of the Act etc. The DC, SP (Superintendent of Police), SDM (sub-divisional magistrate), district education-in-charge and even college principals are members of the Task Force. [Male, law enforcement officer, aged 52, Kurukshetra]

Some public sector programme implementers suggested that a significant component of their work involved inspections of whether announcements that disclosure of the sex of the foetus is not conducted in the facility were appropriately displayed, whether records were properly maintained and up-to-date, and whether health care providers adhered to various rules of the PCPNDT Act, such as advance information about a change of address, as the following excerpts depict:

I am aware that a notice has been sent to 34 clinics to rectify small problems like errors in registration, reports etc. [Female, PO/CDPO, ICDS, aged 52, Sonipat]

(Ultrasonography) Centres have to take one-month prior permission from the DAA if they want to change the place, the machine or the operator. They have to get a new registration stamp on the certificate in case of any of these changes. Once we lodged a complaint against a person who had officially expressed interest for a change of place, then kept the machine in his house illegally. Aside from that, if a centre is found not to display the advertisement board or the registration certificate, it can be penalised. [Male, law enforcement officer, aged 52, Kurukshetra]

There was a rule under Section 13 that within seven days people have to inform the District Appropriate Authority if there is any change of place or of the doctor who operates the ultrasound machine. However, often during this gap of seven days, people take advantage of the opportunity and practice sex-selection activities with another unregistered doctor and machine. We have taken up this issue before the Central Supervisory Board and they have passed an amendment of a one-month advance notification before any such change is made. [Female, law enforcement officer, aged 27, Panchkula]

Also mentioned by a few public sector programme implementers were efforts to encourage other health care providers and frontline workers to inform them about possible infringements, and one interesting example from Kurukshetra, about efforts to engage directly with communities, is reproduced below:

We are also trying to promote the toll free number 102 for registering complaints under the PNDT Act regarding unqualified operators, unregistered centres, centres involved in sex selection etc..... ANMs, ASHAs and AWWs act as informants. General surgeons and NGOs also report to us. [Male, law enforcement officer, aged 57 , Sonipat] 
The Health Department has announced rewards for workers who bring in this kind of information, but Anganwadi Workers are hesitant to speak out as, after all, they are locals and are afraid of repercussions from the community. We train our Anganwadi Workers to keep a special watch on those who get pregnant for the second time and to be alert about any sex-selection practices in the area..... we keep our workers updated about raids and ask them to be watchful about sex ratios. In this way, the workers can inform us about various incidents and help us to take suitable action. [Female, PO/CDPO, ICDS, aged 57, Sonipat]

Overall, most public sector programme implementers with the authority to conduct inspections and raids described the work in their districts to have been successful, as attested by the following excerpts:

I have done at least 15 inspections in the last three months.... Recently, there was a case of conviction where the accused was punished with three years' imprisonment; however, there are 10 or 12 more such cases in the district that have still not been convicted. Cases have to be cleared in six months time..... I definitely think the AA (Appropriate Authority) is functioning better than before. (Inspection) teams are performing more efficiently and action is taken much more swiftly than before. [Male, law enforcement officer, aged 57 , Sonipat]

Last year, we conducted six raids, and this year, three so far. There are many cases going on right now; two are in the high court. We try our best to carry out our legal responsibilities in the district. The result is manifested through the increasing figure of the sex ratio, which went up from 771 in 2001 to 890 in 2013..... [Male, law enforcement officer, aged 52, Kurukshetra]

\section{Perspectives of NGO programme implementers}

NGO programme implementers also described the raids and inspections that took place to enforce the law in Sonipat, but suggested that they took place rarely and that NGOs were typically excluded from these activities. Several had no personal experience of inspections or raids or their community-level repercussions, but reported what they had read in the newspapers, for example:

The Civil Surgeon in our district makes sure that sex detection is not happening. There is at least one news item in the paper every ten days that this team has raided somewhere today and somewhere else tomorrow. There are raids in Sonipat and Guahana, and if they find something, proper action is taken. Some nursing homes and ultrasound centres have been sealed. It's usually conducted without warning... [Male, NGO programme implementer, aged 39, Sonipat]

Raids do not happen frequently-once in a year or six months. I don't know who is doing these raids, I read about them from the newspapers.... I have heard that in some places, an official went in the disguise of a customer. The doctor was caught but I did not hear that any legal action was taken against him, just that his licence was cancelled..... The (Appropriate) Authority has never included NGOs (in the team) during raids or inspections; I think NGOs should be included in raids and inspections so we can see what is going on.... [Male, NGO programme implementer, aged 49, Sonipat]

They have a committee that conducts the operations and they don't involve non-governmental organisations in their work. Yes, the committee is working far better now. But, NGOs are not helping in implementation of the law; I think they should also be included in such activities. [Male, NGO programme implementer, aged 31, Sonipat]

\section{Scepticism about the effectiveness of the PCPNDT Act}

All three categories of key informants perceived a number of challenges that inhibit the effectiveness of the implementation of the PCPNDT Act. Several spoke about the fact that only health care providers are punished and not women and their family, and more seriously, most key informants recognised that interference from influential individuals in the district and state had, on occasion, inhibited the effective implementation of the Act.

\section{Perspectives of health care providers}

Narratives of all health care providers suggest their familiarity with the sealing of equipment and facilities, suspension of providers' licences, and the prosecution and imposition of monetary fines on providers. Health care 
providers were unanimous in their perception that notwithstanding the PCPNDT Act, women and families who sought the disclosure of the sex of the foetus and/or underwent a sex-selective abortion were never penalised; most suggested that this was a serious lapse and impeded efforts to improve adherence to the law. For example:

Doctors and radiologists are prosecuted, but no strict action is taken against those who come to take services (disclosure of the sex of the foetus and/or abortion of a female foetus). The process starts with the woman who comes for the service; she is equally guilty. Doctors do not invite the patient, they come to the doctor on their own; hence, they are also guilty and should be punished. [Female, general physician/ MBBS doctor, aged 40, Sonipat]

Only doctors and radiologists who are caught are prosecuted. But I have never heard that strict action is taken against the lady who takes services although she is equally guilty. Those who are pressurising her to do this (seek disclosure of foetal sex and/or abort a female foetus) should also be caught; but, it has never happened. [Female, ANM, aged 48, Sonipat]

The Act says that the ones getting it (sex determination test and/or sex-selective abortion) done and the one doing it are both criminals; but, our society is just anti-doctor, and the woman is not at fault and is left alone (not penalised). [Female, radiologist, aged 40, Kurukshetra]

I have not heard about any family or woman who has been prosecuted for sex selection. If they are, it will further help in creating a sense of fear among people and a drop in such practices. [Female, Staff Nurse, aged 27, Kurukshetra]

A number of health care providers expressed scepticism about the gaps in the implementation of the PCPNDT Act. Several suggested that law-abiding providers were harassed in many ways: they were held up on irrelevant issues, the paperwork demands on them were excessive, and they were not permitted to practise except during prescribed hours. Others also cited corruption, suggesting the reopening of many facilities that are sealed, and doctors whose licences were withdrawn resuming practice within a few months because of pressure from politicians and others in power, as described in the following excerpts:

At times, we face difficulty; for example, a particular time is specified for us to carry out ultrasound tests. Now, if a serious patient comes after the (specified) time, we are deterred from conducting ultrasound tests, and if the patient needs the test urgently, we have to take permission from the $\mathrm{CMO}$, fill out paperwork, all of which requires a lot of time. Then what should we do? Should we attend to the serious patient or fulfil the paperwork requirements? Like this, there are other loopholes, which should be taken care of. Otherwise, everything is fine. [Female, obstetrician-gynaecologist, aged 60, Sonipat]

It is a burden.... I have decreased the number of ultrasound tests I do because I do not have time.... there is so much paperwork to be filled etc that I do not get time for OPD (outpatient department) work. So, where I used to do sixty (tests), now I don't even do forty.... the number is around thirty now because I do not have time. One ultrasound would take between 30 to 45 minutes. [Female, obstetrician-gynaecologist, aged 50, Kurukshetra]

There are people who come and check our records etc. But everyone knows about us, that here, nothing (illegal) happens. They come and inspect the machines that are lying here; if there are patients being treated, they check with them to see what is going on. And then they check my records and registers..... And these nonsensical PNDT rules that they have in place..... not wearing coats, why a copy of the Act is not properly displayed..... It can also happen that our Civil Surgeons get embroiled in a political matter, because it could happen sometimes that maybe you caught a doctor or someone for a wrongdoing but then there is pressure exerted on you from higher up the ladder. You would get calls for the person to be released. [Male, general physician/MBBS doctor, aged 59, Kurukshetra]

\section{Perspectives of public sector programme implementers}

Public sector programme implementers voiced many concerns that posed challenges to the effectiveness of the implementation of the PCPNDT Act. Their concerns also focused on corruption within the system and a few did indeed mention that women and families were never punished, but, in contrast to those of health care providers, also included concerns about the limited power and inadequate training of members of the Appropriate Authority, 
lack of community support for the law, overburdened staff and frequent transfers and change of responsibilities of district officials as narrated below:

No, till today no women has been accused or punished. According to the (PCPNDT) Act, women or families who commit sex-selective tests are also responsible and should be punished but they escape by saying that they just came to see the doctor for treatment. I mean to say that they put the entire blame on the doctor! [Female, law enforcement officer, aged 66, Sonipat]

The AA who oversees the execution of raids does not provide proper technical documentation. Its members are not aware of what information is needed, how to conduct raids effectively and how to document evidence technically. Therefore, what we get is half-processed documentation of cases. Once, I got a case in which a raid had been conducted of a female gynaecologist who had aborted a female foetus. Even though the female foetus was recovered, it was not presented properly and there was no technical documentation. No legal training is provided to the AA, and its members are not aware of medical practices..... Sonipat is bordered by UP on one side and Delhi on the other. Thus, people go to Narela and UP to do sex detection and get abortions. This way (by doing so), the matter automatically goes out of our jurisdiction..... a doctor against whom the AA had once lodged a complaint was convicted because he had a portable ultrasound machine that was not registered. Later, when the doctor was brought to court, he said that the higher health authorities had given him registration. In the case of the woman who had aborted a female foetus, the witness changed her statement, and the lady doctor said, 'How can you prove that the foetus was of the woman in question?' The AA does not have the training to collect evidence. [Female, law enforcement officer, aged 35, Sonipat]

Once we raided two doctor-turned-politicians and experienced a lot of problems during law enforcement. Other than that, as we are not proficient with legal affairs, errors take place from our side too. Though we know that any contravention of the PCPNDT Act under Section 23 is punishable, the court demands many other supporting documents to prove the case even when they are not required. For example, it demands witnesses to prove the offence even when there are reports and documents duly signed by that person. Our lawyers are also not sincere and, as a result, cases often go in favour of the convict. The Act therefore cannot be implemented the way it should be unless there are lawyers specialised in the PCPNDT Act..... [Male, law enforcement officer, aged 57 Sonipat]

Definitely there are leakages and foul play. You also must know how much corruption exists nowadays. And in the Health Department, it is no less. The health personnel are much involved in corruption. Doctors, nurses, everybody is involved. Sometimes, even if someone is caught red-handed, no action is taken against him because of political interference. The vigilance team is pressurised and proceedings are not carried out. Money and politics are part of the corruption, and the accused is released. Because connections are used, the law enforcing authorities-even if they want to-fail to take any action against the accused. [Female, law enforcement officer, aged 66, Sonipat]

District programme implementers from Kurukshetra and state programme implementers expressed similar views. For example:

Until now, I have not heard of any woman who comes for sex selection being prosecuted. Women are often let off as we do not have any strong evidence against them.... First, the lack of awareness in society; second, less power in the hands of the authorities who work for the implementation of the law; and finally, strong backing from the higher authorities to carry on with illegal practices. [Male, law enforcement officer, aged 56, Kurukshetra]

People are afraid to reveal sex-selection practices; hence, government and NGOs find it difficult to get information about illegal practices. In addition, doctors and health care providers who provide such services have contacts in high places, and can easily pay off the police or other law enforcement officials. [Female, AWW, aged 52, Kurukshetra]

The convicted are mainly doctors and are often acquitted as they can easily pay off the law officials..... Government officials do not take cases of sex selection seriously even if taken to court. This is why in the last few years, we have kept our own legal advisors; when a case is in court, we appoint them on a contractual basis. [Male, law enforcement officer, aged 52, Kurukshetra] 
People are overburdened with work in our department. A single person has to deal with many issues and as a result, does not do justice to his/her work. Civil Surgeons are loaded with too many administrative responsibilities and are unable to go for proper inspections. Frequent transfers and change of responsibilities is another problem..... even though we have suggested that a separate authority be given charge of PCPNDT (work), this has not materialised due to a shortage of doctors and programme officers..... Incidents of political influence take place; this is where all our efforts go in vain and our morale drops..... The DAA holds meetings irregularly because of its busy schedule. Until today, only one DAC meeting has been conducted during 2014-15; it shows the lack of interest of the administration..... [Female, law enforcement officer, aged 52, Panchkula]

\section{Perspectives of NGO programme implementers}

NGO programme implementers from Sonipat articulated many of the same challenges as did health care providers and public sector programme implementers. Their narratives focused on corruption within the system, and at least two additional challenges, namely the dearth of NGOs permitted to play an active role in the activities of the Appropriate Authority, and the lack of coordination among the various departments implementing the PCPNDT Act:

The biggest problem is that before any action is taken, there are orders from above for the release of the doctor. So, the authorities are helpless and this is the biggest challenge here. People who are well off easily escape from these laws. So, nothing is exposed, only because of money and status, and the guilty are not punished. [Male, NGO programme implementer, aged 41, Sonipat]

Laws are not properly implemented. Everything happens secretly; the administration knows where violations are happening. Why doesn't the government use the CID? Why conduct just one or two police raids and then no subsequent investigation or inspection? ..... The law has no effect: nobody fears the law; there are many ways of getting around the law. Before a raid, there may be some warning given to the (concerned) doctors..... Some five to seven years ago, a doctor was caught; but later, nothing was done against him and he is still continuing his practice. But, the person who reported the doctor was wrongly punished..... It is true that those who break the law are mainly ministers and those in positions of authority. Through their power, they influence activities and legal processes-so, corruption is definitely a problem..... Harsh punishment is not given-the hospital is closed for a few days and then it reopens; by doing so, service providers are not afraid and can continue their activities. [Male, NGO programme implementer, aged 46, Sonipat]

Inspections happen but everything is fixed. This mahaluma (section) comes under doctors: it is they who carry out this illegal work and they are the ones charged with preventing sex-selection tests and sex-selective abortion.... Till now, I have not seen any case where the health division has accused someone or helped arrest a doctor. Sometimes, we get to know that a nursing home has been sealed but then what happens to that nursing home is not revealed because reports are never made. Everything is settled within the system itself instead of the inspectors informing us about when they are going to conduct an inspection, how many Janch Kendras (ultrasonography facilities) they have inspected, how many were found guilty, how many cases have been submitted to the court, how many were arrested-all this should be spread (disseminated) but it never is.... Political interference is everywhere. Corruption is increasing. [Male, NGO programme implementer, aged 62, Sonipat]

There are some (service providers) who even get caught and cases are prepared against them, but because they have political acquaintances, they create pressure and take advantage of one or the other loophole in the legal system and get exempted from the charges! I am talking about both radiologists and gynaecologists. At times, the (Appropriate) Authority is also pressurised to let go the guilty because some doctors know persons in powerful positions. So, before carrying out proceedings against them, the Authority is called up and asked to spare the person (Veh mera aadmi hai, usspar karwahi maat karna, meaning, 'He is my colleague, do not take any action against him), and thus, the Authority fails to take any action against the accused. [Male, NGO programme implementer, aged 46, Sonipat]

A number of NGO programme implementers highlighted the exclusion of NGOs from raids and inspections as a key challenge. A few suggested that it was not effective to have just doctors monitoring the activities of other doctors. For example: 
The (Appropriate) Authority has never included NGOs during raids or inspections. I think NGOs should be included in raids and inspections so we can see what is going on.... [Male, NGO programme implementer, aged 49 , Sonipat]

They never let our NGO members participate in raids, and I don't think they include members of Self-Help Groups either.... [Male, NGO programme implementer, aged 39, Sonipat]

If NGOs are involved, then I don't think any muddle will exist. Up till now, only doctors have been designated to keep vigilance over other doctors; therefore, who knows what is happening between them. Chances are that the inspection team informs the doctor before conducting a raid in his/her nursing home and as such, the raid is just a formality. Therefore, I think that people like us, who work for social benefit, should be given training and included in the inspection team to bring in transparency in the work. [Male, NGO programme implementer, aged 52, Sonipat]

Many people and departments are working on this issue but the biggest hurdle is that none of them coordinates with each other; everybody is working at their own level and according to their own will. Everybody is putting in individual effort to end this practice. I think that only if everybody comes in sync with each other, we can remove this evil practice from our society. [Male, NGO programme implementer, aged 46 , Sonipat]

\section{Summary of the perspectives of women and key informants about the implementation of the PCPNDT Act}

This chapter has highlighted, from women's perspectives, their experience with regard to the implementation of the PCPNDT Act in their district, and their attitudes about the punishment to be meted out to health care providers and women or families who violate the Act. It also explores, from key informants' perspectives, their experiences with regard to the implementation of the Act, the extent to which they believe it is effective, and their insights into outstanding challenges in implementing the Act.

Although, as seen in Chapter 3, most women had heard of the PCPNDT Act and were aware that both those seeking disclosure of the sex of the foetus and those who disclose such information may be prosecuted, large proportions from both districts (70-72\%) perceived that violations of the Act continue to take place. However, somewhat more women from Kurukshetra than Sonipat had heard about raids taking place in their district (26\% versus 21\%), and differences were particularly wide among rural respondents (24\% versus $16 \%)$. Attitudes were also probed and suggest that 92-94 percent of women from the two districts believed that health care providers who disclose the sex of the foetus and those seeking disclosure should be prosecuted; yet, about one-third from each district believed that, or were undecided about whether the law should permit women with two or more daughters to know the sex of their foetus and terminate a pregnancy carrying a female foetus. Finally, notwithstanding their greater awareness of the Act, and their greater familiarity with efforts to enforce the Act, women from Kurukshetra were more skeptical than those from Sonipat about whether the practice would diminish because of these actions (23-25\% versus $30-31 \%$ believed that health care providers would stop disclosing the sex of the foetus, and women and families would stop seeking disclosure).

Key informants-health care providers, public sector programme implementers, and NGO programme implementers alike-described a range of practices adopted to enforce the law: these typically included regular inspections of ultrasonography facilities, periodic update meetings with health care providers, raids, sealing of equipment and closing of facilities, prosecution of violators and fines. While sting operations were rarely undertaken, district programme implementers from Kurukshetra described such an operation that succeeded in catching the violators red-handed. Many described stringent measures that must be taken prior to conducting prenatal diagnostic tests on pregnant women, ranging from a full history, to inclusion of personal documentation and a photograph, to a written undertaking that she was not seeking the test for sex detection purposes. Others described newer strategies including rewards to community members and frontline workers identifying those violating the law, use of frontline workers to track all pregnant women from the time their pregnancy is identified to its outcome, and pledges by health care providers on the Bhagavad Gita not to disclose the sex of the foetus or conduct sex-selective abortions. Districtwise differences were, by and large, mild. 
Challenges in enforcing the law were described by all three groups of key informants, and those from both districts. As women had perceived, so too, all three groups of key informants recognised that doctors were often forewarned about inspections/raids, and that political interference or interference from powerful individuals often hampered the ability of the authorities to enforce the law; also mentioned was corruption and the ability of certain health care providers to pay off the raiding teams or avoid prosecution. Several key informants also pointed out that law enforcement activities rarely addressed women and families who sought disclosure, concentrating rather on health care providers alone. In addition, some key informants, particularly public sector programme implementers and NGO programme implementers, noted that those implementing the law-for example, those conducting raids and building cases for prosecution-were insufficiently trained in law enforcement and the collection of evidence and, as a result, many court cases could not be pursued. Finally, a number of NGO programme implementers criticised law enforcement activities for excluding NGO programme implementers, arguing that this exclusion inhibited the effectiveness of law enforcement teams, while some asserted that lack of coordination between workers and departments implementing the PCPNDT Act was a major obstacle to the elimination of sex-selection practices. 


\section{Chapter 5}

\section{What works to reduce gender-biased sex selection: Programmes to enhance the status of the girl child through educational entitlements and conditional cash transfers}

Almost all women in both districts were aware of educational entitlements for girls, but only about two-fifths had used them. In contrast, conditional cash transfer schemes were better known and utilised: in each district, three-quarters of women were aware of the Ladli Scheme, two-thirds had enrolled their daughters in it, and about one-quarter intended to do so. In Kurukshetra, rural women were as likely and urban women significantly more likely to access most entitlements and conditional cash transfer schemes (Ladli Scheme) than their counterparts in Sonipat. Two-thirds of women in both districts intended to use the conditional cash transfer amount at maturity for their daughter's marriage: significantly more women in Kurukshetra (two-fifths) than Sonipat (one-quarter) specifically for her dowry, and significantly fewer (one-third versus one-half), for her further education. Key informants generally believed that educational entitlements and conditional cash transfer schemes are effective in changing parents' attitudes towards girls as liabilities by encouraging immunisation and education, and defraying marriage costs, but doubted whether they could influence deeply-entrenched son preferences and gender-biased sex-selection. Many key informants also expressed dissatisfaction over the daunting paperwork for and malpractices in the enrollment process that deterred many parents and excluded the really needy. Even so, state officials and a few district officials in Kurukshetra believe that positive perception changes are evident among people-about the birth of daughters, disclosure of sex, and sex-selective abortion.

Haryana has a number of programmes and schemes that focus on raising the status of the girl child. Implemented by the central and state governments as well as NGOs, they offer educational entitlements, including the provision of such school-related benefits as free textbooks and school uniforms and scholarships, as well as free bicycles for girls in secondary school. Conditional cash transfer schemes are also available; and involve the deposit of cash transfers in the name of the girl (or her parents) when certain conditions (such as immunisation, school enrolment, completion of school etc.) are met. The eligibility criteria and benefits of these schemes differ-for example, some are only available to parents from socially excluded castes and tribes, those from poor households, those who have been sterilised, or those with a second daughter. The prime schemes available in the state are the Apni Beti Apna Dhan Scheme (discontinued from the birth cohort of 1999) and the Ladli Scheme. The Apni Beti Apna Dhan Scheme was a longstanding scheme, which offered payments for girls at birth and on the achievement of various milestones (from birth registration to delayed marriage). The Ladli Scheme is more recent and ongoing. Its key objectives are to combat gender-biased sex selection, restore balance in the sex ratio at birth, and encourage the birth of girls. It is open to all couples who are resident of Haryana, have a second daughter born on or after 20 August 2005, irrespective of their caste and economic status, whose birth has been registered, and who is not receiving benefits from any other scheme. Under this scheme, a sum of Rs. 5,000 is given to parents on the birth of this child and for five years thereafter. Cash transfers are credited directly into the girl's account (held jointly with her mother in a Kisan Vikas Patra) for five years on the achievement of various milestones related to her growth from birth to age 18 as mentioned above. The bond in the name of the girl matures when she reaches 18 , provided that she remains unmarried (Department of Women and Child Development, Government of Haryana, n.d.; Sekher, 2010). Other schemes are also available that have similar objectives, for example, the Balika Samriddhi Yojana, discontinued in 2006, which was available only to girls from poor families (below the poverty line), and provides a post-delivery grant of Rs. 500 and increasing scholarship amounts for girls according to the class in which they are studying, from Rs. 300 per year for those in Classes 1-3 to Rs. 1,000 per year for those in Class 10 (Ministry of Women and Child Development, n.d.). 
Many believe that these educational entitlements and cash transfers hold promise for reducing the practice of gender-biased sex selection by enabling parents to defray the costs of rearing daughters and discouraging them from perceiving daughters as burdens.

Our study probed women's awareness and use of educational entitlements and cash transfer schemes on the one hand, and women's perceptions of the advantages of accessing these schemes on the other. In the case of key informants, it sought to explore their awareness of and involvement in delivering these schemes as well as their perceptions of the usefulness of these schemes in reducing son preference and gender-biased sex-selection practices. In this chapter, we explore the experiences and perspectives of women and key informants on these issues.

\section{A. Perspectives of women}

Our survey explored women's awareness and use of various educational entitlements and cash transfer schemes for girls. These included unconditional entitlements such as free textbooks, school uniforms, bicycles for girls in secondary school and scholarships on the one hand, and on the other, special conditional cash transfer programmes that provide cash awards to girls on achieving various milestones ranging from birth registration and adherence to immunisation schedules to enrolment in primary school to delaying marriage beyond age 18. A number of conditional cash transfers exist that are well known in Haryana, including the now discontinued Apni Beti Apna Dhan Scheme, the current Ladli Scheme and other schemes. Nongovernmental organisations also work in this area, focusing on educating girls, conducting group marriages and so on-activities intended to discourage parents from perceiving girls as burdens. In this chapter, we focus on the extent to which women in each district were aware and had availed of any such educational entitlement or conditional cash transfer scheme for their daughters as also their perceptions of the benefits of the schemes, and the perspectives of key informants, largely programme managers/ implementers from public and NGO sectors engaged in delivering available programmes and schemes, about the reach and effectiveness of these ventures.

\section{Women's awareness and use of educational entitlements for daughters}

With regard to women's awareness about educational entitlements for girls, the survey inquired whether women were aware of such entitlements as schoolbooks, uniforms, bicycles and scholarships, and whether their daughter had received any of these entitlements. Findings are presented in Table 5.1 and show that almost all women had heard about free textbooks and uniforms for girls (98-100\%) as also about scholarship schemes for girls (95-97\%). While differences were narrow, in urban areas, significantly more women from Kurukshetra than from Sonipat reported such awareness. Considerably fewer women had heard about the bicycle scheme for girls; however, significantly more women from Kurukshetra than Sonipat so reported (81\% versus $61 \%)$ and differences were significant in both rural and urban areas.

Few women with an eligible daughter (aged 6 and above) reported that their daughter had availed of these benefits. Indeed, just 38-43 percent and 38-40 percent of women, respectively, reported that their daughter had received free textbooks and school uniforms. More rural than urban women reported that their daughter had received free textbooks (52\% versus $6-17 \%$ ) and school uniforms (49-51\% versus $5-16 \%)$; interdistrict differences were evident only among urban respondents, with those from Kurukshetra significantly more likely than those from Sonipat to report availing of both benefits (16-17\% versus $5-6 \%)$.

Education is provided free of cost to girls up to the level of a college education; even so, scholarships and stipends are available to school-going girls to cover other costs. Table 5.1 also shows that considerable percentages of women with eligible daughters (aged 6 and above) reported that one or more daughters had received a scholarship (24\%-37\%); interdistrict differences were insignificant except in urban areas where more women from Kurukshetra than Sonipat (12\% versus 3\%) so reported.

The bicycle scheme is open only for girls entering secondary school; hence, we restricted the sample for this indicator to women with a daughter aged 13 and above. Given our eligibility criteria, few women were thus eligible, and findings suggest that very few of these women reported that their daughter had received a free bicycle (2-4\%). 
Table 5.1: Awareness and use of educational entitlements for girls

Percentage of women reporting awareness of and percentage of women with an eligible daughter, reporting the use of educational entitlements for girls, according to residence, Kurukshetra and Sonipat

\begin{tabular}{|c|c|c|c|c|c|c|}
\hline \multirow{2}{*}{$\begin{array}{l}\text { Awareness and use of educational } \\
\text { entitlements }\end{array}$} & \multicolumn{2}{|c|}{ Urban } & \multicolumn{2}{|c|}{ Rural } & \multicolumn{2}{|c|}{ Total } \\
\hline & Kurukshetra & Sonipat & Kurukshetra & Sonipat & Kurukshetra & Sonipat \\
\hline $\begin{array}{l}\text { Heard about free textbooks, school } \\
\text { uniforms for girls }\end{array}$ & $99.6^{*}$ & 97.0 & 99.7 & 98.9 & $99.7^{*}$ & 98.3 \\
\hline $\begin{array}{l}\text { Heard about scholarship schemes } \\
\text { for girls }\end{array}$ & $97.1^{*}$ & 93.9 & 96.8 & 95.4 & 96.9 & 95.0 \\
\hline Heard about bicycle scheme for girls & $80.9^{* * *}$ & 62.1 & $80.8^{* *}$ & 60.7 & $80.8^{* * \star}$ & 61.1 \\
\hline Number of women & 278 & 266 & 277 & 280 & 555 & 546 \\
\hline $\begin{array}{l}\text { Daughter has received free } \\
\text { textbooks }\end{array}$ & $17.3^{*}$ & 6.0 & 51.8 & 51.6 & 42.5 & 38.3 \\
\hline $\begin{array}{l}\text { Number of women with an eligible } \\
\text { daughter (aged } 6+\text { ) }\end{array}$ & 121 & 100 & 116 & 115 & 237 & 215 \\
\hline $\begin{array}{l}\text { Daughter has received free school } \\
\text { uniforms }\end{array}$ & $15.6^{* *}$ & 5.0 & 48.5 & 50.8 & 39.6 & 37.5 \\
\hline $\begin{array}{l}\text { Number of women with an eligible } \\
\text { daughter (aged } 6+\text { ) }\end{array}$ & 121 & 100 & 116 & 115 & 237 & 215 \\
\hline Daughter has received a scholarship & $12.4^{*}$ & 3.0 & 45.8 & 32.7 & 36.8 & 24.0 \\
\hline $\begin{array}{l}\text { Number of women with an eligible } \\
\text { daughter (aged } 6+\text { ) }\end{array}$ & 121 & 100 & 116 & 115 & 237 & 215 \\
\hline Daughter has received a free bicycle & - & - & - & - & 2.1 & 4.3 \\
\hline $\begin{array}{l}\text { Number of women with an eligible } \\
\text { daughter (aged 13+) }\end{array}$ & 19 & 15 & 11 & 19 & 30 & 34 \\
\hline
\end{tabular}

Note: ${ }^{*},{ }^{* *}$ and ${ }^{* * *}$ indicate that differences between Kurukshetra and Sonipat, Kurukshetra urban and Sonipat urban, and Kurukshetra rural and Sonipat rural are significant at $p<.05, p<.01$, and $p<.001$, respectively; - not shown; based on fewer than 25 respondents.

\section{Women's awareness of and their daughters' enrolment in conditional cash transfer schemes}

The survey also inquired specifically about women's awareness of any scheme that offered cash transfers for girls, irrespective of whether they were aware of its name and, if so, whether their daughter was enrolled in the scheme. Findings, presented in Table 5.2, suggest that conditional cash transfer schemes were well known in study districts; indeed, about four in five women reported awareness of these schemes (81\%), ranging from 76 percent in urban Kurukshetra to 81-82 percent in rural Kurukshetra and rural and urban Sonipat (Table 5.2). Among all the schemes, the Ladli Scheme was best known, with more than three-quarters of women (77\%) reporting awareness; interdistrict differences in both urban and rural areas were insignificant. We note that this Scheme is available only to families with a second daughter, and women who had two or more daughters reported even greater levels of awareness of the Ladli Scheme-89 percent and 92 percent of women from Sonipat and Kurukshetra, respectively, ranging from 93-99 percent among women in rural areas to 82-85 percent of women in urban areas (not shown in table).

Many fewer were familiar with the Apni Beti Apna Dhan Scheme; now, significantly more women from Sonipat (23\%) than Kurukshetra (16\%), with little rural-urban disparity. In contrast, and not unexpectedly, just two to five percent were aware of the Balika Samriddhi Yojana, a scheme that was implemented from 1997 but was discontinued in 2006 (Sekher, 2010) and four to five percent had heard about other schemes.

Table 5.3 presents women's specific awareness of the Ladli and Apni Beti Apna Dhan Schemes in respect of eligibility criteria and other requirements. Of women aware of the Ladli Scheme, three-quarters of those from Kurukshetra (76\%) compared to significantly fewer-two-thirds-of those from Sonipat (66\%)-were aware of 
Table 5.2: Awareness of conditional cash transfer schemes for girls

Percentage of women reporting awareness of conditional cash transfer schemes for girls, according to residence, Kurukshetra and Sonipat

\begin{tabular}{lrrrrrr}
\hline \multirow{2}{*}{$\begin{array}{l}\text { Awareness of conditional cash } \\
\text { transfer schemes }\end{array}$} & \multicolumn{2}{c}{ Urban } & \multicolumn{2}{c}{ Rural } & \multicolumn{2}{c}{ Total } \\
\cline { 2 - 7 } & Kurukshetra & Sonipat & Kurukshetra & Sonipat & Kurukshetra & Sonipat \\
\hline Heard of: & 72.5 & 76.5 & 79.1 & 77.7 & 77.4 & 77.3 \\
$\quad$ Ladli Scheme & 3.6 & 5.6 & $1.4^{*}$ & 4.9 & $2.0^{*}$ & 5.1 \\
$\quad$ Balika Samriddhi Yojana & 19.5 & 24.1 & $14.9^{*}$ & 21.8 & $16.1^{*}$ & 22.5 \\
$\quad$ Apni Beti Apna Dhan Scheme & 2.6 & 6.0 & 4.7 & 4.6 & 4.1 & 5.0 \\
Other schemes & 76.1 & 82.1 & 82.3 & 80.5 & 80.7 & 81.0 \\
Any of the above & $\mathbf{2 7 8}$ & $\mathbf{2 6 6}$ & $\mathbf{2 7 7}$ & $\mathbf{2 8 0}$ & $\mathbf{5 5 5}$ & $\mathbf{5 4 6}$ \\
Number of women & & & & & & \\
\hline
\end{tabular}

Note: ${ }^{*}$ indicates that differences between Kurukshetra and Sonipat, Kurukshetra urban and Sonipat urban, and Kurukshetra rural and Sonipat rural are significant at $p<.05$.

Table 5.3: Specific awareness of Ladli and Apni Beti Apna Dhan Schemes

Percentage of women reporting specific awareness of eligibity criteria, registration requirements and benefits of the Ladli and Apni Beti Apna Dhan Schemes, according to residence, Kurukshetra and Sonipat

\begin{tabular}{|c|c|c|c|c|c|c|}
\hline \multirow{2}{*}{$\begin{array}{l}\text { Awareness of specific features of } \\
\text { the schemes }\end{array}$} & \multicolumn{2}{|c|}{ Urban } & \multicolumn{2}{|c|}{ Rural } & \multicolumn{2}{|c|}{ Total } \\
\hline & Kurukshetra & Sonipat & Kurukshetra & Sonipat & Kurukshetra & Sonipat \\
\hline \multicolumn{7}{|l|}{ Ladli Scheme } \\
\hline Knows eligibility criteria & 74.6 & 68.9 & 76.5 & 65.1 & $76.0^{*}$ & 66.3 \\
\hline $\begin{array}{l}\text { Knows required documents for } \\
\text { availing benefits }\end{array}$ & 6.5 & 8.5 & $5.4^{*}$ & 16.6 & $5.7^{*}$ & 14.1 \\
\hline $\begin{array}{l}\text { Knows age at which a girl gets } \\
\text { access to her bank account }\end{array}$ & 62.8 & 54.4 & 67.1 & 69.5 & 66.1 & 64.9 \\
\hline $\begin{array}{l}\text { Knows the amount that a girl } \\
\text { gets from the Scheme on maturity } \\
\text { (Rs. } 80,000-100,000 \text { ) }\end{array}$ & 21.6 & 13.9 & 18.0 & 14.1 & 18.9 & 14.0 \\
\hline $\begin{array}{l}\text { Knows two or more of the above } \\
\text { four requirements }\end{array}$ & 56.9 & 47.4 & 58.2 & 57.8 & 57.9 & 54.6 \\
\hline $\begin{array}{l}\text { Number of women aware of the } \\
\text { Ladli Scheme }\end{array}$ & 201 & 203 & 219 & 218 & 420 & 421 \\
\hline \multicolumn{7}{|l|}{ Apni Beti Apna Dhan Scheme } \\
\hline Knows eligibility criteria & 7.7 & 8.0 & 19.3 & 25.7 & 15.6 & 19.9 \\
\hline $\begin{array}{l}\text { Knows required documents for } \\
\text { availing benefits }\end{array}$ & 0.0 & 3.1 & 0.0 & 0.0 & 0.0 & 1.0 \\
\hline $\begin{array}{l}\text { Knows age at which a girl gets } \\
\text { access to her bank account }\end{array}$ & 56.7 & 52.9 & 56.8 & 64.4 & 56.7 & 60.6 \\
\hline $\begin{array}{l}\text { Knows the amount that a girl } \\
\text { gets from the Scheme on maturity } \\
\text { (Rs. } 25,000 \text { ) }\end{array}$ & $9.2^{*}$ & 0.0 & 12.1 & 4.7 & $11.2^{*}$ & 3.1 \\
\hline $\begin{array}{l}\text { Knows two or more of the above } \\
\text { four requirements }\end{array}$ & $14.9^{*}$ & 6.4 & 21.3 & 22.3 & 19.2 & 17.1 \\
\hline $\begin{array}{l}\text { Number of women aware of Apni } \\
\text { Beti Apna Dhan Scheme }\end{array}$ & 53 & 63 & 42 & 62 & 95 & 125 \\
\hline
\end{tabular}

Note: ${ }^{1}$ One daughter in the case of all schemes except the Ladli Scheme, for which only a second daughter is eligible; ${ }^{*}$ indicates that differences between Kurukshetra and Sonipat, Kurukshetra urban and Sonipat urban and Kurukshetra rural and Sonipat rural are significant at $p<.05$. 
its eligibility criteria, and 65-66 percent were aware of the girl's age at which the bond in her name matures. Considerably fewer were aware, however, of the documents required to enroll girls for the Ladli Scheme (6\% of the women from Kurukshetra and $14 \%$ of those from Sonipat) or the amount that a girl may receive on its maturity (14-19\%). Overall, nearly three in five women from both districts were aware of two or more of the four requirements of the Ladli Scheme.

Fewer women who were aware of the Apni Beti Apna Dhan Scheme were aware of the details of the Scheme (Table 5.3); this is not surprising since the Scheme had been discontinued. For example, although 57-61 percent knew that a girl receives the full benefit of the Scheme when she turns 18 , many fewer were aware of its eligibility criteria (16-20\%) or the amount that a girl received on maturity (3-11\%); hardly any woman (0-1\%) was aware of the necessary documentation for enrollment in the Scheme. Further, fewer than one-fifth of the women were aware of at least two of the four requirements of the Scheme (17-19\%).

The survey also sought to explore women's perceptions about the benefits of conditional cash transfer schemes. As shown in Table 5.4, the vast majority (95\%) found these schemes useful and most (83-89\%, not shown in table) perceived that they would help to reduce discrimination against girls. Notably, however, most women perceived them as support for parents and not daughters who were the registered beneficiaries of the schemes. For example, large proportions of women reported that the schemes were useful in defraying the costs of raising a daughter (39\% in Kurukshetra and 59\% in Sonipat), arranging a daughter's marriage (61\% in Kurukshetra and 42\% in Sonipat), and more generally, in helping parents (24-28\%). Relatively few women suggested that the schemes would enable girls to save money (22\% in Kurukshetra and 29\% in Sonipat). A few women also reported disadvantages, notably the paperwork involved in registering their daughters as beneficiaries of the schemes (6-7\%) (not shown in table).

Table 5.4: Perceived benefits of conditional cash transfer schemes

Percentage of women reporting perceived benefits of conditional cash transfer schemes, according to residence, Kurukshetra and Sonipat

\begin{tabular}{|c|c|c|c|c|c|c|}
\hline \multirow{2}{*}{$\begin{array}{l}\text { Perceived benefits of conditional } \\
\text { cash transfer schemes }\end{array}$} & \multicolumn{2}{|l|}{ Urban } & \multicolumn{2}{|l|}{ Rural } & \multicolumn{2}{|l|}{ Total } \\
\hline & Kurukshetra & Sonipat & Kurukshetra & Sonipat & Kurukshetra & Sonipat \\
\hline Give girls some savings & 23.1 & 32.1 & 21.0 & 27.9 & $21.5^{*}$ & 29.2 \\
\hline $\begin{array}{l}\text { Help defray costs of raising a girl } \\
\text { child }\end{array}$ & 52.4 & 62.0 & $35.1^{* * *}$ & 57.7 & $39.4^{\star * *}$ & 59.0 \\
\hline Help parents & 20.2 & 22.2 & 30.2 & 24.3 & 27.7 & 23.6 \\
\hline Help arrange girls' marriage & $51.8^{* *}$ & 34.3 & $64.6^{* *}$ & 46.0 & $61.4^{* * *}$ & 42.4 \\
\hline Nothing to like about & 3.8 & 8.3 & 4.9 & 3.5 & 4.7 & 5.0 \\
\hline $\begin{array}{l}\text { Number of women who had heard } \\
\text { about a conditional cash transfer } \\
\text { scheme }\end{array}$ & 211 & 218 & 228 & 226 & 439 & 444 \\
\hline
\end{tabular}

Note: ${ }^{*}{ }^{* *}$ and ${ }^{* * *}$ indicate that differences between Kurukshetra and Sonipat, Kurukshetra urban and Sonipat urban, and Kurukshetra rural and Sonipat rural are significant at $p<.05, p<.01$, and $p<.001$, respectively.

The main scheme in which women reported enrolling their daughter was the Ladli Scheme, and hence we focus on enrollment in this Scheme only. Table 5.5 presents the utilisation of the Ladli Scheme by the surveyed women as well their intent to use it in future. Findings suggest that among women with two or more daughters, about two-thirds of women from both districts had enrolled their daughter in the Ladli Scheme (64-66\%). A much larger proportion of women from rural than urban areas had done so. For example, in rural areas, 69 percent and 74 percent of women from Kurukshetra and Sonipat, respectively, had enrolled their second daughter in the Scheme; in comparison, in urban areas, more women from Kurukshetra than Sonipat had done so (58\% versus $30 \%)$. In addition, about one-quarter of all women reported that they intended to enroll their daughter in the Scheme (24-25\%).

Very few women with daughters were eligible for benefits related to the Apni Beti Apna Dhan Scheme, since the Scheme had been discontinued for those born in 1999 and thereafter, and few women in our sample had daughters aged 16 and above. Hardly any woman reported that her daughter was enrolled in any other scheme. 
That conditional cash transfer schemes were widely used in both districts was evident, moreover, from the finding that the majority of women in both districts were acquainted with at least one family that had availed of a conditional cash transfer scheme for their daughter (62\% in Kurukshetra, 53\% in Sonipat) (not shown in table). ${ }^{2}$

Table 5.5: Utilisation of the Ladli Scheme

Among women with two or more daughters, percentage who reported using the Ladli Scheme, and percentage who intend to use the Scheme in future, according to residence, Kurukshetra and Sonipat

\begin{tabular}{|c|c|c|c|c|c|c|}
\hline \multirow[t]{2}{*}{ Enrollment in the Ladli scheme } & \multicolumn{2}{|c|}{ Urban } & \multicolumn{2}{|c|}{ Rural } & \multicolumn{2}{|c|}{ Total } \\
\hline & Kurukshetra & Sonipat & Kurukshetra & Sonipat & Kurukshetra & Sonipat \\
\hline Daughter currently enrolled & $57.6^{*}$ & 29.8 & 68.7 & 73.5 & 66.1 & 63.8 \\
\hline Intend to enroll daughter in future & $27.7^{*}$ & 43.8 & 22.9 & 20.0 & 24.0 & 25.3 \\
\hline $\begin{array}{l}\text { Do not intend to enroll daughter in } \\
\text { future }\end{array}$ & $14.7^{*}$ & 26.8 & 8.4 & 6.5 & 9.9 & 10.9 \\
\hline $\begin{array}{l}\text { Number of eligible women (with at } \\
\text { least two daughters) }\end{array}$ & 82 & 57 & 96 & 95 & 178 & 152 \\
\hline
\end{tabular}

Note: ${ }^{*}$ indicates that differences between Kurukshetra and Sonipat, Kurukshetra urban and Sonipat urban, and Kurukshetra rural and Sonipat rural are significant at $p<.05$.

We asked women whose daughters had been registered under a conditional cash transfer scheme about how they intended to use the money due to their daughter from the scheme on maturity. Their responses are presented in Table 5.6. While leading responses related to arranging for the daughter's marriage, a considerable proportion of women also intended to use the money for their daughter's higher education. However, interdistrict differences were evident. While two-thirds of women from both districts reported that they intended to use the money for their daughter's marriage (66-69\%), more women from Kurukshetra than Sonipat specifically indicated that they would use the money for their daughter's dowry (43\% versus $24 \%$ ). Conversely, significantly fewer women from Kurukshetra than Sonipat intended to use the benefits for the further education of their daughter (33\% versus 50\%).

Table 5.6: Intended use of the conditional cash transfer maturity amount

Among women with a daughter enrolled in a conditional cash transfer scheme, percentage of women reporting intended use of the cash transfer amount received at maturity, according to residence, Kurukshetra and Sonipat

\begin{tabular}{lcccccc}
\hline \multirow{2}{*}{$\begin{array}{l}\text { Intended use of conditional } \\
\text { cash transfer amount }\end{array}$} & \multicolumn{2}{c}{ Urban } & \multicolumn{2}{c}{ Rural } & \multicolumn{2}{c}{ Total } \\
\cline { 2 - 6 } & Kurukshetra* & Sonipat & Kurukshetra & Sonipat & Kurukshetra & Sonipat \\
\hline $\begin{array}{l}\text { For daughter's higher } \\
\text { education }\end{array}$ & 58.8 & 79.4 & $26.4^{*}$ & 46.1 & $32.9^{*}$ & 49.8 \\
For daughter's marriage & 47.3 & 47.0 & 70.7 & 71.8 & 66.0 & 69.0 \\
For giving dowry & 20.8 & 20.8 & $49.0^{* *}$ & 24.3 & $43.3^{* *}$ & 23.9 \\
For household expenses & 2.1 & 0.0 & 1.7 & 2.8 & 1.8 & 2.5 \\
$\begin{array}{l}\text { Number of women whose } \\
\text { daughter is enrolled in any }\end{array}$ & & & & & & $\mathbf{1 1 6}$ \\
CCT scheme & $\mathbf{4 8}$ & $\mathbf{1 9}$ & $\mathbf{6 8}$ & $\mathbf{7 1}$ & $\mathbf{9 0}$ \\
\hline
\end{tabular}

Note: ${ }^{*}$ and ${ }^{* *}$ indicate that differences between Kurukshetra and Sonipat, Kurukshetra urban and Sonipat urban, and Kurukshetra rural and Sonipat rural are significant at $p<.05$ and $p<.01$, respectively.

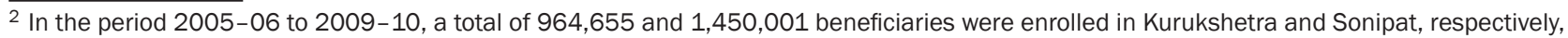
under the Ladli Scheme (Sekher, 2010).
} 


\section{B. Perspectives of key informants}

All key informants-health care providers, and programme implementers/managers from the public and NGO sectors-were probed about educational entitlements and other programmes and cash transfer schemes for girls in their districts, and the extent to which they perceived these entitlements and programmes to affect attitudes about having daughters. While all three groups had some familiarity with efforts made through the media, it was largely public sector and NGO programme implementers who had direct experience in implementing these programmes and schemes and on whose narratives we rely to shed light on conditional and non-conditional cash transfers for girls.

\section{Programmes and schemes intended to raise the value of girls}

All key informants were asked about their awareness of programmes and schemes intended to raise the value of girls and their views about these programmes and schemes. Again, health care providers were less likely to report detailed awareness of these programmes and schemes than were public sector and NGO programme implementers.

\section{Perspectives of health care providers}

Most health care providers (19 of 23) had heard about schemes that provide cash transfers to parents of daughters, although just a few could identify the name of such schemes (a few were familiar with the Ladli Scheme). Health care providers held mixed opinions about the benefits of these schemes. Some suggested that they were successful in changing parents' perceptions about girls as liabilities and burdens, others argued that these schemes may be useful for the poor and poorly educated, and yet others, that while the cash transfers helped, they could not change norms about having a son and that money was not the critical factor in determining whether to opt for gender-biased sex selection. For example:

The government has now come up with a very good scheme, the 'Ladli Yojana', which is very beneficial for girls. These schemes are helping middle and poor class people so that they don't consider girls as a burden. In my view, these kinds of schemes can help a lot to change the mentality of people, and I believe that the situation is changing. [Female, obstetrician-gynaecologist, aged 42, Sonipat]

I don't think that government schemes would have much impact on these things (gender-biased sex selection) and if they do have an impact, it is just 10-15 percent, because this small economic contribution (cash transfer) cannot change the mentality of people. [Female, ANM, aged 50, Sonipat]

Maybe these schemes matter in rural areas but not in urban areas. In rural areas, people may start thinking differently because these schemes are being run.... The poor may feel: 't is OK; we are getting some help for having daughters'. [Female, obstetrician-gynaecologist, aged 44, Kurukshetra]

These schemes do have a role to play..... a big role. When people get their second daughter, they do feel bad, but they also feel better because (beneficial) things are being done by the government. But I don't think they stop; if they have two daughters, then the third one has to be a boy. [Female, obstetriciangynaecologist, aged 50, Kuruksehtra]

Yes, you can say that government schemes have some impact on people regarding this (gender-biased sex selection). However, I do not think that it has any great influence in reducing sex-selection practices, as nowadays money is not such an important factor. [Female, ANM, aged 42, Kurukshetra]

Yes, government schemes have the maximum impact on people regarding son preference. People today are very relaxed as the government is providing them with facilities if a girl is born. For example, the Ladli Scheme is such a venture; it has helped people to remain stress free even when a second girl child is born in the family. [Female, Staff Nurse, aged 30, Kurukshetra]

\section{Perspectives of public sector programme implementers}

Public sector programme implementers were largely aware (five of six public sector officials in Sonipat, four of five in Kurukshetra, and two of three in Panchkula) of educational entitlements and conditional cash transfer schemes for girls, and several reported a role in raising community awareness of such entitlements and schemes, and assisting families in completing the paperwork for these schemes. In both districts, almost all public sector informants were aware of at least two conditional cash transfer schemes, including the amounts offered through these schemes, and several were also familiar with educational entitlements for girls, as corroborated by the following excerpts: 
In addition, girls are also given books, dresses (uniforms), (school)bags and bicycles free of cost from the government. [Female, PO/CDPO, ICDS, aged 52; Sonipat]

We have a scheme called Ladli which gives cash benefits to the second girl in a family. Forms are circulated and get filled through Anganwadi Workers of our department and then the supervisor verifies them. An amount of Rs. 5,000 for five consecutive years is deposited with LIC (Life Insurance Corporation of India); when she reaches 18 years, it (the maturity amount of the bond) will be given to the girl. If forms are filled at the time of the girl's birth, they will probably get an amount of Rs. 85,000, and if a late application is made, it will be a little less. Ladli started only in 2005, so nobody has received money yet. People are now getting money from the scheme called ABAD (Apni Beti Apna Dhan) which was in operation before Ladli. Ladli is only for the second child though the names of both girls appear on the form. The beneficiaries will get the money when they show the LIC certificates that are given to them each year..... [Female, PO/CDPO, ICDS, aged 57, Sonipat]

For girls, the government has started the Ladli Yojana, Asha Yojana, etc. Apart from this, many steps have been taken to make education easily accessible to them, and ensure that financial help is available at the time of their marriage. Their school uniform, fees, books and cycle for daily transportation etc. are given free of cost by the government. The Ladli Yojana is run for girls from every caste and religion however the Asha Yojana is run only for those girls belonging to BPL (below poverty level) and Scheduled Caste/ Tribe categories. I have seen that those who are really poor and needy do not have BPL cards whereas rich people have them and they also take all the benefits the card provides! Under the Ladli Scheme, the government for five years fills a bond of Rs. 5,000 every year, which becomes nearly Rs. 1 lakh when the girl turns 18, or at the time of her marriage. [Female, law enforcement officer, aged 66, Sonipat]

Yes, starting from 2005, I think today there are more such programmes than ever before to raise the value of girls in the society. Other than the Ladli Scheme, the Social Welfare Department also organises Ladli Suraksha Pension Yojana, Kanyadaan Yojana etc. [Female, PO/CDPO, ICDS aged 52, Kurukshetra]

We provide various government schemes to encourage the birth of a daughter. For example, the Ladli Scheme, which, at the birth of a second daughter, gives Rs. 5,000 for five consecutive years, and KSY (Kishori Shakti Yojana) that aims to improve girls' health, provide them with nutritional supplements and raise awareness among them. We arrange 'Best Mother' awards for those who have two daughters and at the Block level, we give awards to girls who come 1st, 2nd, and 3rd in the State Board Exams. We also organise Sports Meets for girls in our district to encourage girls' participation in sports. In addition, the WDC (Women's Development Corporation) provides loans for higher education and gives a five percent subsidy on the interest (on the loan amount). [Female, PO/CDPO, ICDS, aged 50, Kurukshetra]

There are a number of schemes that work to raise the value of girls in our district: the Shiksha Rin Yojana, the Gramin Khel Pratiyogita, the KSY, the Rajiv Gandhi Yojana, Ladli Yojana etc. In addition, schools provide extra benefits to girls, and people take advantage of these benefits and programmes. We help people as much as we can to avail of these opportunities. [Female, AWW, aged 38, Kurukshetra]

Most public sector programme implementers reported success in delivering conditional cash transfer schemes and agreed that educational entitlements and cash transfer schemes for girls were useful in changing attitudes towards girls, encouraging parents to immunise and educate their daughters, and helping poor parents to defray the costs of their daughter's education and marriage. Like health care providers, they too were sceptical, however, about whether conditional cash transfers could change deeply-held preferences for sons or deter son-less couples away from gender-biased sex selection. For example:

These schemes, to some extent, are helpful in changing attitudes towards girls, but I don't think they have changed preferences for sons. If they had been useful, the sex ratio of the district would not have declined. [Female, PO/CDPO, ICDS, aged 57, Sonipat]

Yes, they (conditional cash transfer schemes) are useful for girls. They have changed attitudes toward girls and improved their status in society. [Female, PO/CDPO, ICDS, aged 52, Sonipat]

People are often anxious about dowry and consider girls a burden because of this. Thus, because conditional cash transfer schemes have been providing money, people have become less afraid of having 
a daughter. The Ladli Scheme is relatively new and I can't comment on its effect. But I had witnessed a change in people's attitude when Apni Beti Apni Dhan was operational in our district-now, people are more likely to immunise their daughters, send them to school and delay their marriage..... [Female, PO/CDPO, ICDS, aged 52, Kurukshetra]

With proper guidance, people (can be made to) understand the importance of the issue and they do not undertake sex-selection tests; but, there are exceptions where our efforts go in vain. There are excellent schemes from the government where girls are given priority and promised several benefits. The thinking has automatically changed among people after they have started getting financial help from the government, and made them treat girls equally as (they do) boys.... The schemes have been successful-among those who avail of the benefits, girls are more likely to be sent to school and less likely to be married early. Those who get full benefits are happy; more programmes have been implemented in our district, the number of beneficiaries has increased, and they treat girls and boys equally.... [Female, AWW, aged 38, Kurukshetra]

Even so, a few programme implementers in districts and state programme implementers did perceive that conditional cash transfer programmes had an effect on changing deeply-held preferences for sons and deterring women away from gender-biased sex selection as described in their responses:

Definitely the Ladli Scheme and other such schemes have made a change in the attitudes of people, especially the poor, about girls' status in society. People feel less burdened because of the money they receive from these schemes (Ladli/conditional cash transfers) and thus less worried about the marriage and education of their daughters. The programmes are well implemented in Kurukshetra and every eligible family receives benefits. We have not done a study to examine the change in attitude, but I feel changes are taking place in people's perceptions about daughters, about disclosure of sex, and sex-selective abortion... There has been an increase in the number of beneficiaries, and it's very easy to (get parents to) enroll (their daughters) in these schemes. [Female, PO/CDPO, ICDS, aged 50, Kurukshetra]

Girls are not seen as a burden on the family. They are being welcomed heartily by the family. People are also performing the 'kuan pujan' ceremony on the birth of a girl, which was earlier, a phenomenon mostly attached to the birth of a boy child. Parents are financially supported by the funds provided under the scheme and thus, nowadays, they do not take the birth of a girl child as a burden that involves conserving money for her dowry and marriage. The scheme (Ladli) is being implemented effectively; as provision of separate staff is available (for its implemention); there is an increase in the number of beneficiaries, from 49,558 in 2007-08 to 105,113 in 2009-10 and 97,947 in 2013-14.... the slight decline recently is due to the amount of fund allocation by the government. [Female, PO/CDPO, ICDS, aged 51, Panchkula]

The delivery of conditional cash transfer schemes and the challenges associated with their implementation were also discussed with the public sector programme implementers. Their perceptions about the implementation of these schemes varied. While several public sector programme implementers reported success in delivering conditional cash transfer schemes, some did admit that tedious registration procedures deterred many couples from even submitting an application for registration in the scheme. Others noted that middlemen were sometimes employed to support parents to fulfil registration requirements, and payments made to such middlemen can be considerable. However, a differing view was expressed by those delivering the ICDS programme, that programme workers assisted parents in registering for schemes and that, as a result, bottlenecks were avoided, for example:

There has been an increase in the number of beneficiaries, and it's very easy to enroll them in the programmes. Our Anganwadi Workers help people to fill up the form and submit the documents, that is, the birth and domicile certificates that are needed. It is a streamlined procedure and people don't even need to go to the concerned office. [Female, PO/CDPO, ICDS, aged 50, Kurukshetra]

We also register those who are beneficiaries of the Ladli Scheme in this area. We help them to fill forms and complete other procedures..... It may be that a few face difficulties in getting benefits (cash transfers)-those who are not educated and have no proper awareness suffer. There are middlemen who take advantage of this and demand a percentage of the cash benefits from people while assisting them with enrollment formalities..... Registration is a simple process and anyone who is eligible can enroll. It has resulted in a change in attitudes about girls, but some find it a complex process and complain. [Female, AWW, aged 38, Kurukshetra] 
Other public sector programme implementers admitted the implementation challenges that resulted in effectively denying eligible parents from availing of these schemes, as explained in the following excerpts:

However, the implementation of this (Ladli) Scheme is poor because some do not get the forms while others are unaware of the Scheme. The same situation exists in the Social Welfare Board (Samaj Kalyan Board). If we don't pay attention, then the authorities of that organisation swallow up the money reserved for scholarships and the Ladli Scheme, and people's needs are not addressed. Many people do not have even the slightest idea about the amount they will receive and when they will receive it. They are scared off when they enquire about such things. As a result, in all, the total benefits of the scheme do not go to the beneficiary, only five percent (does). All the work is done on paper, and the remaining 95 percent of the money is scraped off by the authorities. This is the reason why this Scheme has proved ineffective in changing the mindset of the people towards their daughters..... We, and members of some NGOs, help people to enroll in these schemes.... There are numerous schemes run by the government and new schemes are also being introduced, but the problem is with their improper implementation and that's why the desired impact is not experienced. [Female, law enforcement officer, aged 66, Sonipat]

Limited funds are our biggest challenge. Once there is proper fund allocation, no beneficiary will be denied registration in the schemes. Poor awareness is also a problem although we put in a lot of effort to publicise the schemes though radio programmes, jingles, distribution of brochures and campaigns. [Female, PO/ CDPO, ICDS aged 51, Panchkula]

\section{Perspectives of NGO programme implementers}

Several NGO programme implementers were engaged in providing for the health, education and marriage of girls in their communities. For example, several NGOs reported providing educational benefits, including scholarships to girls, conducting mass marriages to help defray marriage-related costs, and helping parents avail of government programmes, most notably the Ladli Scheme. For example:

To stop sex determination we have started arranging community marriages. We organise mass marriages so that parents do not feel that daughters are a big responsibility, which is very difficult to fulfill. Once I organised a community marriage of eleven couples. Aside from this, we work on providing information about government schemes, which are specifically for girls, such as the Ladli Yojona and many others..... and helping people access them, as the implementation part of these schemes is weak, the process of registering is very long, and to get the facilities of a scheme parents have to engage with it continuously. [Male, NGO programme implementer, aged 46, Sonipat]

We help parents to get their girls married so that the daughter will not be thought of as a burden anymore. At the time of the girl's wedding, we give them a TV, refrigerator, washing machine, sewing machine, utensils or some ration etc. We try to give them some useful item instead of cash because cash is spent quickly. We have also adopted a government school. [Male, NGO programme implementer, aged 46, Sonipat]

All NGO programme implementers were aware of conditional cash transfers and other schemes for girls. Almost all were aware, in particular, of the Ladli Scheme, and several had personal experience in helping the community members they served to avail of conditional cash transfer schemes for which they were eligible. Most expressed concern about the challenges parents faced in registering for the Ladli and other schemes, noted that parents were often badly treated when they approached officials for registration or information, and corruption prevailed in the registration process. Even the most positive among NGO programme implementers believed that while parents welcomed the cash transfer, these cash transfers were unlikely to affect son preference. For example:

A lot of work is going on for girls through the Haryana government. Because of these schemes, people don't see girls as a burden.... There are education schemes and girls get free education till senior secondary school; even their books, uniforms and transport are free. There is a scheme called Ladli in this district where the government takes care of girls' upbringing and at the time of their marriage they get Rs. 1,100 or 5,100. This is a very well-known scheme. But again, it happens that influential people help their own. Even today, caste and religion are important. If the village head belongs to a higher caste, then only higher caste people will benefit from these schemes. I think these schemes are only on paper and their benefits do not reach the individual. Those who are influential get benefits but those who are weak do not. I don't think it 
is difficult to get registered in these schemes because there are many organisations in villages that help people to get registered. There is no problem in urban areas. People are not so happy with the schemes; if I am earning Rs. one lakh now, I would wish to earn Rs. 10 lakh from this scheme. In total, the benefits from these schemes are not sufficient.... The government is really trying to improve the sex ratio; there are many schemes. They may have a small impact, but the rich will do these things on their own even without these schemes.... I think NGOs should be included in these things (the implementation of these schemes) so that everyone can benefit and corruption (in the registration process) can be controlled. [Male, NGO programme implementer, aged 41, Sonipat]

Schemes are secondary; if you are educated, you allow a girl to be born, but if you are not giving birth to them, what good will these schemes do? Education is more important than schemes; education is free up to senior secondary school level, and girls get free transport, scholarships. Other than this, there is the Ladli Scheme going on here for girls; they get benefits. I only know they get some economic help but I don't know how much. I don't know whether the benefits are reaching the really needy. Those who get benefits are happy. They think they are at least getting some help from the government, so it helps in improving girls' education. .....Parents already want to marry their daughter late, not because of these schemes. [Male, NGO programme implementer, aged 39, Sonipat]

Implementation of schemes is poor-the process of application is long, and to get the facilities, parents have to engage with the authorities continuously; so, people suffer in (the process of) getting benefits from the scheme. But the schemes also have some impact. People are now getting the fruits of these schemes and their perceptions are changing gradually. But in the end, it is only education that will reduce activities such as sex selection and sex-selective abortion..... Girls are given free education, books, notebooks. Also, there is the Ladli Scheme; but people are not well informed about this Scheme. There is a person in my locality with two daughters, I told him to go to the concerned authority for enrollment; he went two or three times but never found the offices. I think those running these schemes are not doing their duty properly. People are not getting facilities from the place where they should get them. Government officials talk to people in a harsh manner, people have to wait in long queues (for registration), getting benefits is also difficult. The government knows that if Rs. 100 is due, only Rs. 10 reaches the people. There is no monitoring of these schemes. Under the Ladli Scheme, some amount of money is deposited into a girl's account, but a very small percentage of people are getting benefits. Corruption is a big issue. The schemes do not have much impact because they have not reached people properly.... I do not think that because of these yojanas (schemes), parents are less likely to want a son. But one good thing is that earlier daughters were thought of as a burden for their family. This mentality is gradually changing-but not because of these schemes, rather because of education and awareness..... [Male, NGO programme implementer, aged 46, Sonipat]

Schemes run only on paper. Among parents who have two or three daughters, very few have availed of these schemes. When one goes to register for the scheme, the officers make parents run here and there (from pillar to post) 50 (innumerable) times, and even after that, they don't let them register for the scheme. So there is no effect of these schemes.... There is a scheme for girls called Ladli, and if properly implemented it can have good effects. In this, every year Rs. 5,000 is deposited in the girl's bank account for five years and at the time of her marriage, the money is given with interest, which can be Rs. 51,000. Other than that, girls get free education up to Class 12, fees, books, uniforms, are all free of cost..... about 95 percent of the people take advantage of the schemes running under (the department of) education, but girls' schemes like Ladli are used by only 10-15 percent. It is because they have to run 50 times around government offices for the paperwork; they are told: 'Bring this form, give me that certificate'. People have to spend around Rs. 500-700 for this work. I mean to say, it is very difficult to enroll in these schemes and that is why people get tired and finally decide not to pursue them. Information about these schemes is printed in newspapers regularly and anyone who reads the newspaper knows about them. I have taken many people around government offices to enroll their daughters in the Ladli Yojana. One has to go to many officers, many times, to get each and every certificate. I finally gave up..... There is corruption, the full amount may be sent by the government but the real beneficiary gets only 20 percent of it, the remaining 80 percent goes into the pocket of government officers....! Families that get the benefits are obviously happy, thinking that the government is giving them at least some help. But there is no effect of these schemes on parents' desire for a son. They still prefer a son even though a son may not grow up to be a good man 
(and look after them in their old age). I mean to say that there is no change in the mentality of parents because of these schemes. [Male, NGO programme implementer, aged 67, Sonipat]

\section{Summary of the perspectives of women and key informants about the reach and effectiveness of educational entitlements and conditional cash transfer schemes for girls}

This chapter has highlighted, from women's perspectives, their awareness of the availability of free textbooks, school uniforms and bicycles, as well as scholarships for girls, and the extent to which their own daughters had availed of these educational entitlements. It explored, similarly, women's awareness of conditional cash transfer schemes, and the extent to which their own daughters were beneficiaries of these schemes, and in particular, the Ladli Scheme. The chapter has also probed the perceptions of key informants about these programmes and schemes for girls, focusing on their awareness of and their role in delivering these programmes and schemes, and their perceptions about the effectiveness of these programmes and schems in general, as well as in terms of changing deeply-rooted son preference.

Most surveyed women were aware that girls were eligible to receive free textbooks and school uniforms, free bicycles, and scholarships. In general, more women from Kurukshetra than Sonipat revealed awareness of these educational entitlements. Far fewer reported that their daughter had received these educational entitlements, and interdistrict differences were mild; however, more women from Kurukshetra than Sonipat reported that their daughter had received a scholarship (29\% versus $18 \%)$. As far as conditional cash transfers for girls are concerned, more than three-quarters of women from both districts had heard about the Ladli Scheme (77\%), but awareness of other schemes was negligible. Of those aware of the Ladli Scheme, awareness about the details of the Scheme was patchy and far from universal. Significantly, more women from Kurukshetra than Sonipat were aware of its eligibility criteria (76\% versus $66 \%$ ), somewhat more were aware of the amount that the girl would receive once the bond matured (19\% versus 14\%), but fewer were aware of the kind of documents required for enrollment (6\% versus 14\%). Two-thirds (64-66\%) of women from Kurukshetra and Sonipat reported that their daughters were enrolled in the Ladli Scheme; while interdistrict differences were negligible among women in rural areas, among those in urban areas, significantly more women from Kurukshetra than Sonipat so reported. About one-quarter of all women also reported that they intended to enroll their daughter in the Scheme. Those whose daughter was enrolled in the Ladli or any other scheme most likely intended to use the maturity amount for their daughter's marriage or dowry, and, secondarily, for their daughter's higher education; more women from Kurukshetra than Sonipat cited dowry, and correspondingly, fewer cited further education.

While awareness of the now discontinued Apni Beti Apna Dhan Scheme was reported by about one-fifth of all surveyed women, very few women reported awareness of other schemes.

Key informants-health care providers, and programme implementers from the public and NGO sectors-had all heard about various educational entitlements and conditional cash transfer schemes for which girls in Haryana are eligible. Like women, most key informants from all three groups knew about the Ladli Scheme; few were aware of other schemes. Several programme implementers from the public and NGO sectors described their own roles in assisting families to comply with the complex documentation requirements for enrollment in the scheme, and several NGO programme implementers described their own efforts in facilitating girls' schooling and arranging group marriages to assist parents in defraying the costs of their daughter's wedding.

Most key informants, irrespective of category, believed that educational entitlements and conditional cash transfer schemes for girls could be successful in ensuring that parents educate their daughters, delay their marriage, and invest in them. However, many, especially those in Sonipat, perceived that conditional cash transfer schemes were not reaching their intended target group because the paperwork required to enroll for these schemes was daunting for many parents, and because of corruption within the registration process, including the presence of middlemen. In contrast, relatively few key informants believed that educational entitlements and conditional cash transfer schemes could be successful in reducing son preference or practices relating to gender-biased sex selection. In short, while all key informants agreed that the schemes could be successful in changing perceptions of daughters as liabilities and burdens, they were sceptical about the role of these schemes in affecting adherence to the PCPNDT Act. Districtwise differences were mild but suggested that a few key informants from Kurukshetra and programme implementers in the state government were more positive than those from Sonipat about the promise of conditional cash transfer schemes in changing perceptions about son preference and gender-biased sex selection. 


\section{Chapter 6}

\section{Key informant perspectives on changes in practices regarding the misuse of sex determination technology, factors underlying improvements in the situation in Kurukshetra, and the way forward}

Key informants, by and large, believed that prenatal sex determination and sex-selective abortion had declined significantly in their district [although they acknowledged that some providers continued to provide services, violators received protection of influential individuals, and women sought services outside their district]. The decline is attributed to the reluctance of health care providers to offer these services; greater community awareness of the PCPNDT Act (emphasised more in Kurukshetra) and a reduction in service-seeking by women, a decline in son preference and a growing recognition of the value of daughters.

Key informants offered several reasons to explain what worked in Kurukshetra as compared to Sonipat. Those from Kurukshetra were more likely and those from Sonipat less likely to attribute the improvement in Kurukshetra's sex ratio to better implementation of the PCPNDT Act and greater community awareness, whereas key informants from Sonipat were more likely and those from Kurukshetra less likely to ascribe it to Sonipat's proximity to states in which sex-selection services are readily available and the predominance of Jats, a caste with a deep-seated preference for sons.

Several recommendations were made for community- and system- or programme-level action. At communitylevel, key informants called for programmes to raise awareness and change attitudes about the role of girls, and empower girls and women, through education, vocational skill-building and economic opportunities; better implementation of government conditional cash transfer schemes for girls; greater engagement of the media, religious leaders and other influential individuals at the community level in changing gender-biased attitudes and practices; and greater involvement of NGOs in delivering programmes. At system- or programme-level, key informants called for harsher law enforcement methods and punishments; greater involvement of the police as well as NGOs in law enforcement activities; more attention to training, equipping and staffing law enforcement authorities; and elimination of malpractices from the system.

All key informants-health care providers as well as programme implementers/managers from the public and NGO sectors-provided considerable insights into questions about district-level changes and factors accounting for such changes in terms of misuse of sex determination technology or violation of the PCPNDT Act. We also explored their perceptions about the factors underlying the improvements in the sex ratio at birth in Kurukshetra, as compared to the lack of improvement in Sonipat. In this chapter, we present their perceptions about these issues, and their recommendations for action to accelerate the shift towards balanced sex ratios at birth in their district.

\section{A. Perspectives of key informants about changes in practices regarding the misuse of technology for gender-biased sex selection}

Key informants were asked their views about whether the situation with regard to the misuse of technology for gender-biased sex selection had changed in their district, and, if so, the reasons for the change. Most key informants believed that the practice had significantly declined, although several acknowledged that the practice had not totally disappeared, and warned that corruption within the system, and willingness of women and families to seek services for sex determination and sex-selective abortion outside the state were hampering the pace at which improvements in sex ratios could take place. While more health care providers than programme implementers from the public and 
NGO sectors perceived that the situation had improved, district-specific differences in perceptions about the decline in the misuse of technology were not apparent.

\section{Perspectives of health care providers}

Responses of health care providers suggest that providers from both districts agreed overwhelmingly that the situation had improved in their district, and that, compared to earlier days, fewer women approached them for disclosure of the sex of the foetus or a sex-selective abortion, and more women with whom they came in contact stopped childbearing after their second daughter. Nevertheless, providers warned that information about places where such services are available was being divulged, both in their own districts and in neighbouring states; Delhi and Uttar Pradesh were most frequently cited as locations where women could access services for gender-biased sex selection easily, particularly by health care providers from Sonipat (eight of 11 health care providers from Sonipat; three of 12 from Kurukshetra). For example:

Although these services are not as easily available as they used to be, people still get the sex determination test done from somewhere or the other. The only difference is that earlier this used to happen in the open, now it is under the table; people are ready to spend as much money as is needed (to obtain the service). [Male, general physician/MBBS doctor, aged 38, Sonipat].

The rich and powerful are the ones who demand services..... The practice has declined; earlier, providers gave these services openly. But those who want the service will (find a way to) get it from elsewhere. [Female, obstetrician-gynaecologist, aged 47, Sonipat]

Earlier, it was very easy; now, (it is) not so-but, it's not impossible. If not in Sonipat, people go elsewhere to get these services. We work in the field, so we are connected to society and encounter these situations. I do not get involved, although I come to know about women who get tested and abort the child. Two years ago, a doctor aborted a female foetus and the woman who got this service told me about it, but after a long time. Even so, more (such incidents) happen in Delhi and UP than in Sonipat. [Female, ANM, aged 50, Sonipat]

People know it's against the rules; so, they do not ask openly. Everyone knows in the cities where one can go to get procedures like this (sex-selective abortion), whether in the same city or a place nearby. So, people don't go to places where these things are not done..... It has, perhaps, decreased a little, but still, if someone really wants it, they would get it done for sure; maybe the practice has decreased by 10-20 percent. [Female, radiologist, aged 40, Kurukshetra]

\section{Perspectives of public sector programme implementers}

District programme implementers were more mixed in their views on whether there had been a decline in the practices of disclosure of the sex of the foetus and termination of pregnancies carrying a female foetus. Most agreed that the practice had indeed declined (four of six programme implementers from Sonipat; four of five from Kurukshetra, who discussed the subject; none of the three state government programme implementers discussed this issue), and several suggested that while health care providers in the districts were no longer engaging in these practices, women were referred to other states to obtain the services, as these excerpts indicate:

In Sonipat, three to four hospitals were caught providing such services and were sealed. Apart from this, many hospitals were given a warning. Still, I think that these things have lessened compared to earlier times. Five to six years ago, all these practices were rampant but they have been abandoned or rather, prevented now, and such practices have declined. [Female, law enforcement officer, aged 66, Sonipat]

There are a number of cases of sex-selective abortion in the area. I know a doctor in Sonipat who was caught in a raid. His case has been continuing..... it is well understood (that the case is one of sex-selective abortion) from the fact that there is a huge gap between two pregnancies-this signals a sex-selective abortion. People often go out of the state to avail of such facilities as it has now become difficult (to get them) in Sonipat. Generally, these sex-selection activities are performed during off (non-working) hours, and there are certain intermediaries and ANMs through whom people avail of such services. Given the poor sex ratio, we cannot say that there is any change. [Female, PO/CDPO, ICDS, aged 57, Sonipat] 
In Kurukshetra, almost all district programme implementers perceived that such illegal practices had declined, but almost all reported that change was gradual and these practices did indeed persist in their district:

Yes, these practices have reduced..... I think, over the past ten years, the demand for the disclosure of the sex of the foetus and incidents of sex-selective abortion have decreased remarkably. [Female, AWW, aged 52, Kurukshetra]

I cannot deny that people still opt for sex determination to make sure of the birth of a boy..... Although son preference is declining, it will take more time to abolish sex-selection practices completely from society. [Female, PO/CDPO, ICDS, aged 50, Kurukshetra]

\section{Perspectives of NGO programme implementers}

The views of NGO programme implementers from Sonipat were particularly mixed about whether there had been a decline in the practices of disclosure of the sex of the foetus and sex-selective abortion. Most agreed that these practices had indeed declined (eight of 12), and, as in the case of health care providers and district programme implementers, several suggested that women from the district sought such services in neighbouring states. For example:

Ten years ago, we heard about these things (sex-determination tests and sex-selective abortions) more frequently.. I think it has gone down very much... there is improvement in Sonipat district, but rural areas have not improved as much because people there are not so aware. Rural people don't want to change even though they may be educated because they still hold on to old traditions and customs. [Male, NGO programme implementer, aged 39, Sonipat]

Four to five years ago, these things (sex-determination tests and sex-selective abortions) were done openly, but now they are happening secretly. The frequency of such incidents is decreasing..... Earlier, there were nearly a hundred doctors providing these services, now only two or three do so. [Male, NGO programme implementer, aged 49, Sonipat]

According to me, these things (sex-determination tests and sex-selective abortions) are happening even today. Earlier, they happened in the open but now things take place in secret. Therefore, everything, that is, knowing the sex of the foetus and sex-selective abortion are taking place at a high rate even today... There is no change because the desire for a son is strong and people know that by means of this test they can accomplish their desire..... today, everyone wants two children only, and if the first one is already a daughter, then the next one has to be a son for sure. [Male, NGO programme implementer, aged 62, Sonipat]

\section{B. To what do key informants attribute the decline in gender-biased sex-selection practices?}

Key informants typically attributed the decline in the disclosure of the sex of the foetus and termination of pregnancies carrying a female foetus to three factors: better implementation of the PCPNDT Act and the reluctance of health care providers to provide these services; greater awareness of the Act at the community level, and a reduction in service-seeking by women; and finally, a decline in son preference and a growing recognition of the value of daughters. Districtwise differences in key informant responses were mild.

\section{Better implementation of the PCPNDT Act}

Most key informants attributed the decline in illegal sex-selection practices to the stricter implementation of the PCPNDT Act and fear of being caught (19 of 23 health care providers; eight of 12 district programme implementers; eight of the 12 NGO programme implementers from Sonipat). Strict implementation of the Act and the resulting greater fear of repercussions among health care providers and communities at large were more likely to be cited as reasons for the decline in the disclosure of the sex of the foetus and sex-selective abortions by key informants in Kurukshetra than in Sonipat, although in both districts, this was the leading reason offered by health care providers (11 of 12 versus eight of 11 health care providers) and district programme implementers (five of six versus three 
of six district programme implementers). Narratives from Sonipat and Kurukshetra were similar. For example, from Sonipat:

The (implementation of the) law (PCPNDT Act) has become very strict so doctors are not providing services (namely, disclosure of the sex of the foetus and abortion of a female foetus). Everyone is under surveillance; everyone is afraid of being caught. [Female, general physician/MBBS doctor, aged 63, Sonipat]

Law (enforcement) is stricter now, facilities (providing illegal sex-selection services) are not so easily available, people are afraid, and so are doctors. Doctors are under surveillance, they are being inspected. [Female, ANM, aged 42, Sonipat]

Strict vigilance and raids have created a sense of fear among people who are doing such illegal (sex-selection) activities. [Male, law enforcement officer, aged 57, Sonipat]

Laws are working properly, nowadays. The most important reason behind the decrease in such practices (disclosure of the sex of the foetus and sex-selective abortion) is the increased strictness of law enforcement. Terror is created among doctors and, as a result, they abstain from providing such services. I think that such services are not happening in cities anymore; but, in villages, untrained people are still involved in such work. [Female, law enforcement officer, aged 66, Sonipat]

Likewise, narratives from Kurukshetra:

It is the fear that people have of the government. The government has become strict, so people do not get it (disclosure of the sex of the foetus and sex-selective abortion) done. [Female, general physician/MBBS doctor, aged 57, Kurukshetra]

Greater vigilance and closer monitoring of providers have made it more difficult to avail of sex-selection services. Today, for an ultrasound test, people have to register their names with proper proofs of identity and address. Strictness in the overall system is the major reason behind the decline. Provision of the ultrasound test has become stringent and procedures of MTP have become more complex than before. [Female, Staff Nurse, aged 40, Kurukshetra]

It (Decline in sex-selection practices) is because of various government initiatives, stringent implementation of the law. [Female, AWW, aged 38, Kuruksehtra]

Early registration and strict monitoring of abortion cases are two more reasons for the improvement (decline in sex-selective abortions) in the district. Thus, I would say that the situation has improved because of the strictness of various legal programmes, the stricter implementation of the Act; also, the monitoring system has become more disciplined and people have become more alert. [Female, law enforcement officer, aged 52, Kurukshetra]

Because of this law (PCPNDT Act) in Sonipat, in the last one or two years, a few doctors were caught providing (illegal sex-selection) services-their machines were sealed one or two doctors were punished in some cases, and some were let off with a warning. I mean that this (Appropriate) Authority is working efficiently. I definitely believe that though slowly, the situation is getting better. [Male, NGO representative, aged 46 , Sonipat]

\section{Greater awareness of the PCPNDT Act at the community level}

Several key informants also cited greater awareness of the PCPNDT Act and suggested that improvements in education had resulted in greater compliance with the law at the community level (16 of 23 health care providers; six of 12 district programme implementers; five of $12 \mathrm{NGO}$ programme implementers from Sonipat). Again, more key informants from Kurukshetra (10 of 12 health care providers; four of six district programme implementers) than Sonipat (six of 11 health care providers; two of six district programme implementers) held this perception. For example, from Sonipat:

It is so; because, though slowly, awareness is increasing among people..,.. [Female, law enforcement officer, aged 66, Sonipat] 
Along with the government, many non-governmental organisations are also working towards removing this evil from society. As a result, I think our society has become more aware now. The government has also come up with numerous schemes for the development of women and girls; this also has an effect on people and thus, people's mindset is changing. [Male, NGO programme implementer, aged 46, Sonipat]

Narratives from Kurukshetra attributed greater awareness of the PCPNDT Act to the efforts of the district authorities as the following excerpts suggest:

We are conducting raids on a regular basis, and social awareness has increased through our various IEC programmes. There are also different awareness-raising programmes which even involve school teachers and students..... [Female, law enforcement officer, aged 52, Kurukshetra]

Here (in Kurukshetra), health care providers play an important role by providing information to people through door-to-door services. In addition, there is strict implementation of the PCPNDT Act. [Female, ANM, aged 42 , Kurukshetra]

\section{Decline in son preference and growing recognition of the value of daughters}

A third key reason, expressed by fewer key informants, was the decline in son preference and a growing recognition of the value of daughters. Nevertheless, several key informants (12 of 23 health care providers; five of 12 district programme implementers; five of $12 \mathrm{NGO}$ programme implementers from Sonipat) suggested that son preference had declined to an extent that more parents appreciated the value of daughters and were more willing to accept a daughter-only family. Interdistrict differences were relatively mild (five of 11 and seven of 12 health care providers from Sonipat and Kurukshetra, respectively; two programme implementersfrom each district; and five of 12 NGO programme implementers from Sonipat). For example, key informants from Sonipat advanced the following reasons:

The value of girls has also increased and they are not seen as a burden. [Female, ANM, aged 42, Sonipat]

Another reason behind the decrease in such (sex-selective abortion) practices is the increase in people's recognition of the value of girls. People are becoming aware of the fact that girls are doing better [than boys] these days: they (girls) also hold good positions and are recognised in every field; there is not a single field where girls are not there! All the schemes and programmes run by the government and the incentives given to girls have also affected such practices. With all these schemes, a difference has definitely been created and the value of girls has increased. [Female, law enforcement officer, aged 66, Sonipat]

The value of girls is also increasing. Now, parents consider a son and a daughter to be equal, that girls do all types of work. [Male, NGO programme implementer, aged 49, Sonipat]

Likewise, key informants from Kurukshetra suggested:

People have changed, become more educated, and there are some who won't abort even if they know the foetus is a girl. [Female, radiologist, aged 40, Kurukshetra]

There is a change in the thinking of people and they have started understanding that a girl is no different from a boy. People have started recognising the value of girls and parents no longer discriminate against them... [Female, ANM, aged 20, Kurukshetra]

The value of girls has increased and people have realised that a daughter can take care of them better than anyone else. [Female, Staff Nurse, aged 30, Kurukshetra]

Also, people have started realising that a girl is no different from a boy. The status of girls in society has increased and this has changed people's thinking about girls. [Female, AWW, aged 38, Kurukshetra]

\section{Other reasons cited}

Other responses, cited by no more than two or three key informants, included community concerns about the long-term consequences of an unbalanced sex ratio at birth and the exorbitant cost of services, as the following excerpts affirm: 
Also, people have started thinking that if all these (illegal sex-selection) practices are allowed to continue, then in future there will be a shortage of girls for marriage. [Female, law enforcement officer, aged 66, Sonipat]

Earlier, people had to invest Rs. 1,000 to Rs. 1,500 for performing such tests but now it costs Rs. 8,000 to Rs. 10,000 per case. Therefore, not everyone can afford such services. [Male, NGO programme implementer, aged 46 , Sonipat]

\section{Perceptions about factors underlying the improvement in the sex ratio at birth in Kurukshetra and lack of improvement in Sonipat}

In the course of key informant interviews, we probed views about the factors underlying some improvement in the sex ratio at birth over the last decade in Kurukshetra as compared with the lack of change in Sonipat. They were asked "In the early 2000s, both Sonipat and Kurukshetra had almost the same sex ratio, but in recent years, Kurukshetra's sex ratio at birth has improved, whereas there has been no change in Sonipat. What do you think the reasons behind this may be?" On the whole, all health care providers (all 11 and all 12 providers from Sonipat and Kurukshetra, respectively) and NGO representatives from Sonipat (12 of 12) responded to this question; so too did most public sector programme implementers (four of six from each district and all three from the state). We acknowledge that several key informants offered commonly accepted stereotypes prevalent in Haryana, for instance, relating to the characteristics of various castes, as described below.

Key reasons cited by the informants for the improvement in Kurukshetra's sex ratio at birth included: better implementation of the PCPNDT Act in Kurukshetra; a more educated and aware population in Kurukshetra than in Sonipat; Sonipat's proximity to Delhi and Uttar Pradesh where, they believed, access to services disclosing the sex of the foetus and sex-selective abortion are readily available; and such sociocultural factors as the caste composition (unlike Kurukshetra, Sonipat has a predominance of Jats, a caste which strongly endorses a preference for sons) and the religious significance of Kurukshetra (which tends to make its residents more accepting of a girl child than those of other districts). Most key informants offered a variety of reasons.

Responses of key informants from the two districts diverged considerably, while within each district, responses of health care providers, district programme implementers and NGO programme implementers (in Sonipat) were similar. For example, relatively few key informants from Sonipat attributed the difference to better implementation of the PCPNDT Act or greater community awareness in Kurukshetra than in Sonipat (three of 11 health care providers, not a single district programme implementer, and three of 12 NGO programme implementers). At the same time, the overwhelming majority attributed the district difference to the proximity of Sonipat to states in which services disclosing foetal sex and sex-selective abortion were more easily available (all 11 health care providers, three of four district programme implementers who responded to the question; 10 of 12 NGO programme implementers from Sonipat), and a few to sociocultural differences (two of 11 health care providers, one of four district programme implementers who responded on this issue, and one NGO programme implementer).

In contrast, key informants from Kurukshetra cited different reasons. The leading reasons cited were the better implementation of the PCPNDT Act in Kurukshetra (cited by five of 12 health care providers, and three of four district programme implementers who responded on this issue), and greater awareness at the community level (cited by eight of 12 health care providers and three of four district programme implementers who addressed this issue). In contrast, just three health care providers and two district programme implementers suggested that Sonipat's greater proximity to Delhi and Uttar Pradesh accounted for the lack of change in its sex ratio; three health care providers refuted this perception, indicating that Kurukshetra also lies in close proximity to states in which services are more easily available. Finally, just two key informants from Kurukshetra (one health care provider and one district programme implementers) cited sociocultural reasons and the predominance of particular castes as reasons for the improved sex ratio at birth in Kurukshetra.

We present below the perspectives of the key informants about each of the leading reasons given above.

\section{Better implementation of the PCPNDT Act in Kurukshetra}

By and large, key informants from Sonipat suggested that the implementation of the PCPNDT Act was similar in Sonipat and Kurukshetra. Indeed, several cited the achievements of their district in implementing the Act: 
All our efforts are well reflected in the current improvement of the sex ratio of the district; it was 839 in 2001 and has increased to 856 in 2011. In 2010, our district got a cash award of Rs. 4 lakh because of the improvement in the sex ratio, and, in 2013, we were given a cash incentive of Rs. 2 lakh..... Awards are given by the Women and Child Development Department, based on the reports of the Civil Registration System (CRS) of the Health Department. [Female, PO/CDPO, ICDS, aged 52, Sonipat]

In Kurukshetra, the district administration has made a lot of effort to improve the sex ratio. It has conducted a number of campaigns especially in areas where the situation was bad. Hence, the improvement of the sex ratio can be attributed to the resulting increase in awareness among the people, besides the strict implementation of the law. I don't know what happens in Sonipat. Each year, there is an award ceremony in the state for (the district recording the greatest) improvement in the sex ratio based on CRS data; we received the 1st prize in 2013-14 because of the commendable improvement in our sex ratio. We are directed to invest the award money to increase awareness among people..... The state government has given the district administration an award of Rs. 5 lakh for improving the sex ratio, and we organise various programmes with this money at village and block levels. This year, our main theme is 'Beti bachao beti padhao' at Gita Jayanti (a festival celebrating the anniversary of the Bhagvad Gita), to raise awareness among people and sensitise health workers like AWWs, Anganwadi Centre helpers, ASHAs, ANMs and workers from the Education Department as well. [Female, PO/CDPO, ICDS, aged 50, Kurukshetra]

Hence, only a few key informants noted that the PCPNDT Act was not as well implemented in their district as in Kurukshetra; one of them suggested that corruption levels were more under control in Kurukshetra than in Sonipat. For example:

The only reason may be that laws are not as strictly implemented here; doctors still do these things (disclosure of sex of the foetus and sex-selective abortion) here. [Male, NGO programme implementer, aged 39, Sonipat]

May be government authorities are stricter in Kurukshetra than Sonipat. There is also more corruption in Sonipat... [Male, NGO programme implementer, aged 46, Sonipat]

Key informants from Kurukshetra, in contrast, emphasised the better implementation of the PCPNDT Act as the main reason for the district's improved sex ratio. For example:

May be the CMO here is more active and has held more meetings, done more checks etc., meaning that the law has been implemented in a very good way in Kurukshetra. [Female, general physician/MBBS doctor, aged 57 , Kurukshetra]

Also, laws are not enforced properly in Sonipat, unlike in Kurukshetra. [Female, Staff Nurse, aged 27, Kurukshetra]

It (the improved sex ratio) is possibly because raids have not been conducted seriously and providers do not work properly in Sonipat, unlike in Kurukshetra where monitoring is very strict and the law is well enforced. [Female, ANM, aged 42, Kurukshetra]

Also, there is strict monitoring in Kurukshetra (unlike) poor monitoring in Sonipat, as well as its closeness to Delhi and Uttar Pradesh. [Female, AWW, aged 38, Kurukshetra]

\section{A more educated and aware population in Kurukshetra}

Although it is not clear that educational attainment levels are higher in Kurukshetra than in Sonipat, or that, in general, lower educational attainment levels are associated with greater violation of the law, a number of key informants cited this as a reason for the improvement in the sex ratio at birth in Kurukshetra, So too, they suggested that community awareness about the PCPNDT Act and about the value of the girl child was likely greater in Kurukshetra than in Sonipat. For example:

In my opinion, perhaps the literacy rate of Kurukshetra is better than that of Sonipat. May be because the people in Kurukshetra are more educated and more aware, the sex ratio there may have improved. [Female, obstetrician-gynaecologist, aged 60, Sonipat] 
I think Kurukshetra has a higher literacy rate than Sonipat and that is because people there are more educated. And, where there is more education, there is more awareness and, thus, people stay away from such blind practices (gender-biased sex selection). [Female, obstetrician-gynaecologist, aged 60, Sonipat]

Education is better in Sonipat than in Kurukshetra; so, that is not a reason. [Male, NGO programme implementer, aged 46, Sonipat]

Another reason might be that the literacy rate of Kurukshetra is higher than that of Sonipat; therefore, people over there are more aware and thus don't get involved in such (sex-selection) practices. [Female, NGO programme implementer, aged 73 , Sonipat]

In contrast, a number of key informants from Kurukshetra attributed the improvement in the district's sex ratio at birth to education and attitudinal changes among its residents as the following excerpts suggest:

I think education plays the most vital role in this regard. There are many villages in Sonipat where the literacy rate is still very low when compared with villages in Kurukshetra..... In addition, there has been a change in the attitude and thinking of the people of Kurukshetra, which is responsible for the improved sex ratio, whereas the situation in Sonipat has not changed. [Female, Staff Nurse, aged 27, Kurukshetra]

In addition, differences in awareness can also be responsible for such disparity. [Female, ANM, aged 42, Kurukshetra]

The biggest difference is the mindset of the people. There is a lack of awareness (about the PCPNDT Act) in Sonipat, whereas in Kurukshetra, things have changed recently. [Female, AWW, aged 38, Kurukshetra]

\section{Sonipat's proximity to Delhi and Uttar Pradesh}

Particularly striking was the considerable number of key informants-almost all from Sonipat and many fewer from Kurukshetra-who cited the district's geographic proximity to Delhi and Uttar Pradesh, where, they believed, services for disclosing the sex of the foetus and providing sex-selective abortion are readily available. They argued, in contrast, that longer distances made it more difficult for women from Kurukshetra to access such services in these states. For example, key informants from Sonipat argued thus:

The other reason may be that the people of Sonipat can get these (gender-biased sex selection) services in Delhi and UP as they are nearby, which (services) people from Kurukshetra can't get. [Female, obstetriciangynaecologist, aged 60, Sonipat]

Another reason is that Sonipat shares its border with Delhi and UP, and I know that many patients receive such services (gender-biased sex selection) from UP or from Delhi NCR. This is also a big reason. [Female, obstetrician-gynaecologist, aged 60, Sonipat]

The main reason is that the district boundary of Sonipat touches the boundary of UP and Delhi NCR. Hence, the people of Sonipat may be getting these (gender-biased sex selection) services from Delhi and UP as they are nearby. On the other hand, people from Kurukshetra can't get the services so easily because of the relatively long distance to these places. [Female, ANM, aged 48, Sonipat]

Sonipat is surrounded by Uttar Pradesh on one side and Delhi on the other. Thus, people go to Narela [in Delhi] and Uttar Pradesh to find out the sex of the foetus and get a sex-selective abortion. [Female, law enforcement officer, aged 35, Sonipat]

The other reason is that people from here go to Delhi and UP to take all types of facilities (determination of foetal sex and sex-selective abortion) whereas people of Kurukshetra are unable to avail of these facilities. [Female, law enforcement officer, aged 66, Sonipat]

I accept that sex-selective abortion happens..... If doctors in the district do not provide these services, people go to Delhi, which is very close by. They get these banned services from Delhi or even Uttar Pradesh whose border is just $10 \mathrm{~km}$ away. [Male, NGO programme implementer, aged 46, Sonipat]

These activities (sex determination and abortion) are present in all the districts; the whole of Haryana is facing this problem, not just one particular district. The reason is that as Sonipat shares its border with 
Delhi, UP and Rajasthan; people go to these places to get these services. This is the main reason behind the low sex ratio of Sonipat. [Female, NGO programme implementer, aged 73, Sonipat]

Few key informants from Kurukshetra espoused this view, and some contradicted it, indicating that the UP border was close to Kurukshetra as well.

In addition, its closeness to Delhi and UP is another reason why Sonipat still has an unbalanced sex ratio. [Female, AWW, aged 52, Kurukshetra]

It is not that Sonipat has access to UP and Kurukshetra does not. Even from Kurukshetra, whoever wants to go (to UP) can go-there is Saharanpur, Panchkula, Chandigarh, Meerut; so, this is not a major reason. [Female, general physician/MBBS doctor, aged 57, Kurukshetra]

\section{Sociocultural differences between the study districts}

Relatively few key informants from Kurukshetra cited sociocultural differences to explain the improvement in the district's sex ratio at birth as compared with that of Sonipat. Nevertheless, these key informants pointed to a similar set of sociocultural factors: the predominance of the Jat community in Sonipat relative to Kurukshetra, who, they argued, continue to hold a strong son preference and are, thus, unwilling to accept daughter-only families. Although evidence suggests that distorted sex ratios at birth and among children are prevalent among Sikhs and people from Punjab, many key informants (mis)perceived that the preponderance of the Punjabi/Sikh community in Kurukshetra and the identification of Kurukshetra as a place of historical and religious importance made its residents less likely to engage in these behaviours. For example, key informants from Sonipat said:

Apart from this, in Sonipat, 'Jats' are more in number and they prefer sons over daughters. The people of this community are illiterate and follow old customs. In my opinion, people from this community demand sex-selective tests and abortion more (than those of other communities); that's why the sex ratio of Sonipat is so low, whereas Kurukshetra, where there are fewer people of this community, is in a better position! In Kurukshetra, there are more people of the Punjabi community; in their society, all these (illegal sex-selection) activities are perceived to be profane and thus they avoid such practices. In Haryana, Rohtak, Jind and Sonipat are districts in which people say 'we don't want girls!' [Female, obstetriciangynaecologist, aged 60, Sonipat]

The communities in Kurukshetra are less backward than those in Sonipat. Backwardness and lower educational levels exist in our Sonipat communities. Sonipat is mostly made up of the Jat community, which is more backward. In Kurukshetra, there are more people from the Punjabi community. [Female, law enforcement officer, aged 66, Sonipat]

Sonipat is a Jat-dominated district whereas there are fewer Jats in Kurukshetra. I think caste is an important factor in this respect, as among Jats, sex-selective abortion is very prevalent. Awareness levels and traditional values are different, and these factors are also responsible (for the lack of improvement in its sex ratio at birth). This large Jat population in Soniput finds sex-selective abortion a good way to ensure few children, yet a desired composition of children. [Male, law enforcement officer, aged 56, Sonipat]

A few key informants from Kurukshetra espoused similar views, for example:

The difference is because in Sonipat, the Jat community has retained traditional preferences for sons in a major way, whereas in Kurukshetra, better education has created huge awareness among the people. [Female, Staff Nurse, aged 40, Kurukshetra]

\section{Recommendations for addressing the unbalanced sex ratio at birth in the study districts}

Key informants were asked for their recommendations at the community level as well as at system and programme levels in order to accelerate improvements in the sex ratio at birth in their respective study districts. A range of recommendations was expressed. 


\section{For community-level action}

All key informants were asked their views about the action that should be taken at the community level to reduce son preference in general, and to address gender-biased sex-selection practices. Their recommendations were multipronged for the most part, and centred around the need for programmes to raise awareness and to change attitudes about the role of girls; to empower girls and women, through education, vocational skill-building and economic opportunities; better implementation of government cash transfer schemes for girls; greater media engagement; engagement of religious leaders and other influential individuals at the community level in changing attitudes and practices; and, particularly among NGO programme implementers, a greater involvement of NGOs in delivering these programmes.

\section{Raise awareness and change attitudes}

Almost all key informants, in both districts ( 21 of 23 health care providers; 13 of 15 public sector programme implementers; eight of 12 NGO programme implementers from Sonipat), called for awareness-raising or education programmes that would inform communities about the PCPNDT Act, the deleterious long-term consequences of unbalanced sex ratios, and the value of girls. Several key informants singled out rural areas, schools, men, and the older generation for special attention, and suggested better managed and coordinated IEC/behaviour change communication programmes. NGO programme implementers called for greater involvement of NGOs in raising awareness and changing attitudes, including in government-run programmes. Recommendations were similar among key informants from both districts; for example:

For this, we should educate children from an early age so that they do not discriminate between boys and girls; because, in future, they will be a part of the society and will have their own family. Other than that, we have to make the present generation aware so that they keep away from these activities (gender discrimination, gender-biased sex selection). We have to bring change at the community level because it is the starting point. If we are able to change the mindset of the community, half the problem will be solved. If no one goes to doctors and radiologists, then to whom they will provide these services? At the community level, we should organise meetings, street plays or other programmes to teach people the importance of having girls and tell them about the problems (that may arise due to a deficit of girls) in future. [Female, ANM, aged 50, Sonipat]

Proper awareness is necessary..... males should also be a part of mobilisation programmes as they are the main decision makers in the family. More NGOs should contribute through campaigns and education programmes. [Female, PO/CDPO, ICDS, aged 57, Sonipat]

Raising awareness among communities is also necessary. There should be discussions on dowry, the status of girls, fundamental rights, and education of daughters; we need to motivate families not to discriminate between a son and a daughter. Thus, sensitisation should be done at all levels-community, doctors and the court where final judgements are passed.... Vigorous IEC programmes on the PCPNDT Act are needed; for example, by organising seminars, holding doctors' meetings, using radio and TV programmes to inform people about the Act etc... But education is most important. [Male, law enforcement officer, aged 57, Sonipat]

We need to work more in the villages. Like in cities, we need to create more awareness in the villages. These days, both teachers and social workers avoid working in villages and this is because of the backwardness, poor education, lack of opportunities and widespread cultural rigidity (that exists) there. Foremost, what we need to do is to show a preference for girls in all programmes and schemes. Parents should be made to feel that daughters are no less than sons. [Female, law enforcement officer, aged 66, Sonipat]

Education and awareness should improve..... the government should give power to NGOs like us to go from door to door to raise awareness..... NGOs like ours should also be included; we can work together with the government to increase awareness. NGOs do not have any personal motives; they work for society. If NGOs get help from the government, we can tackle this problem in five to seven years instead of 15..... [Male, NGO programme implementer, aged 41, Sonipat]

We need to change the mentality of the people. Meetings (sabhas) should be held where people can interact to raise awareness..... stress should be laid on education. [Female, general physician/MBBS doctor, aged 57, Kurukshetra] 
There should be proper programmes to generate awareness at the community level to eradicate traditional perceptions about having a son. Teachers should take the responsibility of raising awareness among children from a young age itself and elders should be given special attention as they are the ones who compel (young) parents to have a son instead of a daughter. [Female, Staff Nurse, aged 35, Kurukshetra]

Training should start from the school itself, so that, in future, these students will be able to judge what is right and wrong, and bring about changes in the situation in the long run. [Male, law enforcement officer, aged 56, Kurukshetra]

Raising awareness of people is most important. The law alone cannot change the situation. I think people should be sensitised to reduce son preference and women should be given proper education, made aware of their rights. [Female, AWW, aged 52, Kurukshetra]

There should be more programmes to sensitise people about gender. Students should be taught that a girl is no different from a boy. [Female, PO/CDPO, ICDS, aged 50, Kurukshetra]

\section{Empower girls and women}

Key informants recommended a number of strategies whereby to empower girls and women and raise the status of the girl child through education, vocational skill-building opportunities and economic opportunities; better implementation of government cash transfer schemes for girls; and reservations for women in elected positions. Several (eight of 23 health care providers; 11 of public sector programme implementers; eight of 12 NGO programme implementers from Sonipat) suggested that programmes that empower women are needed in order to change community perceptions about females. Some specifically called for measures to enhance the security of girls (three of 23 health care providers; four of 15 public sector programme implementers; no NGO programme implementers), strengthen government cash transfer schemes for girls, remove bottlenecks in the registration process and ensure greater accountability of those delivering these schemes for girls (three of 23 health care providers; seven of 15 public sector programme implementers; four of 12 NGO programme implementers from Sonipat). A large number of NGO representatives (five of 12) also called for the greater involvement of NGOs in community-based awareness raising, in empowering women and girls, and in implementing conditional cash transfer schemes for girls. For example:

The government should give priority to the wellbeing of girls and schemes for girls should be well implemented. Presently, out of 100 only five percent of these schemes are properly implemented. The government is spending the required amount on these schemes but they are not reaching the poor and needy. [Female, law enforcement officer, aged 66, Sonipat]

Girls who are fighting sex selection in their home or their in-laws' home should be protected and given due respect by the government so that society derives some inspiration from them.... There should be an agency that informs people about different government schemes so that they (girls and women) can take full advantage of the schemes. Monitoring of schemes should be done by NGOs..... more should be done to empower women and make them self-reliant-until a woman overcomes the fear that her in-laws will throw her out of the house or her husband will divorce her, that nothing is going to change.... Boys and girls should be taught values that they are equal, girls should be given the same freedom as boys. [Male, NGO programme implementer, aged 62, Sonipat]

We need to work on social conditions-education as well as empowerment of girls. If you have seen the serial Udaan, you must have seen that until every girl is empowered, nothing fruitful can happen. So, educate your girls. Do not educate only boys. Educate girls. Even Mahatma Gandhi has said that if there are two families, the one with educated girls is the one that goes ahead. This is why daughters need to be made independent and need to be educated. If a girl is educated, suppose she is an IAS officer or a doctor or engineer, how can she be pressurised (to do a sex-selective abortion)? It is the uneducated daughter-inlaw who is dependent on the family, on whom pressure is put. She has to survive and she is pressurised to do these things. Whenever someone's first-born is a daughter, then her entire education and all her necessities of life should be taken over by the government. She should get benefits and free education. And then the first daughter should get reservation, separate from the caste-based reservations that are already in place. If there is another daughter, then the subsidies should be doubled and reservations for her should 
be even higher. People should feel that if a daughter is born, then the goddess Lakshmi (goddess of wealth) herself has arrived. Even in Parliament, since women constitute 50 percent (of the population), 50 percent of seats should be reserved for them. [Male, general physician/MBBS doctor, aged 59, Kurukshetra]

They (The government) should be told to pay attention to girls, including their security..... It is because of the rising crimes against women that a lot of people prefer not to give birth to girls. So, the government should provide full security for every girl. Nowadays, till the daughter comes back home, the mother is worried and if she gets a little late..... So, this is a very big reason. [Female, general physician/MBBS doctor, aged 57, Kurukshetra]

Also, there is a need to educate girls and make them independent. Education should be free for them (girls); that way (by doing so), a girl will not be considered a burden to her family and society will understand her value... [Male, law enforcement officer, aged 56, Kurukshetra]

Skill-building programmes for women can change people's perceptions about daughters. When women start earning, they can look after their parents, and this brings in changes in people's perceptions about daughters.... [Female, AWW, aged 52, Kurukshetra]

I cannot say one programme is better than another. The government should take care of the safety of women and abolish the dowry system so parents are less worried about and not as afraid of having a daughter..... Although girls can claim a part of the family property, they do not ask for their share due to the traditional system prevailing in society according to which they are not considered a part of the family after marriage. [Female, PO/CDPO, ICDS, aged 50, Kurukshetra]

\section{Engage the media}

A number of key informants (nine of 23 health care providers, three of 15 public sector programme implementers; three NGO programme implementers from Sonipat) called on the media to convey information relating to the PCPNDT Act, and change attitudes about the value of girls. For example:

Every day, different posts or programmes should be telecast or printed in the media, so that people understand that there is no difference between boys and girls, and that girls have their own value. [Female, obstetrician-gynaecologist, aged 60, Sonipat]

There should be more seminars and TV programmes to ensure a wider spread of the message that a daughter is no different from a son. [Female, Staff Nurse, aged 35, Kurukshetra]

There should be more TV programmes and films that talk about the achievements of girls and women. [Male, law enforcement officer, aged 56, Kurukshetra]

The media have the capacity to reach a large number of people in a short period and TV has an influence on the thinking of people..... [Female, AWW, aged 52, Kurukshetra]

\section{Engage influential individuals}

A few key informants (three of 23 health care providers; two of 12 district programme implementers; two of 12 NGO programme implementers from Sonipat) recommended a greater role for opinion makers, including religious leaders, locally elected representatives, frontline health workers and other individuals in positions of authority at the community level in changing attitudes and practices, and mobilising communities:

I think the government should take the help of religious leaders to raise awareness among people because even today, more than 70 percent of our population obeys religious leaders. So, I think that their help will be highly effective. Other than this, we can also take the help of members of Panchayati Raj institutions like the Sarpanch, Mukhiya, Ward members and other important people of the village because they have considerable influence and the whole village obeys them. [Female, ANM, aged 50, Sonipat]

To assist locals in understanding the law, paralegal volunteers should be trained on all legal issues related to the PCPNDT Act. We should also employ ASHAs, ANMs, AWWs to provide information and change attitudes. [Female, law enforcement officer, aged 35, Sonipat] 
We have to teach people that sex-selective abortion is bad, and take help in doing so from Panchayats, godmen and the media because they have a lot of impact on people. [Male, NGO programme implementer, aged 46 , Sonipat]

\section{For system- and programme-level action}

Recommendations for system- and programme-level action called for stricter implementation of the PCPNDT Act. Several measures were advocated: harsher enforcement methods and punishments; greater involvement of the police in conducting raids; more attention to training, equipping and staffing the Appropriate Authorities; greater collaboration with NGOs in enforcing the Act; and finally, the elimination of corruption from the system.

\section{Use harsher measures to enforce the PCPNDT Act}

Almost all health care providers (21 of 23), public sector programme implementers (10 of 15), and NGO programme implementers from Sonipat (eight of 12) called for harsher enforcement of the PCPNDT Act, including more sting operations, more stringent punishment for offenders, the application of trackers on all ultrasound machines, naming and shaming of offenders, and the tracking and scrutinisation of all women identified at the community level to be pregnant, as well as those seeking ultrasound services. For example:

Two years ago, a nursing home in Sonipat was caught (violating the PCPNDT Act) by the (raiding) team and was sealed. But, after two or three months, it reopened and is running till today. In my view, this is wrong. The doctor deserved a harsher punishment. I would also like to say that through the media, these people's names should be exposed so that there is a fear among them and they will never do that (sex-selective abortion). Together with these (punishments), there should be regular updates regarding the culprit: what is happening with him and the full inside story.... Till now, we have not had sting operations but if they happen, they (the Appropriate Authority) can catch someone (the violator) red-handed, and give them as harsh a punishment as possible so that nobody dares to repeat it (sex-selection practices) in the future. [Female, general physician/MBBS doctor, aged 62, Sonipat]

I would say-implement the law more strictly, keep vigilance over everyone and whenever anybody gets caught performing such services (disclosing the sex of the foetus and aborting a female foetus), take strict action against them, and give updates about the proceedings so that everyone knows what is happening within the system. Therefore, with the help of the media, all these things should be exposed so that these people (offenders of the PCPNDT Act) lose their reputation, and others stay away from such practices forever! [Female, obstetrician-gynaecologist, aged 47, Sonipat]

Providers, whether trained or untrained, should be caught with the help of sting operations. They should be given harsh punishment and jailed. The machines and nursing homes should be banned forever and their license should also be cancelled. There should be strict action taken against them and they should be punished severely, so that other providers will not do these things (sex-selection practices) in future. [Female, ANM, aged 48, Sonipat]

CCTV (closed circuit TV) cameras should be installed so that if someone says something of this nature (about disclosing the sex of the foetus or aborting a female foetus), the footage can be recorded and viewed later. Just as you are recording, if in the same way recordings are made then whoever comes and talks about all this (sex determination, sex-selective abortion)....their faces would be recognised and they could be punished. If you have to catch anyone, the solution is very simple. Send a decoy patient and that patient would go to the doctor and tell him what she wants done-like a sting operation. One will have to do a sting operation and only then can they (unscrupulous doctors) be caught red-handed. [Male, general physician/ MBBS doctor, aged 59, Kurukshetra]

Laws should be implemented more stringently and punishment should be tougher e.g., licenses should be cancelled for life if a person is caught performing sex-selective services. I think people who practice sex-selective abortions deserve punishment similar to what a murderer gets-a monetary fine is not sufficient. [Female, Staff Nurse, aged 40, Kurukshetra]

Raids are needed; there is a need to make people afraid if we have to make a difference. [Female, PO/ CDPO, ICDS, aged 57; Sonipat] 
There should be trackers (installed) in every ultrasound machine so that we can do our monitoring effectively. Although tracking started in 2009, it couldn't be properly implemented in Haryana as the trackers were reported to give erroneous results.... Since people cross state borders, there should be a system whereby we can track trans-border activities..... Ultrasonologists and radiologists should take an oath not to take part in any sex-selection practices. Stricter monitoring is needed, including regular inspections, frequent raids and auditing. [Male, law enforcement officer, aged 57, Sonipat]

I think there should be a hidden informer who keeps a watch on all the Janch Kendras (ultrasonography centres). Just as there are hidden informers working against terrorists, there should also be a hidden source keeping watch on ultrasonography centres, and, if they (law enforcement authorities) have a doubt, they should take immediate action... [Male, NGO programme implementer, aged 62, Sonipat]

Strict vigilance over doctors and locals can ensure proper implementation of the law. Attachment of identification proof during registration should also be mandatory for pregnant women seeking ultrasound tests, in order to manage the system properly. Here (in this district), we also ask for a photo of the woman..... [Female, law enforcement officer, aged 52, Kurukshetra]

The government should do this much-it should keep a sharp vigilance on all the pregnant women in a village with the help of ASHAs and ANMs. It should keep an account of how many women are pregnant; where their deliveries are taking place; how many women have sons and how many have daughters; how many pregnant women have not had a delivery; and what is the reason behind not delivering the child. Once you do this, you will get crystal clear results! [Female, obstetrician-gynaecologist, aged 47, Sonipat]

\section{Increase involvement of the police}

A number of key informants expressed concern that too much power is vested in a single fraternity-medical officers-in enforcing the PCPNDT Act. They suggested that given that both those responsible for inspections, raids and prosecution of violators belonged to the same fraternity as those they were expected to monitor, chances of prior warning, lenient action, and overlooking of violations could result. Five key informants-largely NGO programme implementers (four of eight from Sonipat who responded to the question) and one of 12 district programme implementers-called for a larger role for the police in enforcing the Act, notably in conducting raids. For example:

Police should also be a part of the system rather than only health officials and committee members. [Female, PO/CDPO, ICDS, aged 57; Sonipat]

Police should be given full authority to take action against any doctor they find performing such activities, and should not be under the (Appropriate) Authority. For example, it should not be necessary for them (the police) to include the (Appropriate) Authority in their investigation or take the permission of the (Appropriate) Authority (to do so). [Male, NGO programme implementer, aged 46, Sonipat]

Both NGOs and the police should be trained in this field (effective enforcement of the PCPNDT Act) so that they can execute their responsibilities properly. [Male, NGO programme implementer, aged 46, Sonipat]

The PCPNDT programme should come under the Police Department along with the Health Department; at present, it is only under the latter. Police take action only when the Health Department asks them. Those who conduct sex selection raids are all doctors and have some relationship with the Health Department-so it is 100 percent 'mili bhagat' (done in collusion). [Male, NGO programme implementer, aged 62, Sonipat]

I will even say that the police should also be given the same power (as the Appropriate Authority) to prevent such illegal work. [Female, NGO programme implementer, aged 45, Sonipat]

\section{Strengthen collaboration with NGOs in enforcing the PCPNDT Act}

A second suggestion, made entirely by NGO programme implementers from Sonipat (eight of 12), called for greater engagement of NGOs in enforcing the PCPNDT Act. These NGO programme implementers argued that NGOs were less likely than others to have vested interests as described in the following excerpts:

I believe instead of making an all-doctors team, the (Appropriate) Authority should also include one or two members from NGOs and one or two from the press/media so that all the activities could be undertaken 
without bias; because, at present, it is sending doctors to investigate the actions of other doctors; who knows what is happening between them? Therefore, if others are included, each will play his role and then there will be unbiased results. Although until now, all inspections and raids were conducted without prior information, some member could secretly leak out such information, and who would know? And, if there are leaks, these people would escape as they would be able to hide everything (the evidence) before the inspection team can reach them. I think, in order to get hold of these people we need to perform sting operations, which are still not done here. Most importantly: all kinds of people should be incorporated in the team. [Male, NGO programme implementer, aged 46, Sonipat]

NGOs working on sex selection issues should also be included. At the moment, the government doesn't listen to those who genuinely work for the cause... I think that the responsibility of preventing sex-selective abortions should be given to NGOs who are not controlled by anyone, and they should be given the right to stop all such illegal acts. [Male, NGO programme implementer, aged 62, Sonipat]

I think that the responsibility for the enforcement of the (PCPNDT) Act, if not given only to a team of doctors but to other people or organisations, will get better and faster results. NGOs should be included and they should have the power to strictly prevent such cases. We should be given full power to initiate proceedings on errant providers. [Female, NGO programme implementer, aged 45, Sonipat]

\section{Step up attention to training, equipping and staffing law enforcement authorities}

A number of key informants noted that those responsible for enforcing the PCPNDT Act were overworked with other responsibilities, were poorly trained in collecting evidence and preparing court cases, and that coordination between various departments and individuals working on the Act enforcement was weak. State-level authorities noted that those responsible for enforcing the Act were overburdened with other responsibilities, resulting in insufficient attention being paid to enforcement. Recommendations, made largely by public sector programme implementers (six of 15), but also by NGO programme implementers (four of 12 from Sonipat) and a single health care provider from Sonipat (of all 23), thus focused on training, coordination and staffing of authorities responsible for enforcing the Act. Several specific suggestions were made; for example:

The government should employ a separate PCPNDT officer and make the Appropriate Authority enforce laws effectively.... [Male, law enforcement officer, aged 57, Sonipat]

Government officials do not take cases of sex selection seriously even if taken to court. The Appropriate Authority does not have the training to collect evidence. For forensic evidence, the sample needs to be sent to a Forensic Laboratory in Madhuban, which is far away, and delays and other difficulties stop them from doing this. The Appropriate Authority does not make enough effort to make the person who has lodged the complaint feel safe. We give judgements based on the case file and material facts presented before us. [Female, law enforcement officer, aged 35, Sonipat]

There should be proper coordination between the departments working for the implementation of the law, and more power should be given to district authorities to ensure prompt action. The government should ensure faithful implementation of the law and eradicate corruption from the system. [Female, AWW, aged 52, Kurukshetra]

I think people are overburdened with work in our department. A single person has to deal with many issues and, as a result, he or she has not been able to do justice to the work. Civil Surgeons are loaded with too many administrative duties and, as a result, they are unable to go for proper (routine) inspections. Instead of giving many responsibilities to a single person, there should be one separate authority to take care of PCPNDT issues dedicatedly..... Only then we can improve, as only then there will be regular inspections, analysis of complaints and proper investigation of complaints. [Female, law enforcement officer, aged 52, Panchkula]

Proper coordination should also be maintained among the various departments and organisations (involved in curbing gender-biased sex selection). Time-to-time training should be given to all these people and meetings should be called to get updates. After getting training, people know what is right or wrong, (they know) the technical things (aspects of the PCPNDT Act). [Female, NGO programme implementer, aged 45 , Sonipat] 


\section{Eliminate corruption from the system}

One of the key challenges cited earlier by almost all key informants related to passing on advance information about raids and corruption within the system, including political interference and demands from influential individuals to squash cases, lift suspensions and so on. Hence, a number of key informants called for action to address such corrupt practices, although most of those making this recommendation did not, for the most part, offer concrete suggestions about how this should be accomplished. Recommendations about doing away with corruption were made by health care providers (two of 23); public sector programme implementers (five of 15) and NGO programme implementers (five of 12 from Sonipat):

Sometimes, doctors are trapped by the higher authorities because of political and other reasons. This should be changed. [Female, law enforcement officer, aged 35, Sonipat]

After catching them red-handed, (the Appropriate Authority) should get rid of the political pressure. And the person who has been caught should be put behind bars; the person who made calls to the Appropriate Authority to release the person should also be publicly exposed. [Male, general physician/MBBS doctor, aged 59, Kurukshetra]

Implementation of the law should be made stricter and there should be no loopholes in it. There should not be any kind of corruption. [Female, general physician/MBBS doctor, aged 57, Kurukshetra]

The convicted are mainly doctors and are often acquitted as they can easily pay off the law officials..... more vigilance is needed. [Male, law enforcement officer, aged 52, Kurukshetra]

Implementation of the law should be strong enough to sidestep any kind of influence, be it local or political; the law should apply to all, irrespective of their power and authority..... [Female, law enforcement officer, aged 52, Panchkula]

The (Appropriate) Authority should be free from anybody's influence, that is, nobody should be able to put pressure on the inspection team and it should be able to take action against the guilty even if the person has connections in high places. [Male, NGO programme implementer, aged 46, Sonipat]

\section{Summarising key informants' perspectives}

This chapter has explored the perspectives of key informants on four specific issues: whether there has been a decline in the practice of disclosure of the sex of the foetus and termination of pregnancies carrying a female foetus; the factors responsible for this decline; the factors underlying the improvement in the sex ratio at birth in Kurukshetra and its lack of change in Sonipat; and recommendations for action at the community and provider or system levels.

Almost all key informants from both districts and those representing the state, believed that the practices of disclosing the sex of the foetus and terminating pregnancies carrying a female foetus had significantly declined, but cautioned that some health care providers continued to provide these services, many violators were protected by influential politicians and others, and women who could not access services within the district went elsewhere to obtain them. The decline in these practices was attributed to three factors: better implementation of the PCPNDT Act and the reluctance of health care providers to provide these services; greater awareness of the Act at the community level and a reduction in service-seeking by women; and finally, a decline in son preference and a growing recognition of the value of daughters. Districtwise differences in key informant responses were mild, but key informants from Kurukshetra appeared to lay more stress on improvements in community awareness than did those from Sonipat.

Although a common set of reasons was offered to explain the improvement in the sex ratio at birth in Kurukshetra versus the lack of change in Sonipat, key informants from the two districts emphasised different reasons. A key reason cited by those in Sonipat included Sonipat's proximity, relative to that of Kurukshetra, to Delhi and Uttar Pradesh where, they believed, access to services disclosing the sex of the foetus and providing sex-selective abortion are readily available. In contrast, relatively fewer key informants from Sonipat attributed the difference to better implementation of the PCPNDT Act or greater community awareness in Kurukshetra than in Sonipat; a few attributed the lack of improvemnt in the sex ratio at birth in Sonipat to its caste composition, and specifically, the predominance of Jats among whom they described son preference to be particularly strong. In contrast, the leading reasons key 
informants from Kurukshetra cited were the better implementation of the Act in Kurukshetra and greater community awareness relative to Sonipat. In contrast, very few agreed with their counterparts in Sonipat that Sonipat's greater proximity to Delhi and Uttar Pradesh or the predominance of particular castes in Sonipat compared to Kurukshetra accounted for the lack of improvement in its sex ratio at birth.

Key informants from all three categories offered a range of recommendations to improve the sex ratio at birth in their districts. These recommendations referred to both action at the community level, and at the system and programme levels. Recommendations for community-level action centred around the need for programmes to raise awareness and to change attitudes about the role of girls; to empower girls and women, through education, vocational skill-building opportunities and economic opportunities; better implementation of government cash transfer schemes for girls; greater media engagement; engagement of religious leaders and other influential individuals at the community level in changing gender-biased attitudes and practices seeking/providing disclosure of foetal sex and sex-selective abortion; and, particularly among NGO representatives, the greater involvement of NGOs in delivering these programmes. Recommendations involving system- or programme-level action called for harsher law enforcement methods and punishments; greater involvement of the police as well as NGOs in conducting raids and other aspects of law enforcement; more attention to training, equipping and staffing law enforcement authorities; and finally, the elimination of corruption from the system. 


\section{Chapter 7}

\section{Tying it all together: What worked and what next?}

Insights gained from the study offer several programme directions to ensure balanced sex ratios at birth:

- Place greater emphasis on communication, advocacy and community mobilisation to change patriarchal norms and enhance understanding of the PCPNDT Act.

- Support more engagement of senior public sector officials and frontline health workers in communication, advocacy and community mobilisation.

- Review and strengthen the PCPNDT Act enforcement structure to ensure effective execution of law enforcement activities and stem corruption within the system.

- Forge closer public-private partnerships-involve NGOs in awareness-raising and attitude-change programmes in the community, and in law enforcement teams to improve effectiveness.

- Make efforts to resolve the challenges expressed by the medical community in complying with the requirements of the PCPNDT Act.

- Address the need to better understand the role of conditional cash transfer programmes and entitlements for girls to remove bottlenecks and malpractice, to relax stringent eligibility criteria that restrict enrolment, and by assessing the reach, acceptability and longer-term effects of programmes on girls' educational and marriage outcomes.

In this chapter, we integrate the findings of previous chapters to draw inferences on what worked and what appeared to be the most promising practices that distinguished the situation in Kurukshetra from that in Sonipat. Although it is unusual to include evidence in table format in a concluding chapter, given the range of indicators covered and the dual sources of information, we include tables that bullet the key similarities and differences observed in various practices across the two districts.

Before addressing these questions, we note that although Kurukshetra recorded some improvement in its sex ratios at birth and among children over the decade 2001 to 2011, both districts continued to have unbalanced sex ratios in 2011. As such, our findings, drawing on both survey and key informant interview (KII) findings, confirm that all three preconditions for distorted sex ratios at birth and among children were prevalent in the two districts. Small family size norms were pervasive, son preference remained deeply entrenched, and the misuse of technology to disclose the sex of the foetus was prevalent. Mild differences were indeed observed, with son preference somewhat more likely to be observed in Kurukshetra than Sonipat, but disclosure of the sex of the foetus somewhat more likely to be reported in Sonipat, notably among those with more than two children. Key findings are summarised in Table 7.1.

\section{What worked?}

Three key programmatic interventions have typically been implemented to address unbalanced sex ratios at birth and among children, namely activities intended to enforce the PCPNDT Act; communication, advocacy and community mobilisation efforts, and the provision of educational entitlements and conditional cash transfers to girls. All three programmatic interventions were implemented in Kurukshetra and Sonipat. Drawing together the perspectives and experiences of women and key informants about each of these areas of intervention, we explore the likely factors that set Kurukshetra apart from Sonipat, and likely account for the improvement in Kurukshetra's sex ratio at birth. The conclusions drawn from this analysis are illustrative.

The key findings in respect of the implementation of the PCPNDT Act are summarised in Table 7.2. Findings suggest that of the three broad areas of intervention, no districtwise differences could be discerned in two. The extent of enforcement of the PCPNDT Act was indeed similar in both districts. While somewhat more women from Kurukshetra 
Table 7.1: Key factors underlying distorted sex ratios at birth, Kurukshetra and Sonipat

\begin{tabular}{|c|c|c|c|}
\hline Key underlying factors & Kurukshetra & Sonipat & $\begin{array}{l}\text { Difference between } \\
\text { districts: survey and KIls }\end{array}$ \\
\hline $\begin{array}{l}\text { Family size and family size } \\
\text { preference }\end{array}$ & Small & Small & None \\
\hline \multirow[t]{2}{*}{ Son preference } & Strong & Strong & $\begin{array}{l}\text { Stronger in Kurukshetra } \\
\text { than Sonipat }\end{array}$ \\
\hline & $\begin{array}{l}\text { Kls suggest son } \\
\text { preference is declining } \\
\text { among better-educated } \\
\text { and younger couples }\end{array}$ & $\begin{array}{l}\text { Kls suggest son } \\
\text { preference is declining } \\
\text { among better-educated } \\
\text { and younger couples }\end{array}$ & $\begin{array}{l}\text { No difference as revealed } \\
\text { by KIls }\end{array}$ \\
\hline $\begin{array}{l}\text { Attitudes about the importance of } \\
\text { sons }\end{array}$ & $\begin{array}{l}\text { Importance of sons widely } \\
\text { articulated }\end{array}$ & $\begin{array}{l}\text { Importance of sons widely } \\
\text { articulated }\end{array}$ & $\begin{array}{l}\text { Similar in both survey and } \\
\text { KIls }\end{array}$ \\
\hline $\begin{array}{l}\text { Practice of conducting ultrasound } \\
\text { test during pregnancy }\end{array}$ & Almost universal & Almost universal & $\begin{array}{l}\text { Practice slightly more } \\
\text { prevalent in Kurukshetra }\end{array}$ \\
\hline $\begin{array}{l}\text { Practice of obtaining information } \\
\text { about sex of foetus (overall) }\end{array}$ & Significant minority (8\%) & Significant minority (8\%) & None \\
\hline $\begin{array}{l}\text { Practice of obtaining information } \\
\text { about sex of foetus (by parity) }\end{array}$ & $\begin{array}{l}\text { Steady increases with } \\
\text { parity }\end{array}$ & Steady increase with parity & No difference \\
\hline $\begin{array}{l}\text { Practice of obtaining information } \\
\text { about sex of foetus at parities } 3+\end{array}$ & $2-4 \%$ & $6-8 \%$ & Higher in Sonipat \\
\hline \multirow[t]{2}{*}{$\begin{array}{l}\text { Respondent or a friend/relative/ } \\
\text { acquaintance had obtained } \\
\text { information about the sex of the } \\
\text { foetus }\end{array}$} & $16 \%$ & $23 \%$ & Higher in Sonipat \\
\hline & $\begin{array}{l}\text { KIs suggest practice } \\
\text { continues; conducted } \\
\text { clandestinely; more } \\
\text { expensive now than before }\end{array}$ & $\begin{array}{l}\text { KIs suggest practice } \\
\text { continues; conducted } \\
\text { clandestinely; more } \\
\text { expensive now than before }\end{array}$ & No difference \\
\hline \multicolumn{4}{|l|}{ Sex-selective abortion } \\
\hline \multirow[t]{2}{*}{$\begin{array}{l}\text { Ever had a sex-selective abortion or } \\
\text { acquainted with someone who had } \\
\text { done so }\end{array}$} & $3 \%$ & $4 \%$ & No difference \\
\hline & $\begin{array}{l}\text { KIs suggest that the } \\
\text { practice continues, among } \\
\text { an estimated } 1 / 10-1 / 100 \\
\text { women }\end{array}$ & $\begin{array}{l}\text { Kls suggest that the } \\
\text { practice continues, among } \\
\text { an estimated } 1 / 10-1 / 100 \\
\text { women }\end{array}$ & $\begin{array}{l}\text { Residents of Sonipat have } \\
\text { easier geographic access } \\
\text { to Delhi and UP where } \\
\text { services are available }\end{array}$ \\
\hline
\end{tabular}

Note: KII = Key informant interview. Significant differences between Kurukshetra and Sonipat are shown in bolded text.

than Sonipat had heard about raids taking place in their district, those in Sonipat were more optimistic about whether the practice would diminish because of these actions; and while almost all women from the two districts believed that health care providers who disclose the sex of the foetus and those seeking disclosure should be prosecuted, large minorities in both districts believed that, or were undecided about whether the law should permit women who have two or more daughters to know the sex of their foetus and terminate a pregnancy carrying a female foetus. Key informants from both districts, likewise, described a similar set of activities employed to enforce the PCPNDT Act: regular inspections of facilities; periodic update meetings with health care providers; raids and, sealing of equipment and closing of facilities violating the Act; prosecution of violators and fines; registration of personal details of all pregnant women seeking prenatal diagnostic tests and even rewards to community members and frontline health workers identifying those violating the law, and use of frontline health workers to track all pregnant women from the time their pregnancy is identified to its outcome. Both women and key informants recognised that advance warning about impending raids took place, and that political interference or interference from powerful individuals often hampered the ability of the authorities to enforce the law; also mentioned was corruption and the ability of certain health care providers to pay off the raiding teams or avoid prosecution. Several key informants, mainly health care providers and somewhat fewer public sector programme implementers, also pointed out that law 
Table 7.2: Implementation of the PCPNDT Act: key findings from Kurukshetra and Sonipat

\begin{tabular}{|c|c|c|c|}
\hline $\begin{array}{l}\text { Enforcement of the PCPNDT } \\
\text { Act }\end{array}$ & Kurukshetra & Sonipat & $\begin{array}{l}\text { Difference between } \\
\text { districts }\end{array}$ \\
\hline $\begin{array}{l}\text { Heard about doctors } \\
\text { being prosecuted or } \\
\text { ultrasonography clinics being } \\
\text { closed for violations of the } \\
\text { Act }\end{array}$ & Moderate (41\%) & Moderate (42\%) & Similar in both \\
\hline $\begin{array}{l}\text { Heard about a raid on a } \\
\text { doctor or ultrasonography } \\
\text { facility }\end{array}$ & Moderate (26\%) & Moderate (21\%) & $\begin{array}{l}\text { Slightly more in } \\
\text { Kurukshetra }\end{array}$ \\
\hline $\begin{array}{l}\text { Know about anonymous } \\
\text { reporting of ultrasonography } \\
\text { facilities }\end{array}$ & Low $(12 \%)$ & Low $(15 \%)$ & Similar in both \\
\hline $\begin{array}{l}\text { Perception that strict law } \\
\text { enforcement will work }\end{array}$ & Low $(23-25 \%)$ & Low (30-31\%) & $\begin{array}{l}\text { Slightly higher in } \\
\text { Sonipat }\end{array}$ \\
\hline \multirow[t]{11}{*}{ How the law is implemented } & $\begin{array}{l}\text { Periodic update meetings with } \\
\text { health care providers }\end{array}$ & & No difference \\
\hline & Inspections and raids & Inspections and raids & \\
\hline & $\begin{array}{l}\text { Maintenance of detailed } \\
\text { records of women seeking } \\
\text { ultrasonography Form F }\end{array}$ & $\begin{array}{l}\text { Maintenance of detailed } \\
\text { records of women seeking } \\
\text { ultrasonography Form F }\end{array}$ & \\
\hline & Prosecution of violators & Prosecution of violators & \\
\hline & Suspension of doctors' licences & Suspension of doctors' licences & \\
\hline & $\begin{array}{l}\text { Sealing of equipment and } \\
\text { facilities }\end{array}$ & $\begin{array}{l}\text { Sealing of equipment and } \\
\text { facilities }\end{array}$ & \\
\hline & Fines for violators & Fines for violators & \\
\hline & $\begin{array}{l}\text { Financial awards for anonymous } \\
\text { reporting }\end{array}$ & $\begin{array}{l}\text { Financial awards for anonymous } \\
\text { reporting }\end{array}$ & \\
\hline & Sting operations (rare) & $\begin{array}{l}\text { AWWs track pregnant women, } \\
\text { especially those with a daughter }\end{array}$ & \\
\hline & & Oath-taking for doctors & \\
\hline & & $\begin{array}{l}\text { NGOs excluded from law } \\
\text { enforcement teams }\end{array}$ & \\
\hline \multirow[t]{6}{*}{ Challenges } & $\begin{array}{l}\text { Action rarely taken against } \\
\text { women }\end{array}$ & $\begin{array}{l}\text { Action rarely taken against } \\
\text { women }\end{array}$ & No difference \\
\hline & $\begin{array}{l}\text { Too much paperwork, undue } \\
\text { harassment of health care } \\
\text { providers }\end{array}$ & $\begin{array}{l}\text { Too much paperwork, undue } \\
\text { harassment of health care } \\
\text { providers }\end{array}$ & \\
\hline & Corruption & Corruption & \\
\hline & $\begin{array}{l}\text { Poorly trained law enforcement } \\
\text { officials to collect and compile } \\
\text { evidence; not motivated to take } \\
\text { case to court }\end{array}$ & $\begin{array}{l}\text { Poorly trained law enforcement } \\
\text { officials to collect and compile } \\
\text { evidence; not motivated to take } \\
\text { case to court }\end{array}$ & \\
\hline & $\begin{array}{l}\text { State and district authorities } \\
\text { overburdened to monitor } \\
\text { and regularly perform law } \\
\text { enforcement activities }\end{array}$ & $\begin{array}{l}\text { State and district authorities } \\
\text { overburdened }\end{array}$ & \\
\hline & & $\begin{array}{l}\text { Exclusion of NGOs from law } \\
\text { enforcement teams allows for } \\
\text { corruption to take place }\end{array}$ & \\
\hline
\end{tabular}

Note: Significant differences between Kurukshetra and Sonipat are shown in bolded text. 
enforcement activities rarely addressed women and families who sought disclosure, concentrating rather on health care providers alone. In addition, some key informants, particularly public sector programme implementers and NGO programme implementers, noted that those implementing the law-for example those conducting raids and building cases for prosecution-were insufficiently trained in law enforcement and the collection of evidence and, as a result, many court cases could not be pursued. Finally, a number of NGO programme implementers criticised law enforcement activities for excluding NGO representatives, arguing that this exclusion inhibited the effectiveness of law enforcement teams.

Perspectives of women and key informants about the reach and effectiveness of conditional cash and other transfers to girls were also similar across the two districts as seen in Table 7.3. Large numbers of women and key informants were aware of the educational entitlements and at least one conditional cash transfer programme,

Table 7.3: Educational entitlements and conditional cash transfer (CCT) schemes for girls: summary of findings, Kurukshetra and Sonipat

\begin{tabular}{|c|c|c|c|}
\hline $\begin{array}{l}\text { Reach and effectiveness } \\
\text { of entitlements and CCT } \\
\text { schemes }\end{array}$ & Kurukshetra & Sonipat & Difference between districts \\
\hline $\begin{array}{l}\text { Awareness among women } \\
\text { about entitlements and } \\
\text { CCT schemes }\end{array}$ & High & High & Higher in Kurukshetra \\
\hline $\begin{array}{l}\text { Utilisation of educational } \\
\text { entitlements for girls } \\
\text { (textbooks, school } \\
\text { uniforms, scholarships, } \\
\text { bicycles) }\end{array}$ & $\begin{array}{l}\text { Very low to moderate } \\
(0-33 \%)\end{array}$ & $\begin{array}{l}\text { Very low to moderate } \\
(5-29 \%)\end{array}$ & Similar in both \\
\hline $\begin{array}{l}\text { Awareness of CCT } \\
\text { programmes }\end{array}$ & High (81\%) & High (81\%) & Similar in both \\
\hline $\begin{array}{l}\text { Awareness of the Ladli } \\
\text { Scheme }\end{array}$ & High (77\%) & High (81\%) & Similar in both \\
\hline $\begin{array}{l}\text { Awareness of conditions/ } \\
\text { benefits relating to the } \\
\text { Ladli Scheme }\end{array}$ & $\begin{array}{l}\text { Varied by condition/benefit } \\
(6-76 \%)\end{array}$ & $\begin{array}{l}\text { Varied by condition/benefit } \\
(14-66 \%)\end{array}$ & Similar in both \\
\hline Enrollment in Ladli Scheme & Moderately high (66\%) & Moderately high (64\%) & Similar in both \\
\hline $\begin{array}{l}\text { Intention to enroll in } \\
\text { Ladli programme (among } \\
\text { unenrolled) }\end{array}$ & High (71\%) & High $(70 \%)$ & Similar in both \\
\hline \multirow[t]{5}{*}{$\begin{array}{l}\text { Perspectives of key } \\
\text { informants about benefits } \\
\text { of CCTs }\end{array}$} & Effective for the poor & $\begin{array}{l}\text { Effective for the poor } \\
\text { Benefits are too small to } \\
\text { affect attitudes }\end{array}$ & $\begin{array}{l}\text { Similar; agree that schemes and } \\
\text { educational entitlements affect } \\
\text { girls' education and marriage, but } \\
\text { sceptical about effects on } \\
\text { gender-biased sex selection; } \\
\text { District Officials in Kurukshetra } \\
\text { somewhat more positive }\end{array}$ \\
\hline & $\begin{array}{l}\text { Will not stop people from } \\
\text { undergoing gender-biased } \\
\text { sex selection }\end{array}$ & $\begin{array}{l}\text { Will not stop people from } \\
\text { undergoing gender-biased } \\
\text { sex selection }\end{array}$ & \\
\hline & $\begin{array}{l}\text { Tedious registration } \\
\text { process }\end{array}$ & $\begin{array}{l}\text { Poor implementation, } \\
\text { tedious registration } \\
\text { process, difficulties in } \\
\text { enrolling }\end{array}$ & \\
\hline & $\begin{array}{l}\text { Corruption and presence of } \\
\text { middlemen }\end{array}$ & Corruption & \\
\hline & $\begin{array}{l}\text { People feel less burdened } \\
\text { about the education and } \\
\text { marriage of daughters }\end{array}$ & & \\
\hline
\end{tabular}

Note: Significant differences between Kurukshetra and Sonipat are shown in bolded text. 
the Ladli Scheme, offered to girls; while somewhat more women from Kurukshetra than Sonipat had availed of educational entitlements, large and similar percentages of women from both districts with an eligible daughter had registered for the Ladli Scheme. Key informants from both districts, irrespective of category, had similar views about the effectiveness of educational entitlements and conditional cash transfer schemes for girls. They agreed that the schemes could be successful in changing perceptions of daughters as liabilities and burdens, but were sceptical about their role in affecting adherence to the PCPNDT Act. Key informants from Kurukshetra (where the sex ratio at birth had improved) and programme implementers representing the state government were, however, somewhat less sceptical than were those from Sonipat.

It is in the areas of communication, advocacy and community mobilisation that districtwise differences were pronounced, and these efforts appeared to be stronger and more wide-ranging in Kuruksehtra than in Sonipat as suggested in Table 7.4 which summarises women's awareness of the PCPNDT Act and their exposure to such efforts. While exposure to television serials espousing gender equality and/or gender-biased sex selection was reported by similar percentages of women from the two districts, other measures-counselling by frontline health workers and efforts by religious leaders appeared to be significantly more likely to be reported by women in Kurukshetra than in Sonipat. Likewise, although more NGO activities were conducted in Sonipat than in Kurukshetra, the latter reported a strong commitment to community mobilisation on the part of the district administration. In particular, the Night Halt or Open Durbar programme enabled district programme implementers, including senior programme officials, to interact on a regular basis with village communities and make efforts to change patriarchal mindsets and raise awareness about various laws and programmes including the PCPNDT Act; it also offered an opportunity to community members to present their concerns to district officials. Also described by key informants in Kurukshetra were programmes conducted by district programme implementers in schools and colleges; these programmes offered senior officials an opportunity to interact with students and teachers, and more specifically, to sensitise students and obtain pledges from teachers to desist from gender-biased sex selection.

Table 7.4: Communication, advocacy and community mobilisation: summary of findings, Kurukshetra and Sonipat

\begin{tabular}{|c|c|c|c|}
\hline Exposure to messages & Kurukshetra & Sonipat & $\begin{array}{l}\text { Difference between } \\
\text { districts }\end{array}$ \\
\hline $\begin{array}{l}\text { Awareness of the law and } \\
\text { that women and health care } \\
\text { providers violating the PCPNDT } \\
\text { Act may be prosecuted }\end{array}$ & Almost universal $(90 \% \mathrm{~s})$ & High $(80 \% s)$ & $\begin{array}{l}\text { Awareness greater in } \\
\text { Kurukshetra }\end{array}$ \\
\hline $\begin{array}{l}\text { Exposure to messages about } \\
\text { the PCPNDT Act }\end{array}$ & $\begin{array}{l}\text { High; mostly media, } \\
\text { advertisements and } \\
\text { signboards; informal } \\
\text { networks }\end{array}$ & $\begin{array}{l}\text { High; mostly media, } \\
\text { advertisements and } \\
\text { signboards; informal } \\
\text { networks }\end{array}$ & $\begin{array}{l}\text { More women exposed in } \\
\text { Kurukshetra }\end{array}$ \\
\hline $\begin{array}{l}\text { Exposure to messages to raise } \\
\text { the status of the girl child, and } \\
\text { encourage equal treatment of } \\
\text { sons and daughters }\end{array}$ & High (93\%) & High (90\%) & Similar in both \\
\hline $\begin{array}{l}\text { Exposure to above messages } \\
\text { from TV serials/films }\end{array}$ & Very high & Very high & Similar in both \\
\hline $\begin{array}{l}\text { Exposure to messages } \\
\text { discouraging gender-biased } \\
\text { sex selection/abortion of the } \\
\text { female foetus }\end{array}$ & Moderately high (84\%) & Moderately high (77\%) & Higher in Kurukshetra \\
\hline $\begin{array}{l}\text { Exposure to above messages } \\
\text { through TV serials/films }\end{array}$ & Moderately high (75\%) & Moderately high (69\%) & Higher in Kurukshetra \\
\hline $\begin{array}{l}\text { Exposure to advertisements in } \\
\text { health care facilities }\end{array}$ & Moderate (38\%-65\%) & Moderate (50\%-60\%) & $\begin{array}{l}\text { Similar in both, but women } \\
\text { in Sonpiat more likely to be } \\
\text { exposed to details about } \\
\text { information a radiologist } \\
\text { can and cannot give. }\end{array}$ \\
\hline
\end{tabular}




\begin{tabular}{|c|c|c|c|}
\hline Exposure to messages & Kurukshetra & Sonipat & $\begin{array}{l}\text { Difference between } \\
\text { districts }\end{array}$ \\
\hline $\begin{array}{l}\text { Exposure to counselling by } \\
\text { frontline health workers about } \\
\text { treating daughters and sons } \\
\text { alike/about saving the girl } \\
\text { child }\end{array}$ & Low (31\%) & Low (23\%) & $\begin{array}{l}\text { Higher in Kurukshetra; } \\
\text { counselling by ASHA more } \\
\text { likely to be reported by } \\
\text { women in Kurukshetra }\end{array}$ \\
\hline $\begin{array}{l}\text { Exposure to activities conducted } \\
\text { by NGOs }\end{array}$ & Very low (10\%) & Very low (8\%) & No difference \\
\hline $\begin{array}{l}\text { Exposure to campaigns or } \\
\text { discourses by religious leaders } \\
\text { discouraging gender-biased } \\
\text { sex selection }\end{array}$ & Low (20\%) & Low (14\%) & Higher in Kurukshetra \\
\hline \multirow{12}{*}{$\begin{array}{l}\text { Delivery of communication } \\
\text { advocacy and community } \\
\text { mobilisation activities (by district } \\
\text { and state officials and NGO } \\
\text { representatives) }\end{array}$} & Mostly by the public sector & $\begin{array}{l}\text { Many activities conducted } \\
\text { together with NGOs }\end{array}$ & \multirow{12}{*}{$\begin{array}{l}\text { Stronger in Kurukshetra; } \\
\text { NGOs active only in } \\
\text { Sonipat }\end{array}$} \\
\hline & Awareness raising campaigns & $\begin{array}{l}\text { Awareness raising } \\
\text { campaigns }\end{array}$ & \\
\hline & Life and livelihood skills & Life and livelihood skills & \\
\hline & & $\begin{array}{l}\text { Sensitisation of } \\
\text { community members, and } \\
\text { interpersonal counseling of } \\
\text { women by frontline health } \\
\text { workers }\end{array}$ & \\
\hline & Beti Bachao Beti Padhao & Beti Bachao Beti Padhao & \\
\hline & $\begin{array}{l}\text { Regular school and college } \\
\text { interactions }\end{array}$ & & \\
\hline & $\begin{array}{l}\text { Interpersonal counseling of } \\
\text { women by frontline health } \\
\text { workers }\end{array}$ & & \\
\hline & $\begin{array}{l}\text { Oath-taking ceremonies in } \\
\text { schools and colleges }\end{array}$ & & \\
\hline & $\begin{array}{l}\text { Night Halt/Open Durbar } \\
\text { programme at the village } \\
\text { level }\end{array}$ & & \\
\hline & & Posters and banners & \\
\hline & & $\begin{array}{l}\text { Economic empowerment of } \\
\text { women }\end{array}$ & \\
\hline & $\begin{array}{l}\text { Mixed responses about the } \\
\text { role of the media }\end{array}$ & $\begin{array}{l}\text { Mixed responses about the } \\
\text { role of the media }\end{array}$ & \\
\hline
\end{tabular}

Note: Significant differences between Kurukshetra and Sonipat are shown in bolded text.

Key informants offered their own perspectives about the factors underlying the improvement in the sex ratio at birth in Kurukshetra versus its stagnation in Sonipat (Table 7.5). While they suggested a common set of factors, districtwise differences were apparent. Key reasons cited by key informants in Sonipat included Sonipat's proximity, relative to that of Kurukshetra, to Delhi and Uttar Pradesh where, they believed, access to services disclosing the sex of the foetus and providing sex-selective abortion are readily available. In contrast, relatively fewer key informants from Sonipat attributed the difference to better implementation of the PCPNDT Act or greater community awareness in Kurukshetra than Sonipat; a few attributed the stagnation in the sex ratio in Sonipat to its caste composition, and specifically, the predominance of Jats among whom they described son preference to be particularly strong. In contrast, the leading reasons key informants from Kurukshetra cited were the better implementation of the PCPNDT Act in the district and greater awareness at the community level in Kurukshetra relative to Sonipat. In contrast, very few key informants agreed with their counterparts in Sonipat that Sonipat's greater proximity to Delhi and Uttar Pradesh or the predominance of particular castes in Sonipat compared to Kurukshetra accounted for the lack of improvement in its sex ratio at birth. 
Table 7.5: Key informant perspectives on factors underlying the improvement in the sex ratio at birth in Kurukshetra: summary of findings, Kurukshetra and Sonipat

\begin{tabular}{|c|c|c|c|}
\hline Key informant perspectives & Kurukshetra & Sonipat & Difference between districts \\
\hline \multirow{4}{*}{$\begin{array}{l}\text { Perspectives on factors } \\
\text { underlying the improvement } \\
\text { in the sex ratio at birth } \\
\text { in Kurukshetra versus the } \\
\text { stagnation in Sonipat }\end{array}$} & $\begin{array}{l}\text { Better implementation of } \\
\text { the PCPNDT Act }\end{array}$ & $\begin{array}{l}\text { Better implementation of the } \\
\text { PCPNDT Act }\end{array}$ & \multirow{4}{*}{$\begin{array}{l}\text { Similar set of factors } \\
\text { described, but emphasis } \\
\text { differ }\end{array}$} \\
\hline & $\begin{array}{l}\text { Greater focus on } \\
\text { communication, advocacy } \\
\text { and community mobilisation } \\
\text { by the public sector }\end{array}$ & $\begin{array}{l}\text { Greater focus on } \\
\text { communication, advocacy } \\
\text { and community mobilisation } \\
\text { by the public sector }\end{array}$ & \\
\hline & $\begin{array}{l}\text { Sonipat's proximity to states } \\
\text { in which services are readily } \\
\text { available }\end{array}$ & $\begin{array}{l}\text { Sonipat's proximity to } \\
\text { states in which services are } \\
\text { readily available }\end{array}$ & \\
\hline & $\begin{array}{l}\text { Differences in caste } \\
\text { composition }\end{array}$ & $\begin{array}{l}\text { Differences in caste } \\
\text { composition }\end{array}$ & \\
\hline
\end{tabular}

Note: Significant differences between Kurukshetra and Sonipat are shown in bolded text.

\section{The way forward}

Several lessons can be drawn from the insights offered in this study that may be relevant for the development and implementation of programmes intended to ensure balanced sex ratios at birth and among children generally, and break down traditional patriarchal norms and preferences for sons in general, and misuse of technology to obtain information about the sex of the foetus and terminate pregnancies carrying a female foetus, in particular. As observed above, the key difference between the experiences of Kurukshetra and Sonipat lay in the greater emphasis in the former on communication, advocacy and community mobilisation, and our recommendations focus on these. We also include more general recommendations on the enforcement of the PCPNDT Act, and educational entitlements and cash transfer programmes for girls that were evident needs in both districts.

\section{Place greater emphasis on communication, advocacy and community mobilisation to change patriarchal norms and enhance understanding of the PCPNDT Act}

While often considered intractable, programmes must continue to challenge existing gender-biased norms relating to the value of the girl child and the need for at least one son. Findings have shown that a reliance on law enforcement programmes is needed that conveys, for example, what was evident in our findings-that young couples hold more gender egalitarian norms, but fall prey to pressures from the older generation to ensure a son; that disturbing proportions of women hold attitudes suggesting that sons are essential to further the family line, that sons ensure their mother's status and security in the marital home, that girls are a drain on the household's resources-and these messages need to be countered convincingly. Actions may include, for example, the inclusion in programmes of positive deviant families whose daughters have been successful and/or support their parents even after marriage; special attention paid to the older generation about adhering to their children's right to decide on the number and composition of their children; and engaging the next generation, namely those in schools and colleges, in espousing gender equality in their own life and future.

There exist a number of laws that have a direct bearing on raising the status of women and girls, including those relating to the right to education, the minimum age at marriage, the prohibition of dowry payments, equal inheritance rights and protection from domestic and sexual violence. These laws are poorly understood at the community level and efforts to address patriarchal norms must encompass efforts to raise awareness of these rights of women and girls.

Communication, advocacy and community mobilisation activities also need to raise in-depth awareness about the PCPNDT Act, for example, the extent to which health care providers, and women and families seeking disclosure of the sex of the foetus may be penalised. We note, however, that simple awareness of the existence of the Act, as well as of the legal consequences for doctors and women of violating the Act was fairly universal in both districts, and no longer needs to be stressed in programmes. What is needed is attention to conveying the unacceptability of violation 
of the Act and building an appreciation of the longer-term social consequences of such violations in terms of the availability of brides, in particular. Frontline health workers, and notably ASHAs and Anganwadi Workers, played an important behaviour change role through interpersonal communication with women, and can play a key role, more broadly, in changing norms and awareness about matters related to gender-biased sex selection and son preference. Engaging influential individuals, notably religious leaders, in conveying these ideas and obtaining pledges at the community level about desisting from such practices appear to be measures, in addition, that have had some success in these districts.

\section{Support greater engagement of senior public sector officials in communication, advocacy and community mobilisation}

The Night Halt or Open Durbar programmes described by key public sector informants from Kurukshetra have apparently had success in linking senior public sector officials responsible for implementing the PCPNDT Act with communities. Those in authority play the role of change agents and their community-level visits enabled greater visibility to the Act, and greater credibility to the messages conveyed. The functioning and effect of this programme need to be better understood, but efforts to link respected opinion makers in positions of authority with community members likely enables community members to express their perspectives, while at the same time, to gain exposure to the perspectives of credible and respected health care providers and lawyers on the Act and on challenging traditional norms.

\section{Review and strengthen the enforcement structure of the PCPNDT Act}

A number of key informants highlighted that fool-proof cases are dismissed at the time of trial because evidence has been inadequately collected or is unavailable; others pointed out that those responsible for implementing the PCPNDT Act tend to have multiple responsibilities and are unable to devote sufficient time to Act enforcement. A key recommendation, thus, is to build the capacity of those responsible for implementing the Act in collecting evidence and preparing a case for trial. Also needed, given that these health care providers and law enforcement authorities are part of the same patriarchal society from which women seeking disclosure of the sex of the foetus come, and may well empathise with women seeking a son, are efforts to sensitise health care providers and law enforcement authorities-ranging from doctors to frontline health workers and from judges to lawyers-about the gender, legal, ethical and rights dimensions of the Act.

At the same time, the structure and responsibilities of officials responsible for administering the Act need to be reviewed, and the need for supplementing the human resources of the Appropriate Authority, and ensuring that staff responsible for implementing the Act are not overburdened with other responsibilities assessed.

Both women and all three categories of key informants expressed scepticism about the ability of the Act to stem the practice of gender-biased sex selection. They argued that greedy health care providers would find a way of disclosing the sex of the foetus, that some health care providers used their influence and resources to squash a case, and that political interference in the operations of the authorities inhibited many cases of violations from reaching the courts. Corruption within the system was described as rampant. Efforts are needed to stem these practices; for example, the anonymous whistle-blowing opportunities or reporting of incidents in which pressure is brought to bear on enforcement authorities may need to be explored.

We note that many key informants, irrespective of category, advocated harsher enforcement methods-for example, monitoring of all pregnant women, especially those with a daughter; installing equipment that enables the authorities to monitor what goes on between a provider and a client, more sting operations and other efforts to catch unscrupulous health care providers red-handed. Such practices have the potential to infringe on clients' right to confidentiality. At the same time, they are far from fool-proof-key informants have noted that women who intend to undergo gender-biased sex selection withhold information about their pregnancies from frontline health workers, and health care providers will find innovative ways of ensuring that discussions about disclosure take place through middlemen, and outside of the facility.

\section{Forge closer public-private partnerships}

The NGO sector, while conducting programmes intended to challenge patriarchal norms on the one hand, and providing educational entitlements and support to families with daughters on the other, has been a relatively 
overlooked resource at the district level. Public-private partnerships may be beneficial in a number of ways. For example, NGO programme implementers may be included in visits made by the authorities to raise awareness and challenge traditional attitudes at the community level; NGOs have a sustained relationship with communities and would be able, thus, to draw on the credibility of the authorities in follow-up action intended to reinforce messages and ideas conveyed in the joint interactions. Likewise, including NGOs in the enforcement of the PCPNDT Act, for example, in conducting raids and enforcing the Act may enable them to serve as a watchdog with regard to political interference or pay-offs from health care providers.

\section{Make efforts to resolve the challenges expressed by the medical community in complying with the requirements of the PCPNDT Act}

Most health care providers supported the PCPNDT Act and acknowledged that the practice of disclosing the sex of the foetus and terminating pregnancies carrying a female foetus had declined. Even so, several complained about cumbersome reporting requirements, undue harassment over small violations such as failure to report a change of address or irregularities in filling forms, and interference in day-to-day activities. Many argued that although the law suggested that women who have been informed about the sex of their foetus, and their family members are also guilty of violating the Act, rarely has action been taken against them. Finally, many argued that efforts should be directed at reducing the demand for services rather than harassing or penalising honest doctors. Indeed, several expressed resentment about the enforcement of the Act and the implications this had on their practice. Dialogue is needed between law enforcement authorities and health care providers that explores the challenges faced by the medical fraternity in complying with the requirements of the Act, and makes efforts to resolve them.

\section{Address the need to better understand the role of conditional cash transfer programmes and educational entitlements for girls}

A considerable proportion of eligible women did indeed make use of educational entitlements and conditional cash transfer programmes for their daughters. Key informants from all three categories agreed, moreover, that availing of these schemes is likely to raise the value of the girl child, enhance her access to education, and delay her marriage, but will not influence the demand for a son or deter families from seeking disclosure of the sex of the foetus. Yet, evidence also suggests that bottlenecks in the application process and demands for payments to complete the application process, inhibit eligible parents from successfully enrolling their daughters in conditional cash transfer schemes; eligibility criteria are also stringent-for example the Ladli Scheme is open only to second and not first daughters, and others are available only for the poor and those from socially excluded castes and tribes. Evaluations are needed that assess the reach, acceptability and longer-term effects of programmes on girls' educational and marriage outcomes. 


\section{References}

Arnold, F., S. Kishor and T.K. Roy. 2002. "Sex-selective abortion in India." Population and Development Review, 28(4): 759-85.

Arnold, F. and S. Parasuraman. 2009. The effect of ultrasound testing during pregnancy on pregnancy termination and the sex ratio at birth in India. Paper presented at the XXVI International Population Conference, International Union for the Scientific Study of Population (IUSSP), Marrakech, Morocco, 27 September-2 October.

Bhat, P.N.M. 2002. “On the trail of ‘missing’ Indian females: II: Illusion and reality.” Economic and Political Weekly, 37(52): 5244-5263.

Bhat, P.N.M. and A.J.F. Zavier. 2007. "Factors influencing the use of prenatal diagnostic techniques and the sex ratio at birth in India." Economic and Political Weekly, 42(4): 2292-2303.

Bongaarts, J. 2013. "The implementation of preferences for male offspring." Population and Development Review, 39(2): 185-208.

Bracken, H. and V. Nidadavolu. 2005. "Mixed messages? An analysis of communication materials on abortion and sex determination in Rajasthan”. Economic and Political Weekly, 40(35): 3856-3862.

Byatnal, A. 2011. “Satara renames its “unwanted’ girls”. The Hindu, Satara, October 23, 2011 (newspaper article).

Das Gupta, S., S. Mukherjee, S. Singh et al. 2008. Knot Ready: Lessons from India on delaying marriage for girls. New Delhi: International Center for Research on Women (ICRW).

Department of Health, Government of Haryana. n.d. Ch. Devilal. Rashtriya Uttan Aivam Parivar Kalyan Yojana: Devi Rupak. Accessed on 30 June, 2015, at http://haryanahealth.nic.in/menudesc.aspx?page=112

Department of Health and Family Welfare, Government of Punjab. n.d. "New Strategies: Balri Rakshak Yojana”. Accessed on 30 June, 2015, at http://www.pbhealth.gov.in/sch1.htm

Department of Medical, Health and Family Welfare, Government of Rajasthan. n.d. "What is Sex Selection". Accessed on 30 June, 2015, at www.hamaribeti.nic.in

Department of Welfare of Scheduled Castes and Backward Castes, Government of Haryana. n.d. Indira Gandhi Priyadarshini Viwah Shagun Yojana. Accessed on 1 July, 2015, at http://www.scbchry.gov.in/indira_gandhi_priyadarshini_viwahshagun yojna.htm

Department of Women and Child Development, Government of Haryana. n.d. Accessed on 30 June, 2015, at http://wcdhry.gov.in/new_schemes.htm\#LADLI

Department of Women and Child Development, Government of Madhya Pradesh. n.d. “Ladli Laxmi”. Accessed on 30 June, 2015 , at http://ladlilaxmi.com/

Department of Women and Child Development, Government of NCT of Delhi. n.d. "Ladli Scheme, 2008". Accessed on 30 June, 2015, at http://wcddel.in/ladli.html

Directorate of Social Justice and Empowerment. n.d. Social Security Pension Scheme. Accessed on 1 July, 2015, at http://www.socialjusticehry.nic.in/Website/SocialSecurity PensionSchemes.pdf

Forum against Sex Selection (FASS). 2012. “Mukhbir Yojana scripts a success story in state”. Forum against Sex Selection. India. Accessed on 30 June, 2015 at https://fassmumbai.wordpress.com/2012/03/24/mukhbir-yojna-scripts-a-successstory-in-state/

Ganatra, B. 2008. "Maintaining access to safe abortion and reducing sex ratio imbalances in Asia”. Reproductive Health Matters, 16 (31 Supplement): 90-98.

George, S.M. 2002. "Sex selection/determination in India: Contemporary Developments." Reproductive Health Matters, 10(19): 190-192.

Girls Count. 2014. PCPNDT Civil Society Report Card: Current Structure and Status of Statutory Mechanisms. New Delhi: Girls Count. 
Government of India. 1971. The Medical Termination of Pregnancy Act (Act. No. 34). New Delhi: Government of India.

Government of India. 2003. The Medical Termination of Pregnancy Rules (Amendment). New Delhi: Government of India.

Guilmoto, C.Z. 2007. “Sex-ratio imbalance in Asia: Trends, consequences and policy responses”. Symposium at The Fourth Asia Pacific Conference on Sexual and Reproductive Health and Rights, Hyderabad, India, October, 2007.

Guilmoto, C.Z. 2011. Sex Imbalances at Birth: Trends, Consequences, and Policy Implications. Accessed on 1 July, 2015, at http://www.unfpa.org/sites/default/files/resource-pdf/Guilmoto_Revised_presentation_Hanoi_Oct2011.pdf

Guilmoto, C.Z. and Rajan, S. I. 2013. Fertility at the District Level in India. Economic and Political Weekly, $48(23), 59$.

Hesketh, T., L. Lu, and Z. W. Xing. 2011. The Consequences of Son Preference and Sex-selective Abortion in China and other Asian Countries. Canadian Medical Association Journal, 183(12): 1374-1377. DOI: 10.1503/cmaj.101368.

International Institute for Population Sciences (IIPS). 2010. District Level Household and Facility Survey (DLHS-3), 2007-08: India. Mumbai: IIPS.

International Institute for Population Sciences (IIPS) and Macro International. 2007. National Family Health Survey (NFHS-3)-India, 2005-06. Mumbai: IIPS.

Ipas. 2013. "Preserving access to safe abortion while addressing gender-biased sex selection in India: Introducing the Campaign for Gender Equality and Safe Abortion". New Delhi: Ipas.

Jaising, I., C. Sathyamala and A. Basu. 2007. From the Abnormal to the Normal: Preventing Sex-selective Abortions through the Law. New Delhi: Lawyers Collective.

Jha, P., R. Kumar, P. Vasa et al. 2006. "Low male-to-female sex ratio of children born in India: national survey of 1.1 million households”. The Lancet, 367(9506): 211-218.

Jha, P., M.A. Kesler, R. Kumar et al. 2011. "Trends in selective abortions of girls in India: analysis of nationally representative birth histories from 1990 to 2005 and census data from 1991 to 2011”. The Lancet, 377(9781): 1921-1928.

Jejeebhoy, S. J., S. Basu., R. Acharya et al. 2015. Gender-biased Sex Selection in India: A Review of the Situation and Interventions to Counter the Practice. New Delhi: Population Council.

John, M.E. 2015. “Adverse Child Sex Ratios and Gender Discrimination: Challenges for Law and Policy”. In: Shiva Kumar, A. K., Rustagi, P., Subrahmanian, R. (eds.) India’s Children: Essays on Social Policy. New Delhi: Oxford University Press.

Joseph, J. and Center for Youth Development and Activities (CYDA). 2007. Report on reflections on the campaign against sex selection and exploring ways forward. Pune: CYDA.

Kishor, S. and K. Gupta. 2009. “Gender equality and women's empowerment in India.” National Family Health Survey (NFHS-3), India, 2005-06. Mumbai: International Institute for Population Sciences; Calverton, Maryland, USA: ICF Macro.

Kulkarni, P.M. 2007. Estimation of missing girls at birth and juvenile ages in India. A paper prepared for the United Nations Population Fund (UNFPA), India.

Kulkarni, P.M. 2014. “The population and development scenario in India.” In: Jejeebhoy, S. J., Kulkarni, P. M., Santhya, K. and Mehrotra, F. (eds.) Population and Reproductive Health in India: An Assessment of the Current Situation and Future Needs. New Delhi: Oxford University Press.

Kulthe B. 2013. "State to finally have a functional women's commission”. Sakal Times, 6 December, 2013 (newspaper article).

Kumar, S. and K. Sathyanarayana. 2012. "District-level estimates of fertility and implied sex ratio at birth in India." Economic and Political Weekly, 47(33): 66-72.

Madhya Pradesh Education Portal. n.d. "Cycle Distribution Monitoring”. Accessed on 30 June, 2015 at http://www. educationportal.mp.gov.in/Cycle/Public/Cycle_Main.aspx

Ministry of Health and Family Welfare (MOHFW). 2003. The Pre-natal Diagnostic Techniques (Regulation and Prevention of Misuse) Act, 1994 (Act no. 57 of 1994) and The Pre-Conception and Pre-natal Diagnostic Techniques (Regulation and Prevention of Misuse) Amendment Act, 2002 (no.14 of 2003). New Delhi: MOHFW, Government of India.

Ministry of Health and Family Welfare (MOHFW). 2006. Handbook on Pre-Conception \& Pre-Natal Diagnostic Techniques Act, 1994 and Rules with Amendments. New Delhi: MOHFW, Government of India. 
Ministry of Health and Family Welfare (MOHFW). 2013. Annual Report 2012-13. New Delhi: MOHFW, Government of India.

Ministry of Health and Family Welfare (MOHFW). n.d. "Action Plan, Save the Girl Child”. New Delhi: MOHFW, Government of India. Accessed on 30 June, 2015 at http://www.pndt.gov.in/index1.asp?linkid=12.

Ministry of Human Resource Development (MOHRD). n.d. "Centrally Sponsored Scheme: Incentives to Girls for Secondary Education". Accessed on 30 June, 2015, at http://mhrd.gov.in/sites/upload files/mhrd/files/upload document/scheme incentive.pdf

Ministry of Women and Child Development (MOWCD). 2011. Annual Report 2010-2011. New Delhi: MOWCD, Government of India.

Ministry of Women and Child Development (MOWCD). n.d. "Balika Samriddhi Yojana." Accessed on 30 June, 2015, at http://wcd.nic.in/BSY.htm

Nanda, P. 2012. Changing the value of girls in Haryana: Evaluation of the Apni Beti Apna Dhan CCT. New Delhi: ICRW Asia Regional Office. Accessed on 30 June, 2015, at http://www.povertyactionlab.org/doc/changing-value-girls-haryana

Naqvi, F. 2006. Images and icons: harnessing the power of mass media to promote gender equality and reduce practices of sex selection. New Delhi, India.

Kumar, N. 2010. Nitish Kumar's Blog. Accessed on 20 March, 2015 at http://nitishspeaks.blogspot.in/2010/04/mukhyamantribalika-cycle-yojna.html.

Office of the Registrar General, India. 2011. Sample Registration System Statistical Report, 2009. Report No. 1 of 2011. New Delhi: Office of the Registrar General, India.

Office of the Registrar General, India. 2013. Sample Registration System Statistical Report, 2011. Report 1 of 2013. New Delhi: Office of the Registrar General, India.

Office of the Registrar General and Census Commissioner, India. n.d. Primary Census Abstracts Data Tables (India and States/ UTs-District levels) (Excel Format). Accessed on 1 July, 2015, at http://www.censusindia.gov.in/pca/default.aspx

Office of the Registrar General and Census Commissioner, India. 2004. Primary Census Abstract Total Population: Table A-5 Census of India 2001.Series1-India. New Delhi: Office of the Registrar General, India.

Office of the Registrar General and Census Commissioner, India. 2013. Census of India 2011: Primary Census Abstract, Data Highlights, India, Series 1. New Delhi: Office of the Registrar General and Census Commissioner, India. Accessed on 1 July, 2015, at http://www.censusindia.gov.in/2011census/PCA/PCA Highlights/pca highlights file/India/Chapter-1.pdf

Plan India. 2013. Annual Report 2012-2013. Accessed on 30 June, 2015, at https://www.planindia.org/annualreport/2012\%E2\%80\%932013

Planning Commission. n.d. Mid-term Appraisal for Eleventh Five Year Plan 2007-2012. Accessed on 12 February, 2015 at http://planningcommission.gov.in/plans/mta/11th mta/chapterwise/chap11 women.pdf

Premi, M. K. 2002. “The Girl Child: Some Issues for Consideration.” Paper presented at the Symposium on Sex Ratio in India, held at the International Institute for Population Sciences, Mumbai, 10-11 January, 2002.

Public Health Foundation of India (PHFI). 2010. Implementation of the PCPNDT Act in India: Perspectives and Challenges. New Delhi: PHFI.

Santhya, K.G. and S. Verma. 2004. “Induced Abortion”. In: Jejeebhoy, S.J (eds.) Looking Back, Looking Forward: A Profile of Sexual and Reproductive Health in India. New Delhi: Rawat Publications.

Sekher, T. V. 2010. Special financial incentive schemes for the girl child in India: A review of select schemes. Mumbai: International Institute for Population Sciences, and New Delhi: United Nations Population Fund.

Sekher, T.V. 2012. Skewed sex ratios, conditional cash transfers and promotion of girl children: The Indian experience." Paper presented at the Annual Meeting of the Population Association of America, San Francisco.

Sekher, T.V. 2015. "Conditional Cash Transfers for the Welfare of the Girl Child: The Indian Experience”. In: Shiva Kumar, A. K., Rustagi, P., Subrahmanian, R. (eds.) India's Children: Essays on Social Policy. New Delhi: Oxford University Press.

Singh, K. 2013. Laws and Son Preference in India: A Reality Check. New Delhi: UNFPA. 
United Nations Population Fund (UNFPA). 2010. Trends in Sex Ratio at Birth and Estimates of Girls Missing at Birth in India. New Delhi: UNFPA.

United Nations Population Fund (UNFPA). 2012. Sex Imbalances at Birth: Current trends, Consequences and Policy Implications. Bangkok, Thailand: UNFPA.

United Nations Population Fund (UNFPA). 2013. Lest more girls go missing: Initiatives of UNFPA India to address genderbiased sex selection. New Delhi: UNFPA. Check this link for LEST....http://countryoffice.unfpa.org/india/drive/ UNFPABOOKFINALSINGLEPAGE16-5-13FORPRINTCC.pdf

United Nations Population Fund (UNFPA). 2013. Lest more girls go missing: Initiatives of UNFPA India to address gender-biased sex selection. New Delhi: UNFPA.

UNFPA and Breakthrough. 2015. Communication Guide: A Key to Building a People's Response to Gender-biased Sex selection. New Delhi: UNFPA and Breakthrough.

Women Power Connect. 2013. A multi-hued experience and a zig-zag journey on the quest for gender equality: Lessons learnt and experiences gained through the community based project on addressing sex selection. New Delhi: Women Power Connect.

Women Power Connect. 2013a. Support to community mobilisation and a people driven response in preventing sex selection and arresting child sex ratio decline: Process documentation of the project. New Delhi: Women Power Connect. 


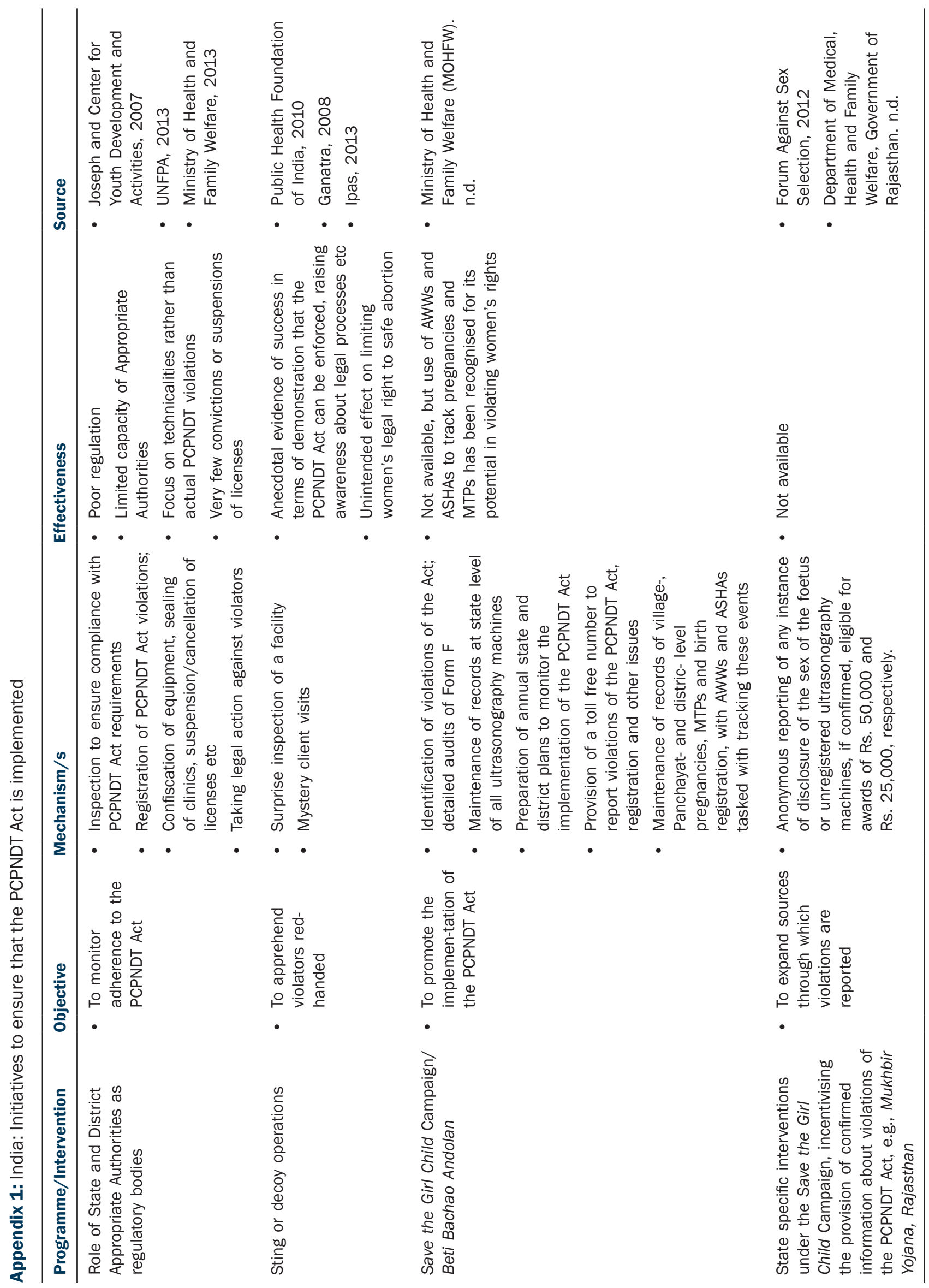




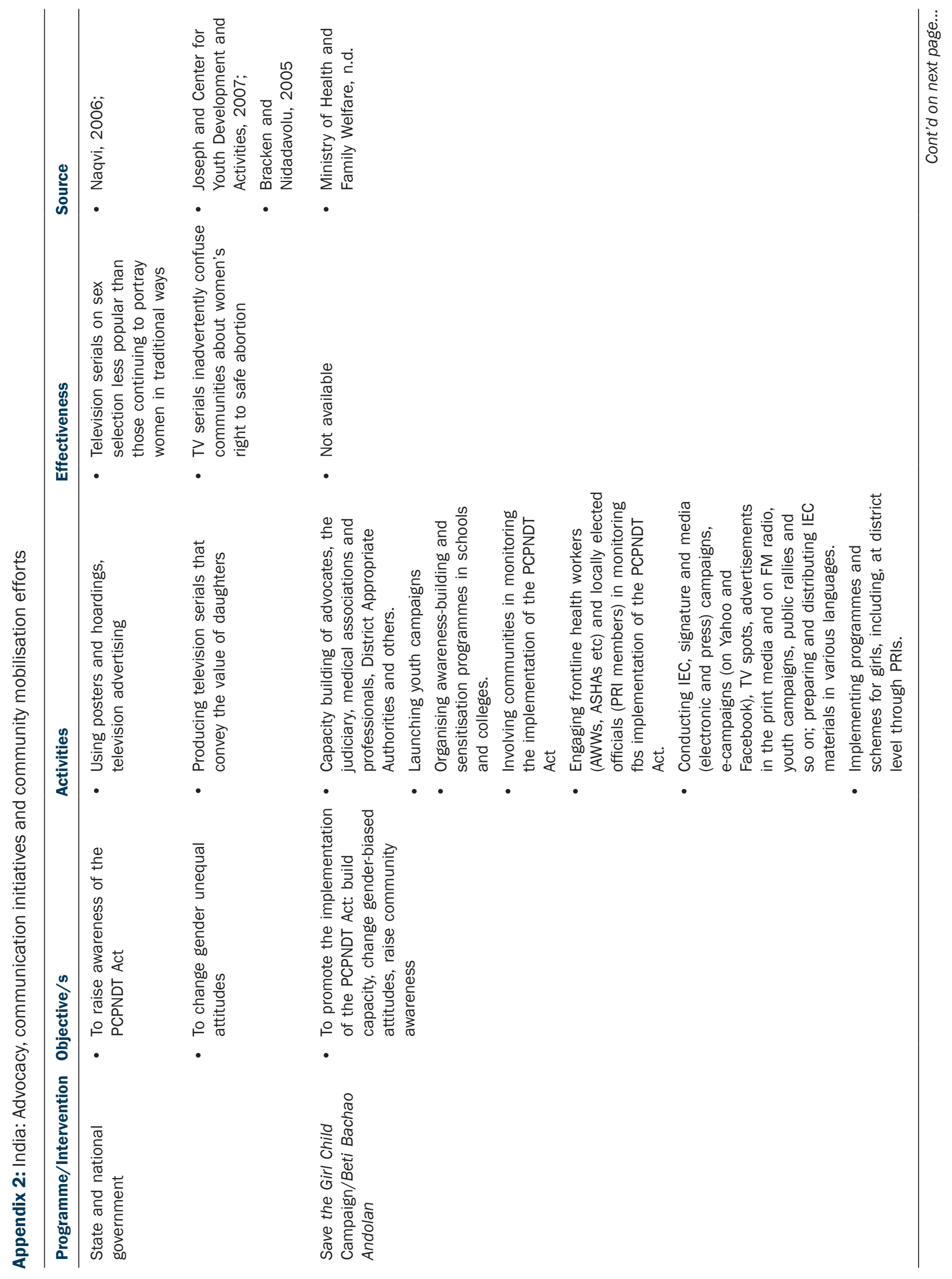




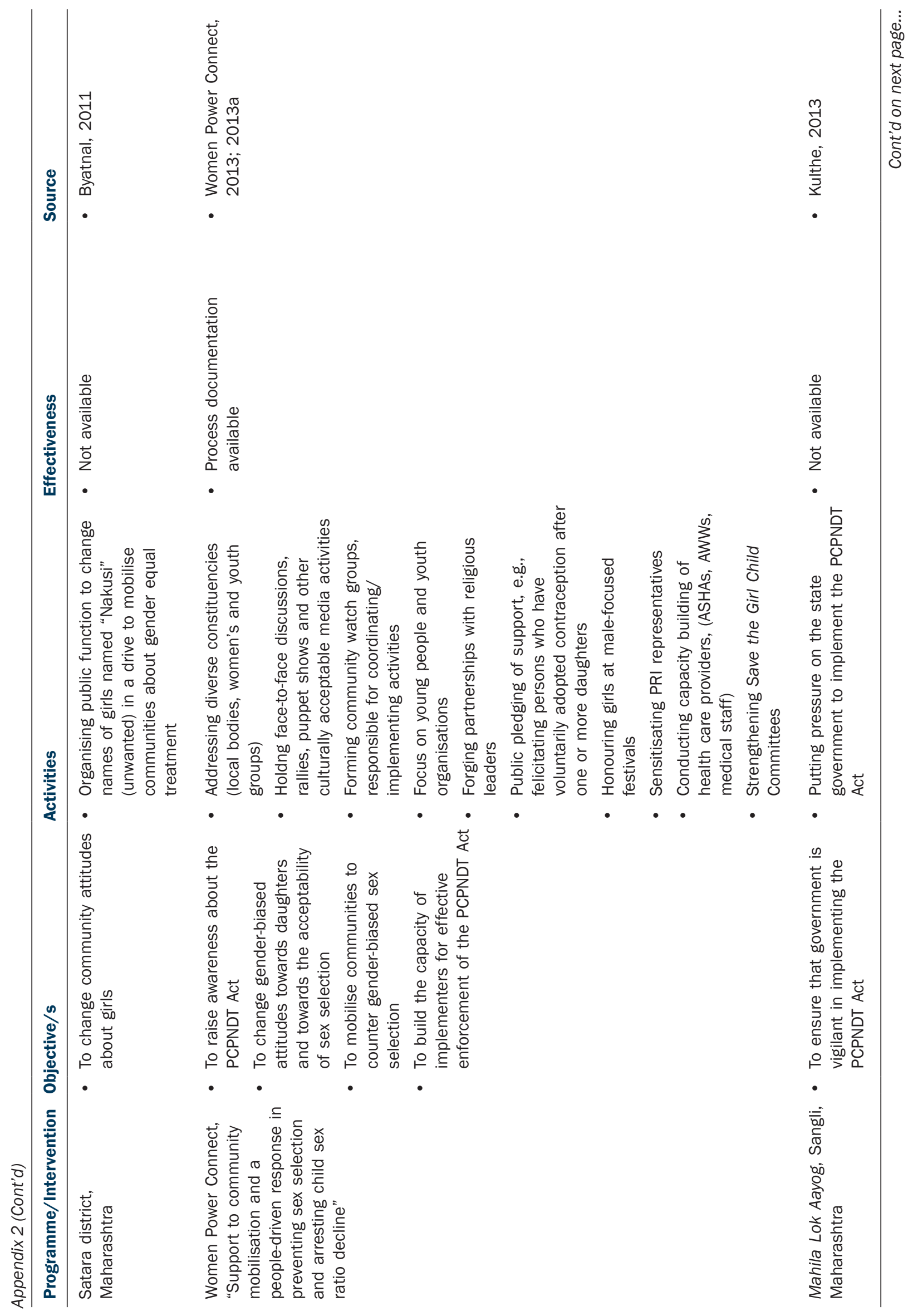




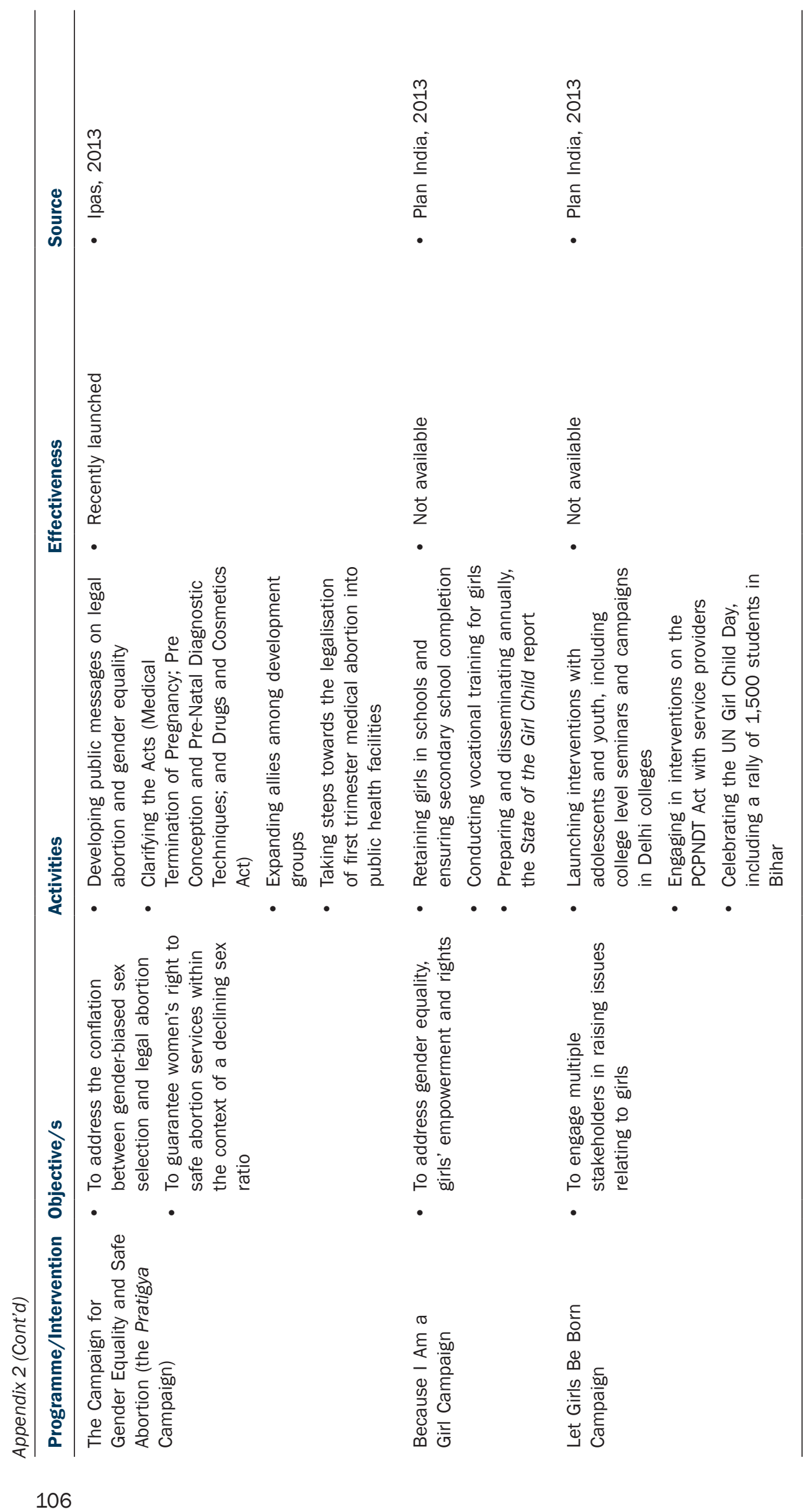




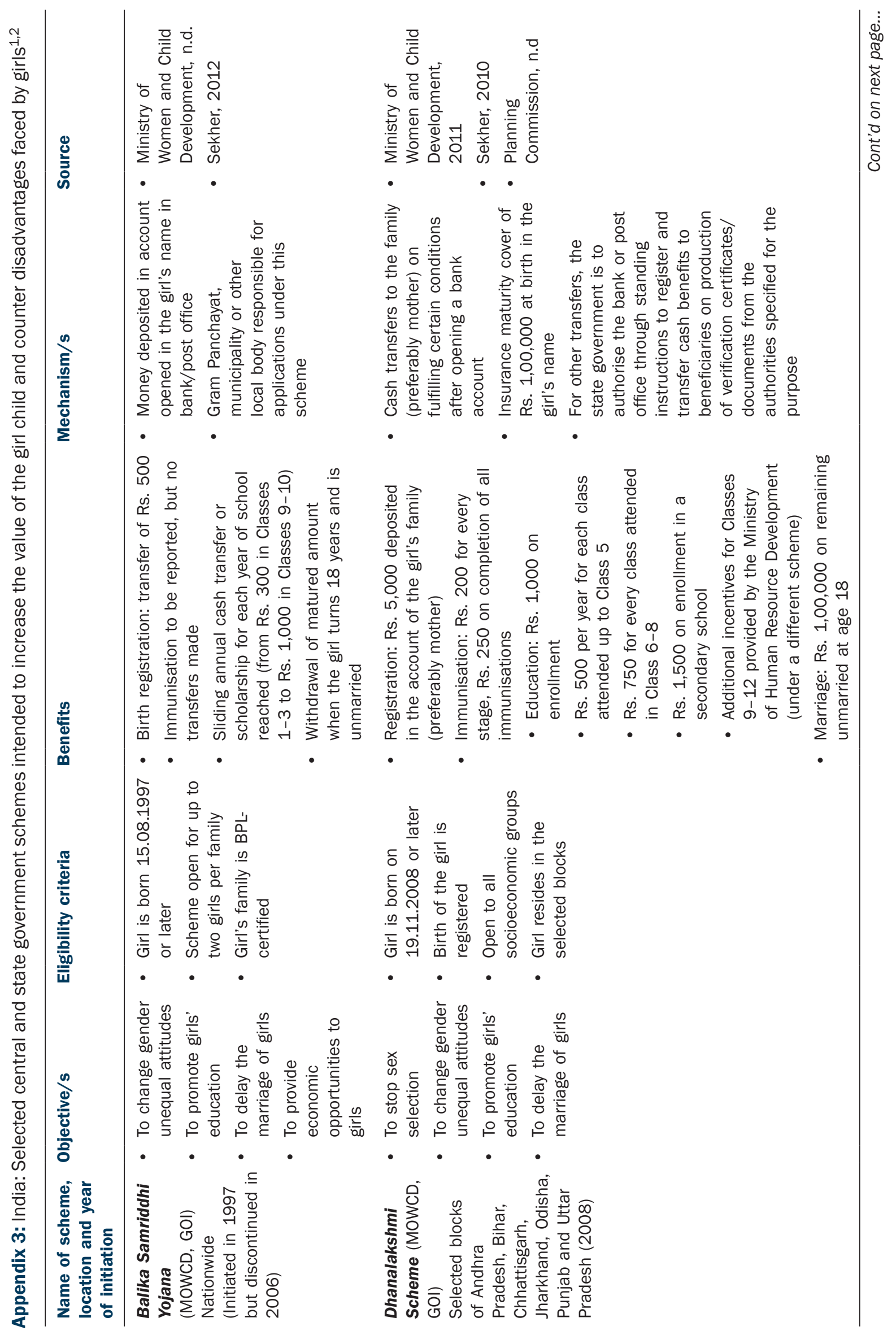




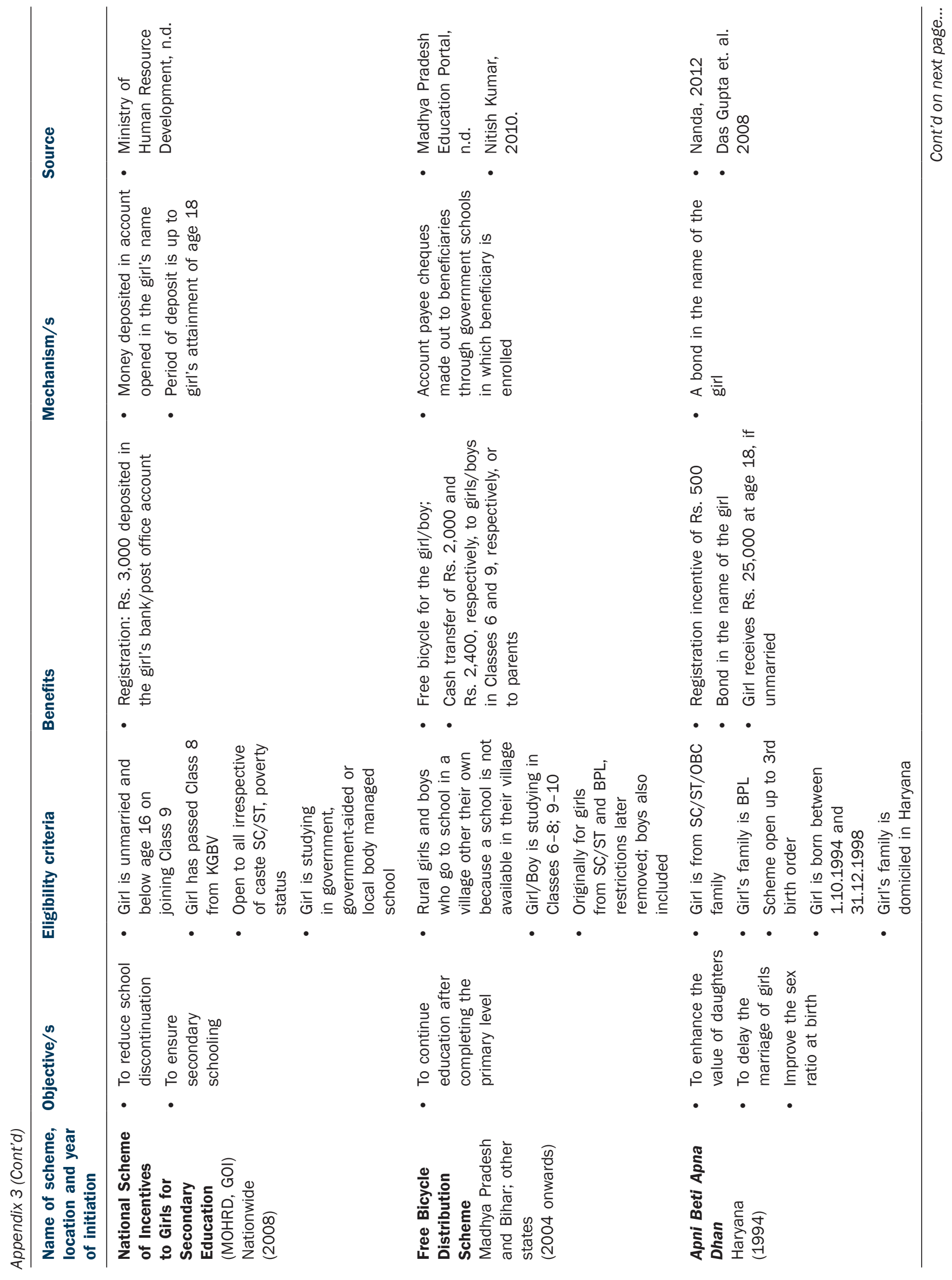




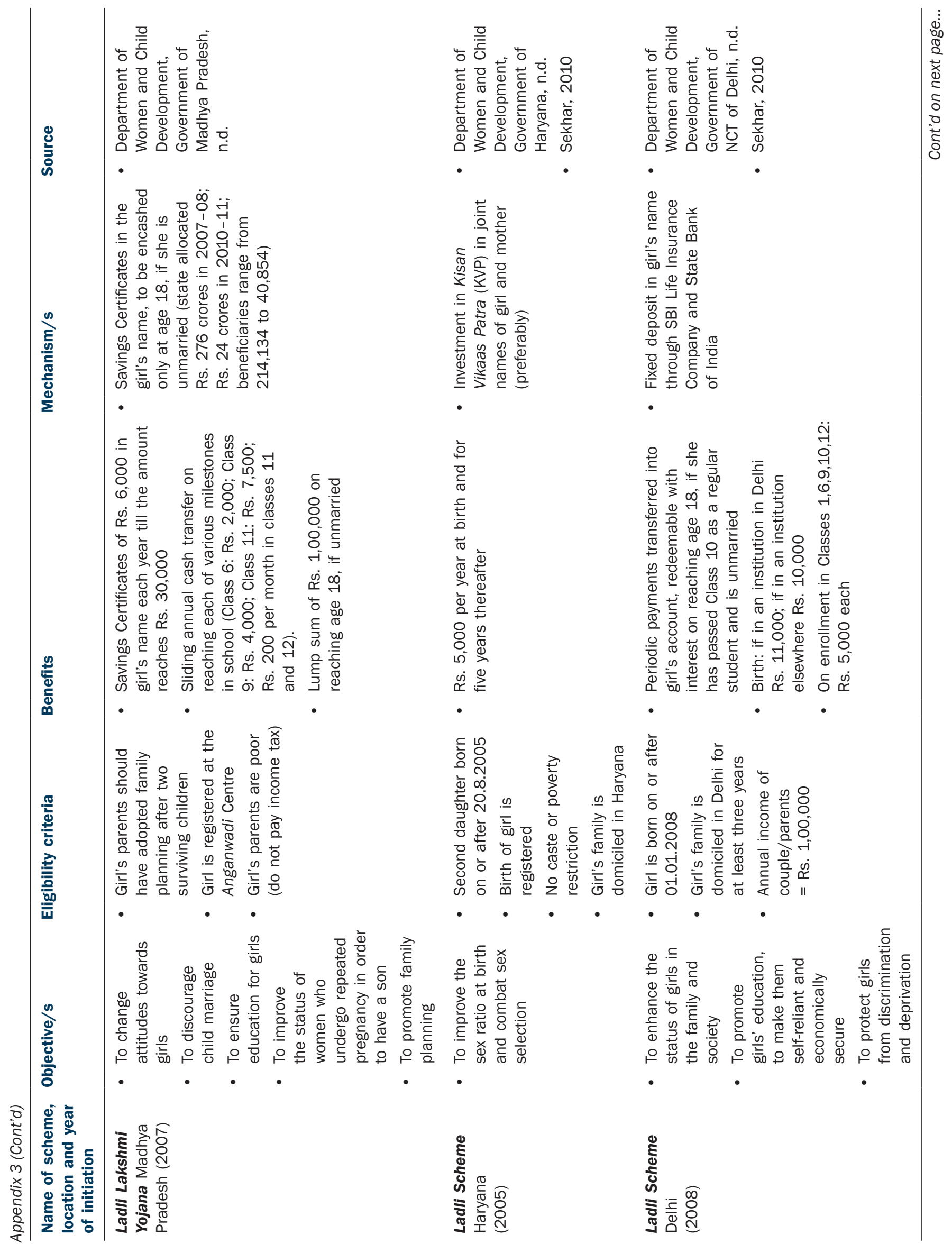




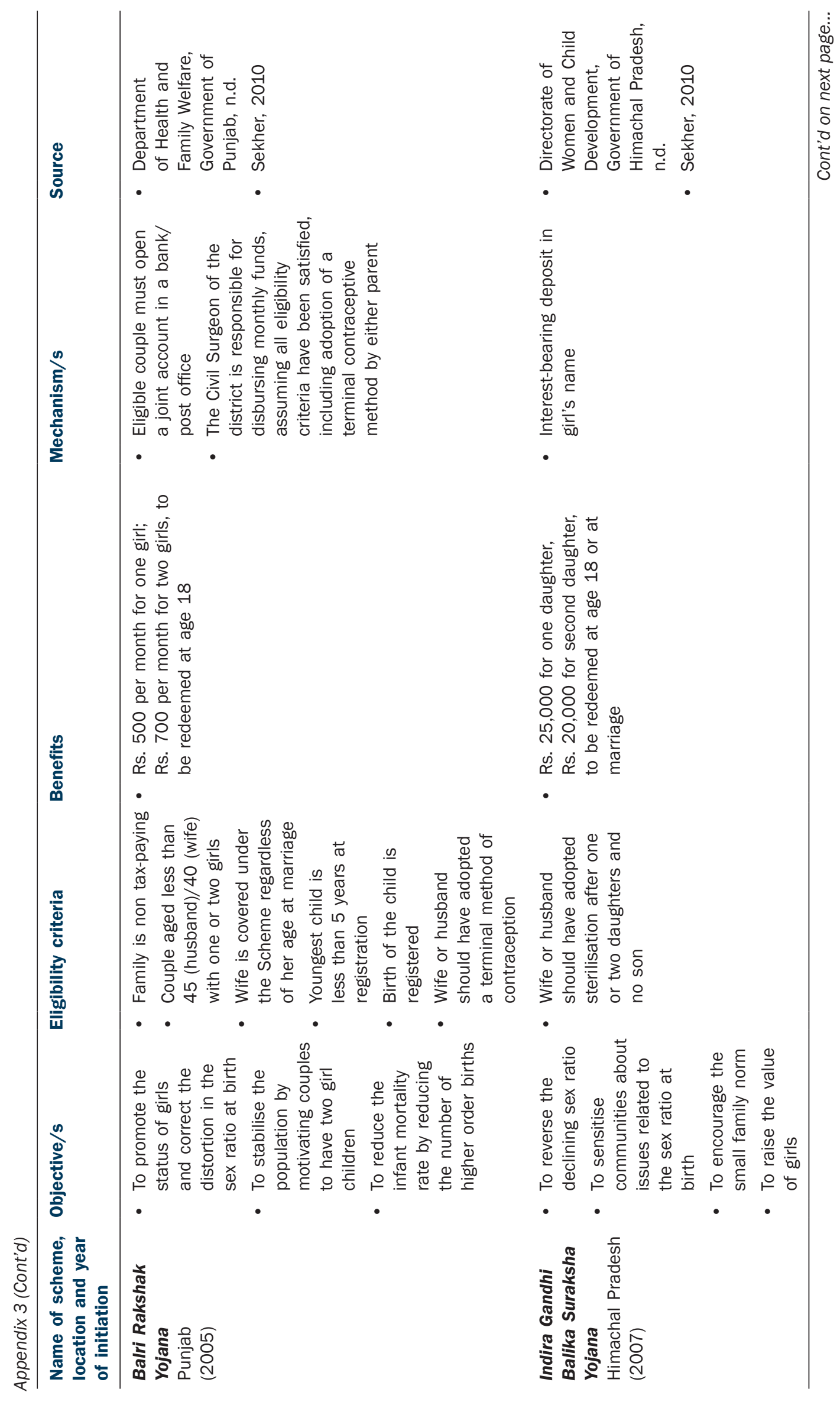




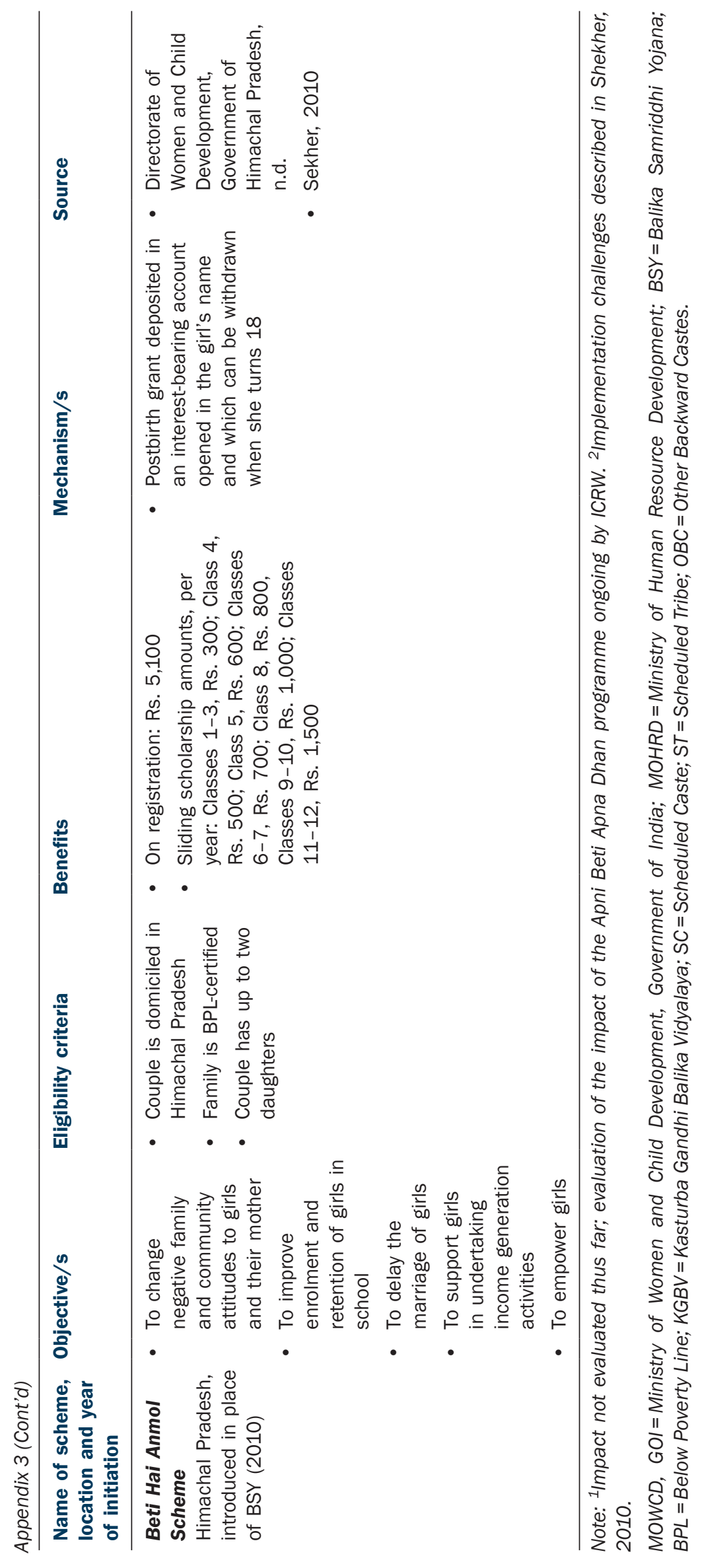




\section{Authors}

Shireen J. Jejeebhoy, Senior Associate, Population Council, New Delhi

Rajib Acharya, Associate I, Population Council, New Delhi

Sharmistha Basu, Programme Officer, Population Council, New Delhi

A J Francis Zavier, Senior Programme Officer, Population Council, New Delhi 


\section{List of Investigators}

Field Supervisors/Editors

Hemraj Daima

Madhulata Gupta

Ruchi Kumari

Bhaskar Mishra

Alok Kumar Pandey

\section{Field Investigators}

Sayra Bano

Salma Khanam

Nanda M. Sahu

Poonam Saini

Laxmi Saini

Priyanka Vaishnav

Zahida

\section{Houselisters and Mappers}

Avadhesh Kumar

Davendra Kumar

Kundan Kumar

Deepak Kumar Pandey

Hrishikesh Pandey

Brahmanand Saraswati

Anil Kumar Sinha

Jaishankar Tiwari 
Printed at :

systemsvision@gmail.com 


\section{POPULATION COUNCIL}

Ideas. Evidence. Impact.

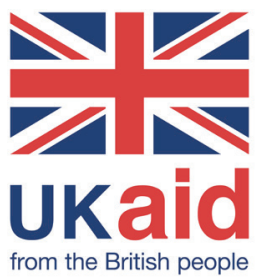

